\title{
WestVirginiaUniversity
}

THE RESEARCH REPOSITORY @ WVU

Graduate Theses, Dissertations, and Problem Reports

2004

\section{Metal -surface reactions in mixed aqueous organic solvents}

\author{
Rafif K. Srour \\ West Virginia University
}

Follow this and additional works at: https://researchrepository.wvu.edu/etd

\section{Recommended Citation}

Srour, Rafif K., "Metal -surface reactions in mixed aqueous organic solvents" (2004). Graduate Theses, Dissertations, and Problem Reports. 2131.

https://researchrepository.wvu.edu/etd/2131

This Dissertation is protected by copyright and/or related rights. It has been brought to you by the The Research Repository @ WVU with permission from the rights-holder(s). You are free to use this Dissertation in any way that is permitted by the copyright and related rights legislation that applies to your use. For other uses you must obtain permission from the rights-holder(s) directly, unless additional rights are indicated by a Creative Commons license in the record and/ or on the work itself. This Dissertation has been accepted for inclusion in WVU Graduate Theses, Dissertations, and Problem Reports collection by an authorized administrator of The Research Repository @ WVU.

For more information, please contact researchrepository@mail.wvu.edu. 
Metal-Surface Reactions in Mixed Aqueous Organic Solvents

Rafif K. Srour

Dissertation submitted to the

Davis College of Agriculture, Forestry and Consumer Sciences at West Virginia University

in partial fulfillment of the requirements

for the degree of

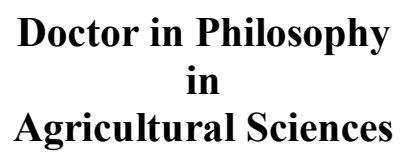

Louis M. McDonald, Jr., Ph.D., Chair

Alan J. Sexston, Ph.D.

Harry O. Finklea, Ph.D.

Jeffery G. Skousen, Ph.D.

Roger C. Viadero, Jr., Ph.D.

Division of Plant \& Soil Sciences

Morgantown, West Virginia

2004

Keywords: Metal-Surface reactions, exchange, sorption, cosolvents, dielectric constants, stability constants, $\mathrm{pH}$ 


\section{ABSTRACT \\ Metal-Surface Reactions in Mixed Aqueous Organic Solvents}

\section{Rafif K. Srour}

The effect of mixed aqueous-organic solvents on exchange and adsorption reactions onto clay minerals is examined in this study while accounting for the effect of cosolvents on metal solution properties, ionic activity and complexation. In the absence of published values, a determination of the primary association constant of selected ions in solution was conducted using conductometric methods. These stability constant values were used to correct for ion-pairing in the exchange and the adsorption experiments. A spectrophotometric determination of $\mathrm{pH}$ was accomplished through the quantification of the conditional dissociation constants, ${ }_{s} \mathrm{~K}_{\mathrm{I}}$, of two indicators (methyl red and phenol red) at constant ionic strength and at $25^{\circ} \mathrm{C} \pm 2.0$ in ethanol and methanol-water mixtures. In these mixtures and under these conditions, solution $\mathrm{pH}$ was determined from measurements of the indicator absorbance ratios at two wavelength $\lambda_{\mathrm{HIn}}$ and $\lambda_{\text {In- }}$ within the range $4.5 \leq \mathrm{pH} \leq 8.5$. Calcium-sodium exchange on Wyoming bentonite in methanol, ethanol and acetone-water systems were investigated at constant total chloride concentration and at room temperature. In all treatments, $\mathrm{Ca}-\mathrm{Na}$ exchange in cosolvents was a surface-controlled phenomenon involving electrostatic and specific solvent-surface interactions. The effect of cosolvents on $\mathrm{Cd}$ and $\mathrm{Zn}$ sorption to Ca-saturated bentonite and illite in mixed alcohol-water systems at low ionic strength and low initial metal concentration in the presence of nitrate varied between metals. $\mathrm{Cd}^{2+}$ sorption to bentonite and illite was independent of the solvent dielectric constant suggesting a specific mechanism for $\mathrm{Cd}^{2+}$ sorption involving inner-sphere complexes with the surface edge sites. $\mathrm{Zn}^{2+}$ sorption to both clay minerals was strongly dependent on $\varepsilon_{\mathrm{r}}$ with both increases (illite) and decreases (bentonite) in retention observed with decreased $\varepsilon_{\mathrm{r}}$. Although it is not yet possible to predict the effects of cosolvents on metal-surface reactions, it is clear that cosolvents can affect metal concentrations in solution, and therefore contaminant transport (increased hydraulic conductivity resulting from flocculation as $\mathrm{Ca}^{2+}$ replaces $\mathrm{Na}^{+}$, and hence greater risk of clay liners failure). Additional study is needed on the effects of cosolvents on surface charge density, changes in the interlayer spacing, surface acidity and $\mathrm{pH}$ changes before and after sorption. 
To my advisor, Dr. Louis McDonald, who made me a better person 


\section{ACKNOWLEDMENTS}

I would like to express my deepest thanks to my family, my father, my mother, Dania, Rabih and Rasha, for giving me all what it takes to accomplish my degree. It was hard for them to watch me go and I apologize for all the pain I caused but I am also grateful for allowing me to pursue my dream. I would also like to thank my niece, yasmina, for bringing joy into my life.

I and heartily thankful to my friends, Mr. Charles Joukhadar and Mr. Rajesh Chintala for their enjoyable company, for constantly helping me during my experimental work and for putting up with all my craziness in the most difficult times of my work.

I would like to express my gratitude to Mr. Nicholas Salazar, Ms. Monica Lecaros and Mr. Sunny Baidwan for their encouragement and support.

I don't know how to thank Ms. Lina Gomez for being my friend and my family in all the good and the bad times.

There are no words that can express who grateful I am to Dr Riad Baalbacki, my teacher, my mentor and my friend. For Dr. Baalbacki has been my shelter everytime my world, infused with work stress and disappointment, seemed to fall apart: For this and for a lot more, I will always be in debt. 


\section{TABLE OF CONTENTS}

\begin{tabular}{|c|c|}
\hline \\
\hline \multicolumn{2}{|c|}{ TABLE OF CONTENTS } \\
\hline \multicolumn{2}{|c|}{ LIST OF TABLES } \\
\hline \multicolumn{2}{|c|}{ LIST OF FIGURES } \\
\hline \multicolumn{2}{|c|}{ LIST OF FIGURES } \\
\hline \multicolumn{2}{|c|}{ 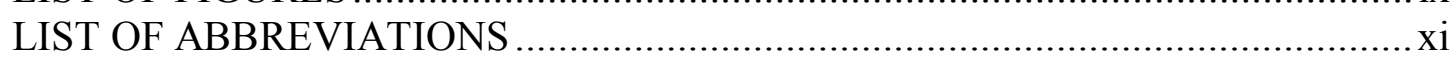 } \\
\hline \multicolumn{2}{|c|}{ 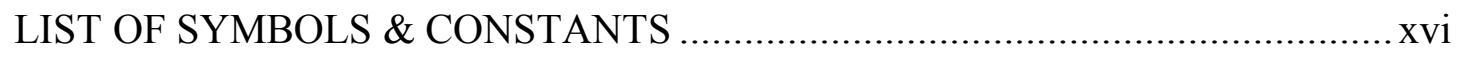 } \\
\hline \multicolumn{2}{|c|}{ CHAPTER I } \\
\hline \multicolumn{2}{|c|}{ INTRODUCTION .... } \\
\hline 1.1 & Overview \\
\hline 1.2 & Solvent Properties \& Classification schemes . \\
\hline 1.3 & Ion-Solvent Interactions.. \\
\hline 1.3 .1 & Ion Solvation... \\
\hline 1.3 .2 & Solubility \\
\hline 1.3 .3 & Complexation . \\
\hline 1.3 .4 & 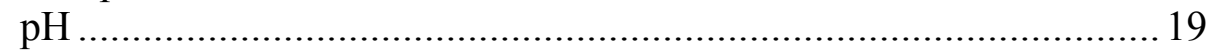 \\
\hline 1.4 & Surface-Solvent Interactions.... \\
\hline 1.4 .1 & Clays Physicochemical Properties.............. \\
\hline 1.4 .2 & Effect of Solvents on Clay Structure. \\
\hline 1.4 .3 & Effect of Solvents on Clay Surface Reactivity...................... \\
\hline 1.5 & 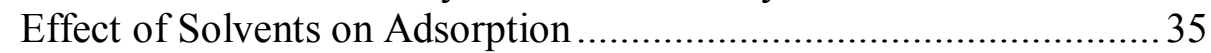 \\
\hline
\end{tabular}

Spectrophotometric Determination of $\mathrm{pH}$ in Mixed Aqueous Alcohol Mixtures Using

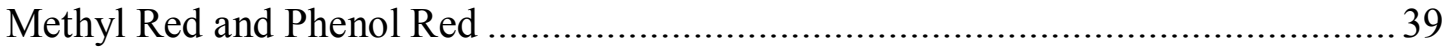

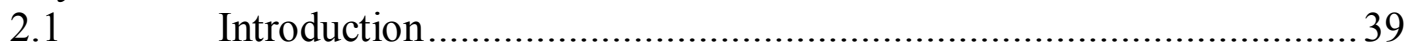

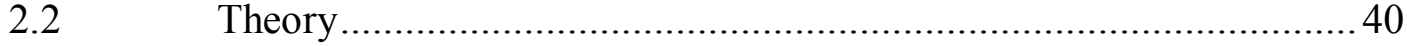

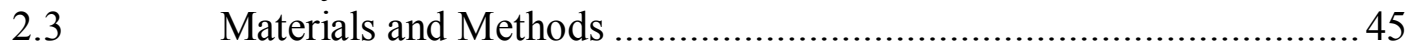

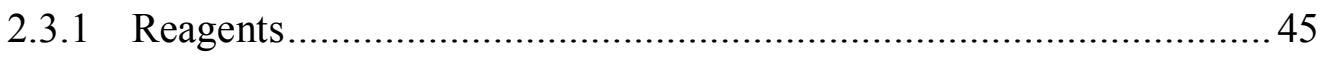

2.3.2 Determination of the conditional dissociation constant, $\mathrm{pK}_{\mathrm{I}}$, of MR

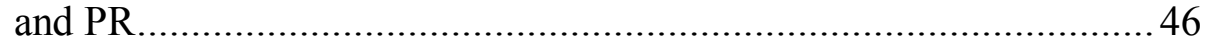

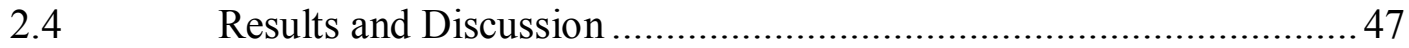

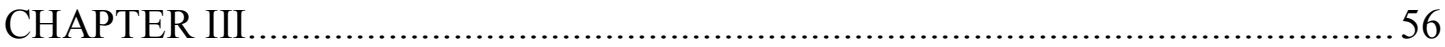

Conductometric Study of Cd(II), Ca(II), Zn(II) Nitrates and $\mathrm{Ca}(\mathrm{II})$ Chlorides in

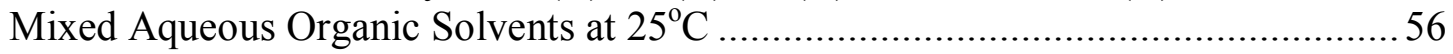

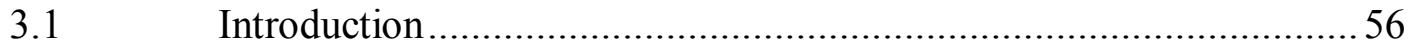

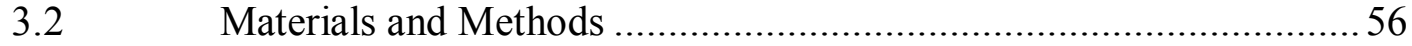

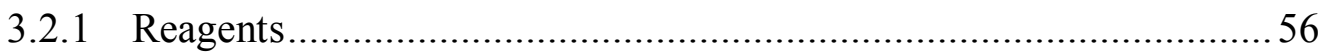

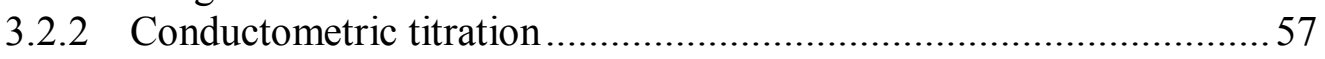

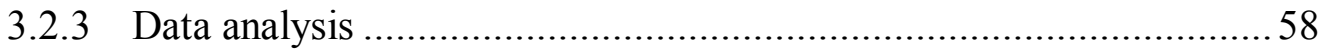

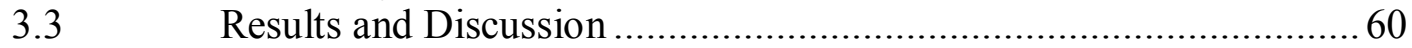

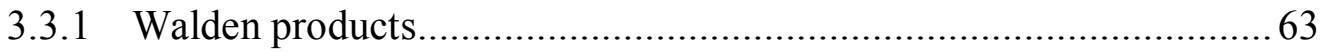

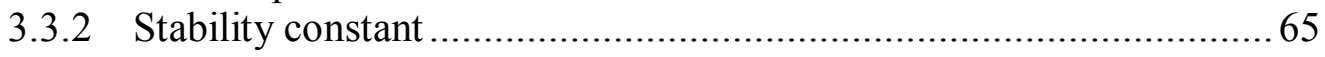

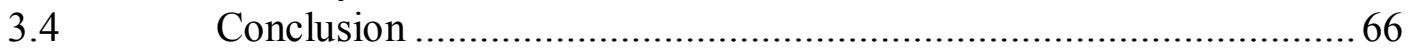


CHAPTER IV

Effect of Cosolvents on Ca-Na Exchange onto Wyoming Bentonite ...........................69

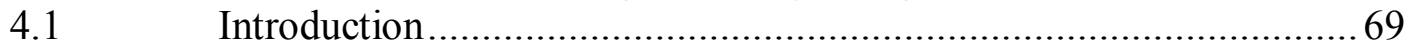

4.2 Materials and Methods .............................................................. 71

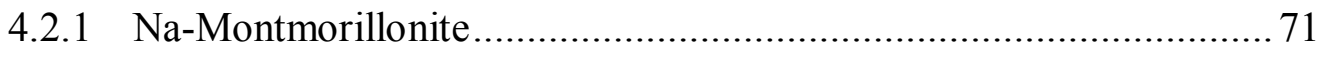

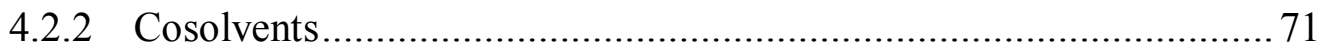

4.2.3 Sodium-Calcium Exchange Experiments ...................................... 72

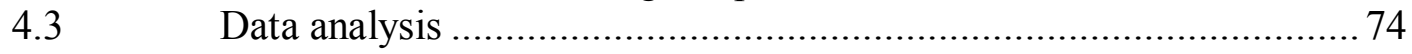

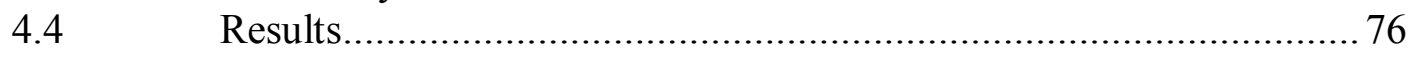

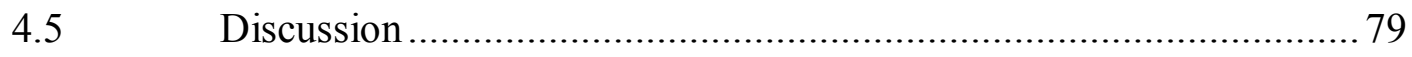

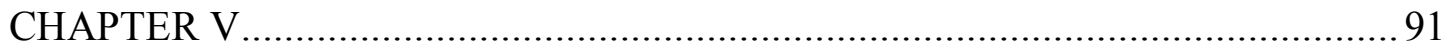

Effect of Cosolvents on the Retention Mechanisms of Cd and Zn on Clay Minerals. 91

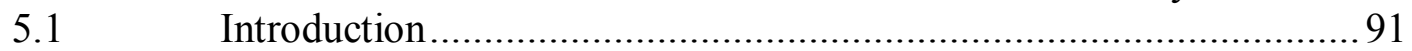

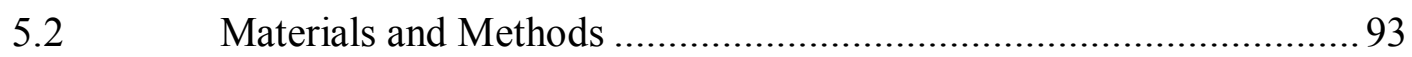

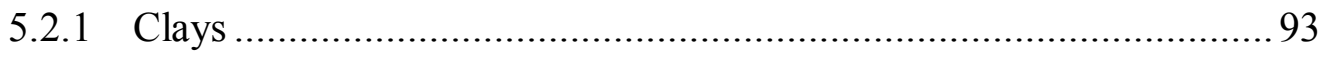

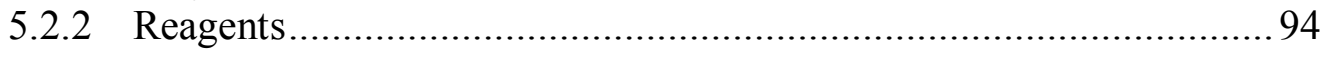

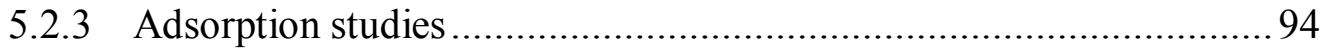

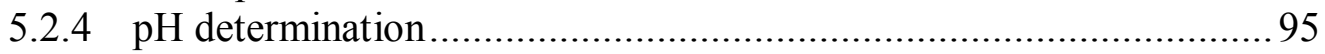

5.2.5 Determination of Stability Constants of the 1:1 ion-pair of $\mathrm{Ca}\left(\mathrm{NO}_{3}\right)_{2} \cdot 4 \mathrm{H}_{2} \mathrm{O}, \mathrm{Zn}\left(\mathrm{NO}_{3}\right)_{2} \cdot 6 \mathrm{H}_{2} \mathrm{O}$ and $\mathrm{Cd}\left(\mathrm{NO}_{3}\right)_{2} \cdot 4 \mathrm{H}_{2} \mathrm{O} \ldots \ldots \ldots \ldots \ldots \ldots . . . . . . . . . .55$

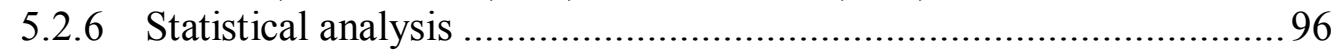

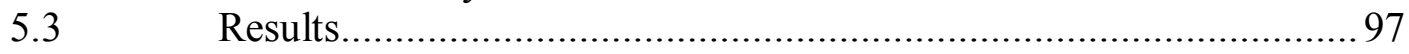

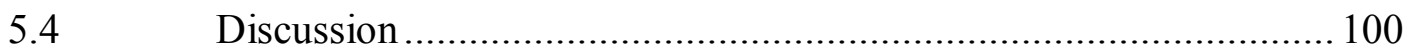

5.4.1 Mechanisms of Cd Retention...................................................... 100

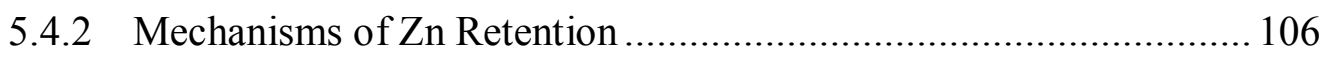

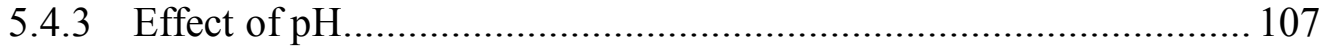

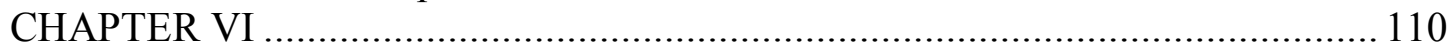

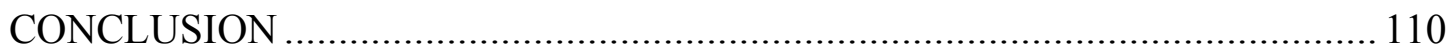

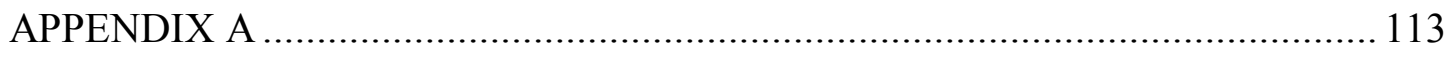

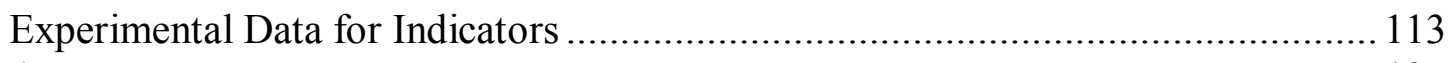

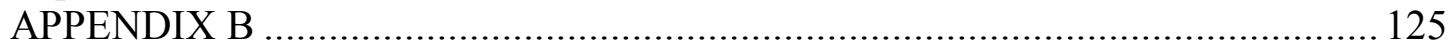

Conductance Data for $\mathrm{Ca}(\mathrm{II}), \mathrm{Cd}(\mathrm{II}), \mathrm{Zn}(\mathrm{II})$ Nitrates and $\mathrm{Ca}(\mathrm{II})$ Chlorides in

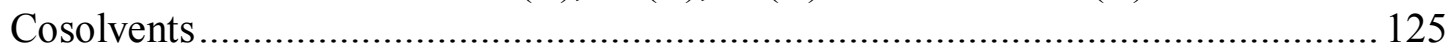

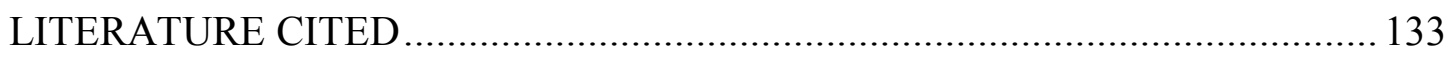




\section{LIST OF TABLES}

Table 1.1. Physical and chemical properties of selected solvents (Izutsu, 2002)........5

Table 1.2. Classification of solvents (Kolthoff, 1974) ............................................6

Table 1.3. Standard Gibbs energies of transfer of ions from water to non-aqueous

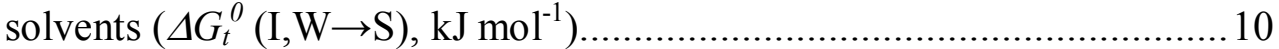

Table 1.4. Medium effects for the proton (Molal scale) in water-methanol solvents at $25^{\circ} \mathrm{C}$, determined by extrapolation methods. (Bates, 1973)......................21

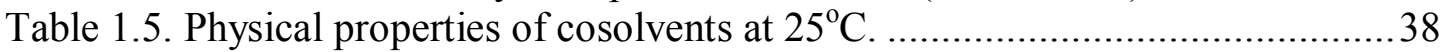

Table 2.1 Values of ${ }_{s} \mathrm{pH}_{\mathrm{RVs}}$ in mixed aqueous alcohol solvents at $25^{\circ} \mathrm{C}$ (Rondinini et

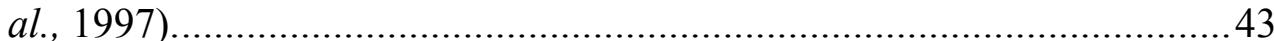

Table 2.2. Experimental data for phenol red indicator in 10\% methanol...................50

Table 2.3. Experimental data for methyl red indicator in $10 \%$ methanol...................51

Table 2.4. Properties of the acidic and basic solutions of PR and MR in various alcohol-water mixtures. .................................................................5. 52

Table 2.5. $\mathrm{pK}_{I}$ for PR and MR in various alcohol-water mixtures............................53

Table 3.1. Limiting equivalent conductance $\left(\Omega^{-1} \mathrm{~cm}^{2} \mathrm{eq}^{-1}\right)$ and ionic association constants, $\mathrm{K}_{1 \mathrm{~A}}$ for various salts at $25^{\circ} \mathrm{C}$

Table 4.1. Experimental data for $\mathrm{Na}-\mathrm{Ca}$ exchange on Wyoming bentonite in methanol-water mixtures at constant total chloride concentration $(\mathrm{TN}=0.03 \mathrm{~N})$ at room temperature

Table 4.2. Experimental data for Na-Ca exchange on Wyoming bentonite in ethanolwater mixtures at constant total chloride concentration $(\mathrm{TN}=0.03 \mathrm{~N})$ at room temperature.

Table 4.3. Experimental data for $\mathrm{Na}-\mathrm{Ca}$ exchange on Wyoming bentonite in acetonewater mixtures at constant total chloride concentration $(\mathrm{TN}=0.03 \mathrm{~N})$ at room temperature.

Table 4.4. Values of $\mathrm{Q}_{0}$ in cosolvent solutions as determined by a cubic polynomial regression of $\mathrm{Q}$ versus equivalent fraction of $\mathrm{Ca}$ in solution.

Table 5.1. Analysis of variance for the partitioning coefficient, $\mathrm{K}_{\mathrm{f}}$, of $\mathrm{Cd}^{2+}$ on clay minerals in mixed aqueous alcohol mixtures.........................................998

Table 5.2. Analysis of variance for the partitioning coefficient, $\mathrm{K}_{\mathrm{f}}$, of $\mathrm{Zn}^{2+}$ on clay minerals in mixed aqueous alcohol mixtures

Freundlich constants for $\mathrm{Cd}^{2+}$ and $\mathrm{Zn}^{2+}$ sorption to Wyoming Bentonite and Illite in methanol-water and ethanol-water mixtures in $2.5 \mathrm{mmol} \mathrm{L}^{-1}$ $\mathrm{Ca}\left(\mathrm{NO}_{3}\right)_{2}$ background electrolyte. (Solution phase concentrations were $\mu \mathrm{mol} \mathrm{L}{ }^{-1}$, solid phase concentrations were $\mu \mathrm{mol} \mathrm{g}{ }^{-1}$ ).

Table A.1. Experimental data for phenol red indicator in water.

Table A.2. Experimental data for methyl red indicator in water............................ 114

${ }^{\mathrm{e}}$ Corrected absorbance calculated using Eq [2.14]............................. 114

Table A.3. Experimental data for phenol red indicator in 30\% methanol............... 115

Table A.4. Experimental data for methyl red indicator in 30\% methanol................ 116

Table A.5. Experimental data for phenol red indicator in 50\% methanol............... 117

Table A.6. Experimental data for methyl red indicator in 50\% methanol................ 118 
Table A.7. Experimental data for phenol red indicator in $10 \%$ ethanol 119

Table A.8. Experimental data for methyl red indicator in 10\% ethanol................... 120

Table A.9. Experimental data for phenol red indicator in 30\% ethanol................... 121

Table A.10. Experimental data for methyl red indicator in 30\% ethanol.................. 122

Table A.11. Experimental data for phenol red indicator in 50\% ethanol................. 123

Table A.12. Experimental data for methyl red indicator in 50\% ethanol................. 124

Table B.1. Conductance of $\mathrm{Ca}\left(\mathrm{NO}_{3}\right)_{2} \cdot 4 \mathrm{H}_{2} \mathrm{O}$ in alcohol-water mixtures at $25^{\circ} \mathrm{C} \ldots . .125$

Table B.2. Conductance of $\mathrm{Cd}\left(\mathrm{NO}_{3}\right)_{2} \cdot 4 \mathrm{H}_{2} \mathrm{O}$ in alcohol-water mixtures at $25^{\circ} \mathrm{C}$...... 126

Table B.3. Conductance of $\mathrm{Zn}\left(\mathrm{NO}_{3}\right)_{2} \cdot 6 \mathrm{H}_{2} \mathrm{O}$ in alcohol-water mixtures at $25^{\circ} \mathrm{C} \ldots . .127$

Table B.4. Conductance of $\mathrm{CaCl}_{2}$ in methanol-water mixtures at $25^{\circ} \mathrm{C}$.................. 128

Table B.5. Conductance of $\mathrm{CaCl}_{2}$ in ethanol-water mixtures at $25^{\circ} \mathrm{C} \ldots \ldots \ldots \ldots \ldots \ldots \ldots . . . .129$

Table B.6. Conductance of $\mathrm{CaCl}_{2}$ in acetone-water mixtures at $25^{\circ} \mathrm{C}$................... 130 


\section{LIST OF FIGURES}

Figure 1.1. The effect of solvent dielectric constant on the electrostatic solvation energy of an ion $\left(r_{i}=0.2 \mathrm{~nm}\right)$.

Figure 1.2. Changes in the single ion activity coefficient as a function of ionic strength at various solvent dielectric constants (for $\mathrm{a}_{i}=4 \mathrm{~nm}$ ).

Figure 1.3. Changes in the ion association constant $\left(\log \mathrm{K}_{\mathrm{A}}\right)$ as a function of the reciprocal of solvent dielectric constant $\left(1 / \varepsilon_{\mathrm{r}}\right)$ for $\mathrm{a}_{\mathrm{B}-\mathrm{F}}=0.6 \mathrm{~nm}$ (Izutsu, 2002).

Figure 1.4. Changes in the electrical potential, $\psi$, as a function of $\mathrm{x}$, the distance from the clay particle for various values of dielectric constant, $\varepsilon_{\mathrm{r}}$ (Fernandez and

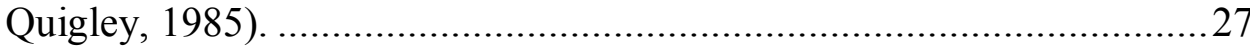

Figure 1.5. Changes in the hydraulic conductivity, $\mathrm{k}$, of the pore fluid of dry clay soils with reciprocal dielectric constant, $\varepsilon_{\mathrm{r}}$. (Data from Fernandez and Quigley, 1985).

Figure 1.6. Effect of cosolvents on the d-spacing of Ca-montmorillonite (Brindley et al., 1969).

Figure 2.1. Absorbance versus wavelength for the acidic (HPR) and the basic (PR') form of phenol red (PR) indicator in 10\% methanol-water mixtures. ......53

Figure 2.2. Absorbance versus wavelength for the acidic (HMR) and the basic (MR') form of methyl red (MR) indicator in 10\% methanol-water mixtures......54

Figure 2.3. Changes in the negative logarithm of the dissociation constant, ${ }_{s} \mathrm{pK}_{I}$, of $\mathrm{MR}$ and $\mathrm{PR}$ in alcohol-water mixtures at constant ionic strength with $100 / \varepsilon_{\mathrm{r}}$. $\mathrm{PR}$, methanol; - PR, ethanol; O MR, methanol; • MR, ethanol.

Figure 3.1. Variation of the Walden products, $\Lambda_{0} \eta$, of nitrate salts with solvent composition at $25^{\circ} \mathrm{C} . \diamond, \mathrm{Ca}\left(\mathrm{NO}_{3}\right)_{2} .4 \mathrm{H}_{2} \mathrm{O} ; \square, \mathrm{Zn}\left(\mathrm{NO}_{3}\right)_{2} .6 \mathrm{H}_{2} \mathrm{O} ; \boldsymbol{\Delta}$, $\mathrm{Cd}\left(\mathrm{NO}_{3}\right)_{2} \cdot 6 \mathrm{H}_{2} \mathrm{O}$. (Error bars are smaller than data points)

Figure 3.2. Variation of the Walden products, $\Lambda_{0} \eta$, of $\mathrm{CaCl}_{2}$ with solvent composition at $25^{\circ} \mathrm{C}$. (Error bars are smaller than data points).

Figure 3.3. Variation of the $\log \mathrm{K}_{1 \mathrm{~A}}$ with the reciprocal dielectric constant in alcoholwater mixtures at $25^{\circ} \mathrm{C}$. (Error bars are smaller than data points).

Figure 3.4. Variation of $\log \mathrm{K}_{1 \mathrm{~A}}$ of $\mathrm{CaCl}_{2}$ with the reciprocal dielectric constant in cosolvents at $25^{\circ} \mathrm{C}$. (Error bars are samller than data points).

Figure 4.1. Changes in the single ion activity ratio (as predicted by Debye-Hückel equation) as a function of $100 / \varepsilon_{\mathrm{r}}$ in $\Delta$ methanol, $\square$ ethanol and $\diamond$ acetone.

Figure 4.2. Ca-Na exchange isotherms on Wyoming Bentonite at $0.03 \mathrm{~mol} \mathrm{~L}-1$ total electrolyte concentration in methanol, ethanol and acetone-water systems.

Figure 4.3. Exchange isotherms for $\mathrm{CaCl}^{+}$(left-hand side) and $\mathrm{Ca}^{2+}$ (right-hand side) on Wyoming bentonite at constant total chloride concentration $(0.03 \mathrm{~mol}$

$\mathrm{L}^{-1}$ ) in methanol water systems, corrected for $\mathrm{CaCl}^{+}$. .86

Figure 4.4. Exchange isotherms for $\mathrm{CaCl}^{+}$(left-hand side) and $\mathrm{Ca}^{2+}$ (right-hand side) on Wyoming bentonite at constant total chloride concentration $(0.03 \mathrm{~mol}$ 
$\left.\mathrm{L}^{-1}\right)$ in ethanol-water systems, corrected for $\mathrm{CaCl}^{+}$. Full symbol; water,

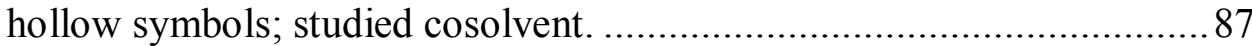

Figure 4.5. Exchange isotherms for $\mathrm{CaCl}^{+}$(left-hand side) and $\mathrm{Ca}^{2+}$ (right-hand side) on Wyoming bentonite at constant total chloride concentration $(0.03 \mathrm{~mol}$ $\left.\mathrm{L}^{-1}\right)$ in acetone-water systems, corrected for $\mathrm{CaCl}^{+}$. Full symbol; water, hollow symbols; studied cosolvent.

Figure 5.1. Effect of $100 / \varepsilon_{\mathrm{r}}$ on the partition coefficient, $\mathrm{K}_{\mathrm{f}}$, of $\mathrm{Cd}^{2+}$ and $\mathrm{Zn}^{2+}$ sorption to clay minerals in $2.5 \mathrm{mmol} \mathrm{L}^{-1} \mathrm{Ca}\left(\mathrm{NO}_{3}\right)_{2}$ background electrolyte....... 104

Figure 5.2. Cosolvent effect on $\%$ metal coverage at low $(2 \mu \mathrm{M})$ and high $(10 \mu \mathrm{M})$ initial metal concentrations, $\mathrm{C}_{\mathrm{i}}$ : $\square$, Low $\mathrm{C}_{\mathrm{i}}$, EtOH; ○, High $\mathrm{C}_{\mathrm{i}}, \mathrm{EtOH} ; \diamond$, Low $\mathrm{C}_{\mathrm{i}}, \mathrm{MeOH} ; \Delta$, High $\mathrm{C}_{\mathrm{i}}, \mathrm{MeOH}$.

Figure 5.3. Effect of $100 / \varepsilon_{\mathrm{r}}$ on the equilibrium $\mathrm{pH}$, as determined by spectrophotometry in $\mathrm{Cd}$ and $\mathrm{Zn}$ sorption to $\square$ Bentonite and $\square$ Illite clays.

Figure B.1. Fuoss and Edelson plots based on Eq [3.6]; $\diamond \mathrm{Ca}$ (II), o Cd (II) and $\Delta$ $\mathrm{Zn}$ (II) nitrates at $25 \mathrm{oC}$ : (a) $10 \% \mathrm{MeOH}$, (b) $30 \% \mathrm{MeOH}$, (c) $50 \% \mathrm{MeOH}$, (d) $10 \% \mathrm{EtOH}$, (e) $30 \% \mathrm{EtOH}$, (f) $50 \% \mathrm{EtOH}$. 131

Figure B.2. Fuoss and Edelson plots for $\mathrm{CaCl}_{2}$ based on $\mathrm{Eq}$ [3.6]; $\square$ methanol, o ethanol, and $\Delta$ acetone-water mixtures at $25^{\circ} \mathrm{C}$. (a) $10 \% \mathrm{wt}$, (b) $30 \% \mathrm{wt}$, (c) $50 \% \mathrm{wt}$, (d) $70 \% \mathrm{wt}$ 


\section{LIST OF ABBREVIATIONS}

\begin{tabular}{|c|c|}
\hline HOAc & Acetic Acid \\
\hline Ac & Acetone \\
\hline HIn & Acid form of an indicator \\
\hline $\mathrm{Al}$ & Aluminum \\
\hline $\mathrm{NH}_{3}$ & Ammonia \\
\hline $\mathrm{NH}_{4}^{+}$ & Ammonium cation \\
\hline $\mathrm{SbCl}_{5}$ & Antimony (V) Chloride \\
\hline$\sim$ & Approximately \\
\hline $\operatorname{In}^{-}$ & Base form of an indicator \\
\hline $\mathrm{Br}^{-}$ & Bromide anion \\
\hline $\mathrm{Cd}$ & Cadmium \\
\hline $\mathrm{Cd}\left(\mathrm{NO}_{3}\right)_{2} \cdot 6 \mathrm{H}_{2} \mathrm{O}$ & Cadmium Nitrate Hexahydrate \\
\hline $\mathrm{Cd}\left(\mathrm{NO}_{3}\right)^{+}$ & Cadmium Nitrate ion-pair \\
\hline $\mathrm{Ca}$ & Calcium \\
\hline $\mathrm{CaCl}_{2}$ & Calcium Chloride \\
\hline $\mathrm{CaCl}^{+}$ & Calcium Chloride ion-pair \\
\hline $\mathrm{Ca}\left(\mathrm{NO}_{3}\right)_{2} \cdot 4 \mathrm{H}_{2} \mathrm{O}$ & Calcium Nitrate Tetrahydrate \\
\hline$\left(\mathrm{C}_{2} \mathrm{H}_{5}\right)_{3} \mathrm{PO}$ & Triethyl Phosphate \\
\hline $\mathrm{CCl}_{4}$ & Carbon Tetrachloride \\
\hline CEC & Cation Exchange Capacity \\
\hline CAS & Chemical Abstracts Service \\
\hline $\mathrm{cm}$ & Centimeter \\
\hline
\end{tabular}




\begin{tabular}{|c|c|}
\hline $\mathrm{cmol}_{\mathrm{c}} \mathrm{kg}^{-1}$ & Centimole of Charge per Kilogram \\
\hline $\mathrm{cP}$ & CentiPoise \\
\hline $\mathrm{Cl}^{-}$ & Chloride ion \\
\hline CMOS & Completely Miscible Organic Solvents \\
\hline [] & Concentration \\
\hline $\mathrm{CN}^{-}$ & Cyanide anion \\
\hline${ }^{\circ} \mathrm{C}$ & Degree Celsius \\
\hline DMSO & Dimethyl Sulfoxide \\
\hline DMF & Dimethyl Formamide \\
\hline $\mathrm{EC}$ & Electrical conductivity \\
\hline$=$ & Equal to \\
\hline $\mathrm{Eq}$ & Equation \\
\hline e.m.f. & Electromotive force \\
\hline $\mathrm{E}_{\mathrm{X}}$ & Electromotive force of the unknown sample, $X$ \\
\hline $\mathrm{E}_{\mathrm{RVS}}$ & Electromotive force of the Reference Value Standard \\
\hline eq $\mathrm{L}^{-1}$ & Equivalent per liter \\
\hline et al. & et allai (and others) \\
\hline EPA & Environmental Protection Agency \\
\hline EtOH & Ethanol \\
\hline EDTA & Ethylene Diamine Tetraacetic Acid \\
\hline e.g. & Example \\
\hline $\mathrm{F}^{-}$ & Fluoride anion \\
\hline (g) & Gaseous phase \\
\hline
\end{tabular}




\begin{tabular}{|c|c|}
\hline $\mathrm{g}$ & Gram \\
\hline $\mathrm{g} \mathrm{cm}^{-3}$ & Gram per centimeter cube \\
\hline$>$ & Greater than \\
\hline $\mathrm{DN}$ & Gutmann's donor number \\
\hline AN & Gutmann's acceptor number \\
\hline hrs & Hours \\
\hline $\mathrm{HF}$ & Hydrofluoric acid \\
\hline $\mathrm{H}^{+}$ & Hydronium ion \\
\hline $\mathrm{HCl}$ & Hydrochloric acid \\
\hline $\mathrm{pH}$ & Hydrogen potential in aqueous solvents \\
\hline${ }_{s} \mathrm{pH}$ & Hydrogen potential in solvent $s$ \\
\hline${ }_{s} \mathrm{pH}_{\mathrm{X}}$ & Hydrogen potential of an unknown, $\mathrm{X}$, in solvent $s$ \\
\hline${ }_{s} \mathrm{pH}_{\mathrm{RVS}}$ & Hydrogen potential of the Reference Value Standard in solvent \\
\hline$s$ & \\
\hline IUPAC & International Union of Pure and Applied Chemistry \\
\hline $\mathrm{Fe}$ & Iron \\
\hline $\mathrm{I}^{-}$ & Iodide \\
\hline $\mathrm{kg}$ & Kilogram \\
\hline $\mathrm{kJ} \mathrm{mol}^{-1}$ & KiloJoule per mole \\
\hline$<$ & Less than \\
\hline $\mathrm{L}$ & Liter \\
\hline $\mathrm{Li}^{+}$ & Lithium ion \\
\hline $\log$ & Logarithm \\
\hline
\end{tabular}




\begin{tabular}{|c|c|}
\hline $\ln$ & Natural Logarithm \\
\hline $\mathrm{Mg}$ & Magnesium \\
\hline Max & Maximum \\
\hline $\mathrm{MeOH}$ & Methanol \\
\hline MR & Methyl Red indicator \\
\hline$\mu \mathrm{g}$ & Microgram \\
\hline $\mathrm{mg}$ & Milligram \\
\hline $\mathrm{mmHg}$ & Millimiter of mercury \\
\hline $\mathrm{mmol}_{\mathrm{c}} \mathrm{kg}^{-1}$ & Millimole of positive charge per kilogram \\
\hline $\mathrm{mV}$ & Millivolt \\
\hline $\min$ & Minutes \\
\hline$\mu \mathrm{Scm}^{-1}$ & MicroSiemens per centimeter \\
\hline mol & Mole \\
\hline $\operatorname{mol~L}{ }^{-1}$ & Mole per liter \\
\hline $\mathrm{mol} \mathrm{kg}^{-1}$ & Mole per kilogram \\
\hline $\mathrm{nm}$ & Nanometer \\
\hline $\mathrm{NO}_{3}$ & Nitrate \\
\hline $\mathrm{N}_{2}$ & Nitrogen gas \\
\hline $\mathrm{N}$ & Normal \\
\hline NMR & Nuclear Magnetic Resonance \\
\hline No & Number \\
\hline ppm & Parts per million \\
\hline PMOS & Partially Miscible Organic Solvents \\
\hline
\end{tabular}




\begin{tabular}{|c|c|}
\hline$\%$ & Percentage \\
\hline$\% \mathrm{wt}$ & Percentage weight \\
\hline \pm & Plus or minus \\
\hline PR & Phenol Red indicator \\
\hline${ }^{31} \mathrm{P}$ & Phosphorus isotope 31 \\
\hline $\mathrm{KH}_{2} \mathrm{PO}_{4}$ & Potassium Dihydrogen Phosphate \\
\hline RVS & Reference value standard \\
\hline $\mathrm{Ag}^{+}$ & Silver ion \\
\hline $\mathrm{Si}$ & Silicon ion \\
\hline $\mathrm{AgCl}$ & Silver Chloride \\
\hline $\mathrm{Na}$ & Sodium \\
\hline $\mathrm{NaOAc}$ & Sodium Acetate \\
\hline $\mathrm{Na}_{2} \mathrm{HPO}_{4}$ & Sodium Hydrogen Phosphate \\
\hline $\mathrm{NaOH}$ & Sodium Hydroxide \\
\hline $\mathrm{H}_{2} \mathrm{SO}_{4}$ & Sulfuric acid \\
\hline$t-\mathrm{BuOH}$ & Tertiary butyl-hydroxide \\
\hline $\mathrm{SCN}^{-}$ & Thiocyanate ion \\
\hline $\mathrm{UV}-\mathrm{Vis}$ & Ultraviolet and visible electromagnetic spectra \\
\hline $\mathrm{v} / \mathrm{v}$ & Volume-to-Volume \\
\hline $\mathrm{Zn}$ & Zinc \\
\hline $\mathrm{Zn}\left(\mathrm{NO}_{3}\right)_{2} \cdot 6 \mathrm{H}_{2} \mathrm{O}$ & Zinc Nitrate Hexahydrate \\
\hline $\mathrm{Zn}\left(\mathrm{NO}_{3}\right)^{+}$ & Zinc Nitrate ion-pair \\
\hline $\mathrm{wt} / \mathrm{wt}$ & Weight-to-weight \\
\hline
\end{tabular}




\section{LIST OF SYMBOLS \& CONSTANTS}

\begin{tabular}{|c|c|}
\hline$A_{\lambda_{H l n}^{H I n}}^{H I}$ & Absorbance of compound HIn at $\lambda_{\mathrm{HIn}}$ \\
\hline $\mathrm{a}$ & Combined cation and anion ion size parameter \\
\hline$a_{B-F}$ & Distance of closest approach \\
\hline$a_{i}$ & Debye-Hückel ion size parameter \\
\hline$A_{D-H}$ & Debye-Hückel parameter \\
\hline$\AA$ & Angstrom \\
\hline$\alpha$ & Polarizability (always negative) \\
\hline$\alpha_{\text {On }}$ & Onsager coefficient \\
\hline$b_{a}$ & Cell path length \\
\hline $\mathrm{b}$ & Parameter in Fuoss definition of ion pairs \\
\hline $\mathrm{B}_{\mathrm{D}-\mathrm{H}}$ & Debye-Hückel parameter \\
\hline $\mathrm{B}_{\mathrm{P}}$ & Boiling point \\
\hline$\beta$ & Onsager coefficient \\
\hline $\mathrm{C}_{\mathrm{i}}$ & Ion concentration \\
\hline $\mathrm{C}_{\mathrm{T}}$ & Total concentration \\
\hline$\delta$ & Onsager's slope \\
\hline$\delta_{\mathrm{s}}$ & Solubility parameter \\
\hline$e_{0}$ & Electronic charge \\
\hline$\varepsilon_{\mathrm{r}}$ & Bulk dielectric constant \\
\hline$\varepsilon_{0}$ & Permittivity of vacuum \\
\hline$\epsilon$ & Molar absorptivity \\
\hline $\mathrm{E}_{\mathrm{C}}$ & Coulombic energy \\
\hline
\end{tabular}




\begin{tabular}{|c|c|}
\hline F & Faraday constant \\
\hline$F_{P}$ & Freezing point \\
\hline$\gamma_{\mathrm{i}}$ & single ion activity coefficient \\
\hline $\mathrm{h}$ & Planck's constant \\
\hline$\eta$ & Absolute viscosity \\
\hline$\{i\}$ & Activity of ion i \\
\hline I & Ionic strength \\
\hline $\mathrm{k}$ & Boltzmann's constant \\
\hline $\mathrm{K}$ & Hydraulic conductivity \\
\hline $\mathrm{K}_{\mathrm{A}}$ & Ion association constant \\
\hline $\mathrm{K}_{\mathrm{ap}}$ & Autoprotolysis constant \\
\hline${ }_{s} \mathrm{~K}_{I}$ & Acid dissociation constant of indicator in solvent $s$ \\
\hline $\mathrm{K}_{1 \mathrm{~A}}$ & Primary ion pair formation constant \\
\hline $\mathrm{K}_{2 \mathrm{~A}}$ & Secondary ion pair formation constant \\
\hline $\mathrm{K}_{\mathrm{f}}$ & Freundlich partition coefficient \\
\hline $\mathrm{K}_{\mathrm{ow}}$ & Octanol-partitioning coefficient \\
\hline $\mathrm{K}_{\mathrm{sp}}$ & Solubility product \\
\hline $\mathrm{K}_{\mathrm{v}}$ & Vanselow selectivity coefficient \\
\hline$\kappa^{-1}$ & Reciprocal Debye length \\
\hline$\Lambda$ & Equivalent conductance \\
\hline$\Lambda_{0}$ & Limiting equivalent conductance \\
\hline$\lambda_{0}$ & Single ion limiting equivalent conductance \\
\hline $\mathrm{L}$ & Ligand \\
\hline
\end{tabular}




\begin{tabular}{|c|c|}
\hline$\lambda$ & Wavelength in nanometer \\
\hline M & Metal ion \\
\hline$m$ & Molality \\
\hline $1 / \mathrm{n}$ & Freundlich parameter \\
\hline $\mathrm{N}_{\mathrm{A}}$ & Avogadro's constant \\
\hline$n_{i}$ & Number of ions (i) \\
\hline$\Omega^{-1}$ & mohs \\
\hline q & Distance parameter in Bjerrum equation \\
\hline$r$ & Distance from surface of ion or particle \\
\hline$r_{B-F}$ & Distance parameter in Bjerrum and Fuoss equation \\
\hline$r_{i}$ & Ionic radius \\
\hline$r_{F}$ & Radius in Fuoss equation \\
\hline$r_{m}$ & Minimum separation distance \\
\hline $\mathrm{R}$ & Universal gas constant \\
\hline$\rho$ & Density \\
\hline$\sigma$ & Effective molecular distance \\
\hline $\mathrm{T}$ & Absolute temperature in Kelvin \\
\hline$V_{i}$ & Volume of titrant \\
\hline $\mathrm{V}_{\mathrm{T}}$ & Total volume \\
\hline $\mathrm{V}_{\mathrm{s}}$ & Solvent volume \\
\hline$\mu$ & Dipole moment \\
\hline $\mathrm{u}_{\mathrm{m}}$ & Potential energy minimum \\
\hline $\mathrm{u}(\mathrm{r})$ & Potential energy \\
\hline
\end{tabular}




$\begin{array}{ll}v & \text { Vibrational frequency of electrons (always negative) } \\ z^{+} & \text {Cation valence } \\ z^{-} & \text {Anion valence } \\ z_{i} & \text { Ion valence } \\ \Phi_{\mathrm{B}} & \text { Born potential energy } \\ \zeta & \text { Proportionality constant } \\ \Phi_{\mathrm{vdW}} & \text { van der Waals potential } \\ \Phi_{\mathrm{m}} & \text { Minimum potential energy } \\ \Phi_{\mathrm{r}} & \text { Lennard-Jones 6-12 pair potential } \\ \psi_{\mathrm{x}} & \text { Electrical potential at distance } r \text { from the clay particle } \\ \psi_{0} & \text { Slectrical potential at the surface of the clay particle } \\ \Delta G_{e l} & \text { Stectrostatic Gibbs free energy } \\ \Delta G_{\text {lattice }}^{0} & \text { Lattice free energy } \\ \Delta G_{t}^{0} & \text { Standard Gibbs energy of transfer } \\ \Delta G_{\text {solv }}^{0} & \text { Solution Gibbs free energy }\end{array}$




\section{CHAPTER I}

\section{INTRODUCTION}

\subsection{Overview}

The disposal of large quantities of industrial, municipal and household wastes into landfills, ponds and injection wells has been practiced for years as it was believed to be a safe practice that would isolate these contaminants from the environment. However, contaminant concentrations in soil/sediment and drinking water samples at some of these sites are far above the US EPA guidelines (Sawhney and Kozloski, 1984). This has raised concerns about groundwater pollution with potentially hazardous chemicals from those underground waste disposal sites.

Despite the increased efforts toward remediation and proper waste disposal, predicting contaminant behavior in these sites has proven difficult. The difficulty arises from the complexity of these sites where high levels of contaminants containing specific radionuclides, metals, organic ligands, and organic solvents exist in various binary and ternary combinations (Riley and Zachara, 1992). These mixtures are likely to exhibit complex geochemical behavior as a result of comingling. Certain components within these mixtures may undergo chemical interactions that either facilitate or retard their dissemination in the environment.

Studies have been conducted to identify these mixtures and the levels at which they exist in the environment (Artiola-Fortuny and Fuller, 1982; Bedient et al., 1983). Fewer studies have aimed at understanding the fundamental chemical and physical nature of their interactions and the processes that result in their subsurface migration (Green et al., 1983; Sheet and Fuller, 1986; Brown and Thomas, 1987). 
In this context, the primary objective of this review is to provide a fundamental understanding of the major reactions controlling ion-solvent and surfacesolvent interactions, in light of the major physicochemical properties of non-aqueous and mixed aqueous organic solvents. Special attention will be given to clay minerals, given their use in landfill liners and their substantial role in determining contaminant transport. A summary of the major work conducted on metal/clay interactions in water miscible organic solvents will also be presented.

It is not the objective of this review to present a complete discussion of nonaqueous and mixed aqueous organic solvent chemistry; several books have been published for this purpose (e.g; Popovytch and Tomkins, 1981; Reichardt, 1988; and Izutsu, 2002). The aim is to present a basic discussion of the important processes governing ion-solvent and surface-solvent interactions to provide a framework for understanding metal/clay behavior in non-aqueous and mixed aqueous organic solutions.

\subsection{Solvent Properties \& Classification schemes}

Solvent properties likely to influence metal/clay interactions are given in Table 1.1 (Reichardt, 1988; Atkins, 1998). The boiling point, $\mathrm{B}_{\mathrm{p}}$, and the freezing point, $\mathrm{F}_{\mathrm{p}}$, determine the liquid range of the solvent. The vapor pressure is important when considering the problem of vaporization and toxicity of solvents. Several empirical parameters have been proposed to quantitatively express the relative acidity and basicity of solvents (Reicherdt, 1988). Gutmann's donor number, DN, is defined as the negative enthalpy of the reaction between the solvent and $\mathrm{SbCl}_{5}$ in 1,2- 
dichloroethane and measures Lewis base strength. The higher the donor number, the stronger is the Lewis base. The Lewis acid strength is given by the acceptor number, AN, which is measured by ${ }^{31} \mathrm{P}$ NMR shift of the reference base $\left(\mathrm{C}_{2} \mathrm{H}_{5}\right)_{3} \mathrm{PO}$ in pure solvent. The higher the acceptor number, the stronger is the Lewis acid. It is generally agreed that in solvents with high permittivities, differences in reactions or equilibria among the solvents are often caused by differences in the solvent acidity/basicity (Izutsu, 2002). The dielectric constant, $\varepsilon_{\mathrm{r}}$, (relative permittivity) influences the electrostatic interactions between charged particles (Izutsu, 2002). An electric dipole consists of two electric charges separated by a distance, $r$. The electric dipole moment, $\mu$, is a vector that points from a negative charge $(-q)$ to a positive charge $(q)$, the magnitude of which is $\mu=q r$ (Atkins, 1998). Dielectric constant, dipole moment, $\mu$, and the relative acidity and basicity of the solvents are often used as criteria to classify solvents.

Several classification schemes for solvents have been proposed because no single scheme is appropriate for all uses. Yalkowsky et al., (1976), classified solvents according to their miscibility with water and their interfacial free energy. Completely miscible organic solvents (CMOS) like lower alcohols and acetonitrile were distinguished from partially miscible organic solvents (PMOS) like o-cresol and trichloroethylene. This classification is usually based on the solubility parameter, $\delta$, (defined as $\delta=\mathrm{C}_{\mathrm{i}}{ }^{1 / 2}$ where $\mathrm{C}_{\mathrm{i}}$ is the electrolyte concentration). Miscible solvents have similar $\delta$-values, immiscible solvents have dissimilar $\delta$-values. Rao and coworkers (Rao et al., 1990, Nkedi-Kizza et al., 1985) used this approach to describe the effect of organic solvents on hydrophobic organic chemicals sorption and transport. A 
commonly used scheme, originally proposed by Kolthoff (Kolthoff, 1974), uses the dielectric constant as well as the acid and base properties of the solvent (Table 1.2). 


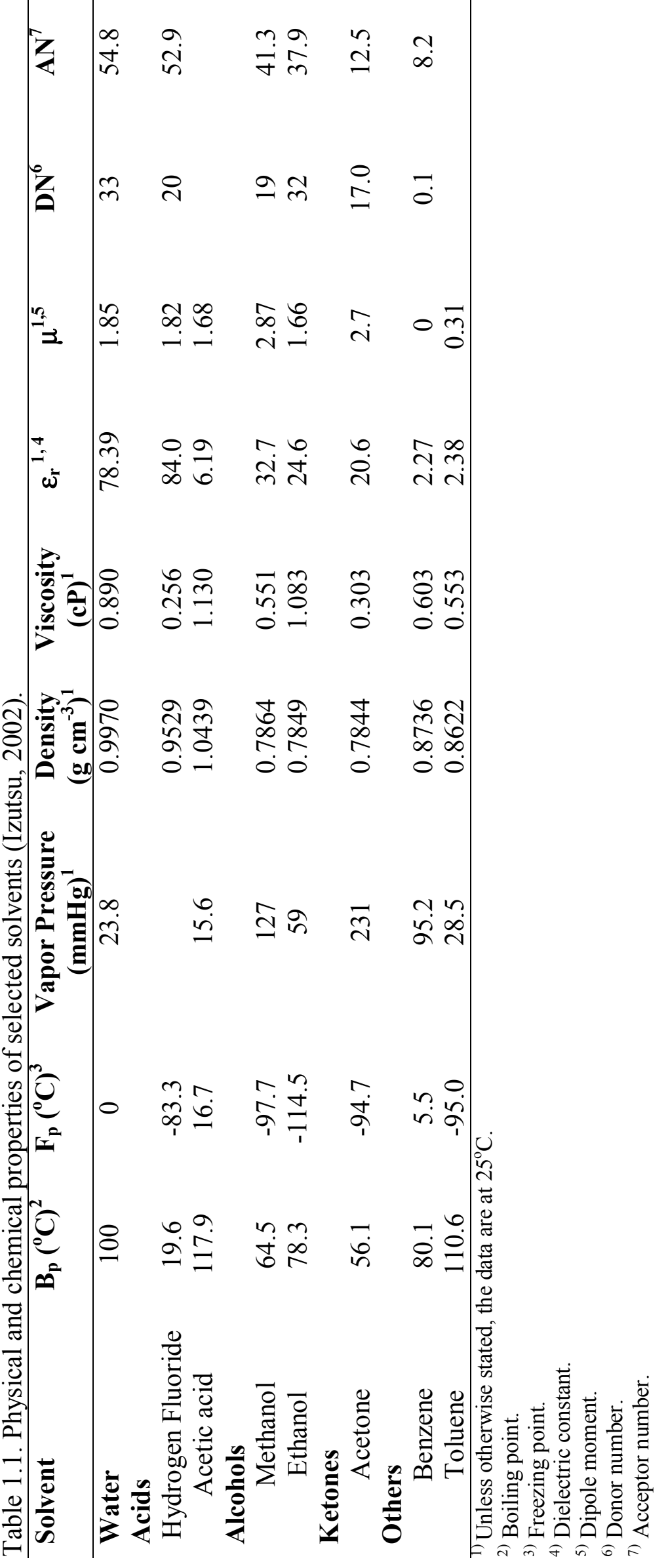


Table 1.2. Classification of solvents (Kolthoff, 1974)

\begin{tabular}{|c|c|c|c|c|c|}
\hline 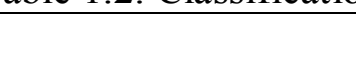 & No. & $\varepsilon_{\mathrm{r}}, \mu^{1)}$ & Acidity $^{2)}$ & Basicity $^{2)}$ & Examples \\
\hline \multicolumn{6}{|l|}{$\begin{array}{c}\text { Amphiprotic } \\
\text { solvents }\end{array}$} \\
\hline \multirow[t]{2}{*}{ Neutral } & $1 \mathrm{a}$ & + & + & + & $\begin{array}{l}\text { Water, methanol, } \\
\text { ethanol }\end{array}$ \\
\hline & $1 b$ & - & + & + & $t-\mathrm{BuOH}$ \\
\hline \multirow[t]{2}{*}{ Protogenic } & $2 \mathrm{a}$ & + & ++ & \pm & $\mathrm{H}_{2} \mathrm{SO}_{4}, \mathrm{HF}$ \\
\hline & $2 b$ & - & ++ & \pm & $\mathrm{CH}_{3} \mathrm{COOH}$ \\
\hline \multirow[t]{2}{*}{ Protophilic } & $3 a$ & + & \pm & ++ & $\mathrm{DMSO}, \mathrm{NH}_{3}$ \\
\hline & $3 b$ & - & \pm & ++ & Tetramethylguanidine \\
\hline \multicolumn{6}{|l|}{ Aprotic solvents } \\
\hline \multirow[t]{2}{*}{ Dipolar protophilic ${ }^{3)}$} & $4 a$ & + & $-( \pm)$ & $++(+)$ & DMSO \\
\hline & $4 b$ & - & - & $++(+)$ & Pyridine \\
\hline \multirow{2}{*}{ Dipolar protophobic } & $5 a$ & + & $-( \pm)$ & - & Acetonitrile \\
\hline & $5 b$ & - & - & - & Methylethylketone \\
\hline Inert & $5 \mathrm{c}$ & - & - & - & $\mathrm{CCl}_{4}$ \\
\hline
\end{tabular}

1) The symbol "+" is for $\varepsilon_{\mathrm{r}} \geq 15$ or $20, \mu \geq 2.5$ and "-" for $\varepsilon_{\mathrm{r}}<15$, or $20, \mu<2.5$.

2) The symbol " + " is for the case comparable with water, " ++ " for case much stronger than water, " \pm " for the case somewhat weaker than water, and "-" for the case much weaker than water.

${ }^{3)}$ Some solvent with $\varepsilon_{\mathrm{r}}<15(\mu<2.5)$ are also classified as "dipolar". 


\subsection{Ion-Solvent Interactions}

\subsubsection{Ion Solvation}

The relative solubility of electrolytes in non-aqueous and mixed aqueous organic solvents are largely influenced by the extent of solvation and the changes in the solution local environment dictated by the structure and macroscopic properties (dielectric constant, viscosity, density, equilibrium constants, etc.) of the solvent, as well as the microscopic properties of the individual molecules (dipole moments, polarizability, H-bonding). Ion solvation has a significant effect on the dissolution of an electrolyte and on chemical reactions and equilibria. The ion-solvent interactions that may participate in ion solvation can be divided into electrostatic, non electrostatic and specific chemical including hydrogen bonding, coordination and acid-base reactions. The simplest model for the electrostatic component of ion-solvent interactions was introduced by Born (Born, 1926). In this model, the solvation energy is defined as the change in the Gibbs free energy $\left(\Delta G_{e l}\right)$ when the ion is transferred from vacuum to a solvent and is estimated by the Born equation

$$
\Delta G_{e l}=-\frac{z_{i}^{2} e^{2} N_{A}}{8 \pi \varepsilon_{0} r_{i}}\left(1-\frac{1}{\varepsilon_{r}}\right)
$$

The choice of solvated ionic radius, $\mathrm{r}_{\mathrm{i}}$, and of the solvent dielectric constant, $\varepsilon_{\mathrm{r}}$, are of critical importance and might explain the failure of the Born equation to adequately describe experimental data (Xue and Traina, 1996a), especially when crystallographic radii and the solvent bulk dielectric constants are used. The Born equation has been modified in various ways and recently, the so-called mean spherical approximation 
(MSA), which takes into account the effect of the solvent on the ionic radii has been used in treating ion solvation.

Figure 1.1 shows the relationship between $\varepsilon_{\mathrm{r}}$ and $\Delta G_{e l}$ for a univalent ion, at constant ionic radius. $\Delta G_{e l}$ decreases rapidly in the low dielectric constant region $\left(\varepsilon_{\mathrm{r}}\right.$ $<10)$ and rather slowly in the high permittivity region. In the high permittivity region, the solvation of the ions is more a function of non-electrostatic ion-solvent interactions, such as the Lewis acid/base strength. Cation solvation becomes stronger with the increase in the donor number of solvents. On the other hand, anion solvation is stronger with the increase in the acceptor number. The capacity of the solvent to form hydrogen bonds becomes more important with small anions such as $\mathrm{F}^{-}, \mathrm{Cl}^{-}$, and $\mathrm{OH}^{-}$.

A quantitative way to describe the effect of solvents on ionic solvation is through the introduction of the Gibbs energy of transfer

$$
\Delta G_{t}^{0}(i, R \rightarrow S)=\Delta G_{\text {solv }}^{0}(i, S)-\Delta G_{\text {solv }}^{0}(i, R)
$$

where $\Delta G_{\text {solv }}^{0}(i, R)$ is the solvation energy of species $i$ in solvent $R$ (reference solvent), $\Delta G_{\text {solv }}^{0}(i, S)$ is the solvation energy of $i$ in solvent $S$ and $\Delta G_{t}^{0}(i, R \rightarrow S)$ is the Gibbs free energy of transfer of species $i$ from solvent $R$ to $S$. Table 1.3 represents the standard Gibbs energy of transfer of some ions from water to non-aqueous solvents (Izutsu, 2002).

In mixed aqueous organic solvents, the situation gets more complicated as interactions between unlike molecules, in addition to ion-solvent interactions arise. In those systems, preferential solvation of the ionic species to the component of the mixture which leads to the more negative $\Delta G_{\text {solv }}^{0}$ is observed. For instance, in a 
solution of $\mathrm{CaCl}_{2}$ in water/methanol mixtures, both $\mathrm{Ca}^{2+}$ and $\mathrm{Cl}^{-}$are largely solvated by water whereas a

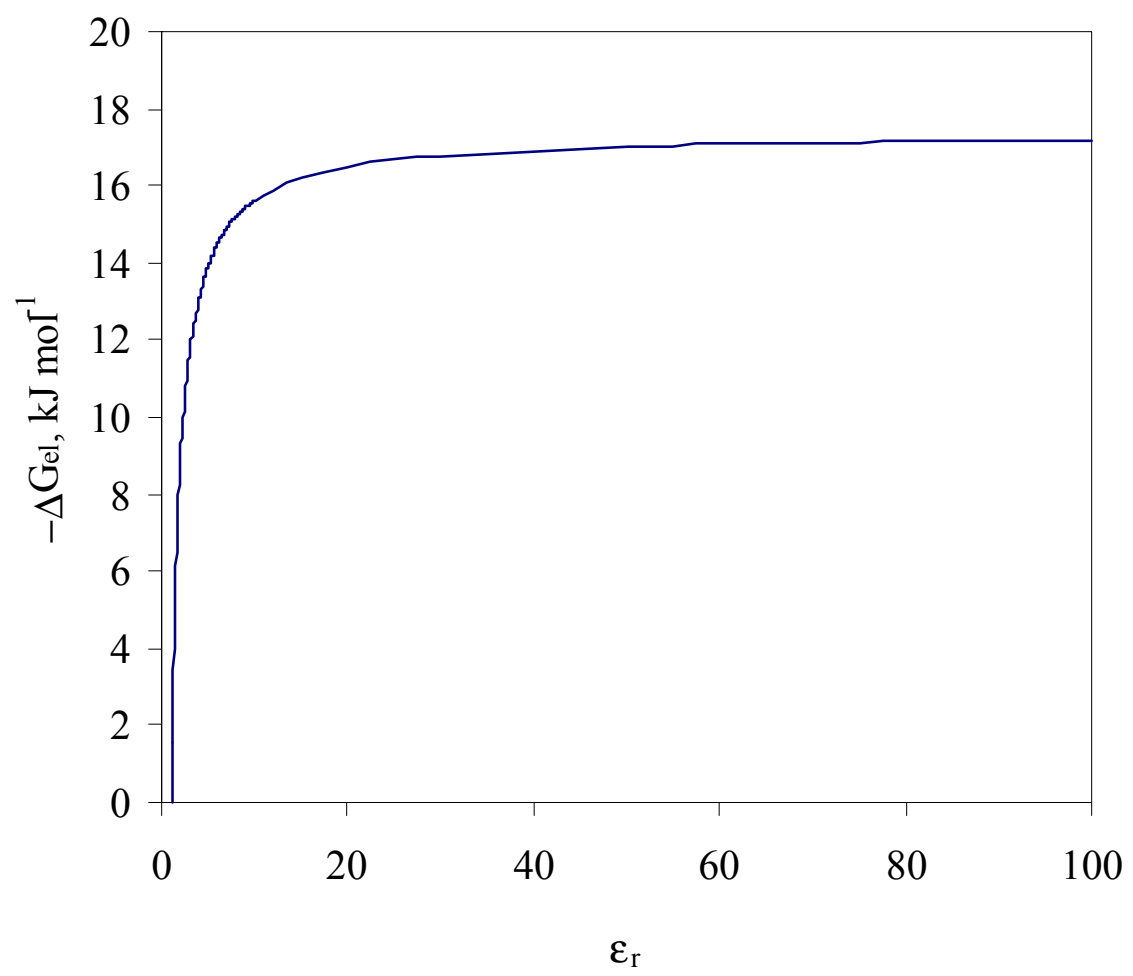

Figure 1.1. The effect of solvent dielectric constant on the electrostatic solvation energy of an ion $\left(r_{i}=0.2 \mathrm{~nm}\right)$. 
Table 1.3. Standard Gibbs energies of transfer of ions from water to non-aqueous solvents $\left(\Delta G_{t}^{0}(\mathrm{I}, \mathrm{W} \rightarrow \mathrm{S}), \mathrm{kJ} \mathrm{mol}^{-1}\right)$.

\begin{tabular}{cccccc}
\hline Ions & Methanol & Ethanol & Acetone & DMF & DMSO \\
\hline $\mathbf{H}^{+}$ & 10.4 & 11.1 & -- & -18 & -19.4 \\
$\mathbf{L i}^{+}$ & 4.4 & 11 & -- & -10 & -15 \\
$\mathbf{N a}^{+}$ & 8.2 & 14 & -- & -9.6 & -13.6 \\
$\mathbf{K}^{+}$ & 9.6 & 16.4 & 4 & -10.3 & 13.0 \\
$\mathbf{A g}^{+}$ & 6.6 & 4.9 & 9 & -20.8 & -34.8 \\
$\mathbf{N H}_{4}^{+}$ & 5 & 7 & -- & -- & - \\
$\mathbf{F}^{-}$ & 16 & -- & 57 & 51 & 40.3 \\
$\mathbf{C l}^{-}$ & 13.2 & 20.2 & 42 & 48.3 & 27.4 \\
$\mathbf{B r}^{-}$ & 11.1 & 18.2 & 25 & 36.2 & 10.4 \\
$\mathbf{I}^{-}$ & 7.3 & 12.9 & -- & 20.4 & -41 \\
$\mathbf{C N}^{-}$ & 8.6 & 7 & -- & 18.4 & 35 \\
\hline
\end{tabular}

solution of silver nitrate in acetonitrile/water, a preferential solvation of $\mathrm{Ag}^{+}$by acetonitrile and of $\mathrm{NO}_{3}^{-}$by water was observed (Reichardt 1988 and references therein).

\subsubsection{Solubility}

The dissolution of a substance requires not only that the lattice energy be overcome but also the interaction energy between the solvent molecules themselves

$$
\Delta G_{\text {so } \ln }^{0}=\Delta G_{\text {solv }}^{0}-\Delta G_{\text {lattice }}^{0}
$$

At equilibrium, $\Delta G_{s o \text { ln }}^{0}$ relates to the solubility product, $\mathrm{K}_{\mathrm{sp}}$, of an electrolyte by

$$
\Delta G_{s o l}^{o}=-R T \ln K_{s p}
$$

For the dissociation of the hypothetical ionic solid $\mathrm{M}_{\mathrm{p}} \mathrm{L}_{\mathrm{q}}$

$$
\mathrm{M}_{\mathrm{p}} \mathrm{L}_{\mathrm{q}} \Leftrightarrow \quad \mathrm{pM}^{+}+\mathrm{qL}^{-}
$$

$\mathrm{K}_{\mathrm{sp}}$ is defined at equilibrium by

$$
\mathrm{K}_{\mathrm{sp}}=\left\{M^{+}\right\}^{p}\left\{L^{-}\right\}^{q}
$$


where \{\} denotes the activities of the individual ions and $\mathrm{p}$ and $\mathrm{q}$ the stochiometric coefficients of the cationic $\left(\mathrm{M}^{+}\right)$and anionic $\left(\mathrm{L}^{-}\right)$species respectively. Any factor affecting free ion activity will have an effect on the solubility product and hence the solubility of the studied compound.

In soil systems, important chemical reactions occur at the colloid/solvent interface or at the ion/solvent interface. In either case, the proximity of the solvent to charged surfaces significantly disrupts its bulk chemical and physical properties (Popovytch and Thomkins, 1981). As we shift from aqueous to mixed aqueous organic solvents, other factors such as volume energies and solvent-solvent interactions may affect ionic solubility. It is generally observed that ionic substances exhibit higher solubility in solvents of high dielectric strength (Reichardt, 1988). However, the relation is not always linear as predicted. In many cases, observed deviations from linearity can be attributed to the microscopic properties of the solvent molecules themselves. For instance, silver salts of large polarizable anions like $\mathrm{SCN}^{-}$ exhibit enhanced solubility in methanol as opposed to water, whereas silver salts of small anions such as $\mathrm{Cl}^{-}$tend to be less soluble (Reichardt, 1988), a difference attributed to the ability of $\mathrm{Cl}^{-}$to form hydrogen bonds with water molecules.

The single ion activity $\{i\}$ describes the thermodynamic behavior of a particular chemical species in solution,

$$
\{i\}=\gamma_{i} C_{i}
$$

where $\gamma_{i}$ denotes the single-ion activity coefficient and $\mathrm{C}_{\mathrm{i}}$ the molar concentration of the ionic species. The single-ion activity coefficient serves to correct for the nonideality of the solution. In ideal dilute aqueous solutions, $\gamma_{i}$ equals 1 and the ionic 
activity equals the molar concentration. In more concentrated aqueous solutions and in complex non-aqueous solution, $\gamma_{i}$ decreases. Several theoretical models have been proposed to calculate the single-ion activity coefficient. Among these, the extended Debye-Hückel equation is widely used

$$
\log \gamma_{i}=-\frac{A_{D-H} z_{i}^{2} I^{\frac{1}{2}}}{1+B_{D-H} a_{i} I^{\frac{1}{2}}}
$$

I is the ionic strength, $\mathrm{a}_{\mathrm{i}}$ is the ion size parameter, and $\mathrm{A}_{\mathrm{D}-\mathrm{H}}$ and $\mathrm{B}_{\mathrm{D}-\mathrm{H}}$ are two parameters defined as

$$
\begin{aligned}
& I=\frac{1}{2} \sum C_{i} z_{i}^{2} \\
& A_{D-H}=\left(2 \pi N_{A} \sigma\right)^{0.5}\left[\frac{e_{0}^{2}}{4 \pi \varepsilon_{r} \varepsilon_{0} K T}\right]^{1.5} \\
& B_{D-H}=e\left(\frac{2 N_{A} \sigma}{\varepsilon_{r} \varepsilon_{0} K T}\right)^{0.5}
\end{aligned}
$$

$\mathrm{A}_{\mathrm{D}-\mathrm{H}}$ and $\mathrm{B}_{\mathrm{D}-\mathrm{H}}$ are both a function of the solvent properties and the temperature of the solution. One way to calculate the single ion activity coefficient in non-aqueous and mixed system is to replace $\varepsilon_{\mathrm{r}}$ and $\sigma$ by their respective values in the studied systems (Bates, 1973). Figure 1.2 illustrates the changes in the single ion activity coefficient as a function of ionic strength for a univalent ion at various solvent dielectric constants. As the solvent dielectric constant decreases, the single ion activity coefficient decreases more rapidly as a function of the ionic strength, I.

The solubility products for a large number of salts have been determined experimentally in non-aqueous and mixed aqueous organic solvents using 
thermodynamic approaches. A list of $\mathrm{K}_{\mathrm{sp}}$ in non-aqueous and mixed aqueous organic solvents is compiled by Timmermans (1960). However, the unlimited number of different solvent compositions which can be prepared from a particular binary system (e.g. organic solvent and water) requires the establishment of equations for the computation of these parameters for any solvent composition from few parameters. The lack of these equations combined with the inherent difficulty in experimentally determining these parameters, may partially explain the scarcity of research on metal/clay interactions in mixed aqueous organic systems in soil science.

\subsubsection{Complexation}

The effect of the dielectric constant on the ion-solvent interactions is more pronounced than what is predicted by the Debye-Hückel theory because specific ionpairing and complexation may be responsible for a greater departure from ideality than non-specific electrostatic interactions. 


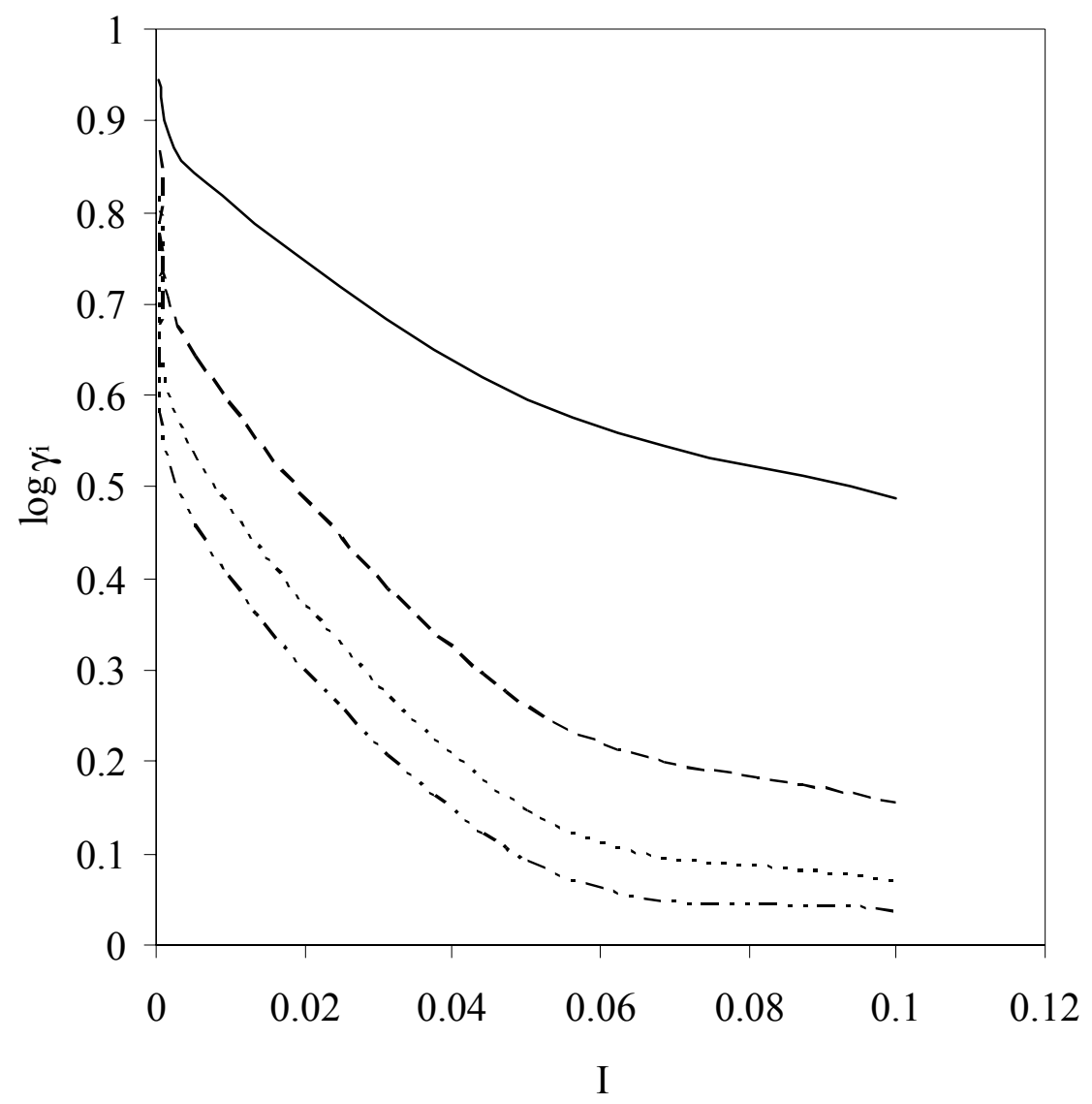

Figure 1.2. Changes in the single ion activity coefficient as a function of ionic strength at various solvent dielectric constants (for $\mathrm{a}_{i}=4 \mathrm{~nm}$ ).

Coulomb's law is often used to quantitatively describe the energy of attraction between oppositely charged ions in solution

$$
E_{C}=\frac{z^{+} z^{-} e^{2}}{r_{i} \varepsilon_{r}}
$$

Coulomb's law predicts that the energy of attraction between oppositely charged ions increases as the solvent dielectric constant, $\varepsilon_{\mathrm{r}}$, decreases. This phenomenon is observed as a result of the decreased shielding of charges by the surrounding solvent molecules induced by decreased $\varepsilon_{\mathrm{r}}$. This increased attraction is 
manifested as an increase in the magnitude of ion-pairing between these charges and the formation of new pairs, ones that would not form otherwise in aqueous solvents.

The most widely used theories on ion association include the Debye-Hückel (Bockris and Reddy, 1973), the Bjerrum (1926) and the Fuoss (1958) theories. The Debye-Hückel theory does not account for ion pairing and its effect on ionic activity. It assumes that the energy resulting from the electrostatic interactions between the ions is small and much less than the energy of thermal agitation. This holds true when the distance between interacting ions is large. As this distance decreases, the electrostatic interactions increases and approaches the energy of thermal agitation. According to Bjerrum, ionic association occurs if the two ions are at a distance $r_{B-F}$ less or equal than $q$, the critical distance at which the energy of electrostatic interaction becomes equal to the energy of thermal agitation. If $r_{B-F}>q$, the ions remain unassociated. This distance $r_{B-F}$ cannot be less than the distance of "closest approach, $a_{B-F} "$, which is equal to the sum of the radii of the associated cation and anion. According to Bjerrum, the association constant, $\mathrm{K}_{\mathrm{A}}$ is expressed by:

$$
K_{A}=\frac{4 \pi N_{A}}{1000} \int_{a_{B-F}}^{q} r_{B-F}^{2} \exp \left(\frac{2 q}{r_{B-F}}\right) d r_{B-F}
$$

According to Fuoss, an ion pair is defined as two oppositely charged ions that are in contact, i.e. at a distance of $r_{F}=a_{B-F}$ and the association constant, $\mathrm{K}_{\mathrm{A}}$, is defined as

$$
K_{A}=\left(4 \pi N_{A} / 3000\right)\left(a_{B-F} / m\right)^{3} \exp \left(2 q / a_{B-F}\right)
$$

Equation [1.15] is obtained from Eq. [1.14] using tabulated values of q:

$$
\begin{aligned}
\log K_{A}= & \log \left(4 \pi N_{A} a_{B-F}^{3} / 3000\right)+ \\
& 0.434\left|z_{+} z_{-}\right| N_{A} e^{2} /\left(4 \pi a_{B-F} \varepsilon_{0} \varepsilon_{r} R T\right)
\end{aligned}
$$


From this equation, a linear relation ship between $\log \mathrm{K}_{\mathrm{A}}$ and $1 / \varepsilon_{\mathrm{r}}$ is expected (Figure 1.3). Figure 1.3 shows this relationship between the ion association constant $\left(\log K_{A}\right)$ and $1 / \varepsilon_{\mathrm{r}}$. Accordingly, only solvents with high dielectric constants $\left(\varepsilon_{\mathrm{r}}>40\right)$ will be capable of reducing the strong electrostatic forces to such an extent as to prevent ion pairing. In aqueous solutions, ion association between cations and large polarizable anions is small except at high ionic strength. In these systems, hydrated ions are highly stabilized by the elevated dielectric constant of water $\left(\varepsilon_{\mathrm{r}}\right.$ equal to 78.39 at $25^{\circ} \mathrm{C}$ ), preventing ions from approaching each other and forming pairs. In solvents of lower dielectric constants such as methanol (32.7) or ethanol (24.5), ionic complexation is favored at extremely low electrolyte concentrations. In solvents of dielectric constants less than 10, essentially no free ions exist, except in very dilute solutions (Reichardt, 1988; Izutsu, 2002).

Both theories, Bjerrum and Fuoss, have been widely used in the interpretation of experimental data involving the association constant, $\mathrm{K}_{\mathrm{A}}$, of electrolytes in nonaqueous media. Often, the discrepancy between the experimentally measured and calculated (using either approach) values of $\mathrm{K}_{\mathrm{A}}$, is attributed to the existence of specific ion-solvent interactions (Fuoss and Edelson, 1951). If $\log \mathrm{K}_{\mathrm{A}}$ varies linearly with $1 / \varepsilon_{\mathrm{r}}$, pairing is assumed to result solely from electrostatic interactions (Hawes and Kay, 1965; Mui and McBride, 1974; Ananthaswamy et al., 1979). If not, specific solvent-solute interactions are invoked (Doe et al., 1990). Xue and Traina (1996b) observed increased stability of $\mathrm{Cu}(\mathrm{II})$ and EDTA complexes in acetone and methanol water mixtures as the fraction of solvent/water increased. They attributed this phenomenon to the increased electrostatic interactions between the two compounds as 
a result of decreased dielectric constant and to changes in the Gibbs energy of solvation associated with complex formations, originating from specific solventsolute interactions. Coulombic forces are the strongest intermolecular forces in amphoteric solvents. However, in protic solvents they are of minor importance and other forces such as ion-dipole and ion-induced dipole are of greater significance (Reichardt, 1988). A detailed discussion of these theories, their applications and limitations is available (Bockris and Reddy, 1973; Yeager and Salkind, 1973; and Izutsu, 2002).

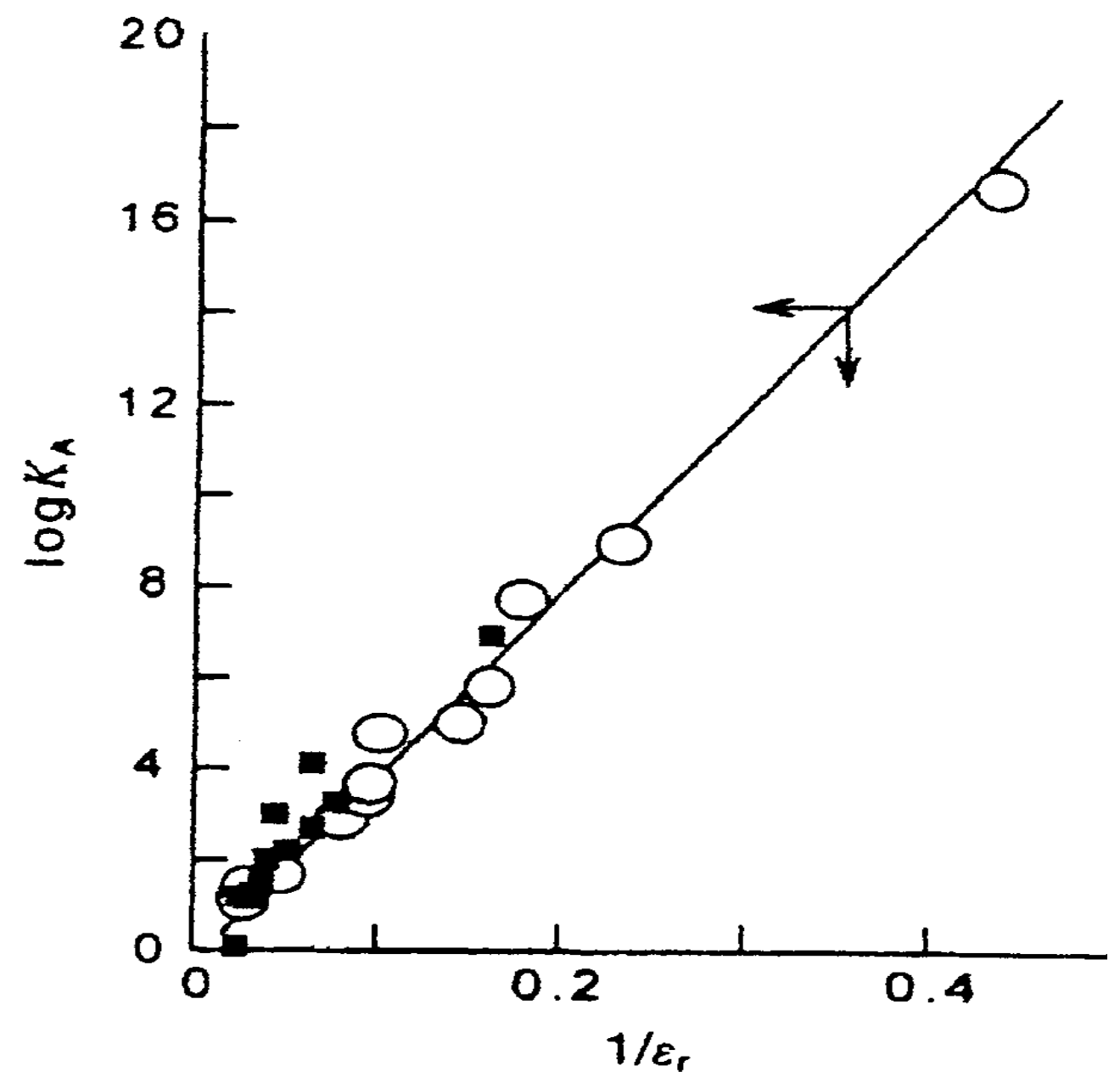

Figure 1.3. Changes in the ion association constant $\left(\log \mathrm{K}_{\mathrm{A}}\right)$ as a function of the reciprocal of solvent dielectric constant $\left(1 / \varepsilon_{\mathrm{r}}\right)$ for $\mathrm{a}_{\mathrm{B}-\mathrm{F}}=0.6 \mathrm{~nm}$ (Izutsu, 2002). 
Ion association is further complicated by the existence of different types of ion pairs, which depending on the strength of ion-solvent interactions can vary from solvent-separated, solvent-shared to contact pairs. Triple and quadruple ion pairs have also been reported in some solvent (Salomon, 1989). Methods used to identify these pairs include infrared, Raman, and dielectric relaxation spectroscopies (Izutsu, 2002).

The most widely used standard methods for the determination of association constants include potentiometry (Gaizer et al., 1985; Doe et al., 1987; Mui and McBride, 1974), spectrophotometry (Ghasemi et al., 2002) and conductometry (Evers and Knox, 1951; Doe et al., 1990). Other methods such as specific ion EMF measurements, nuclear magnetic resonance (NMR), and polarography are used under specific circumstances (Martell and Motekaitis, 1992). NMR has been widely used to provide microscopic information on metal-ligand complexes such as the identification of protonation and metal coordination sites on ligands.

Conductance measurements constitute one the most sensitive and widely used physical method for investigating electrolyte solutions. It can be applied to a wide variety of solvents over wide temperature and pressure ranges. When combined with theoretical equations, useful information can be obtained on ionic mobility, ion-size parameters, and association constants (Yeager and Salkind, 1973). All conductance measurements consist of measuring the changes in the conductance of a solution as a function of the electrolyte concentrations. These measurements are relatively easy but require a high degree of precision, especially accurately known concentrations, true resistance readings, solvent corrections and good temperature control. For detailed consideration of techniques employed in conductometry, the reader is referred to the 
textbook by Yeager and Salkind (1973) and the review by Nancollas and Tomson (1982).

Several equations have been developed to treat conductance data. The most commonly used equation for both undissociated and associated electrolytes is the Fuoss-Onsager equation (Fuoss and Onsager, 1957; and Fuoss and Onsager, 1958). Other equations such as the Shedlovsky (Shedlovsky, 1932) and the Pitt equation are also used, primarily for symmetrical electrolytes. For asymmetrical electrolytes, the most commonly used equations are the Fuoss-Edelson (Fuoss and Edelson, 1951) and the Lee-Wheaton (Lee and Wheaton, 1978) equations.

The association constants of several metal perchlorates in non-aqueous solvents have been determined using conductometric methods (Doe et al., 1984, Doe et al., 1990). Conductometric measurements are often limited by the assumptions of the theoretical equations used in data treatment. Most equations deal with only one kind of ion-pair; the zero valent pair for symmetric electrolytes and the monovalent pair for asymmetric electrolytes. In non-aqueous and mixed aqueous organic solvents, these assumptions are often questionable because several other pairs can be present in large concentrations.

\subsection{4 $\mathrm{pH}$}

The effect of $\mathrm{pH}$ on soil chemical reactions in dilute aqueous systems is well-documented (Sposito, 1984). Soil pH plays a major role in controlling precipitation/dissolution, adsorption/desorption, flocculation/deflocculation and chelation reactions. 
In dilute aqueous media, $\mathrm{pH}$ is defined as

$$
{ }_{w}^{w} p H=-\log _{w} a_{H^{+}}=-\log _{w}^{w} \gamma_{H^{+}}{ }_{w} m_{H^{+}}
$$

The subscript and the superscript on the left side indicate the medium in which the activity coefficient is measured and the medium to which this measured value refers respectively. In aqueous systems, data related to $\mathrm{pH}$ definition and measurements are abundant.

In non-aqueous system, the situation is very different. The scarcity of data defining a normal $\mathrm{pH}$ scale in non-aqueous systems is related to the absence of an "intersolvental" scale with ultimate reference to the solvent water. This hinders any meaningful comparison with $\mathrm{pH}$ defined in the studied solvent and that defined in aqueous systems (Mussini et al., 1985). In these systems, the ${ }_{\mathrm{s}}^{\mathrm{s}} \mathrm{pH}$ value measured in the solvent $s$ and quoted on the $\mathrm{pH}$ scale specific to the studied solvent can be expressed as ${ }_{\mathrm{w}}^{\mathrm{s}} \mathrm{pH}$ on one "intersolvental" scale by the following conversion equation:

$$
{ }_{w}^{s} p H=-\log \left({ }_{w}^{s} \gamma_{H^{+}} m_{H^{+}}\right)={ }_{s}^{s} p H-\log \left({ }_{w}^{s} \gamma_{H}^{0}\right)
$$

with:

$$
{ }_{w}^{s} \gamma_{H^{+}}={ }_{s}^{s} \gamma_{H^{+}}{ }^{s}{ }_{w}^{s} \gamma_{H^{+}}^{0} \quad \text { and }{ }_{w}^{s} \gamma_{H^{+}}^{s} \rightarrow 1 \text { as } \mathrm{s} \rightarrow \mathrm{W}
$$

where ${ }_{w}^{s} \gamma_{H^{+}}$is the total medium effect and ${ }_{w}^{s} \gamma_{H}^{0}$ the primary medium effect, which incorporates the activity change associated with the change of the medium from water to solvent. Changes in the nature and composition of the solvent often produces large changes in the activity coefficient of the chemical species and consequently in the proton potential. Therefore, the single ion activity coefficient, $\gamma_{\mathrm{i}}$, reflects changes in both the interionic attractions and the medium effect largely stimulated by a drop in the medium dielectric constant. 
Several studies have been conducted to measure the primary medium effects in various solvents by incorporating thermodynamic principles with electrochemical measurements in galvanic cells. The inconsistency and the poor reproducibility of these results (Table 1.4) limit their use in $\mathrm{pH}$ calculation and the adoption of the $\mathrm{pH} /$ electrode measurement systems as a universal device to measure $\mathrm{pH}$ in nonaqueous and mixed aqueous systems.

Table 1.4. Medium effects for the proton (Molal scale) in water-methanol solvents at $25^{\circ} \mathrm{C}$, determined by extrapolation methods. (Bates, 1973).

\begin{tabular}{cccc}
\hline & \multicolumn{3}{c}{$\log _{w}{ }_{w}^{s} \gamma_{H}^{0}$} \\
\cline { 2 - 4 }$(\mathrm{w} / \mathrm{w})$ & Izmailov & Feakins & Alfenaar and deligny \\
\hline 10 & & -0.38 & -0.21 \\
20.22 & 0.14 & -0.69 & - \\
50 & 0.43 & -2.41 & - \\
68.33 & 0.7 & -3.44 & -2.7 \\
87.7 & $\overline{1.45}$ & $-\overline{4.00}$ & $-\overline{1.45}$ \\
90 & 3.21 & -2.25 & \\
100 & & & \\
\hline
\end{tabular}

According to Yamazaki et al., (1992), the spectrophotometric method of $\mathrm{pH}$ measurement rivals the usual $\mathrm{pH}$ meter technique in both reliability and convenience. It is true that the hydrogen electrode is the fundamental standard by which values of $\mathrm{pH}$ are assigned (Bates, 1973), however, this normal $\mathrm{pH}$ scale is limited to dilute aqueous solutions and cannot be used at very high concentrations of either acids or bases, nor in non-aqueous and mixed solvents mainly because of diffusion potential problems and strong ionic activity coefficient deviations. There is also the problem of comparing the $\mathrm{pH}$ values of aqueous and non-aqueous solutions and the establishment of an "intersolvental" pH scale as described above. 
Indicator dyes, as defined by Ostwald are "weak acids or bases that exhibit a change in color on the conversion of the acidic form to the basic form, or vice versa". Since color changes accompany change in the relative concentration of the acid and the base form, spectrophotometric measurement of the degree of light absorption can be used to measure $\mathrm{pH}$. The only problem relies in determining the dissociation constants of the indicator in the specific non-aqueous or mixed solvent. For this purpose, there is a need to combine both potentiometry and spectrophotometry to get reliable absorption and $\mathrm{pH}$ data. For mixed aqueous organic solvent, the IUPAC Commission on Electroanalytical Chemistry has recommended a method for $\mathrm{pH}$ measurements in organic solvent mixtures of high permittivity $\left(\varepsilon_{\mathrm{r}}>30\right)$ (Mussini et al., 1985).

\subsection{Surface-Solvent Interactions}

This section will focus on the effect of solvents on the physical and chemical properties of clay minerals and the forces that govern their interactions with other clay minerals and inorganic pollutants. Special attention will be given to the effect of solvents on exchange and adsorption reactions, the two most important chemical processes that determine metal mobility in the environment. A review of the literature on the work on clay-solvent interactions will also be presented.

\subsubsection{Clays Physicochemical Properties}

Clay minerals, particularly phyllosilicates, are layer type aluminosilicates that are abundant in terrestrial biogeochemical cycles and in the containment of toxic 
waste materials. Clay minerals are stacked, polymeric sandwiches of tetrahedral and octahedral sheet structures (Sposito, 1999) that are classified first into "layer types" based on the number of tetrahedral and octahedral sheets and second into "group types" differentiated by the kind of isomorphic substitution occurring in their layer structure. The 1:1 layer structures consist of one octahedral sheet and one tetrahedral sheet, with the apical $\mathrm{O}^{2-}$ ions of the tetrahedral sheets being shared with the octahedral sheet. The most common type of 1:1 clay minerals is kaolinite. The 2:1 layer type has one octahedral sheet fused between two tetrahedral sheets. Three clay mineral groups have these structures: illite, vermiculite and smectites. These clay minerals are differentiated by their layer charge, which generally decreases in the order illite $(-1) \rightarrow$ vermiculite $(-0.9$ to -0.6$) \rightarrow$ smectites $(-0.6$ to -0.25$)$, and in the degree and place of isomorphic substitution (vermiculite has a higher degree of isomorphic substitution in the tetrahedral sheet than smectites). Despite their high layer charge, illite minerals have very low cation exchange capacity $\left(20-40 \mathrm{cmol}_{\mathrm{c}} \mathrm{kg}^{-1}\right.$ of clay). In these minerals, most of the negative charge in the interlayer spaces is balanced by the monovalent cation $\mathrm{K}^{+}$, whose small ionic radii and strong interaction with the siloxane cavity causes the interlayer space to collapse, reducing both the accessible surface charge and interlayer swelling of the clay. The colloidal size and large surface areas of these clay minerals endow them with unique surface reactivity that allows them to play a major role in the biogeochemical cycling of metals, nutrients and contaminants.

The reactivity of 2:1 clay minerals is largely determined by the reactivity of the siloxane cavity (a hexagonal cavity created by the corner-sharing tetrahedral $\mathrm{Si}$ ), 
which in turn depends on the nature of the charge distribution in the clay layer (Sposito, 1984). Neutral siloxane surfaces are hydrophobic surfaces that result form the absence of nearby isomorphic substitution (talc and pyrophyllite). The neutral siloxane surfaces function as weak Lewis bases with a low affinity for water. From a surface reactivity standpoint, these surfaces are inert and interact with solutes mainly via van der Waals or London forces (Johnston \& Tombacz, 2002). If isomorphic substitution of structural $\mathrm{Al}$ by $\mathrm{Fe}$ (II) or Mg occurs in the octahedral sheet, the result is a delocalized excess of negative charge that makes it possible for the surface to form strong complexes with cations and with water molecules. If isomorphic substitution of Si with $\mathrm{Al}$ occurs in the tetrahedral sheet, the result is a more localized excess negative charge that allows a much stronger adsorption of cations to the surface. These two types of substitution usually result in the formation of constant or permanent charge sites as opposed to conditionally charged sites (also referred to as variable or $\mathrm{pH}$-dependent sites). These $\mathrm{pH}$-dependent sites usually occur on the edges of 2:1 and 1:1 phyllosilicates clay minerals. Their relative contribution the total cation exchange capacity of 2:1 clay minerals is small compared to the permanent charge sites $(15 \%$ in the case of montmorillonite, and $30 \%$ in the case of illite as determined by Anderson and Sposito, 1991). However, they are considered to play a major role in the specific adsorption of metals, especially at low levels of metal contamination (Ziper et al., 1988; VanBladel et al., 1993).

In addition to their surface reactivity, clays are also distinguished by their physical properties; most importantly surface area, elasticity and swelling potential. Smectites and vermiculite have a larger surface area $\left(600-800 \mathrm{~m}^{2} \mathrm{~g}^{-1}\right)$ than illite (70- 
$\left.120 \mathrm{~m}^{2} \mathrm{~g}^{-1}\right)$. Smectites have a larger swelling potential than vermiculite. Illites are considered non-expandable. The large swelling capacity of smectites is responsible for their low hydraulic conductivity.

Because clays have high surface charge, low hydraulic conductivity and large surface area, they have been used as liners in waste landfills. Nevertheless, when some contaminants in those waste disposal landfills were able to find their way into the subsurface environment (Riley and Zachara, 1992), questions were raised as to the appropriateness of clays as landfill liners. In a study conducted by Green et al. (1983), significant interactions of clays with organic solvents were believed to be responsible for pollutants migration to underground subsurface environment. To understand the behavior of these clays in non-aqueous and mixed-water systems, it is important to consider the effect of the solvent physicochemical properties on the reactivity as well as the structure of clay minerals.

\subsubsection{Effect of Solvents on Clay Structure}

The swelling and collapse of clay interlayers are governed by the same forces that control the flocculation and dispersion of clay suspensions. These forces are essentially the Born repulsive forces, van der Waals attractive forces, electrostatic or diffuse double layer forces and the hydration forces that can either be repulsive or attractive depending on the nature of the clay surface. The Born repulsive energy, $\Phi_{\mathrm{B}}$, results from the overlap of the electron clouds of two molecules approaching each other and are usually given by the following equation

$$
\Phi_{\mathrm{B}}=+\frac{\xi}{r^{12}}
$$


The van der Waals energies are of three types: the Keesom-van der Waals arising from the attraction between permanent dipoles, the Debye-van der Waals arising from the attraction of induced dipoles and the London-van der Waals arising from oscillating charges due to the positive nucleus and the negative electron charge. The net attractive van der Waals potential $\left(\Phi_{\mathrm{vdW}}\right)$ is expressed by the following equation

$$
\Phi_{\mathrm{vdW}}=-\frac{1}{\left(4 \pi \varepsilon_{r}\right)^{2}}\left(2 \alpha_{0,1} \mu_{1}^{2}+\frac{2}{3} \frac{\mu_{1}^{4}}{K_{B} T}+\frac{3}{4} h v_{1} \alpha_{0,1}^{2}\right) r^{-6}
$$

The distribution of the electrical potential around clay particles can be described by Gouy-Chapman theory as follows:

$$
\psi_{r}=\psi_{0} e^{-x x}
$$

and

$$
\kappa=\sqrt{\left(8 \pi e \sum n_{i} z_{i}^{2}\right) /\left(\varepsilon_{r} k T\right)}
$$

where $\psi_{\mathrm{x}}$ is the potential at distance $\mathrm{x}$ from the clay particle, $\psi_{0}$ is the potential at the surface of the clay particle and $\mathrm{K}^{-1}$ is Debye length $\left(\mathrm{m}^{-1}\right)$. If all chemical variables are held constant except $\varepsilon_{\mathrm{r}}$, the electrical potential may be calculated and plotted as a function of $r$ (Figure 1.4). Decreasing the medium dielectric constant as a result of changing the solvent or adding a cosolvent to water will increase the net van der Waals (Eq 1.30) attractive forces, decrease the thickness of the diffuse double layer (Eq 1.33), and promote flocculation. However, the effect is not as straightforward as it seems, decreasing $\varepsilon_{\mathrm{r}}$ will also decrease the ionic strength of the solution as a result of both pairing and decreased ionic activity. This will increase the thickness of the 
diffuse double layer and increase the long range repulsive forces to promote clay dispersion.

The hydration force is a function of both the hydration energies of the intercalated cation and the hydration energy of the clay surface and can oscillate between attractive (for hydrophobic surfaces) and repulsive (hydrophilic surfaces). These forces are very important in controlling the swelling and collapse of 2:1 clay minerals (Israelachvili, 1987).

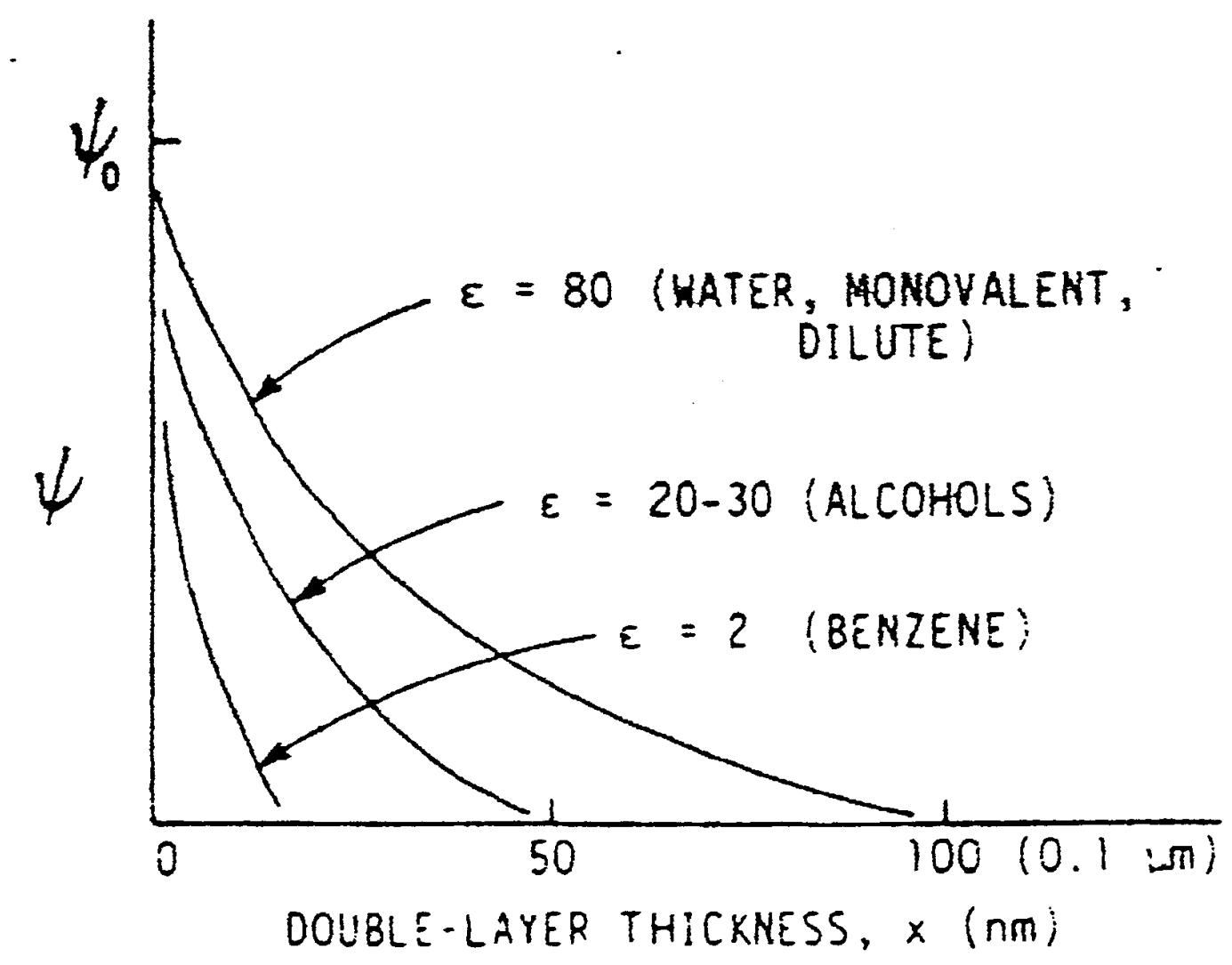

Figure 1.4. Changes in the electrical potential, $\psi$, as a function of $\mathrm{x}$, the distance from the clay particle for various values of dielectric constant, $\varepsilon_{\mathrm{r}}$ (Fernandez and Quigley, 1985). 
Numerous studies have been conducted on the behavior of clay minerals in non-aqueous solvents. Green et al., (1983) studied the interactions of clay soils with water and organic solvents. He concluded that, the greater the solvent dielectric constant, the greater the swelling of a given clay soil. In his study, all clay soils evaluated contained water at optimum moisture content. Intercalation of clays involved competition between solvent molecules and water for favorable sites in the interlayer region. For this reason, weakly polar solvents such as $\mathrm{CCl}_{4}$ did not intercalate. The high correlation between the octanol-partitioning coefficient $\left(\mathrm{K}_{\mathrm{ow}}\right)$ and the degree of swelling indicated that $\mathrm{K}_{\mathrm{ow}}$ is related to the solvent solubility in the soil pore water.

Fernandez and Quigley (1985) observed that the hydraulic conductivity of initially dry clays increased with decreasing solvent dielectric constant (Figure 1.6). These results were attributed to the compression of the diffuse double layer (Eq 1.33). No change in the hydraulic conductivity was observed when wet clays were permeated with water-insoluble hydrocarbons (benzene, xylene, and cyclohexane). This difference in the behavior of dry and wet clays suggests more a specific solventsurface interactions (specific ion and surface solvation) rather than simple compression of the diffuse layer (low dielectric constant will decrease the ionic strength and increase the thickness of the diffuse layer). 


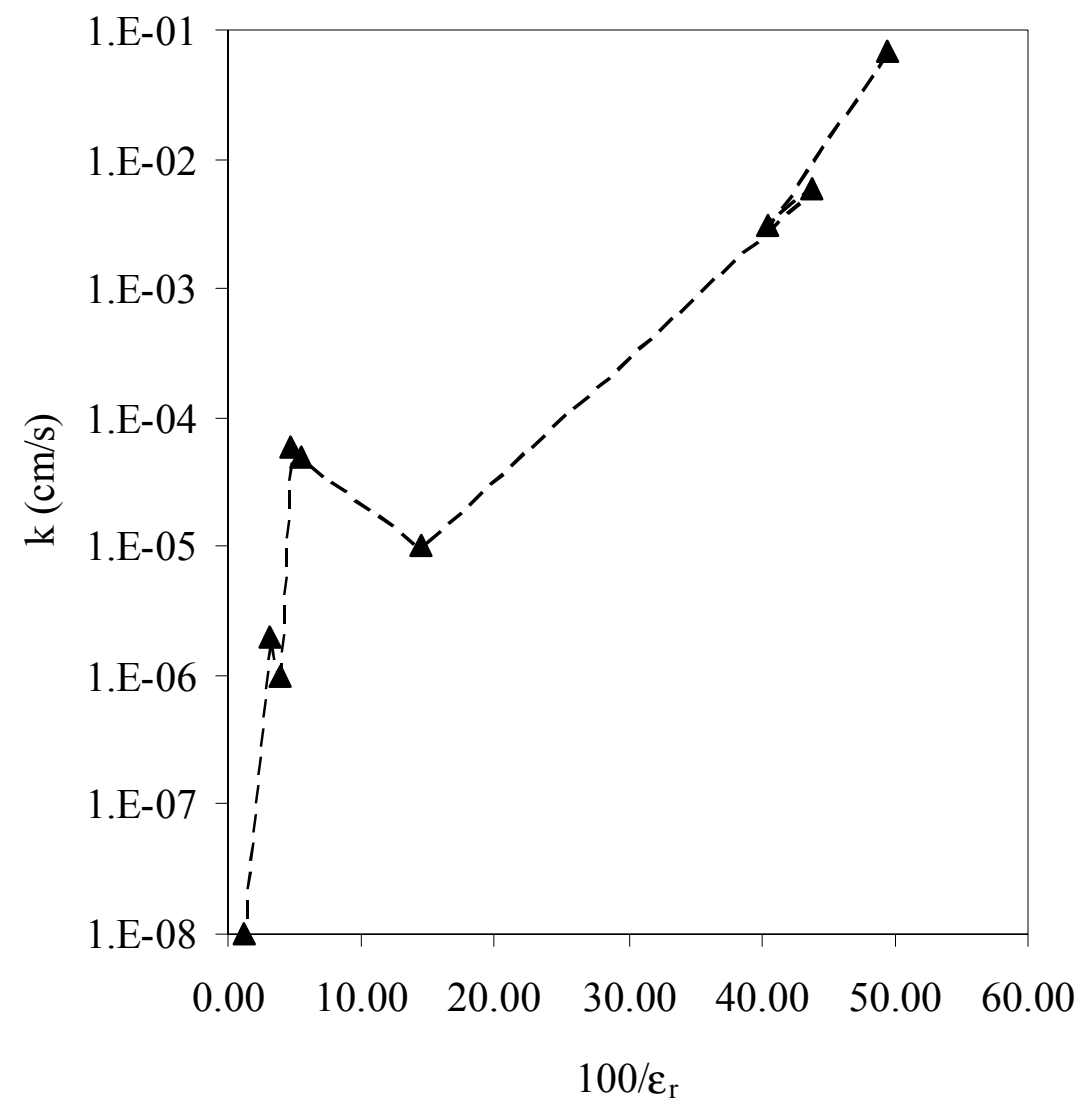

Figure 1.5. Changes in the hydraulic conductivity, $\mathrm{k}$, of the pore fluid of dry clay soils with reciprocal dielectric constant, $\varepsilon_{\mathrm{r}}$. (Data from Fernandez and Quigley, 1985). 
Additional support for the specific solvation hypothesis is provided by Brindley et al (1969), who studied the intracrystalline swelling of initially dry Camontmorillonite in water mixed organic solvents. Figure 1.6 shows different behavior of 1-2 ethandiol and methanol saturated clays even though the two solvents have similar dielectric constant. Collapse of the interlayer spacing occurred only after a threshold value of the organic solvent fraction $\left(f_{c}\right)$ is reached. This threshold value was dictated by the dielectric constant of the solvent-water mixture.

Barshad (1952) observed that the interlayer expansion of vermiculite and montmorillonite depended on the hydration status of the clay: both clays failed to expand if completely dehydrated. From a calculation of the extent of expansion $(\AA)$, he concluded that expansion depended on the length of the immersion liquid molecule and on the type of packing. The important conclusions he reached were the following: expansion of these clay minerals was greater for smaller radius, low charge cations and the effect of the total charge of the crystal lattice on expansion was greater, the smaller the cation charge. Barshad (1952) rationalized his findings by invoking the important role the interlayer cations play in activating and binding the interlayer surfaces. Depending on the position of the interlayer cations (within the interlayer cavity or midplane between the two oxygen layers), it is not surprising that the ease of expansion was greater, the smaller the cation, the greater the valence of the cation and the smaller the total charge of the interlayer surfaces. When related to the dielectric constant, the expansion both increased and decreased by lowering the dielectric constant of the liquid in contact with the surfaces, depending on the starting value of 
the dielectric constant under consideration. This anomaly seemed to resolve itself by a consideration of the relative magnitude of the

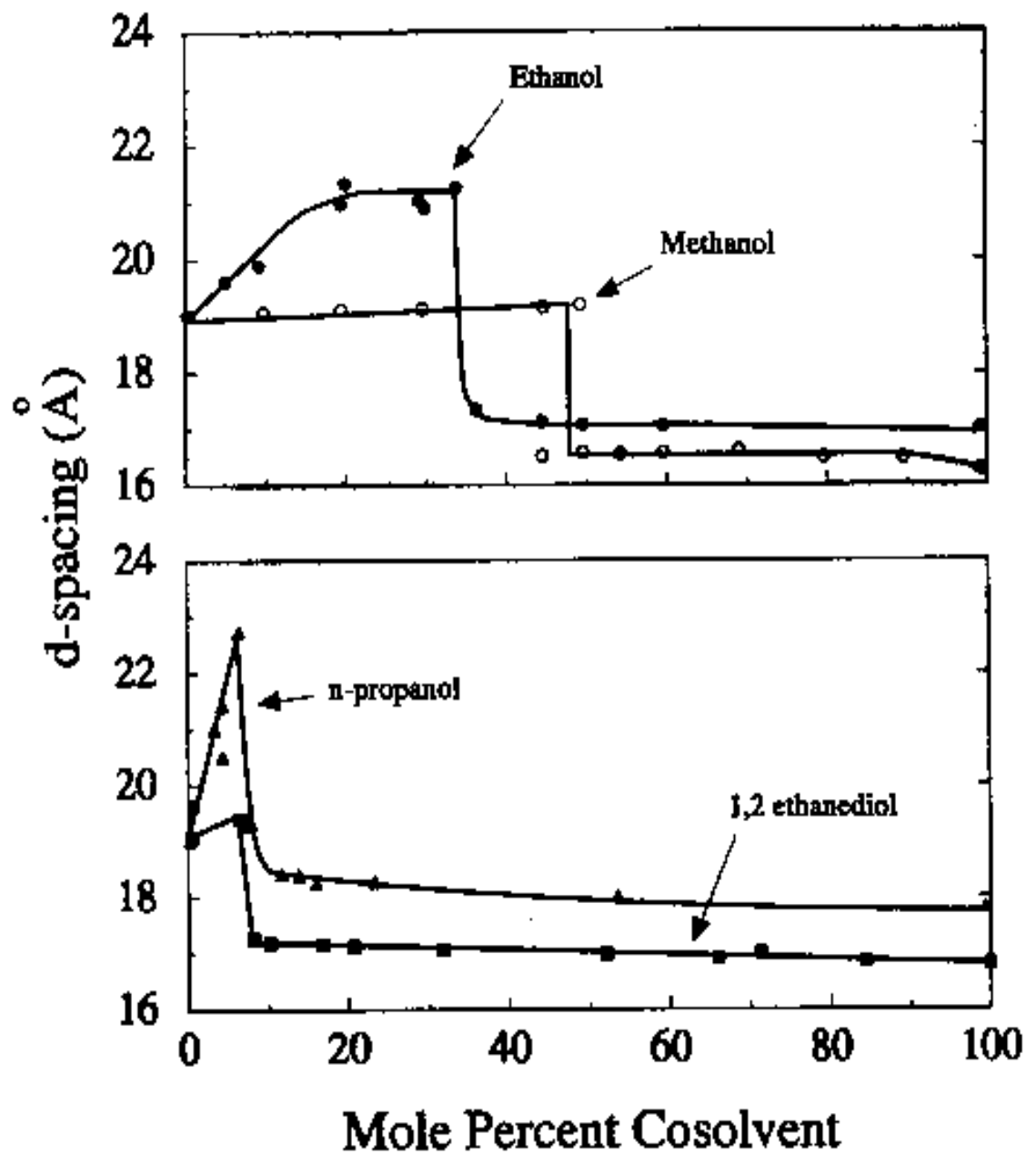

Figure 1.6. Effect of cosolvents on the d-spacing of Ca-montmorillonite (Brindley et al., 1969). 
interlayer attractive force of the crystal lattice itself and the attractive force between the crystal lattice and the absorbed molecules. Expansion is proportional to $\varepsilon$ as long as the interlayer attractive forces are only slightly smaller than the attractive forces between the lattice and the adsorbed molecule. But if these latter forces are greatly increased over the former, expansion would be inversely proportional to $\varepsilon_{\mathrm{r}}$.

Olejnik et al., (1974) observed that the intracrystalline swelling of montmorillonite in polar organic solvents increased with an increase in the solvent dielectric constant, with the magnitude of increase being larger for monovalent cations. When $\varepsilon_{\mathrm{r}}$ is kept constant, the degree of swelling was inversely related to the degree of methyl substitution in the organic polar solvent as a result of dipole moment.

Berkheiser and Mortland (1975) found little correlation between the intracrystalline swelling of clay and the solvent bulk physicochemical properties (dielectric constant, acid/base character, dipole moment, etc.). No relationship between the charge density and expansion occurred except in water. Considerable variety in the stereochemistry of $\mathrm{Cu}(\mathrm{II})$ ions in the interlayers was found.

Brown and Thomas (1987) conducted a study on the soil's hydraulic conductivity as affected by clay expansion in non-aqueous media. As $\varepsilon_{\mathrm{r}}$ decreased, the clays electrophoretic mobility and zeta potential decreased and particles were drawn closer together until they flocculated.

Sheets and Fuller (1986) studied the transport of Cd by organic solvents in soils. Ethylene glycol was found to reduce $\mathrm{Cd}$ adsorption in soils rich in $\mathrm{CaCO}_{3}$ mainly because of physical coating of the clay particles with the solvent molecules, 
decreased solubility of $\mathrm{CaCO}_{3}$, and inhibited chemisorption of $\mathrm{Cd}$ on the soil surfaces. In silt soils rich in smectites, the decreased adsorption was attributed to the induced collapse of the interlayer spaces. In clayey soils, mostly kaolinite, increased adsorption of $\mathrm{Cd}$ was related to increased electrostatic forces due to reduced competition between the solvation energy of adsorption and the solvation energy of solubilization.

\subsubsection{Effect of Solvents on Clay Surface Reactivity}

The effect of solvents on clay surface reactivity has been investigated for oxides, hydroxide, and silicates and excellent review is available (Kosmulski, 1999). Increased surface acidity (Leoppert et al., 1979), decreased surface potential (Kosmulski and Matijevic, 1992), decreased surface charge density (Kosmulski, 1990; Kosmulski, 1996), and increased organic solvent adsorption (Kosmulski, 1993) with decreased dielectric constant are typically reported.

Leoppert et al., (1979) observed that the effects of non-aqueous solvents on clay surface reactivity were largely determined by the properties of the solvent $\left(\varepsilon_{\mathrm{r}}\right.$, acid-base character most importantly) and the interactions between the solvent and the exposed $\mathrm{Al}$ and $\mathrm{Si}$ atoms. Organic solvents with low dielectric constant increased surface acidity, with underlying mechanisms differing from one group of solvents to the other. Protic solvents increased the surface acidity of kaolinite by allowing sharp end point detection and stabilization of atoms at the crystalline surface edges. Weakly polar solvents increased the polarity of the hydrated water whereas dipolar aprotic completely displaced hydration water from the surface sites. 
In his study of rutile, Kosmulski (1990) found that the solvent adsorption was responsible for reducing the negative surface charge by complexing with some of the hydroxide ions, usually involved in surface charge formation. The situation differs in alumina, where alcohol adsorption didn't block a significant number of surface hydroxide and proved non-competitive in relation to the formation of surface charge and ion adsorption. The exact mechanisms underlying these observed differences were not fully discerned.

Xue and Traina (1996a) described an increase in the number of apparent surface sites of goethite in acetone and methanol-water mixed systems with increasing cosolvent volume fraction as compared to aqueous systems. This was attributed to the increased strength of some originally weak iron oxide and iron hydroxide bonds in water. In addition, the low dielectric constant observed at high cosolvent fractions decreased the solubility of $\mathrm{H}^{+}$ions and reduced the solvation forces that usually compete with surface sites for $\mathrm{H}^{+}$protonation.

The effect of cosolvents on the selectivity of a charged surface for a specific cation is often overlooked. Little if any work has been done on cation exchange reactions in solvents other than water. Factors such as cation properties (ionic activity, solvated radius, valency and hydration energy) and surface characteristics (total cation exchange capacity, acid-base character, and tendency to form inner/outer sphere complexes and to undergo configurational changes) affect the preference of a particular surface for one ion over the other. At constant ionic strength, monovalent cations are usually selectively exchanged for polyvalent ones in aqueous solvents. In mixed-water systems, a shift in the surface selectivity for lower valence ions is 
expected to occur at high cosolvent fraction as a result of increased ion pairing, more pronounced for polyvalent ions, and changes in the mineral surface structure and reactivity.

\subsection{Effect of Solvents on Adsorption}

Most of the work on inorganic chemical sorption in non-aqueous systems was conducted by Kosmulski (1995 and 1994), who studied extensively the behavior of oxides in mixed systems. Decreased adsorption of $\mathrm{Na}$ onto oxide surfaces, and decreased surface charge density $\left(\sigma_{0}\right)$ was observed when water was replaced with a mixed solvent. These results were explained by suggesting an electrostatic adsorption of monovalent cations as a result of an increase in the local concentration of counterions around the oxide surface without a direct surface-ion contact.

In his review of the oxide/electrolyte behavior in mixed solvents, Kosmulski (1995) presented a thorough explanation of the general laws governing the interactions between oxide/electrolyte in mixed solvents with a critical assessment of the current findings in this domain and the future needed advances. In the absence of both a common $\mathrm{pH}$ definition and a method to measure $\mathrm{pH}$ in mixed solvent, results regarding ion adsorption, surface charge reactivity, and solubility remains skeptical and of limited applicability. The adoption of the Born equation to solely explain ion

behavior in mixed systems has proven inadequate because specific solvent-water and the solvent ion interactions are not considered.

The same conclusion was reached by McDonald (1995) who worked on Zn, $\mathrm{Cd}$, and $\mathrm{Sr}$ adsorption onto Bentonite clays in ethanol-water and methanol-water 
systems. The Eisenman theory of exchange reactions seemed more pertinent in qualitatively explaining the observed increases in $\mathrm{Zn}$ adsorption, decreases in $\mathrm{Cd}$ adsorption and the unchanged $\mathrm{Sr}$ adsorption. Eisenman attributes the total change in exchange energy to a combination of Coulombic forces, hydration enthalpies and anionic radii.

In this context, the objective of this dissertation is to examine the effect of cosolvents on metal-surface reactions onto clay minerals. This will be accomplished through the study of two types of surface reactions: exchange and adsorption. Both reactions commonly describe the retention of metals on clay surfaces with differences lying in the mechanism of this retention (Evangelou, 1998). The former involves outer-sphere complexation where non-specific long- range electrostatic forces govern the interactions between the metal and the surface, whereas the latter involve innersphere complexes where specific electrostatic and non-electrostatic forces are implicated. A proper modeling of cosolvent effects on metal sorption and exchange necessitates a quantification of its effect on metal solution properties, most importantly ionic activity and complexation. For this purpose and in the absence of published values, a determination of the stability constants of major ions in solution should be conducted. Moreover, a quantification of the hydrogen ion activity, $\mathrm{pH}$, in cosolvents should be conducted given the importance of $\mathrm{pH}$ in adsorption experiments.

Of the many mixtures that are of environmental concern, metal aqueousorganic solvent interactions with clay minerals are of interest to this study primarily because of their importance as contaminants in landfill sites and the lack of scientific 
knowledge regarding their geochemical dynamics in subsurface environments. The organic solvents selected for this study represent a relatively varied range of neutral amphiprotic (methanol and ethanol) and dipolar protophobic (acetone). Although both methanol and ethanol belong to the same solvent category, their properties are very different with methanol more closely related to water (in terms of dielectric constant and polarity) than ethanol (very low dielectric constant). Their major characteristics are presented in Table 1.5. Cadmium is a soft Lewis acid, calcium and sodium are hard Lewis acids and zinc is intermediate. In addition, $\mathrm{Zn}$ and $\mathrm{Cd}$ are major pollutants in soil/sediments and groundwater (Riley et al., 1992). 
Table 1.5. Physical properties of cosolvents at $25^{\circ} \mathrm{C}$.

\begin{tabular}{ccccc}
\hline Solvent & $\% \mathrm{wt}$ & $\varepsilon_{\mathrm{r}}$ & $\rho\left(\mathrm{kg} / \mathrm{m}^{3}\right)$ & $\eta(\mathrm{cP})$ \\
\hline Water $^{\mathrm{a}}$ & 0 & 78.48 & 997.1 & 0.890 \\
Methanol $^{\mathrm{b}}$ & 10 & 74.21 & 981.6 & 1.098 \\
& 30 & $65.19^{\mathrm{e}}$ & 951.4 & 1.444 \\
& 50 & 56.05 & 915.6 & 1.572 \\
& 70 & $46.90^{\mathrm{e}}$ & 871.5 & 1.339 \\
\hline Ethanol $^{\mathrm{e}}$ & 8.6 & $73.08^{\mathrm{e}}$ & 977.1 & $1.230^{\mathrm{e}}$ \\
& 10 & $72.29^{\mathrm{e}}$ & 981.9 & 1.510 \\
& 26.6 & $63.01^{\mathrm{e}}$ & 947.2 & $2.103^{\mathrm{e}}$ \\
& 30 & $61.11^{\mathrm{e}}$ & 953.9 & 2.667 \\
& 46.3 & $51.99^{\mathrm{e}}$ & 907.3 & $2.874^{\mathrm{e}}$ \\
& 50 & $49.92^{\mathrm{e}}$ & 913.9 & 2.813 \\
Acetone $^{\mathrm{d}}$ & 67 & $40.41^{\mathrm{e}}$ & 877.4 & $2.701^{\mathrm{e}}$ \\
& 10 & 73.02 & 983.1 & 0.952 \\
& 30 & 61.04 & 953.7 & 1.075 \\
& 50 & 48.22 & 915.9 & 0.911 \\
& 70 & 36.42 & 886.7 & 0.747
\end{tabular}

${ }^{\mathrm{a}} \varepsilon_{\mathrm{r}}$ and $\rho$ were obtained from Janz and Tomkins, $\eta$ from CRC

${ }^{\mathrm{b}} \varepsilon_{\mathrm{r}}$ was obtained From Janz and Tomkins, $\rho$ from CRC, $\eta$ from Timmermans

${ }^{\mathrm{c}} \varepsilon_{\mathrm{r}}$ and $\eta$ were obtained From Timmermans, $\rho$ from CRC

${ }^{\mathrm{d}} \varepsilon_{\mathrm{r}}$ and $\rho$ were obtained From Timmermans, $\rho$ from Janz and Tomkins

${ }^{\mathrm{e}}$ Interpolated values 


\section{CHAPTER II}

Spectrophotometric Determination of $\mathrm{pH}$ in Mixed Aqueous Alcohol Mixtures Using Methyl Red and Phenol Red

\section{$2.1 \quad$ Introduction}

$\mathrm{pH}$ determination in non-aqueous and mixed aqueous organic solvents is of importance in the study of metal-surface reactions in soil systems contaminated with cosolvents (Kosmulski, 1992). pH affects surface reactions both indirectly, through its effects on solution properties (complexation, solubility and ionic strength) and directly through its effects on surface charge density. Both potentiometric and spectrophotometric methods are available for $\mathrm{pH}$ measurement. Potentiometric $\mathrm{pH}$ measurements in nonaqueous and mixed aqueous organic solvents are cumbersome and involve nonthermodynamic assumptions such as a constant residual liquid junction-potential in solutions of different ionic strength than the standard buffers (Bates, 1973). These measurements require preconditioning of the $\mathrm{pH}$ electrode, the time of which can vary from 10-20 days (Xue and Traina, 1996a) and, at the time of taking readings, several minutes for the electrode potential to stabilize. Standard procedures for potentiometric $\mathrm{pH}$ measurements have been published by the IUPAC; however, they are limited to the aqueous organic solvents (ethanol, methanol, ethandiol, etc.) for which a primary reference value standard has been defined (Rondinini et al., 1998).

Spectrophotometric techniques using $\mathrm{pH}$ indicators present an alternative to potentiometric $\mathrm{pH}$ measurement methods (Yamazaki et al., 1992; Yamazaki et al., 1993; Yao and Byrne, 2001). Since measurements are made via absorbance ratios, $\mathrm{pH}$ 
is directly related to the indicator molecular properties and calibrating buffers are not required (Robert-Baldo et al., 1985). One disadvantage of the spectrophotometric method is the a priori determination of the dissociation constants of the particular indicators. However, once the indicator dissociation constants have been determined, the spectrophotometric method offers a fast, reliable and accurate method to determine $\mathrm{pH}$.

In this study, we determined the conditional dissociation constants, ${ }_{s} \mathrm{~K}_{I}$, of two sulphonephthalein indicators, methyl red (MR) and phenol red (PR), in mixed aqueous organic solvents (at a constant ionic strength) to provide a quantitative basis for $\mathrm{pH}$ measurements in these solvents. MR and PR are particularly good acids to study since both their acid and base forms have strong absorption peaks in the visible portion of the spectrum. Their acid dissociation constants are not greatly affected by changes in ionic strength and temperature (Yao and Byrne, 2001; Robert-Baldo et al., 1985), and their color change intervals covering a $\mathrm{pH}$ range of 4.5-8.5 can be conveniently obtained using a simple $\mathrm{HOAc}-\mathrm{NaOAc}(\mathrm{MR})$ and $\mathrm{KH}_{2} \mathrm{PO}_{4}-\mathrm{Na}_{2} \mathrm{HPO}_{4}$ (PR) buffer systems (Kolthoff, 1953). The mixed aqueous-organic solvents chosen for this study represent the solvents of interest in the study of metal-surface reactions, more specifically metal adsorption on clay minerals.

\section{$2.2 \quad$ Theory}

The spectrophotometric determination of $\mathrm{pH}$ in aqueous media can be extended to non-aqueous and mixed aqueous organic solvents using the HendersonHasselbach equation, 


$$
{ }_{s} p H=-\log _{s}\left[H^{+}\right]={ }_{s} p K_{I}+\log \frac{{ }_{s}\left[\operatorname{In}^{-}\right]}{{ }_{s}[H \operatorname{HI}]}
$$

which follows from the indicator dissociation reaction

$$
\mathrm{HIn} \rightarrow \mathrm{In}^{-}+\mathrm{H}^{+}
$$

The conditional dissociation constant of the indicator species, ${ }_{s} \mathrm{~K}_{I}$, is defined as

$$
{ }_{s} K_{I}=\frac{{ }_{s}\left[H^{+}\right]_{s}\left[\mathrm{In}^{-}\right]}{{ }_{s}[H I n]}
$$

In these equations, the left hand subscript indicates the solvent $s$ in which measurements are made, $\left[\mathrm{H}^{+}\right]$is the concentration of the hydrogen ion on the molal scale, ${ }_{s} p K_{I}=-\log _{s} K_{I}$, and $[\mathrm{HIn}]$ and $\left[\mathrm{In}^{-}\right]$are the concentrations of the protonated and unprotonated forms of the indicator species.

The use of Eq [2.1] requires determination of the ${ }_{s} \mathrm{pK}_{I}$ of the indicator species in the solvent $s$. In the absence of any published literature value, these ${ }_{s} \mathrm{pK}_{I}$ in nonaqueous and mixed aqueous organic solvents can be determined using buffer solutions of varying ratios and constant total ionic strength (Tobey, 1958; Yao and Byrne, 2001) by rearranging Eq [2.1]

$$
{ }_{s} p K_{I}={ }_{s} p H-\log \frac{{ }_{s}\left[\mathrm{In}^{-}\right]}{{ }_{s}[H I n]}
$$

In this equation, ${ }_{s} \mathrm{pH}$ can be measured potentiometrically using a procedure developed by the IUPAC Commission on Electroanalytical Chemistry for organic solvent mixtures of high permittivity, $\varepsilon_{\mathrm{r}}>30$, (Mussini et al., 1985). In this procedure, the relationship between the ${ }_{s} \mathrm{pH}$ values of the sample, ${ }_{s} \mathrm{pH}_{\mathrm{X}}$, and the Reference Value 
Standard, $\mathrm{pH}_{\mathrm{RVS}}$, in the solvent $s$, and the electromotive forces (e.m.f.) of cells $\mathrm{I}, \mathrm{E}_{\mathrm{X}}$, and II, $\mathrm{E}_{\mathrm{RVS}}$, is given by

$$
\begin{array}{l|l|l|}
\begin{array}{l}
\text { Reference } \\
\text { electrode }
\end{array} & \begin{array}{l}
\text { Salt } \\
\text { bridge in } \\
\text { solvent } \mathrm{s}
\end{array}|| \text { Solution X in s } \\
\begin{array}{l}
\text { Reference } \\
\text { electrode }
\end{array} & \begin{array}{l}
\text { Salt } \\
\text { bridge in } \\
\text { solvent } \mathrm{s}
\end{array}|| \begin{array}{l}
\text { Solution RVS } \\
\text { in s }
\end{array} \mid \\
{ }_{s} p H_{X}={ }_{S} p H_{R V S}+\frac{{ }_{S} E_{R V S}-{ }_{S} E_{X}}{(\ln 10)(R T / F)}
\end{array}
$$$$
\mathrm{H}^{+} \text {sensing electrode }
$$$$
\mathrm{H}^{+} \text {sensing electrode }
$$

In these cells, the liquid junction potential at $\|$ is assumed to be equal. The Reference Value Standard chosen for these measurements is typically a solution of $0.05 \mathrm{~mol} \mathrm{~kg}^{-1}$ potassium hydrogen phthalate prepared in the solvent $s$ and for which a reference $\mathrm{pH}$ value ${ }_{s} \mathrm{pH}_{\mathrm{RVS}}$ is given. At $25^{\circ} \mathrm{C}$, values of $\mathrm{pH}_{\mathrm{RVS}}$ in selected mixed aqueous organic solvents can be found in Rondinini et al., (1997). At any temperature, these values can also be calculated using the following polynomial regression equation (Rondinini et al., 1998),

$$
\begin{aligned}
{ }_{s} p H_{R V S}= & 4.005+22.17 x-9.19 x^{1.5}+32.26 x^{2}- \\
& 0.821 \varepsilon_{r} x+0.01049 \varepsilon_{r}^{2} x-1.590 K_{a p} x^{2}-0.75 u_{1} x^{0.5}
\end{aligned}
$$

where $u_{1} z=(T-\theta) / \theta(1+z), \theta=298.15 K, \mathrm{x}$ is the alcohol mole fraction in the mixture, and $\mathrm{K}_{\mathrm{ap}}$ is the autoprotolysis constant of the pure alcohol component at 298.15 K. Selected values of $\mathrm{K}_{\mathrm{ap}}$ in nonaqueous and aqueous organic solvents can be found in Rondinini et al., (1987). A regression equation to calculate these values for some mixed aqueous organic solvents was developed by Roses et al., (1993). In this 
study, values for ${ }_{s} \mathrm{pH}_{\mathrm{RVS}}$ and $\mathrm{K}_{\mathrm{ap}}$ were taken from the literature and are given in Table 2.1.

Table 2.1 Values of ${ }_{s} \mathrm{pH}_{\mathrm{RVS}}$ in mixed aqueous alcohol solvents at $25^{\circ} \mathrm{C}$ (Rondinini et al., 1997).

\begin{tabular}{ccc}
\hline Solvent & \% wt Cosolvent & ${ }_{s} \mathrm{pH}_{\mathrm{RVS}}{ }^{*}$ \\
\hline Water & 0 & 4.005 \\
\cline { 2 - 3 } Methanol & 10 & 4.243 \\
& 30 & 4.626 \\
Ethanol & 50 & 5.125 \\
& 10 & 4.230 \\
& 30 & 4.686 \\
& 50 & 5.096 \\
\hline
\end{tabular}

${ }^{*}$ Values that were not available at a specific cosolvent fraction were interpolated from existing data.

In equations [2.1] and [2.3], the ratio $\left[\mathrm{In}^{-}\right] /[\mathrm{HIn}]$ is obtained by measuring the absorbance of a solution that contains both forms of an indictor at two wavelengths. The first wavelength $\left(\lambda_{\mathrm{HIn}}\right)$ is chosen where the acid and not the basic form of the indicator strongly absorbs and the second wavelength $\left(\lambda_{\text {In }}{ }^{-}\right)$is chosen where the basic and not the acidic form of the indicator absorbs.

If Beer's law is obeyed, the absorbances at $\lambda_{\mathrm{HIn}}$ and $\lambda_{\text {In }}{ }^{-}$of a particular indicator are given by

$$
A_{\lambda_{H I n}^{H I n}}^{H I}=\in_{\left(H I n, \lambda_{H I n}\right)} \times b_{a} \times[H I n]
$$

and

$$
A_{\lambda_{I n^{-}}}^{I n^{-}}=\in \in_{\left(I n^{-}, \lambda_{I n^{-}}\right)} \times b_{a} \times\left[\operatorname{In}^{-}\right]
$$

where $A_{\lambda_{H I n}}^{H I n}$ and $A_{\lambda_{I n^{-}}}^{I n^{-}}$are the absorbance of the acidic form of the indicator, HIn (right hand superscript) at $\lambda_{\mathrm{HIn}}$ (right hand subscript) and the basic form of the indicator, $\mathrm{In}^{-}$, 
at $\lambda_{\text {In }}{ }^{-}$respectively. $\in_{\left(H I n, \lambda_{H I n}\right)}$ and $\in_{\left(I n^{-}, \lambda_{l n^{-}}\right)}$are the molar absorptivities of HIn at $\lambda_{\mathrm{HIn}}$ and $\operatorname{In}^{-}$at $\lambda_{\text {In }}{ }^{-}$respectively and $b_{a}$ is the cell path length. At any $\mathrm{pH}$, the total concentration $\left(\mathrm{C}_{\mathrm{T}}\right)$ of both forms of indicator is

$$
C_{T}=[H I n]+\left[\operatorname{In}^{-}\right]
$$

In extremely acidic solution, where $\mathrm{HIn}>>\operatorname{In}^{-}$and $\mathrm{C}_{\mathrm{T}}=[\mathrm{HIn}]$

$$
A_{\lambda_{H I n}(a c i d i c)}=\epsilon_{\left(H I n, \lambda_{H I n}\right)} \times b_{a} \times C_{T}
$$

Likewise, in extremely basic solution where $\operatorname{In}>>\mathrm{HIn}^{-}$and $\mathrm{C}_{\mathrm{T}}=\left[\operatorname{In}^{-}\right]$

$$
A_{\lambda_{l^{-}-(b a s i c)}}=\epsilon_{\left(I^{-}, \lambda_{h^{-}}\right)} \times b_{a} \times C_{T}
$$

At any $\mathrm{pH}$, the ratio $[\mathrm{In}] /[\mathrm{HIn}]$ can be obtained by combining Eq $2.6-2.10$ to give

$$
\frac{\left[I^{-}\right]}{[H I n]}=\frac{A_{\lambda_{l n^{-}}}\left(C_{T} / A_{\left.\lambda_{n^{-}} \text {(basic }\right)}\right)}{A_{\lambda_{H I n}}\left(C_{T} / A_{\lambda_{H I n}(\text { acidic })}\right)}
$$

or

$$
\frac{\left[I^{-}\right]}{[H I n]}=\frac{A_{\lambda_{n^{-}}}}{A_{\lambda_{H ! n}}} \times R_{I}
$$

where

$$
R_{I}=\frac{A_{\lambda_{\text {HIn }} \text { (acidic) }}}{A_{\lambda_{h^{n}} \text { (basic) }}}
$$

All the absorbances used in these equations are background corrected such that

$$
A_{\lambda_{H l l n}}^{H I n}=A_{\lambda_{H l n}}^{H I n}(\text { measured })-A_{\lambda_{l^{-}}}^{H I n}(\text { acidic })
$$

where $A_{\lambda_{H I n}}^{H I n}$ is the corrected absorbance, $A_{\lambda_{H I n}}^{H I n}$ (measured) is the measured absorbance and $A_{\lambda_{n^{-}}}^{\text {HIn }}$ (acidic) is the absorbance of HIn at $\lambda_{\text {In }^{-}}$from the most acidic solution (Braun, 1982). $\mathrm{pK}_{I}$ is then calculated by combining Eq [2.3] and [2.12] 


$$
{ }_{s} p K_{I}={ }_{s} p H-\log \frac{A_{\lambda_{I n^{-}}}}{A_{\lambda_{H I n}}} \times R_{I}
$$

using either of two equivalent methods, an algebraic method or a graphical method.

In the algebraic method, sets of ${ }_{s} \mathrm{pH}$ and absorbance values are substituted in Eq [2.15] and the ${ }_{s} \mathrm{pK}_{I}$ is calculated for each set. The ${ }_{s} \mathrm{pK}_{I}$ reported is then the average of the calculated ${ }_{s} \mathrm{pK}_{I}$. In the graphical method, $\log \left[\mathrm{In}^{-}\right] /[\mathrm{HIn}]$ is plotted against ${ }_{s} \mathrm{pH}$ and ${ }_{s} \mathrm{pK}_{I}$ is obtained as the $\mathrm{x}$-intercept. The line should have a slope of -1 .

For any solution and within the buffer region of the selected indicator, ${ }_{s} \mathrm{pH}$ can be determined by rearranging Eq [2.15]

$$
{ }_{s} p H={ }_{s} p K_{I}+\log \frac{A_{\lambda_{I n^{-}}}}{A_{\lambda_{H I n}}} \times R_{I}
$$

In Eq [2.16], all parameters must be known except for $A_{\lambda_{I n^{-}}}$and $A_{\lambda_{H I n}}$ which are measured spectrophotometrically for each unknown sample.

\subsection{Materials and Methods}

\subsubsection{Reagents}

The solvents used in this study were deionized water, methanol (HPLC grade, CAS: 67-56-1, Fisher Scientific, Pittsburgh, PA) and ethanol (Reagent grade). Cosolvent fractions were prepared by weight $(10 \%, 30 \%$ and $50 \%)$ using $\mathrm{N}_{2}$ purged distilled water. Properties of these cosolvents are given in Table 1.5.

The stock solution of MR $\left(5.49 \times 10^{-3} \mathrm{~mol} \mathrm{~L}^{-1}\right)$ was prepared by dissolving an appropriate amount of reagent grade methyl red sodium salt $\left(\mathrm{C}_{15} \mathrm{H}_{14} \mathrm{~N}_{3} \mathrm{NaO}_{2}, \mathrm{CAS}\right.$ : 845-10-3, Acros Organics, NJ) in 95\% ethanol and diluting with distilled water 
(Tobey, 1958). The stock solution of PR $\left(5.31 \times 10^{-3} \mathrm{~mol} \mathrm{~L}^{-1}\right)$ was prepared by dissolving reagent grade phenol red sodium salt $\left(\mathrm{C}_{19} \mathrm{H}_{13} \mathrm{NaO}_{5}\right.$, CAS: 34427-61-1, Acros Organics, NJ) in distilled water (Kolthoff, 1953). Working solutions of acids $(\mathrm{HCl})$, bases $(\mathrm{NaOH})$ and buffers $\left(\mathrm{HOAc}, \mathrm{NaOAc}, \mathrm{KH}_{2} \mathrm{PO}_{4}, \mathrm{Na}_{2} \mathrm{HPO}_{4}\right)$ were prepared in various weight percent cosolvents. Concentrations of indicator in this work were $2.197 \times 10^{-5} \mathrm{~mol} \mathrm{~L}^{-1}$ for MR and $2.125 \times 10^{-5} \mathrm{~mol} \mathrm{~L}^{-1}$ for PR.

\subsubsection{Determination of the conditional dissociation constant, $s K_{I}$, of $M R$}

and $P R$

The first step in this experiment involved determining the wavelengths at which $\mathrm{HMR}$ and $\mathrm{MR}^{-}$and $\mathrm{HPR}$ and $\mathrm{PR}^{-}$exhibited absorption maxima. For each indicator, this was done by investigating the absorbance versus wavelength relationship of two solutions: An acidic solution which contained the indicator entirely in the form HIn and a basic solution which contained the indicator entirely in the form $\operatorname{In}^{-}$(Kolthoff, 1953). Absorption maxima and peak width were recorded in every percent weight cosolvent.

The second step involved determining the relative amounts of the acid and base forms of each indicator as a function of $\mathrm{pH}$. This was done by preparing a series

of solutions of constant total ionic strength $\left(\mathrm{I}=2.5 \times 10^{-3} \mathrm{~mol} \mathrm{~L}^{-1}\right)$, constant total amount of indicator and varying amount of buffer solutions in each percent weight cosolvent (Tobey 1958). The absorbance of the solution at $\lambda_{\mathrm{HIn}}$ and $\lambda_{\mathrm{In}}{ }^{-}$were determined using a Cary $50 \mathrm{UV}-\mathrm{V}$ is spectrophotometer (Variance Instruments, Walnut Creek, Ca) equipped with a dip probe. In each cosolvent, baseline corrections 
were done by measuring the absorbance of a blank solution containing the solvent of interest (e.g. 10\% methanol) and subtracting it from the absorbance of the samples at $\lambda_{\text {HIn }}$ and $\lambda_{\text {In }}{ }^{-}$

In each solution and at each cosolvent fraction, e.m.f was measured in $\mathrm{mV}$ using an Accumet $\mathrm{pH}$ meter equipped with an Sure-flow glass combination electrode (Orion $囚)$ preconditioned in a solution that contained the cosolvent of interest for at least 10 days (in order to reduce electrical potential drifts) (Xue and Traina, 1996a). Prior to any measurement, the $\mathrm{pH}$ electrode was calibrated using a standard $0.05 \mathrm{~mol}$ $\mathrm{kg}^{-1}$ potassium hydrogen phthalate prepared in the cosolvent of interest and the e.m.f. was recorded (Rondinini et al., 1998). Depending on the solvent type, the time needed for readings to stabilize varied from 5-20 min.

\subsection{Results and Discussion}

Figure 2.1 and 2.2 illustrate the type of plots obtained for PR and MR indicators respectively in $10 \%$ methanol. The absorption maxima of $\mathrm{HIn}$ and $\mathrm{In}^{-}$for MR were $\lambda_{\mathrm{HMR}}=520 \mathrm{~nm}$ and $\lambda_{\mathrm{MR}}{ }^{-}=425 \mathrm{~nm}$ and $\lambda_{\mathrm{HPR}}=433 \mathrm{~nm}$ and $\lambda_{\mathrm{PR}}{ }^{-}=558 \mathrm{~nm}$ for PR. These results as well as the calculated dissociation constants for MR and PR in water correlate well with published literature values (Tobey, 1958; Yao and Byrne, 2001). No change in the wavelength at which the absorption maxima of the acidic and basic solution occurred. However, changes in the peak width among cosolvents were recorded. This change in peak width can be attributed to the presence of several species of the indicator (potential isomers) molecule (Bates, 1973). 
The experimental data for PR and MR in all cosolvents are presented in Appendix A (A.1-A.12). A sample of these data (10\% methanol) is presented in Tables 2.2 and 2.3 for PR and MR respectively. The properties of all acidic and basic solutions in the various alcohol-water mixtures are presented in Table 2.4. A summary of $\mathrm{pK}_{I}$ is represented in Table 2.5 . These ${ }_{s} \mathrm{pK}_{I}$ are calculated algebraically as the average of the various ${ }_{s} \mathrm{pK}_{I}$ determined for each indicator in each cosolvent within the indicator buffer region. These ${ }_{s} \mathrm{pK}_{I}$ are conditional dissociation constants and can only be used in the studied cosolvents under a constant ionic strength $\left(\mathrm{I}=2.5 \times 10^{-3} \mathrm{~mol} \mathrm{~L}^{-1}\right)$ and temperature $\left(25^{\circ} \mathrm{C} \pm 2.0\right)$. The temperature variation is somewhat large $\left( \pm 2.0^{\circ} \mathrm{C}\right)$ and represents the range of temperatures of all the studied solutions in the various cosolvents during the overall period of study (one month). However, the effect of temperature on the dissociation constants of phenol red and methyl red is relatively small (only apparent at the third decimal place) and can be, for the purpose of this study considered to be negligible (Yao and Byrne, 2001; Robert-Baldo et al., 1985; Kolthoff, 1953).

Figure 2.3 shows the variation of the negative logarithm of the dissociation constants of MR and PR in the studied alcohol-water mixtures. As the solvent dielectric constant decreased, the dissociation constant of both PR and MR in methanol-water mixtures decreased $\left(78.48<\varepsilon_{\mathrm{r}}<74.21\right.$ corresponding to $\left.0<\% \mathrm{wt}<10 \%\right)$, then increased $\left(74.21<\varepsilon_{\mathrm{r}}<56.05\right.$ corresponding to $\left.10<\% \mathrm{wt}<50 \%\right)$. In ethanol-water mixtures, ${ }_{s} \mathrm{pK}_{I}$ of both indicators increased as the solvent dielectric constant decreased. The nonlinear variation of $\mathrm{pK}_{I}$ with the reciprocal solvent dielectric constant indicates that the dissociation of the studied indicators in alcohol-water 
mixtures is not solely a function of the solvent dielectric constant. Other specificsolvent-indicator interactions, the nature of which could not be deduced from the current study, are indicated.

In these mixtures and for the same conditions under which these dissociation constants were determined $\left(\mathrm{I}=2.5 \times 10^{-3} \mathrm{~mol} \cdot \mathrm{L}^{-1}\right.$, and $\left.\mathrm{T}=25^{\circ} \mathrm{C} \pm 2.0\right)$, $s \mathrm{pH}$, on the free hydrogen ion scale, can be estimated from measurements of the indicator absorbance $\operatorname{ratios}\left(A_{\lambda_{h^{-}}} / A_{\lambda_{H I n}}\right)$ of any solution whose ${ }_{s} \mathrm{pH}$ is unknown using Eq [2.16] where ${ }_{s} \mathrm{pK}_{I}$ and $\mathrm{R}_{\mathrm{I}}$ are obtained from Tables 2.5 and 2.4, respectively. These two indicators can be used to determine $\mathrm{pH}$ within the range $4.5 \leq \mathrm{pH} \leq 8.5$. 
Table 2.2. Experimental data for phenol red indicator in $10 \%$ methanol.

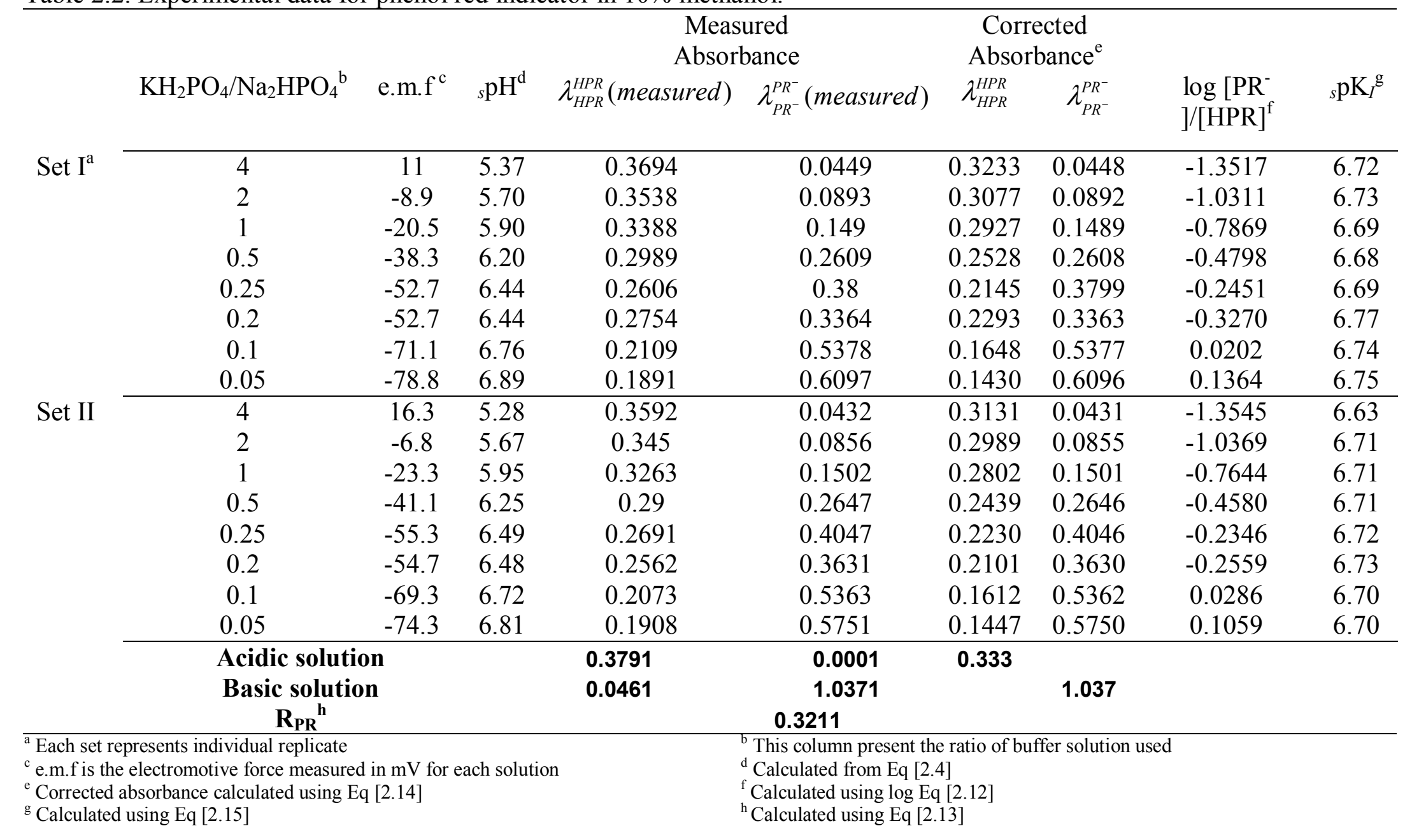


Table 2.3. Experimental data for methyl red indicator in $10 \%$ methanol.

\begin{tabular}{|c|c|c|c|c|c|c|c|c|c|}
\hline & \multirow[b]{2}{*}{$\mathrm{HOAc} / \mathrm{NaOAc} \mathrm{c}^{\mathrm{b}}$} & \multirow[b]{2}{*}{ e.m. $f^{c}$} & \multirow[b]{2}{*}{${ }_{s} \mathrm{pH}^{\mathrm{d}}$} & \multicolumn{2}{|c|}{ Measured Absorbance } & \multicolumn{2}{|c|}{$\begin{array}{c}\text { Corrected } \\
\text { Absorbance }\end{array}$} & \multirow[b]{2}{*}{$\begin{array}{l}\log \left[\mathrm{MR}^{-}\right. \\
] /[\mathrm{HMR}]^{\mathrm{f}}\end{array}$} & \multirow[b]{2}{*}{${ }_{s} \mathrm{pK}_{I}$} \\
\hline & & & & $\lambda_{M R^{-}}^{M R^{-}}($measured $)$ & $\lambda_{H M R}^{H M R}($ measured $)$ & $\lambda_{M R^{-}}^{M R^{-}}$ & $\lambda_{H M R}^{H M R}$ & & \\
\hline \multirow[t]{8}{*}{ Set $\mathrm{I}^{\mathrm{a}}$} & 2 & 120.5 & 3.52 & 0.1824 & 0.6527 & 0.1356 & 0.6437 & -0.2244 & 3.74 \\
\hline & 1.5 & 113.2 & 3.64 & 0.209 & 0.6032 & 0.1622 & 0.5942 & -0.1184 & 3.76 \\
\hline & 1 & 102.6 & 3.82 & 0.2431 & 0.49 & 0.1963 & 0.481 & 0.0548 & 3.76 \\
\hline & 0.5 & 85 & 4.12 & 0.3106 & 0.3271 & 0.2638 & 0.3181 & 0.3586 & 3.76 \\
\hline & 0.25 & 67 & 4.42 & 0.349 & 0.2027 & 0.3022 & 0.1937 & 0.6255 & 3.80 \\
\hline & 0.2 & 61 & 4.52 & 0.3594 & 0.1627 & 0.3126 & 0.1537 & 0.7356 & 3.79 \\
\hline & 0.1 & 44.1 & 4.81 & 0.3965 & 0.1096 & 0.3497 & 0.1006 & 0.9559 & 3.85 \\
\hline & 0.05 & 28 & 5.08 & 0.4109 & 0.0689 & 0.3641 & 0.0599 & 1.1750 & 3.90 \\
\hline \multirow[t]{11}{*}{ Set II } & 2 & 120.1 & 3.52 & 0.2007 & 0.6824 & 0.1539 & 0.6734 & -0.1890 & 3.71 \\
\hline & 1.5 & 113.5 & 3.63 & 0.2275 & 0.6267 & 0.1807 & 0.6177 & -0.0818 & 3.72 \\
\hline & 1 & 102.1 & 3.83 & 0.2686 & 0.5195 & 0.2218 & 0.5105 & 0.0900 & 3.74 \\
\hline & 0.5 & 85.3 & 4.11 & 0.3247 & 0.3484 & 0.2779 & 0.3394 & 0.3652 & 3.75 \\
\hline & 0.25 & 66.7 & 4.43 & 0.3714 & 0.2189 & 0.3246 & 0.2099 & 0.6414 & 3.78 \\
\hline & 0.2 & 61.2 & 4.52 & 0.3813 & 0.1865 & 0.3345 & 0.1775 & 0.7272 & 3.79 \\
\hline & 0.1 & 44 & 4.81 & 0.4081 & 0.1133 & 0.3613 & 0.1043 & 0.9916 & 3.82 \\
\hline & 0.05 & 27.1 & 5.10 & 0.4192 & 0.0739 & 0.3724 & 0.0649 & 1.2108 & 3.88 \\
\hline & \multirow{3}{*}{\multicolumn{3}{|c|}{$\begin{array}{c}\text { Acidic solution } \\
\text { Basic solution } \\
\mathbf{R}_{\mathbf{M R}}\end{array}$}} & 0.0468 & 1.0485 & \multirow{3}{*}{\multicolumn{2}{|c|}{0.3671}} & & \\
\hline & & & & 0.4139 & 0.0090 & & & & \\
\hline & & & & & 2.8316 & & & & \\
\hline $\begin{array}{l}{ }^{2} \text { Each set } \\
\text { c e.m.f is t } \\
\text { e Correcte } \\
{ }^{g} \text { Calculat }\end{array}$ & $\begin{array}{l}\text { resents individual repli } \\
\text { electromotive force me } \\
\text { bsorbance calculated us } \\
\text { using Eq [2.15] }\end{array}$ & $\begin{array}{l}\text { ed in } m \\
\mathrm{Eq}[2.1\end{array}$ & ion & & $\begin{array}{l}\text { his column present the ra } \\
\text { alculated from Eq [2.4] } \\
\text { alculated using log Eq [2. } \\
\text { alculated using Eq [2.13] }\end{array}$ & io of bu & & & \\
\hline
\end{tabular}


Table 2.4. Properties of the acidic and basic solutions of PR and MR in various alcohol-water mixtures.

\begin{tabular}{|c|c|c|c|c|c|}
\hline \multirow[b]{2}{*}{ Solvent } & \multirow[b]{2}{*}{$\%$ wt } & \multicolumn{2}{|c|}{ Phenol Red } & \multicolumn{2}{|c|}{ Methyl Red } \\
\hline & & $\mathbf{R}_{\mathbf{P R}}{ }^{\mathbf{a}}$ & $\begin{array}{c}\text { Measured } \\
\text { Absorbance }\end{array}$ & $\mathbf{R}_{\mathrm{MR}}$ & $\begin{array}{c}\text { Measured } \\
\text { Absorbance }\end{array}$ \\
\hline \multirow[t]{2}{*}{ Water } & 0 & 0.3270 & $\lambda_{P R^{-}}^{H P R}=0.0024$ & 2.9339 & $\lambda_{M R^{-}}^{H M R}=0.0737$ \\
\hline & & & $\lambda_{H P R}^{P R^{-}}=0.0439$ & & $\lambda_{H M R}^{M R^{-}}=0.0431$ \\
\hline \multirow[t]{6}{*}{ Methanol } & 10 & 0.3211 & $\lambda_{P R^{-}}^{H P R}=0.0001$ & 2.8316 & $\lambda_{M R^{-}}^{H M R}=0.0468$ \\
\hline & & & $\lambda_{H P R}^{P R^{-}}=0.0461$ & & $\lambda_{H M R}^{M R^{-}}=0.0090$ \\
\hline & 30 & 0.3226 & $\lambda_{P R^{-}}^{H P R}=0.0038$ & 2.9255 & $\lambda_{M R^{-}}^{H M R}=0.0908$ \\
\hline & & & $\lambda_{H P R}^{P R^{-}}=0.0393$ & & $\lambda_{H M R}^{M R^{-}}=0.0318$ \\
\hline & 50 & 0.3247 & $\lambda_{P R^{-}}^{H P R}=0.0017$ & 2.6951 & $\lambda_{M R^{-}}^{H M R}=0.1053$ \\
\hline & & & $\lambda_{H P R}^{P R^{-}}=0.0403$ & & $\lambda_{H M R}^{M R^{-}}=0.0224$ \\
\hline \multirow[t]{6}{*}{ Ethanol } & 10 & 0.3263 & $\lambda_{P R^{-}}^{H P R}=0.0029$ & 2.8667 & $\lambda_{M R^{-}}^{H M R}=0.0720$ \\
\hline & & & $\lambda_{H P R}^{P R^{-}}=0.0413$ & & $\lambda_{H M R}^{M R^{-}}=0.0420$ \\
\hline & 30 & 0.3338 & $\lambda_{P R^{-}}^{H P R}=0.0043$ & 2.7097 & $\lambda_{M R^{-}}^{H M R}=0.0779$ \\
\hline & & & $\lambda_{H P R}^{P R^{-}}=0.0351$ & & $\lambda_{H M R}^{M R^{-}}=0.0239$ \\
\hline & 50 & 0.3303 & $\lambda_{P R^{-}}^{H P R}=0.0002$ & 2.7258 & $\lambda_{M R^{-}}^{H M R}=0.1170$ \\
\hline & & & $\lambda_{H P R}^{P R^{-}}=0.0401$ & & $\lambda_{H M R}^{M R^{-}}=0.0383$ \\
\hline
\end{tabular}

a These values are calculated using Eq [2.13]

$\mathrm{b}$ These values are needed for the corrections of measured absorbance in every solution (Refer to Eq [2.14]) 
Table 2.5. ${ }_{s} \mathrm{pK}_{I}$ for PR and MR in various alcohol-water mixtures.

\begin{tabular}{cccc}
\hline & & \multicolumn{2}{c}{${ } \mathbf{p} \mathbf{K}_{\boldsymbol{I}}$} \\
\cline { 3 - 4 } Solvent & \% wt & Phenol Red & Methyl Red \\
\hline Water & 0 & $8.05 \pm 0.03$ & $5.07 \pm 0.09$ \\
Methanol & 10 & $6.71 \pm 0.03$ & $3.78 \pm 0.06$ \\
& 30 & $7.04 \pm 0.04$ & $3.94 \pm 0.07$ \\
Ethanol & 50 & $8.77 \pm 0.06$ & $5.50 \pm 0.04$ \\
& 10 & $8.09 \pm 0.02$ & $5.08 \pm 0.03$ \\
& 30 & $8.43 \pm 0.03$ & $5.46 \pm 0.04$ \\
& 50 & $8.50 \pm 0.1$ & $5.38 \pm 0.06$ \\
\hline
\end{tabular}

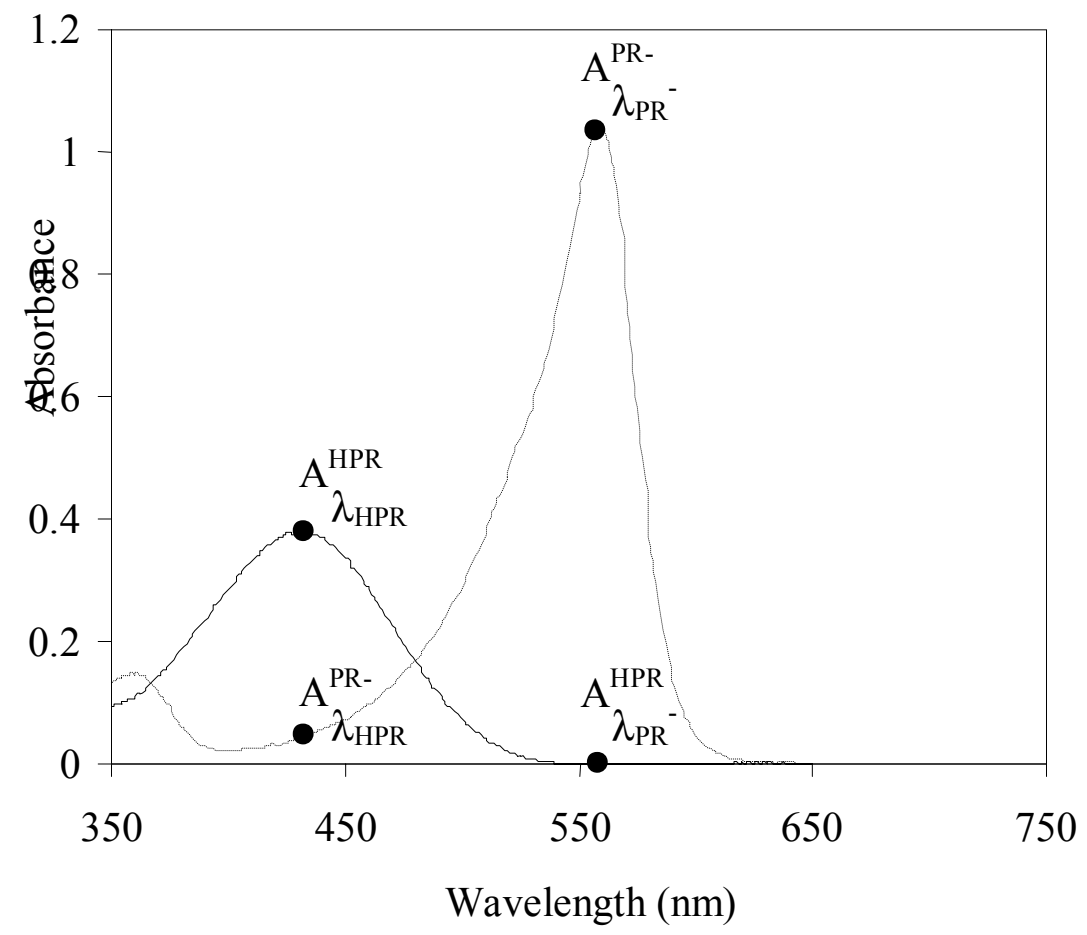

Figure 2.1. Absorbance versus wavelength for the acidic (HPR) and the basic (PR') form of phenol red (PR) indicator in 10\% methanol-water mixtures. 


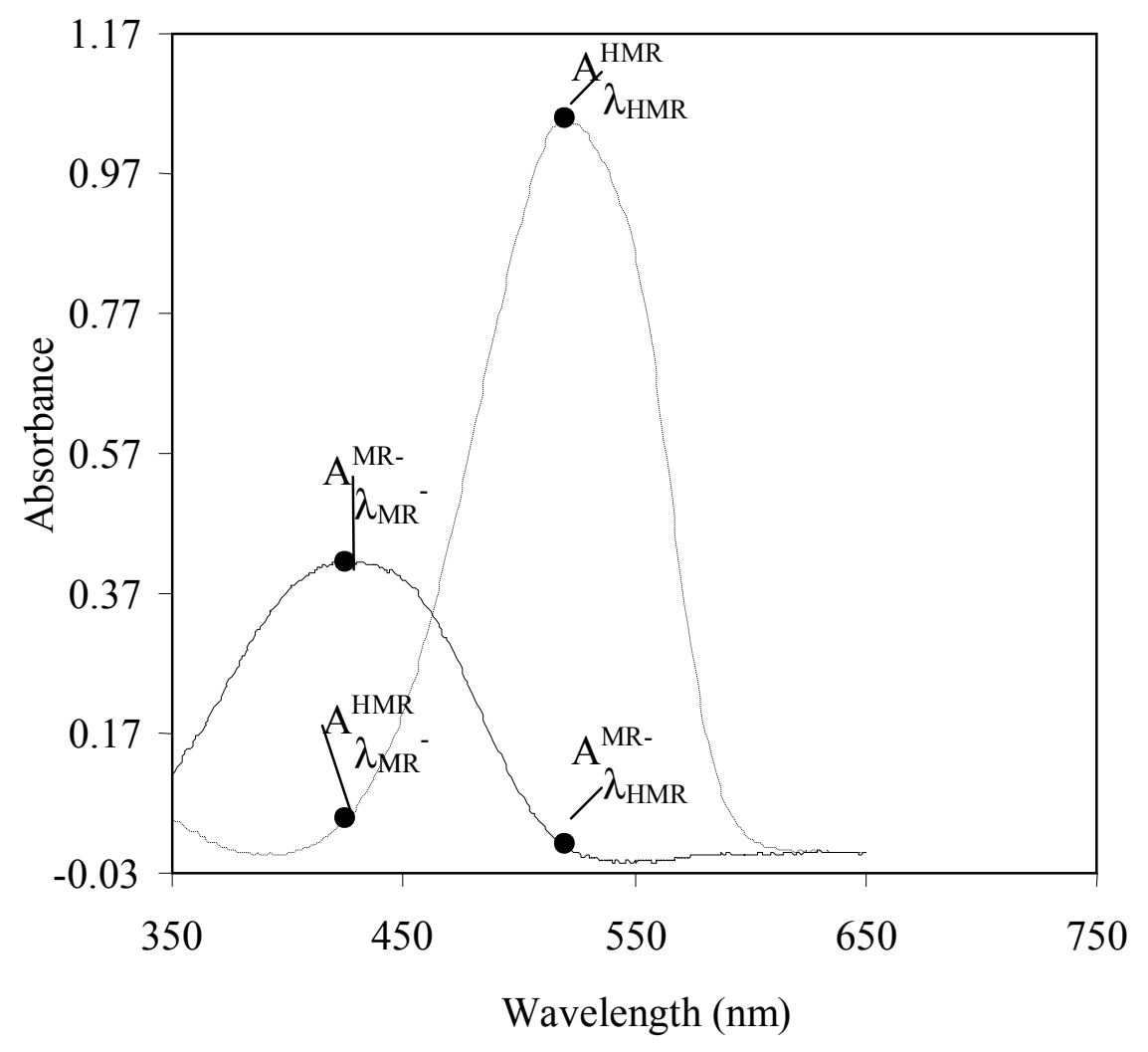

Figure 2.2. Absorbance versus wavelength for the acidic (HMR) and the basic ( $\left.\mathrm{MR}^{-}\right)$ form of methyl red (MR) indicator in 10\% methanol-water mixtures. 


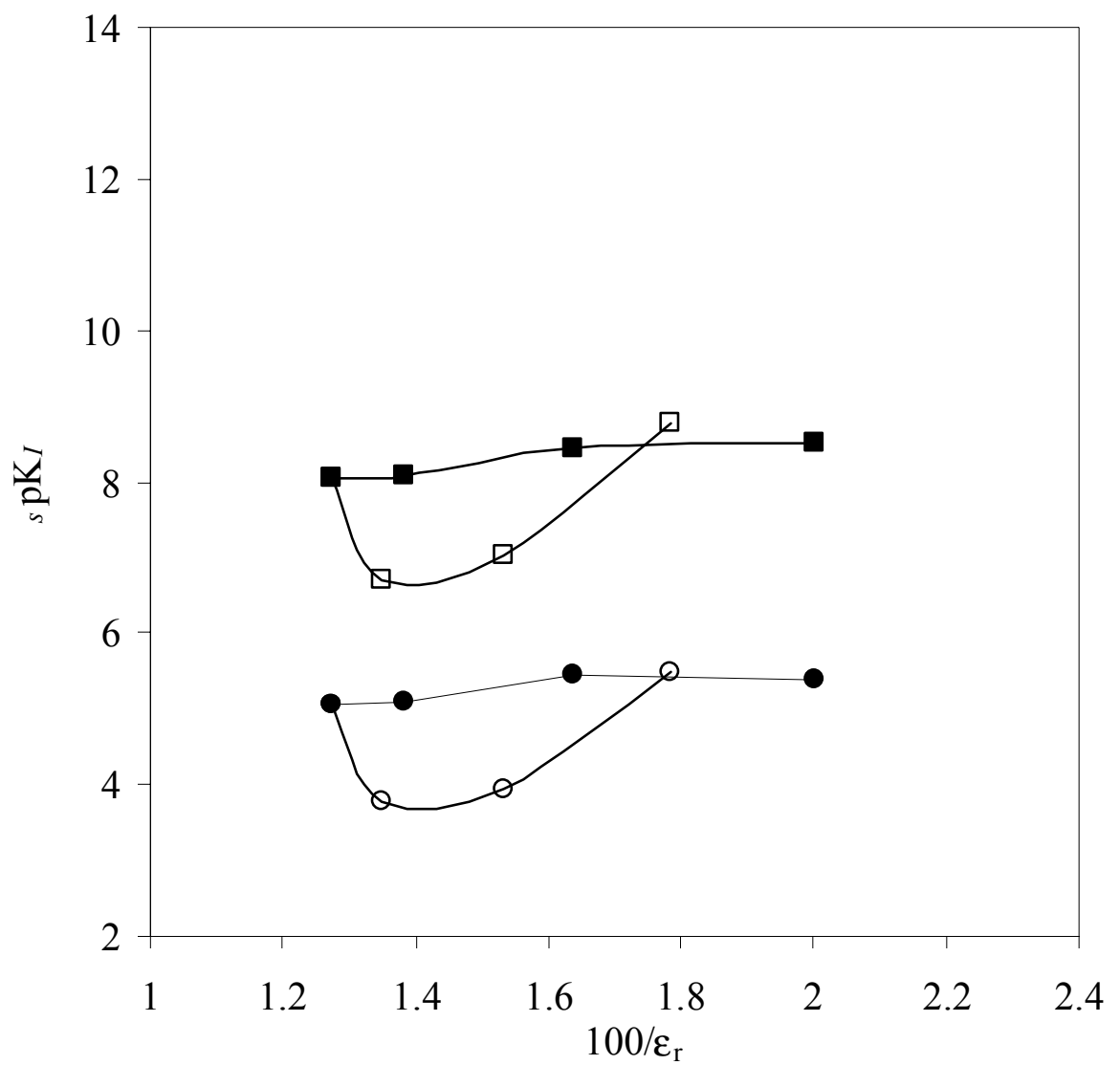

Figure 2.3. Changes in the negative logarithm of the dissociation constant, $\mathrm{pK}_{I}$, of MR and PR in alcohol-water mixtures at constant ionic strength with $100 / \varepsilon_{\mathrm{r}}$. $\square$ PR, methanol; - PR, ethanol; ○ MR, methanol; • MR, ethanol. 


\section{CHAPTER III}

Conductometric Study of Cd(II), Ca(II), Zn(II) Nitrates and Ca(II) Chlorides in Mixed Aqueous Organic Solvents at $25^{\circ} \mathrm{C}$

\subsection{Introduction}

In the studies of soil chemical reactions, it is often necessary to keep ionic strength constant without affecting other chemical equilibria. Generally, this ionic strength varies from low (mostly in sorption studies) to high (exchange reactions). At high ionic strength, ion-pairing is often too large and is responsible for a large drop in the ionic activity. In aqueous solutions with low ionic strength, this effect is often small and enough to be ignored. In non-aqueous and mixed aqueous organic solvents with low dielectric constants, even low ionic strength solutions are capable of some degree of ionic association (Doe et al., 1984). For this purpose and in the absence of published values, studies of electrolytic conductance in mixed non aqueous solvents have been initiated in order to provide experimental data on the primary ionassociation constant, $\mathrm{K}_{1 \mathrm{~A}}$, of some electrolytes of interest in soil science studies. These electrolytes include $\mathrm{Ca}\left(\mathrm{NO}_{3}\right)_{2}, \mathrm{Cd}\left(\mathrm{NO}_{3}\right)_{2}, \mathrm{Zn}\left(\mathrm{NO}_{3}\right)_{2}$ and $\mathrm{CaCl}_{2}$.

\subsection{Materials and Methods}

\subsubsection{Reagents}

Certified reagent grade $\mathrm{Ca}\left(\mathrm{NO}_{3}\right)_{2} \cdot 4 \mathrm{H}_{2} \mathrm{O}$ (Fisher Scientific, Pittsburgh, PA, CAS: 13477-34-4), $\mathrm{Cd}\left(\mathrm{NO}_{3}\right)_{2} \cdot 4 \mathrm{H}_{2} \mathrm{O}$ (Fisher Scientific, Pittsburgh, PA, CAS: 1002268-1), $\mathrm{Zn}\left(\mathrm{NO}_{3}\right)_{2} \cdot 6 \mathrm{H}_{2} \mathrm{O}$ (Fisher Scientific, Pittsburgh, PA, CAS: 7779-88-6), and 
anhydrous $\mathrm{CaCl}_{2}$ (Fisher Scientific, Pittsburgh, PA, CAS: 10043-52-4) were used to prepare titrant solutions. The exact concentration of each titrant was calculated after standardization with $0.01 \mathrm{~N}$ EDTA. The solvents used in this study were deionized water, methanol (HPLC grade, Fisher Scientific, Pittsburgh, PA CAS: 67-56-1), ethanol (Reagent grade) and acetone (HPLC grade, Fisher Scientific, Pittsburgh, PA, CAS: 67-64-1). The electrical conductivity of each solvent was recorded and the reported values were $0.39,0.04,0.1$, and $0.01 \mu \mathrm{S} / \mathrm{cm}$ for each solvent respectively. All cosolvent fractions were prepared by weight.

\subsubsection{Conductometric titration}

Conductivity measurements in mixed aqueous organic solvents are highly sensitive to atmospheric pressure and carbon dioxide (Yeager and Salkind, 1973). Therefore special care was taken to ensure complete isolation of the system from the atmosphere. Before each run, the water-jacketed reaction cell was rinsed several times with the solvent of interest and then flushed for approximately 10 min with highly purified nitrogen gas (Ultra Pure nitrogen, Airgas, Bowling Green, KY) which bubbled through the solvent just before entering the cell (Broadwater et al.,1976). A known volume of mixed aqueous alcohol solvent, $\mathrm{V}_{\mathrm{s}}$, (weighed and corrected for density) was carefully transferred to the cell and purged with solvent-saturated nitrogen until the measured electrical conductivity (EC) stabilized. This value was recorded and subtracted from all subsequent EC readings. After thermal equilibrium had been attained $\left(25^{\circ} \mathrm{C} \pm 0.1\right)$, and the solvent EC determined, an exact volume of titrant, $\mathrm{V}_{\mathrm{i}}$, was added using an autotitrator (DL50, Mettler Toledo) and the solution 
was allowed to equilibrate for $3 \mathrm{~min}$ before the specific conductivity and the solution temperature were recorded using an LF 3000 Microprocessor Conductivity meter equipped with a TetraConL conductivity measuring cell (WTW). For every $\mathrm{V}_{\mathrm{i}}$, the solution equivalent concentration, $\left(\mathrm{C}_{\mathrm{i}}\right.$, eq $\left.\mathrm{L}^{-1}\right)$, and the equivalent conductivity $\left(\Lambda, \mathrm{ohm} \mathrm{cm}^{2} \mathrm{eq}^{-1}\right)$, was calculated as

$$
C_{i}=2\left(\frac{n_{i} \times V_{i}}{V_{T}}\right)
$$

and

$$
\Lambda=E C / C_{i}
$$

where

$$
V_{T}=V_{s}+V_{i}
$$

$\mathrm{n}$ is the number of moles of titrant per liter solution, and $\mathrm{V}_{\mathrm{T}}$ is the total solution volume in ml. At all times during the titration, the solution was continuously stirred and a solvent-saturated $\mathrm{N}_{2}(\mathrm{~g})$ pressure head maintained. Each titration was generally completed within one hour.

\subsubsection{Data analysis}

The densities, $\rho$, dielectric constants, $\varepsilon$, and absolute viscosity, $\eta$, used in calculations were obtained from the literature and are summarized in Table 1.5. In cases where values for a specific cosolvent fraction were not available, they were obtained by interpolation of existing data. The conductometric data was treated with the Fuoss and Edelson method (Fuoss and Edelson, 1951). For (2:1) electrolytes, the following equilibria are considered: 


$$
\begin{gathered}
M^{2+}+L^{-} \stackrel{K_{1 A}}{\Leftrightarrow} M L^{+} \\
M L^{+}+L^{-1} \stackrel{K_{2 A}}{\Leftrightarrow} M L_{2}
\end{gathered}
$$

Fuoss and Edelson assumed that $\mathrm{K}_{1 \mathrm{~A}}>>\mathrm{K}_{2 \mathrm{~A}}$ and hence developed the following equation:

$$
\Lambda F=\Lambda_{0}-X K_{1 A} / \Lambda_{0}
$$

where

$$
\begin{aligned}
& X=C_{i} \gamma_{M} \Lambda F\left(\Lambda F-\Lambda_{0} / 2\right) \\
& F=\left\{1 /\left(1-\delta C_{i}^{0.5}\right)+\left(\Lambda_{0}-\lambda_{0}\right) / 2 \Lambda\right\} /\left\{1+\left(\Lambda_{0}-\lambda_{0}\right) / 2 \Lambda_{0}\right\} \\
& \delta=\alpha \Lambda_{0}+\beta \\
& \left.\alpha=5.60 \times 10^{6} q /\left\{\varepsilon_{r} T\right)^{1.5}\left(1+q^{0.5}\right)\right\} \\
& \beta=123.8 /\left[\eta\left(\varepsilon_{r} T\right)^{0.5}\right] \\
& q=(2 / 3)\left(1+\lambda_{0} / \Lambda_{0}\right)^{-1}
\end{aligned}
$$

Here, $\Lambda_{0}$ is the limiting equivalent conductance, $\lambda_{0}$ is the equivalent conductance of the anion, $\delta$ is the Onsager's slope for a 2:1 electrolyte, divided by $\Lambda_{0}$. The ion activity coefficient of $\mathrm{M}^{2+}, \gamma_{\mathrm{M}}$ was calculated using the extended Debye-Hückel equation, (Eq 1.8). In all cosolvents, the ion size parameter, $\mathrm{a}_{\mathrm{i}}$, for $\mathrm{Ca}$ and $\mathrm{Zn}$ was assumed equal $6 \AA$ and for $\mathrm{Cd}, 5 \AA$; the values that are used in water (Kielland, 1937).

For each treatment, two replicates were performed. The values of $\lambda_{0}\left(\mathrm{NO}_{3}\right)^{-}$ and $\lambda_{0}(\mathrm{Cl})^{-}$were not available at the various percent weight cosolvent and since they 
are needed for the computation of $\Lambda_{0}$ and $\mathrm{K}_{1 \mathrm{~A}}$, they were assumed equal to their values in the pure solvent, that is for $\mathrm{NO}_{3}{ }^{-}$, these were 60.95 and $24.82 \Omega^{-1} \mathrm{~cm}^{2} \mathrm{eq}^{-1}$ in methanol and ethanol respectively; and for $\mathrm{Cl}^{-}$, these were 52.38, 21.85, and 109.30 $\Omega^{-1} \mathrm{~cm}^{2} \mathrm{eq}^{-1}$ in methanol, ethanol, and acetone respectively (Izutsu, 2001and references therein). Eq 3.6 was solved for the two unknown parameters $\Lambda_{0}$ and $\mathrm{K}_{1 \mathrm{~A}}$ using an iterative procedure until $\Lambda_{0}$ and $\mathrm{K}_{1 \mathrm{~A}}$ became constant.

\subsection{Results and Discussion}

The experimental data are summarized in Appendix B (Table B.1-B.6). The errors in these tables are the standard deviations. Each series represents a separate replicate. The Fuoss-Edelson plots (Eq 3.6) for $\mathrm{Ca}\left(\mathrm{NO}_{3}\right)_{2} \cdot 4 \mathrm{H}_{2} \mathrm{O} \mathrm{Cd}\left(\mathrm{NO}_{3}\right)_{2} \cdot 4 \mathrm{H}_{2} \mathrm{O}$, $\mathrm{Zn}\left(\mathrm{NO}_{3}\right)_{2} \cdot 6 \mathrm{H}_{2} \mathrm{O}$ and $\mathrm{CaCl}_{2}$ systems at $25^{\circ} \mathrm{C}$ are also presented in Appendix B (Figure B.1 and B.2). These plots represent individual data replicate and were chosen at random among the two series.

All these plots are linear which indicates that pairing other than the monovalent pair is minor (Fuoss and Edelson, 1951). Table 3.1 contains the limiting equivalent conductance, $\Lambda_{0}$, the primary association constants, $\mathrm{K}_{1 \mathrm{~A}}$, and their standard deviations. Except for water, the values of $\mathrm{K}_{1 \mathrm{~A}}$ and $\Lambda_{0}$ were interpolated graphically from the Fuoss-Edelson plots, Figures B.1 and B.2, with $\Lambda_{0}$ being the intercept and $\mathrm{K}_{1 \mathrm{~A}}$ the slope $*$ intercept. The values of $\lambda_{0}\left(\mathrm{NO}_{3}\right)^{-}$and $\lambda_{0}(\mathrm{Cl})^{-}$, necessary for the computation of $\Lambda_{0}$ and $\mathrm{K}_{1 \mathrm{~A}}$, were assumed equal to their values in the pure solvents primarily because no data were available for the $\lambda_{0}$ 's of all the studied electrolytes at the various mixed aqueous-organic solvent concentrations. The only data for $\lambda_{0}$ 's 
were available for $\mathrm{Cl}^{-}$ions in ethanol-water mixtures at $25^{\circ} \mathrm{C}$ in Spivey and Shedlovsky (1967). However, they were not adopted in this study for consistency purpose and because the computation of these values, according to the authors, involved large errors and "their use is subject to considerable uncertainty". Nevertheless, $\lambda_{0}$ does not control strongly the values of $\mathrm{K}_{1 \mathrm{~A}}$ and $\Lambda_{0}$ (Doe et al., 1984). The lack of data also prevented the use of transport numbers for the calculation of $\lambda_{0}$ 's.

The values of $\mathrm{K}_{1 \mathrm{~A}}$ of the various electrolytes in water were taken from the literature (Smith and Martell, 1976). Other values are reported elsewhere and they range from -1 to 0.98 (Lindsay, 1979, CRC). The large variation in these values reflects the differences in the methods (potentiometric, spectrophotometric, NMR etc...) as well as the assumptions (ionic strength, activity versus concentration constants, etc...) used for their determination. For all studied electrolytes, these values are lower than what we expect if we interpolate our data to zero cosolvent fractions but they still depict the large variation found in the literature. 
Table 3.1. Limiting equivalent conductance $\left(\Omega^{-1} \mathrm{~cm}^{2} \mathrm{eq}^{-1}\right)$ and ionic association constants, $\mathrm{K}_{1 \mathrm{~A}}$ for various salts at $25^{\circ} \mathrm{C}$.

\begin{tabular}{|c|c|c|c|}
\hline Solvent & $\% \mathrm{wt}$ & $\Lambda_{0}$ & $\mathrm{~K}_{1 \mathrm{~A}}$ \\
\hline & & \multicolumn{2}{|c|}{$\mathrm{Ca}\left(\mathrm{NO}_{3}\right)_{2} \cdot 4 \mathrm{H}_{2} \mathrm{O}$} \\
\hline & 0 & $130.96^{\mathrm{a}}$ & $10^{-4.80 \mathrm{~b}}$ \\
\hline \multirow[t]{3}{*}{ Methanol } & 10 & $108.21 \pm 0.01$ & $10.78 \pm 0.21$ \\
\hline & 30 & $79.99 \pm 0.01$ & $14.44 \pm 0.33$ \\
\hline & 50 & $71.95 \pm 0.02$ & $23.04 \pm 0.18$ \\
\hline \multirow[t]{5}{*}{ Ethanol } & 10 & $103.17 \pm 0.18$ & $10.79 \pm 0.34$ \\
\hline & 30 & $64.14 \pm 0.01$ & $17.20 \pm 0.08$ \\
\hline & 50 & $51.50 \pm 0.03$ & $22.93 \pm 0.05$ \\
\hline & & \multicolumn{2}{|c|}{$\mathrm{Cd}\left(\mathrm{NO}_{3}\right)_{2} \cdot 4 \mathrm{H}_{2} \mathrm{O}$} \\
\hline & 0 & $124.26^{\mathrm{c}}$ & $2.04^{b}$ \\
\hline \multirow[t]{3}{*}{ Methanol } & 10 & $94.80 \pm 0.01$ & $12.38 \pm 0.06$ \\
\hline & 30 & $69.61 \pm 0.01$ & $14.77 \pm 0.92$ \\
\hline & 50 & $63.14 \pm 0.07$ & $28.02 \pm 0.06$ \\
\hline \multirow[t]{5}{*}{ Ethanol } & 10 & $90.38 \pm 0.03$ & $13.02 \pm 0.23$ \\
\hline & 30 & $55.59 \pm 0.01$ & $18.33 \pm 0.03$ \\
\hline & 50 & $45.36 \pm 0.02$ & $34.12 \pm 1.10$ \\
\hline & & \multicolumn{2}{|c|}{$\mathrm{Zn}\left(\mathrm{NO}_{3}\right)_{2} \cdot 6 \mathrm{H}_{2} \mathrm{O}$} \\
\hline & 0 & $124.26^{\mathrm{c}}$ & $2.51^{b}$ \\
\hline \multirow[t]{3}{*}{ Methanol } & 10 & $96.60 \pm 0.06$ & $12.12 \pm 0.60$ \\
\hline & 30 & $69.56 \pm 0.02$ & $14.92 \pm 0.01$ \\
\hline & 50 & $63.35 \pm 0.01$ & $28.82 \pm 0.25$ \\
\hline \multirow[t]{5}{*}{ Ethanol } & 10 & $89.09 \pm 0.02$ & $11.29 \pm 0.13$ \\
\hline & 30 & $55.29 \pm 0.04$ & $19.50 \pm 0.24$ \\
\hline & 50 & $45.69 \pm 0.01$ & $36.81 \pm 0.16$ \\
\hline & \multicolumn{3}{|c|}{$\mathrm{CaCl}_{2}$} \\
\hline & 0 & $135.7^{\mathrm{a}}$ & $2.63^{b}$ \\
\hline \multirow[t]{4}{*}{ Methanol } & 10 & $108.60 \pm 0.32$ & $27.38 \pm 0.05$ \\
\hline & 30 & $77.75 \pm 0.13$ & $31.52 \pm 0.28$ \\
\hline & 50 & $67.40 \pm 0.06$ & $43.01 \pm 0.10$ \\
\hline & 70 & $70.59 \pm 0.23$ & $61.41 \pm 2.25$ \\
\hline \multirow[t]{4}{*}{ Ethanol } & 10 & $99.33 \pm 0.28$ & $28.69 \pm 0.73$ \\
\hline & 30 & $61.64 \pm 0.05$ & $55.95 \pm 0.06$ \\
\hline & 50 & $48.51 \pm 0.02$ & $58.90 \pm 0.35$ \\
\hline & 70 & $44.11 \pm 0.05$ & $84.56 \pm 0.70$ \\
\hline \multirow[t]{4}{*}{ Acetone } & 10 & $112.16 \pm 0.16$ & $38.23 \pm 1.84$ \\
\hline & 30 & $87.25 \pm 0.35$ & $149.96 \pm 0.38$ \\
\hline & 50 & $76.16 \pm 0.22$ & $219.43 \pm 1.92$ \\
\hline & 70 & $76.03 \pm 0.26$ & $487.48 \pm 13.60$ \\
\hline
\end{tabular}

${ }^{a}$ Values for the limiting equivalent conductance of the studied electrolytes in water were computed from ionic equivalent conductance data $\left(\Omega^{-1} \mathrm{~cm}^{2} \mathrm{~mol}^{-1}\right)$ using Kohlrausch's Law of Independent Migration of Ions $\left(\Lambda_{0}=v_{+} \lambda_{+}^{0}+v_{-} \lambda_{-}^{0}\right)$ where $\lambda_{\mathrm{Ca}^{2+}}^{0}=119.0 ; \lambda_{\mathrm{Cl}^{-}}^{0}=76.36 ; \lambda_{\mathrm{NO}_{3}^{-}}^{0}=71.46$ (Atkins, 1998).

${ }^{\mathrm{b}}$ Values for $\mathrm{K}_{1 \mathrm{~A}}$ for water were obtained from Smith and Martell (1976).

${ }^{\mathrm{c}}$ The value of $\lambda_{\mathrm{Cd}^{2+}}^{0}$ in water was assumed equal to $\lambda_{\mathrm{Zn}^{2+}}^{0}=105.6 \Omega^{-1} \mathrm{~cm}^{2} \mathrm{~mol}^{-1}$ (Atkins, 1998). 


\subsubsection{Walden products}

Figure 3.1 shows the variation of the Walden products, $\Lambda_{0} \eta$, for nitrate salts in methanol and ethanol. For both solvents, the Walden products for $\mathrm{Zn}\left(\mathrm{NO}_{3}\right)_{2} \cdot 6 \mathrm{H}_{2} \mathrm{O}$ and $\mathrm{Cd}\left(\mathrm{NO}_{3}\right)_{2} \cdot 6 \mathrm{H}_{2} \mathrm{O}$ are nearly identical. These ions have similar ionic sizes and their properties are largely masked by the strong acid properties of the solvents. The higher mobility of $\mathrm{Ca}\left(\mathrm{NO}_{3}\right) \cdot 4 \mathrm{H}_{2} \mathrm{O}$ is attributed to the smaller hydrated radius of $\mathrm{Ca}$.

In methanol, the Walden products for all three nitrate salts are largely independent of solvent composition. This indicates that the mobility of these electrolytes in methanol is primarily determined by the solvent bulk viscosity and that the ion size parameter does not vary with methanol-water composition (Stoke's Law). In ethanol-water mixtures (Figure 3.1), the variation in the Walden products indicates that the mobility of these electrolytes is not solely dependent on the solvent bulk viscosity, but also depends on ion solvation. The observed maxima in $\Lambda_{0} \eta$ for the three electrolytes at about 30\% ethanol agrees with the results reported by Spivey and Shedlovsky (1967) and were interpreted as the result of the large disruption caused by the addition of ethanol on water structure in the vicinity of the ions. Ion solvation is also responsible for the decrease in the Walden products of $\mathrm{CaCl}_{2}$ in methanol, ethanol and acetone (Figure 3.2). Again, a structure enhancement is observed around 20-30\% ethanol. 

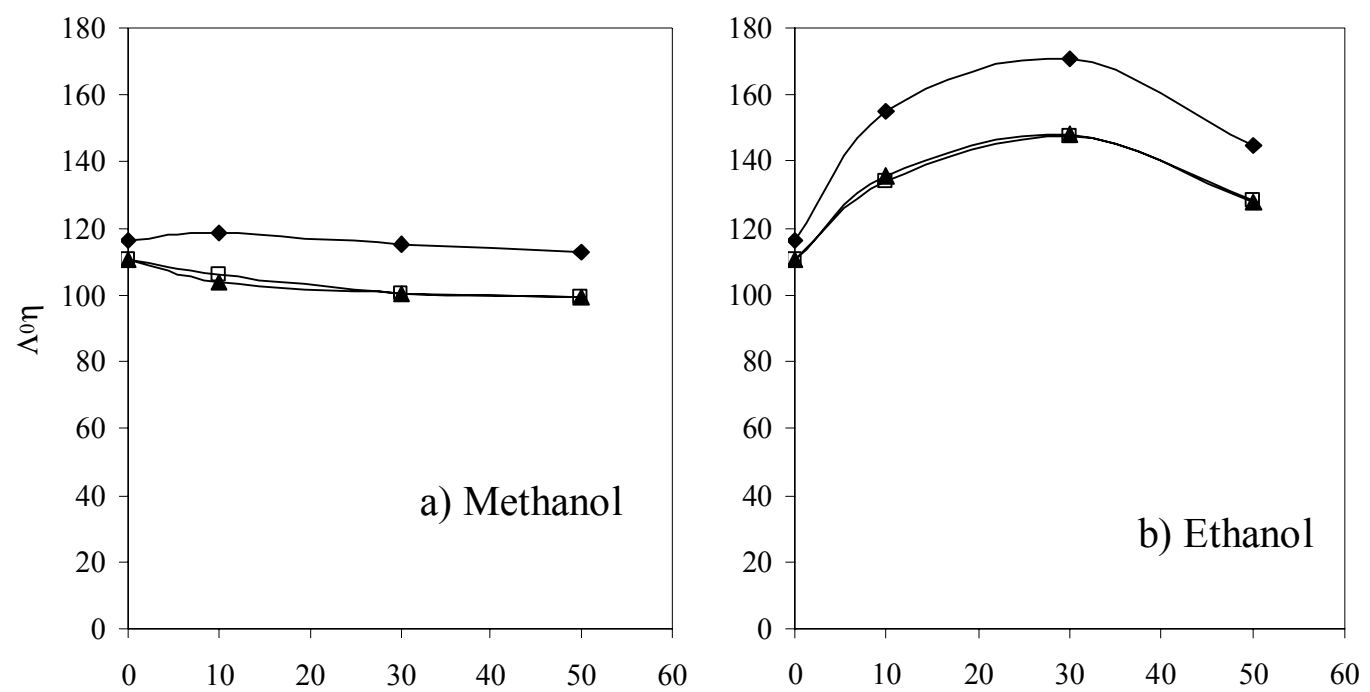

Percent weight solvent

Figure 3.1. Variation of the Walden products, $\Lambda_{0} \eta$, of nitrate salts with solvent composition at $25^{\circ} \mathrm{C} . \bullet, \mathrm{Ca}\left(\mathrm{NO}_{3}\right)_{2} \cdot 4 \mathrm{H}_{2} \mathrm{O} ; \square, \mathrm{Zn}\left(\mathrm{NO}_{3}\right)_{2} \cdot 6 \mathrm{H}_{2} \mathrm{O} ; \boldsymbol{\Delta}, \mathrm{Cd}\left(\mathrm{NO}_{3}\right)_{2} \cdot 6 \mathrm{H}_{2} \mathrm{O}$. (Error bars smaller than data points). 


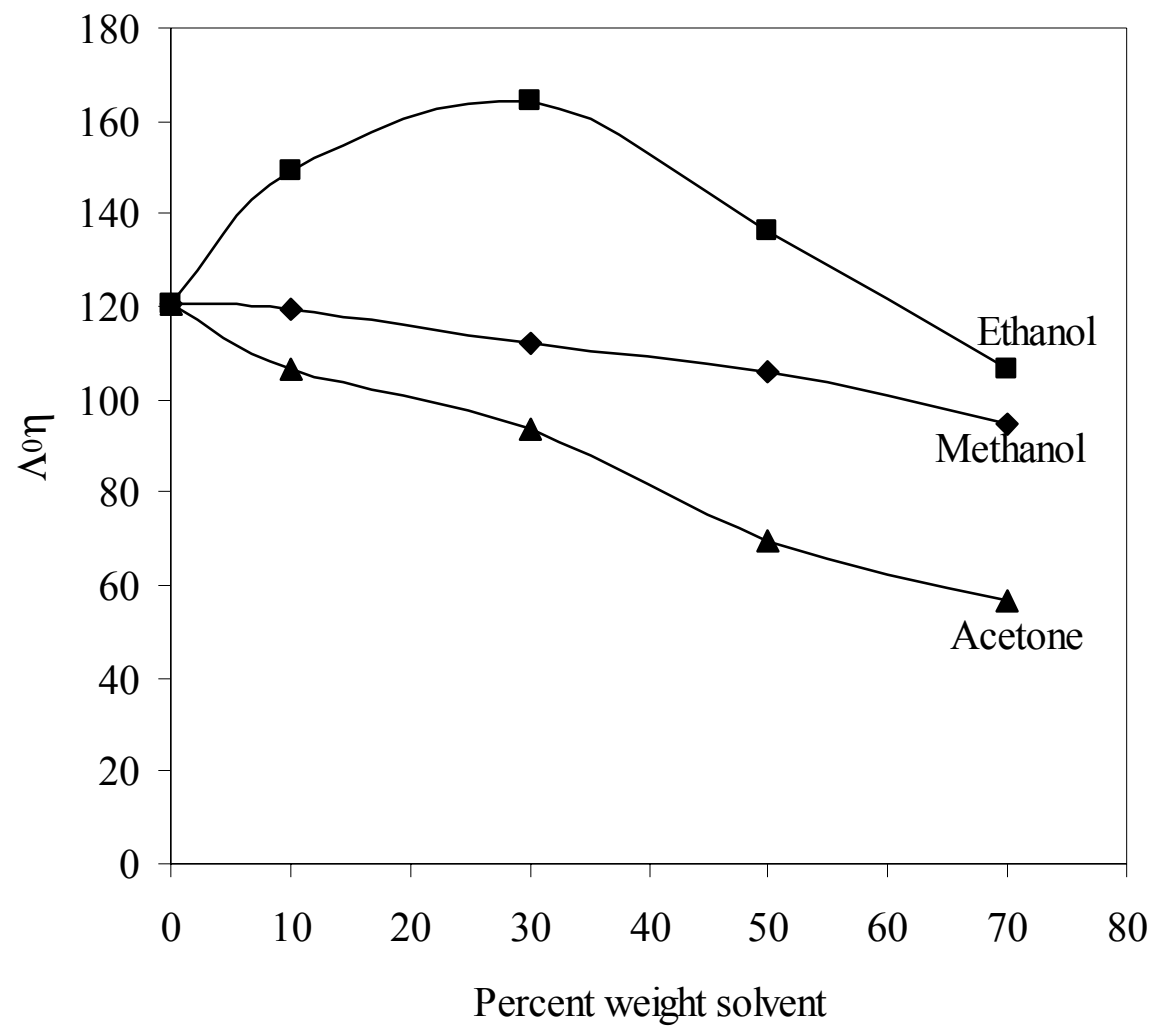

Figure 3.2. Variation of the Walden products, $\Lambda_{0} \eta$, of $\mathrm{CaCl}_{2}$ with solvent composition at $25^{\circ} \mathrm{C}$. (Error bars smaller than data points).

\subsubsection{Stability constant}

Figure 3.3 presents the variation in the association constant of $\mathrm{Ca}$ (II), $\mathrm{Cd}$ (II) and $\mathrm{Zn}$ (II) nitrates as a function of the reciprocal dielectric constant. For each electrolyte, this relationship is linear $\left(\mathrm{R}^{2} \geq 0.91\right)$ suggesting that the ionic association of these electrolytes in the studied cosolvents is primarily determined by electrostatic attractions between oppositely charged ions. The large difference between $\log \mathrm{K}_{1 \mathrm{~A}}$ of $\mathrm{Ca}\left(\mathrm{NO}_{3}\right)^{+}$(only observed at lower solvent dielectric constant or $\sim 50 \%$ cosolvent composition) and $\log \mathrm{K}_{1 \mathrm{~A}}$ for $\mathrm{Cd}\left(\mathrm{NO}_{3}\right)^{+}$or $\mathrm{Zn}\left(\mathrm{NO}_{3}\right)^{+}$indicates the lower pairing potential of $\mathrm{Ca}$ (II) ions and may be the consequence of the harder Lewis acid character of Ca (II) (Doe et al., 1984). 
Formation constants for $\mathrm{CaCl}^{+}$were larger than for $\mathrm{Ca}\left(\mathrm{NO}_{3}\right)^{+}$in all solvents and at all solvent concentrations. In methanol-water mixtures, $\log \mathrm{K}_{1 \mathrm{~A}}$ for $\mathrm{CaCl}^{+}$ increased linearly $\left(\mathrm{R}^{2} \geq 0.99\right)$ with the reciprocal of the solvent dielectric constant, $\varepsilon_{\mathrm{r}}$, suggesting that in these two cosolvents, the ion-pair formation is largely regulated by the solvent dielectric constant (Figure 3.4). In ethanol $\left(\mathrm{R}^{2}=0.86\right)$ and acetone-water mixtures $\left(\mathrm{R}^{2}=0.81\right)$, other specific solvent-solute interactions are apparent especially at low acetone concentrations.

\subsection{Conclusion}

The stability constants of $\mathrm{CaCl}^{+}$and $\mathrm{M}\left(\mathrm{NO}_{3}\right)^{+}(\mathrm{M}=\mathrm{Ca}, \mathrm{Cd}$, and $\mathrm{Zn})$ in ethanol and methanol-water mixtures, as determined by conductometric titration, seem to involve, in addition to electrostatic interactions, specific solvent-solute interactions. These appear to be related to the acid-base character of both the solvent and the solute. The mobility of the three nitrate salts in methanol-water mixtures, at infinite dilution, as shown by the variation in the Walden product with solvent composition, seems to be solely dependent on the bulk viscosity of the solvent. In ethanol, solvent-solvent interactions such as ion solvation and water structure disruption seem to occur. This conclusion also applies to $\mathrm{CaCl}_{2}$ mobility at infinite dilution in the three water-mixed solvents (methanol, ethanol and acetone). 


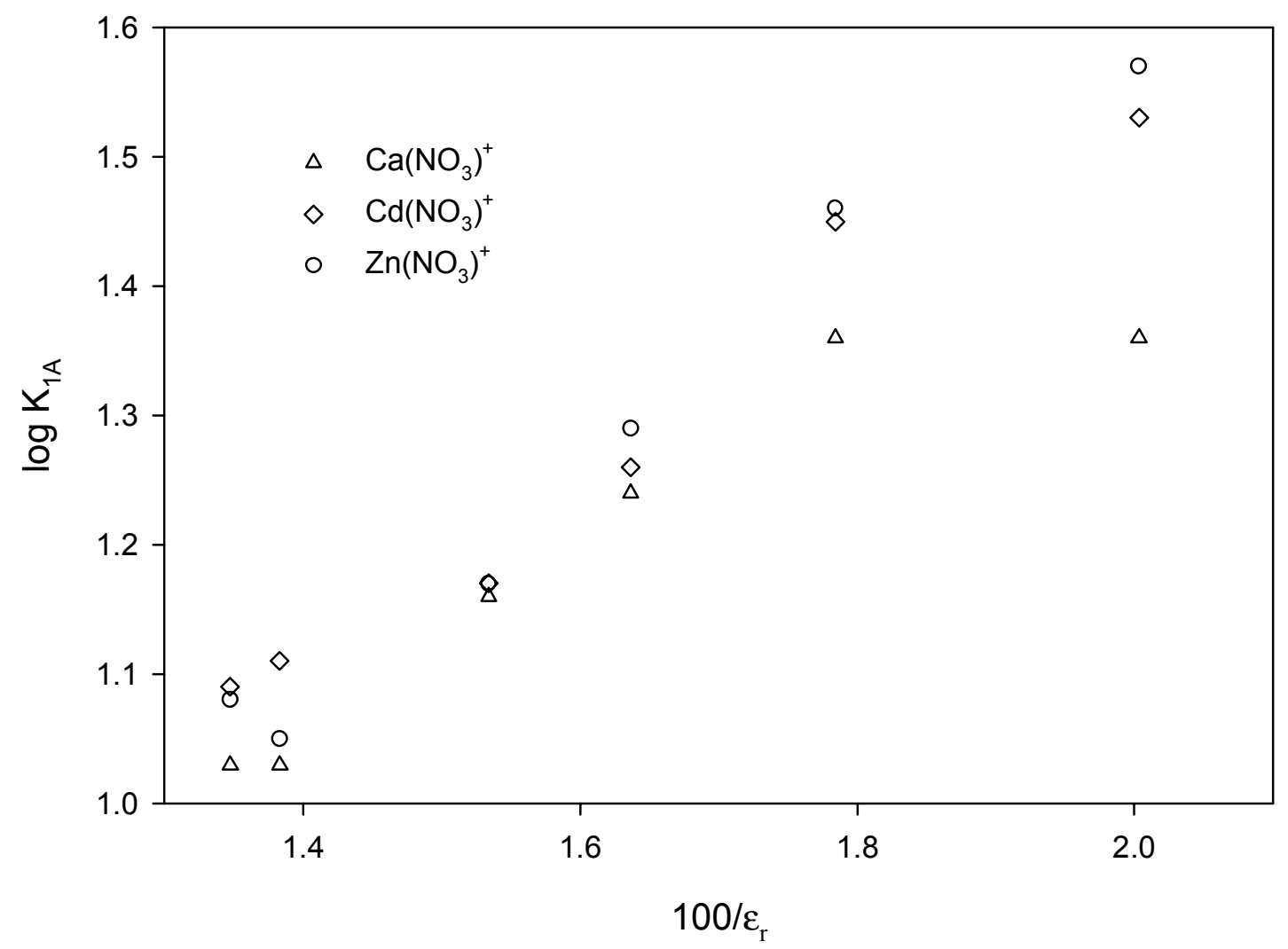

Figure 3.3 Variation of $\log \mathrm{K}_{1 \mathrm{~A}}$ with the reciprocal dielectric constant in alcoholwater mixtures at $25^{\circ} \mathrm{C}$. (Error bars smaller than data points). 


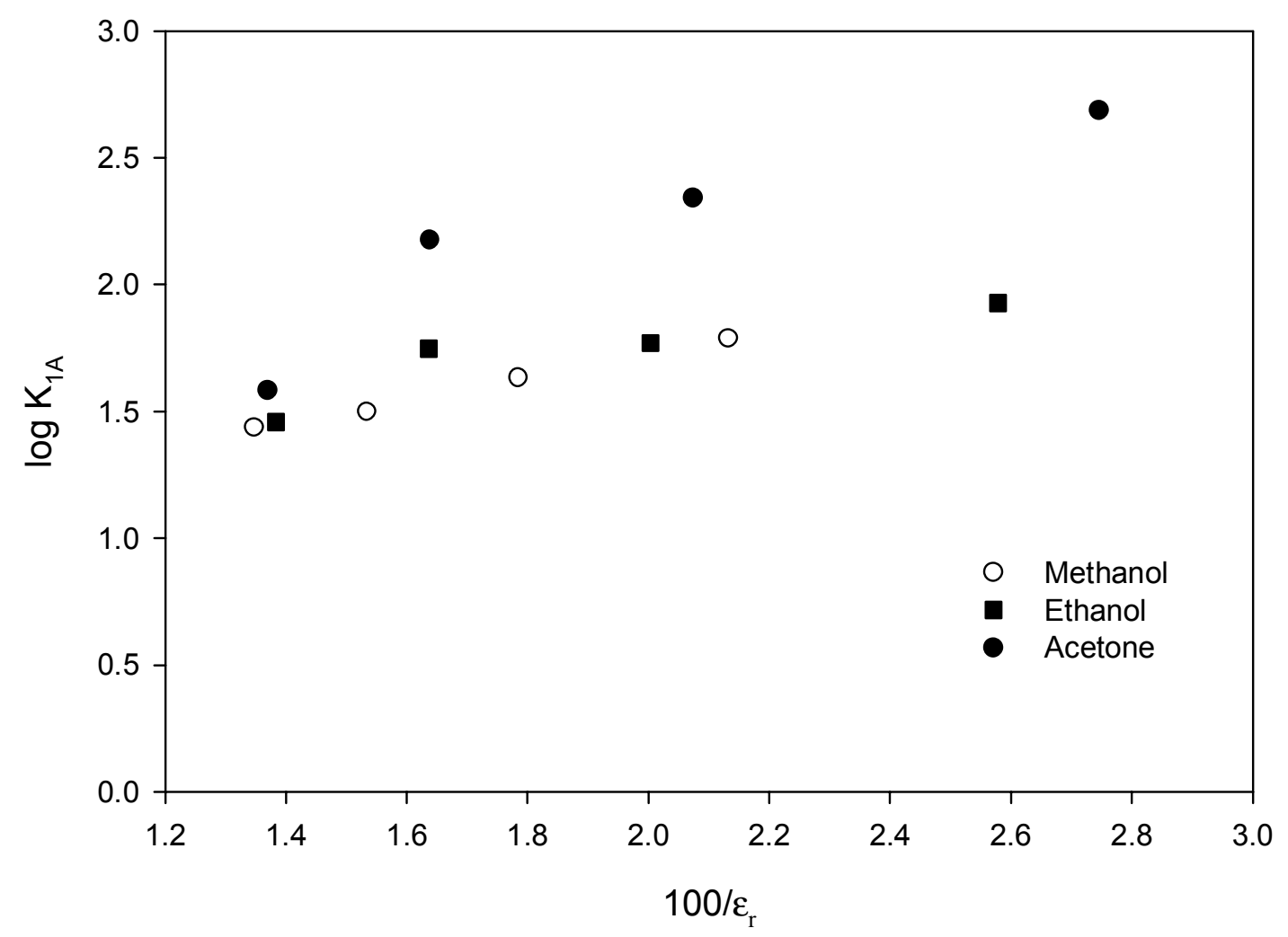

Figure 3.4. Variation of $\log \mathrm{K}_{1 \mathrm{~A}}$ of $\mathrm{CaCl}_{2}$ with the reciprocal dielectric constant in cosolvents at $25^{\circ} \mathrm{C}$. (Error bars smaller than data points). 


\section{CHAPTER IV}

Effect of Cosolvents on Ca-Na Exchange onto Wyoming Bentonite

\subsection{Introduction}

In soils and waste contaminated sites, the net effect of solvents on the behavior of inorganic contaminants will result from a combination of its effects on the solution and the surfaces properties. Solvent effects on the physical properties of soils and clays have been reported (Brown and Thomas, 1987; Fernandez and Quigley, 1985), but there has been little work on solvent effects on metal surface reactions (Kosmulski, 1994; Miller et al., 1992) and none on clay minerals. Studying Ca-Na exchange reactions on Wyoming bentonite in mixed aqueous organic solvents offers many advantages. This system is well studied in aqueous solvents (Van Bladel and Gheyi, 1980; Sposito et al., 1983; Amrhein and Suarez, 1991; Zhang and Sparks, 1996) and it is established that, in the absence of significant ion pairing and complexation, the long range electrostatic attraction of cations to the surface favor the adsorption of $\mathrm{Ca}^{2+}$ as opposed to $\mathrm{Na}^{+}$ions. As ion-pairing increases, this selectivity tends to decrease (Sposito et al., 1983). Both $\mathrm{Ca}$ and $\mathrm{Na}$ are hard Lewis acids; $\mathrm{Ca}$ is a divalent cation with strong hydration energy, small size and high charge density, whereas $\mathrm{Na}$ is a monovalent cation with low hydration energy, small size and low charge density. Calcium and $\mathrm{Na}$ both tend to form outer-sphere surface complexes with the hard Lewis base Wyoming bentonite.

For the exchange reaction

$$
2 \mathrm{NaX}+\mathrm{Ca}^{2+} \Leftrightarrow \mathrm{CaX}+2 \mathrm{Na}^{+}
$$

The Vanselow selectivity coefficient is defined as: 


$$
K_{v}=\frac{\left\{\mathrm{Na}^{+}\right\}^{2} N_{\mathrm{Ca}}}{\left\{\mathrm{Ca}^{2+}\right\} N_{\mathrm{Na}}^{2}}=\frac{\left[\mathrm{Na}^{+}\right]^{2}}{\left[\mathrm{Ca}^{2+}\right]} \times \frac{\gamma_{\mathrm{Na}}^{2}}{\gamma_{\mathrm{Ca}^{2+}}} \times \frac{N_{\mathrm{Ca}}}{N_{\mathrm{Na}}^{2}}
$$

where $\mathrm{X}$ indicates a solid phase exchanging surface with a charge of $-2,\{\}$ refers to the activity of the specific cation, $\mathrm{N}_{\mathrm{Ca}}$ and $\mathrm{N}_{\mathrm{Na}}$ are the mole fractions of $\mathrm{Ca}$ and $\mathrm{Na}$ on the exchanger sites respectively. Eq [4.2] is rearranged

$$
\frac{N_{C a}}{N_{N a}^{2}}=K_{v} \times \frac{\left[\mathrm{Ca}^{2+}\right]}{\left[\mathrm{Na}^{+}\right]^{2}} \times \frac{\gamma_{\mathrm{Ca}^{2+}}}{\gamma_{\mathrm{Na}^{+}}^{2}}
$$

The effect of a solvent on the selectivity of a surface for a particular cation would result from its combined effect on the solution properties (single ion-activity coefficients and free metal concentrations) and the surface properties (adsorbed metal fraction). Increasing cosolvent fraction will decrease $\frac{\gamma_{\mathrm{Ca}^{2+}}}{\gamma_{\mathrm{Na}^{+}}^{2}}$ (Figure 4.1) and decrease $\left[\mathrm{Ca}^{2+}\right]$ due to increased ion-pairing (more pronounced for divalent $\mathrm{Ca}^{2+}$ than the monovalent $\mathrm{Na}^{+}$). Assuming no changes in the exchanger activity coefficients or in $\mathrm{K}_{\mathrm{v}}$, this should decrease $\frac{N_{C a}}{N_{N a}^{2}}$ (increase Na-loading). Increasing cosolvent concentration is in fact expected to increase selectivity of the surface by increasing Coulombic attractions $\left(\mathrm{Ca}^{2+}>\mathrm{Na}^{+}\right)$. Other shifts in position on the isotherm or of the isotherm itself with cosolvent fraction, after correction for changes in the solution phase metal activity, may indicate changes in exchanger activity coefficients or some other solvent-specific effects.

It is the objective of this study to determine the net effect of cosolvents on the changes in the selectivity of Wyoming bentonite for $\mathrm{Ca} / \mathrm{Na}$ ions by examining the effect of the solvent dielectric constant on both the surface and the solution properties. Given the inherent difficulty 
in measuring the activities of ions in the solid phase, only the activities of ions in solution will be corrected for both changes in single-ion activity coefficient (Debye-Hückel equation) and free metal concentration (ion-pairing).

\subsection{Materials and Methods}

\subsubsection{Na-Montmorillonite}

Wyoming Bentonite clay was obtained from the American Colloid Company at Upton Plant, Wyoming. Before clay separation, soluble and insoluble salts, organic matter and iron oxides were removed according to standard procedures (Kunze and Dixon, 1986). The $<2.0 \mu \mathrm{m}$ clay fraction was separated by repeated washing and centrifugation. Na-saturated clays were prepared by repeated equilibration with $1 \mathrm{M} \mathrm{NaCl}$. Excess salts were removed by dialysis against distilled water until an $\mathrm{AgNO}_{3}$ test indicated that the equilibrium solution was free of chloride ions. The salt-free gel was freeze-dried and stored for further analysis.

\subsubsection{Cosolvents}

The solvents used in this study were deionized water, HPLC grade methanol and acetone and reagent grade ethanol. All solvents were used without further purification. Cosolvent fractions $(0,10,30,50$, and $70 \%)$ were prepared on weight basis for methanol and acetone. For ethanol, volume fractions were used. For ease of comparison, these volume fractions were converted to weight percentages using density data. The properties of these cosolvents are presented in Table 1.5. 


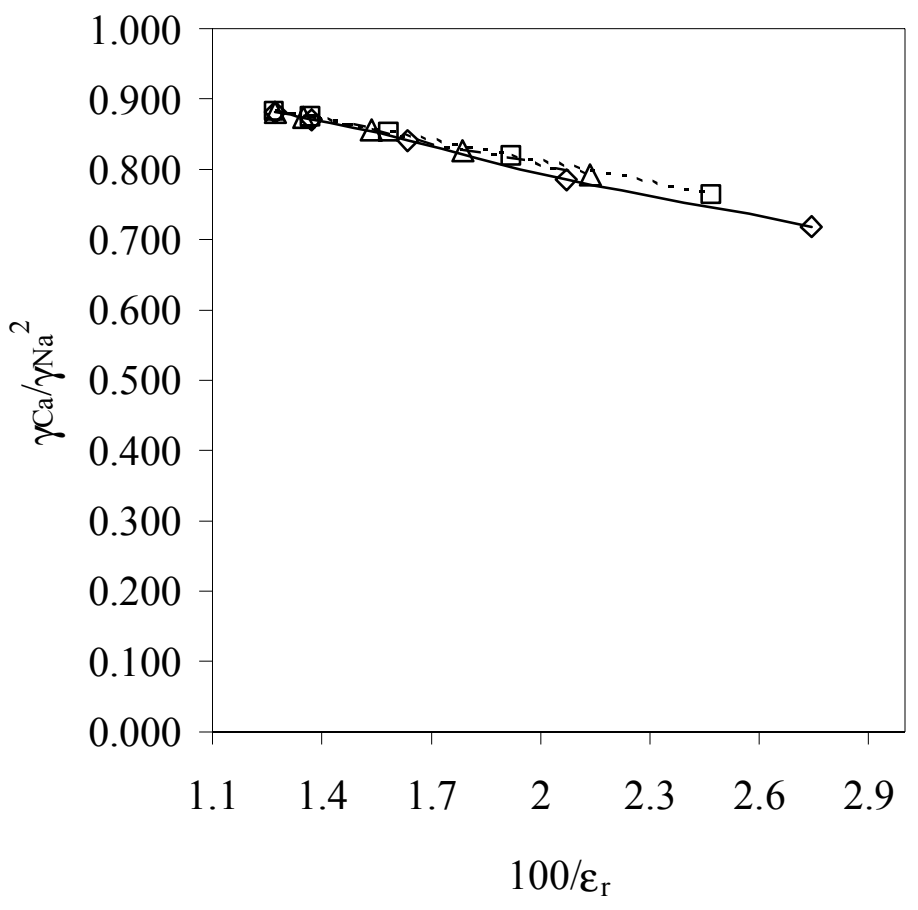

Figure 4.1. Changes in the single ion activity ratio (as predicted by Debye-Hückel equation) as a function of $100 / \varepsilon_{\mathrm{r}}$ in $\Delta$ methanol, $\square$ ethanol and $\diamond$ acetone.

\subsubsection{Sodium-Calcium Exchange Experiments}

In methanol and acetone experiments, $0.1 \mathrm{M}$ of $\mathrm{NaCl}$ and $\mathrm{CaCl}_{2}$ stock solutions were prepared by adding appropriate amounts of oven-dried $\left(105^{\circ} \mathrm{C}\right.$ overnight) anhydrous $\mathrm{CaCl}_{2}$ and $\mathrm{NaCl}$ salts to $50 \mathrm{ml}$ of cosolvent solution. The stock solutions were then used to prepare a series of mixed $\mathrm{CaCl}_{2} / \mathrm{NaCl}$ solutions with a constant total chloride concentration $(\mathrm{TN}=0.03 \mathrm{~N})$ and differing soluble calcium fraction, $\mathrm{X}_{\mathrm{Ca}}$. The solution compositions were $0.05,0.1,0.2,0.4,0.6$ 
and $0.8 \mathrm{X}_{\mathrm{Ca}}$. Approximately $0.05 \mathrm{~g}$ of Na-montmorillonite was added to tared $15 \mathrm{ml}$ polyethylene centrifuge tubes and reacted with $10 \mathrm{ml}$ of the mixed solutions for methanol and acetone.

For ethanol experiments, concentrated stock solutions of various $\mathrm{X}_{\mathrm{Ca}}$ but constant total chloride concentration $\left(0.03 \mathrm{~mol} \mathrm{~L}^{-1}\right)$ were prepared in distilled water. Appropriate volumes of water and ethanol were added to $15 \mathrm{ml}$ tared polyethylene tubes containing $0.05 \mathrm{~g}$ of $\mathrm{Na}-$ montmorillonite to yield $10 \%, 30 \%, 50 \%$ and $70 \%(\mathrm{v} / \mathrm{v})$ solvent concentration. Exactly $0.1 \mathrm{ml}$ of each of the stock solutions were then added to make a series of samples varying in their composition but having all a constant total chloride concentration $\left(\mathrm{TN}=0.03 \mathrm{~mol} \mathrm{~L}{ }^{-1}\right)$. There were two replicates of each cosolvent at each cosolvent fraction.

Clays were uniformly dispersed using a vortex mixer and centrifuge tubes were equilibrated by rotating end-over-end in a rock tumbler for $12 \mathrm{hr}$. After equilibration, tubes were centrifuged at $5000 \mathrm{rpm}$ for $20 \mathrm{~min}$, and the supernatant solutions were collected for $\mathrm{Ca}$ and $\mathrm{Na}$ determination. Exactly $1 \mathrm{ml}$ of supernatant was removed and evaporated to dryness in Pyrex tubes in a digestion block at $130^{\circ} \mathrm{C}$. The evaporates were dissolved in an acidified lanthanum oxide solution and $\mathrm{Na}$ and $\mathrm{Ca}$ were determined using atomic absorption and emission spectrophotometry. These measured values of $\mathrm{Ca}$ and $\mathrm{Na}$ were used to calculate the equilibrium concentrations of $\mathrm{Ca}^{2+}$ and $\mathrm{Na}^{+}$ions in the supernatant solution of the $\mathrm{Na}-\mathrm{Ca}$ exchange reaction. The centrifuge tubes were weighed to determine the mass of the entrained solution in each clay sample. The volume of entrained solution was calculated using appropriate cosolvent density values (Table 1.5).

The clays were then extracted two times with $10 \mathrm{ml}$ of concentrated $\mathrm{MgCl}_{2} \cdot 6 \mathrm{H}_{2} \mathrm{O}$ by shaking, centrifuging and decanting. Extracting solutions of $1 \mathrm{M} \mathrm{MgCl}_{2} \cdot 6 \mathrm{H}_{2} \mathrm{O}$ were prepared in 
corresponding cosolvent solution fractions except for $50 \%$ and $70 \%$ acetone, where $0.1 \mathrm{M}$ $\mathrm{MgCl}_{2} \cdot 6 \mathrm{H}_{2} \mathrm{O}$ was used. The supernatant solution from each clay sample was collected and $\mathrm{Na}$ and $\mathrm{Ca}$ were determined as described above.

\subsection{Data analysis}

To calculate single-ion activity coefficients, the parameters $\mathrm{A}_{\mathrm{D}-\mathrm{H}}$ and $\mathrm{B}_{\mathrm{D}-\mathrm{H}}(\mathrm{Eq} 1.10$ and 1.11) were calculated for each cosolvent fraction by replacing $\varepsilon_{\mathrm{r}}$ and $\rho$ with their corresponding values (Table 1.5). The ion size parameters for $\mathrm{Na}, \mathrm{Ca}$, and $\mathrm{CaCl}^{+}$were taken as equal to their values in water that is 4.0, 6.0 and $5.1 \AA$, respectively (Kielland, 1937). The adsorbed metal charges of $\mathrm{Na}$ and $\mathrm{Ca}$ on the exchangers were calculated as follows:

$$
\begin{aligned}
& q_{N a}=n_{N a}-\frac{C_{N a} V_{e}}{M_{\text {Clay }}} \\
& q_{C a}=2 *\left(n_{C a}-\frac{C_{C a} V_{e}}{M_{\text {Clay }}}\right)
\end{aligned}
$$

where $n$ is the number of moles of $\mathrm{Ca}$ or Na per kilogram of clay extracted by $\mathrm{MgCl}_{2} \cdot 6 \mathrm{H}_{2} \mathrm{O}$ solutions, $\mathrm{C}$ is the molar concentration of $\mathrm{Ca}$ and $\mathrm{Na}$ ions in the equilibrium supernatant solution, $\mathrm{V}_{\mathrm{e}}$ is the volume in liters of the entrained solution and $\mathrm{M}_{\text {clay }}$ is the mass of clay in $\mathrm{kg}$. The total adsorbed metal charge, $\mathrm{Q}$, is given by the equation

$$
Q=q_{N a}+q_{C a}
$$

where $\mathrm{q}_{\mathrm{Na}}$ and $\mathrm{q}_{\mathrm{Ca}}$ are defined in equations [4.4] and [4.5].

The non-preference isotherm for Na-Ca exchange (Sposito, 1981) was, 


$$
E_{C a}=1-\left[1+\frac{2 \gamma_{C a}}{(T N) \gamma_{N a}^{2}}\left(\frac{1}{\left(1-E_{C a}^{\prime}\right)^{2}}-\frac{1}{E_{C a}^{\prime}}\right)\right]^{-0.5}
$$

where

$$
E_{C a}^{\prime}=\frac{2\{C a\}}{2\{C a\}+\{N a\}}
$$

$\mathrm{E}_{\mathrm{Ca}}^{\prime}$ is the charge fraction of $\mathrm{Ca}$ in solution, $\mathrm{E}_{\mathrm{Ca}}$ is the equivalent fraction of $\mathrm{Ca}$ on the exchanger and $\mathrm{TN}$ is the total chloride normality $(0.03 \mathrm{~N})$.

The adsorbed $\mathrm{Ca}^{2+}$ charge fraction was corrected for $\mathrm{CaCl}^{+}$by adopting the method developed by Sposito et al.,(1983). The total adsorbed metal charge, $\mathrm{Q}_{0}$ is calculated as follows

$$
Q_{0}=q_{\mathrm{Na}^{+}}+q_{\mathrm{Ca}^{2+}}+q_{\mathrm{CaCl}^{+}}
$$

and $\mathrm{q}_{\mathrm{CaCl}}{ }^{+}$was calculated as follows

$$
q_{C a C l^{+}}=Q-Q_{0}
$$

In the objective of isolating the effect of solvents on the selectivity of bentonite surfaces for $\mathrm{Ca}$ and $\mathrm{Na}$ ions, it was important to correct for ion-pair formation in solution and its adsorption on the surface. In this context, the association constants, $\mathrm{K}_{1 \mathrm{~A}}$, of $\mathrm{CaCl}^{+}$were experimentally determined (Table 3.1) using conductometric methods (Fuoss and Edelson, 1951). The value of the $\log \mathrm{K}_{1 \mathrm{~A}}$ for $\mathrm{CaCl}^{+}$in water was taken from the literature (Smith and Martell, 1976). Other values were reported elsewhere. (Lindsay (1979) reports a value of -1 for the thermodynamic stability constant). The $\mathrm{NaCl}^{\circ}$ pairs were assumed to be negligible (Spivey and Shedlovsky, 1967) and hence were not included in the calculation of the ion activities. 
The adsorbed fraction of $\mathrm{CaCl}^{+}$on the exchanger, $\mathrm{q}_{\mathrm{CaCl}+}$, was calculated using $\mathrm{Eq}$ [4.10]. The value of $\mathrm{Q}_{0}$ can be measured by determining $\mathrm{Q}$ [Eq 4.9] in an exchange experiment in a medium where no ion-pair formation is expected (perchlorate, for instance) or by extrapolating Q measured in an exchange experiment conducted in chloride background to the condition of vanishing $\mathrm{q}_{\mathrm{Ca}}$. In cosolvent systems where ion-pair formation is significant even with poor-pair forming ligands such as perchlorates (Doe et al., 1983), the second option seemed more appropriate to calculate $\mathrm{Q}_{0}$. Therefore, in every treatment and at every cosolvent fraction, $\mathrm{Q}$ was plotted as a function of the equivalent fraction of $\mathrm{Ca}$ in solution and $\mathrm{Q}_{0}$ (Table 4.4) was taken to be equal to the cubic polynomial regression estimate of Q when the clay was Na-saturated.

\subsection{Results}

The equilibrium and exchanger compositions for $\mathrm{Na}-\mathrm{Ca}$ exchange reactions onto bentonite clays are summarized in Tables 4.1-4.3. In each table, the fourth and the fifth column represent the equilibrium activity of $\mathrm{Ca}$ and $\mathrm{Na}$ respectively. Within a single treatment, the greater the concentration of $\mathrm{Ca}$ and $\mathrm{Na}$, the larger the decrease in effective molar concentration (activity), this decrease being more prominent for $\mathrm{Ca}$ than $\mathrm{Na}$. Acetone had a larger effect on ion activities than did ethanol, which in turn had a larger effect than methanol. As the solvent dielectric constant decreases, the activity of the ions is expected to decrease due to decreased single ion activity coefficient (Eq 1.8-1.10) and increased ion-pairing (Eq 1.12).

In methanol-water treatment (Table 4.1), the seventh column presents the adsorbed $\mathrm{Ca}$

charge in $\mathrm{mol}_{\mathrm{c}}$ per $\mathrm{kg}^{-1}, \mathrm{q}_{\mathrm{Ca}}$, on Wyoming bentonite surfaces. Within a single cosolvent treatment and as the percent weight cosolvent increased, $\mathrm{q}_{\mathrm{Ca}}$ increases with increasing $\mathrm{X}_{\mathrm{Ca}}$. This trend 
coupled with the decreased activity of $\mathrm{Ca}$ in solution might indicate, at first sight, an increased preference of the exchanging surface for $\mathrm{Ca}$ ions with increasing $\mathrm{X}_{\mathrm{Ca}}$ and with increasing percent weight cosolvent. In ethanol and acetone-water systems (Table 4.2 and 4.3) and within each percent weight cosolvent, $\mathrm{q}_{\mathrm{Ca}}$ is increasing with increased $\mathrm{X}_{\mathrm{Ca}}$. Across treatments, $\mathrm{q}_{\mathrm{Ca}}$ is rather constant.

The values of the total adsorbed metal charge in $\mathrm{mol}_{\mathrm{c}} \mathrm{kg}^{-1}, \mathrm{Q}$, are reported in column 8 in Tables 4.1-4.3. Different trends are observed among various cosolvents. In methanol-water treatments and for constant $\mathrm{X}_{\mathrm{Ca}}$ (Table 4.1), $\mathrm{Q}$ increases with increasing weight percent methanol especially at $50 \%$ and $70 \%$. Within a single treatment, Q is fairly constant and any observed increase is within experimental error. In ethanol and acetone-water treatments, $Q$ is fairly constant. The observed increase in the total adsorbed metal charge, Q, in methanol-water systems, at higher cosolvent weight percent, can be attributed to assigning all of the adsorbed $\mathrm{Ca}$ (II) species a +2 valence when in fact one of the absorbed species is the monovalent complex, $\mathrm{CaCl}^{+}$(Sposito et al., 1983).

Figure 4.2 presents the fractional isotherms for $\mathrm{Na}-\mathrm{Ca}$ exchange on Wyoming bentonite. In these plots, the equivalent fraction of $\mathrm{Ca}$ in solution was corrected for single-ion activity coefficients, but not for the formation of $\mathrm{CaCl}^{+}$pairs. All isotherms were above the nonpreference isotherm, indicating a greater selectivity of the surface for $\mathrm{Ca}$ ions. As the weight percent methanol increased, a shift in the isotherms toward greater Ca preference is observed at low equivalent $\mathrm{Ca}$ fraction $(<0.2)$. At higher $\mathrm{Ca}$ fractions, all isotherms converged but showed a tendency of decreased $\mathrm{E}_{\mathrm{Ca}}$ as the percent weight methanol increased (as shown by the shift in the individual points towards the rich Na-end as the methanol concentration increased). In ethanol- 
water mixtures, no increased preference for Ca was shown. At the Ca-rich end of the isotherm, increasing cosolvent concentration increased Na-loading in methanol, ethanol, and to a lesser extent in acetone. This observation is consistent with the increasing formation of $\mathrm{CaCl}^{+}$pairs in low $\varepsilon_{\mathrm{r}}$ solutions. The same effect is observed at the Na-rich end of the isotherm in ethanol and acetone. However, in methanol, increasing cosolvent concentration increased Ca-loading at the Na-rich end of the isotherm. This may indicate a methanol specific effect on metal ion activity coefficients in solution and on the surface. All isotherms converged and exhibited a greater compression towards lower $\mathrm{E}_{\mathrm{Ca}}^{\prime}$ and $\mathrm{E}_{\mathrm{Ca}}$ as the percent solvent fraction increased. In acetonewater mixtures, increasing cosolvent concentration decreased the preference of the surface for $\mathrm{Ca}$ ions.

Table 4.4 presents the calculated values of $\mathrm{Q}_{0}$ in various cosolvents. In all treatments, $\mathrm{Q}_{0}$ is rather constant at all cosolvent weight percentage and the observed difference is considered to be within experimental error. After the determination of $\mathrm{Q}_{0}$, the exchange isotherms in Figure 4.1 were corrected for $\mathrm{CaCl}^{+}$formation both in solution and on the surface (Figures 4.3, 4.4, and 4.5 for methanol, ethanol and acetone-water treatment, respectively). In these figures, each percent weight cosolvent was plotted separately with water for ease of comparison. In all treatments, the fraction of $\mathrm{CaCl}^{+}$on the surface generally increased as the equivalent fraction of $\mathrm{CaCl}^{+}$in solution increased with some distinct trends among and within cosolvents, indicating that $\mathrm{Ca}-\mathrm{Na}$ exchange on Wyoming bentonite in a chloride background involves the ternary exchange system $\mathrm{Ca}-\mathrm{Na}-\mathrm{CaCl}^{+}$. In $10 \%$ methanol, $\mathrm{E}_{\mathrm{CaCl}+}$ increases with $\mathrm{E}^{\prime} \mathrm{CaCl}^{+}$however the magnitude of increase was small (Figure 4.3). For all other cosolvent concentrations, adsorption of $\mathrm{CaCl}^{+}$was 
significant. In acetone-water treatments (Figure 4.5), the preference of the surface for $\mathrm{CaCl}^{+}$ increases almost linearly with $\mathrm{E}^{\prime} \mathrm{CaCl}+$ at all percent weight cosolvent. In the water treatment, our results are in good agreement with those described by Sposito et al., (1983). Others (Amrhein and Suarez, 1991; and Zhang and Sparks, 1996) have reported no evidence for the adsorption of $\mathrm{CaCl}^{+}$ions in water. Demonstrating whether $\mathrm{CaCl}^{+}$adsorption is significant or not is not the objective of this study, it is rather the identification of the major processes that control the selectivity of bentonite for a specific cation in cosolvents where the magnitude of pairing is significant. This wouldn't be possible unless $\mathrm{CaCl}^{+}$formation both in solution and on the surface is accounted for.

In ethanol-water treatments (Figure 4.4), no distinct trend can be distinguished. An exact explanation for these differences in behavior among and within cosolvents is currently unavailable. However, increased stability of $\mathrm{CaCl}^{+}$in the solutions rather than on the surface or decreased affinity of bentonite surfaces for $\mathrm{CaCl}^{+}$; as a result of greater competition between $\mathrm{Na}^{+}$ and $\mathrm{CaCl}^{+}$for external surface sites at the Ca rich end, (Sposito et al.,1983) in media of lower dielectric constant than water are suggested. This might explain why the affinity of bentonite for $\mathrm{CaCl}^{+}$in all treatment was less than that in water.

\subsection{Discussion}

Prior to $\mathrm{CaCl}^{+}$correction, our results (Tables 4.1-4.3 and Figure 4.2) indicate a preference of bentonite surfaces for $\mathrm{Ca}^{2+}$ ions in all solvents as measured by the relative position of each cosolvent fractional isotherm with respect to the water isotherm and to the nonpreference isotherm. The change in the position of the fractional isotherm especially for acetone- 
water mixtures and methanol-water mixtures at low equivalent $\mathrm{Ca}$ fraction $(<0.2)$ indicate that the selectivity of bentonite for $\mathrm{Ca}$ ions in cosolvents is a surface-controlled phenomenon essentially driven by solvent-surface interactions. In ethanol, the preference of the surface seems driven by solution-solvent interactions.

The predicted increase in $\mathrm{K}_{\mathrm{V}}$ in response to cosolvents was apparent in methanol and ethanol only after correcting for formation of $\mathrm{CaCl}^{+}$. In acetone, there was evidence of increased Na-loading at the high cosolvent fraction (Figure 4.5) but no increase in $\mathrm{Ca}^{2+}$ selectivity.

In ethanol and ethanol-water mixtures, the observed increase in the preference of bentonite clays for $\mathrm{Ca}^{2+}$ after $\mathrm{CaCl}^{+}$correction, is attributed to a combination of dielectric (increased $\mathrm{Ca}^{2+}$ adsorption with decreased $\varepsilon_{\mathrm{r}}$ in both methanol and ethanol-water mixtures) and specific surface-cosolvent effects. This is indicated by the gradual decrease in the surface preference for $\mathrm{Ca}^{2+}$ (as shown by the magnitude of difference between the water and the respective fractional isotherm), as we move from methanol to ethanol to acetone-water systems after corrections for both single ion activity coefficient and ion-pairing.

This increased preference for $\mathrm{Ca}^{2+}$ cannot be solely explained by enhanced Coulombic attractions between the surface and the divalent cation as a result of decreased solvent dielectric constant because if this is the case, than the magnitude of preference should decrease from acetone $>$ ethanol $>$ methanol. Dielectric saturation of the bentonite surfaces may be larger in methanol than in ethanol and acetone. 
Table 4.1. Experimental data for Na-Ca exchange on Wyoming bentonite in methanol-water mixtures at constant total chloride concentration $(\mathrm{TN}=0.03 \mathrm{~N})$ at room temperature.

\begin{tabular}{|c|c|c|c|c|c|c|c|c|}
\hline Solvent & $\mathbf{X}_{\mathbf{C a}}$ & $\mathrm{C}_{\mathrm{Na}}$ & $\mathrm{C}_{\mathrm{Ca}}$ & (Na) & (Ca) & $\mathbf{q}_{\mathrm{Na}}$ & $\mathbf{q}_{\mathrm{Ca}}$ & $\mathbf{Q}$ \\
\hline \multirow[t]{6}{*}{ Water } & 0.05 & $2.92 \mathrm{E}-02$ & $5.59 \mathrm{E}-04$ & $2.45 \mathrm{E}-02$ & $2.94 \mathrm{E}-04$ & $0.404 \pm 0.027$ & $0.508 \pm 0.020$ & $0.912 \pm 0.029$ \\
\hline & 0.1 & $2.80 \mathrm{E}-02$ & $1.29 \mathrm{E}-03$ & $2.34 \mathrm{E}-02$ & $6.81 \mathrm{E}-04$ & $0.238 \pm 0.040$ & $0.715 \pm 0.059$ & $0.953 \pm 0.048$ \\
\hline & 0.2 & 2.39E-02 & $3.24 \mathrm{E}-03$ & $2.00 \mathrm{E}-02$ & $1.70 \mathrm{E}-03$ & $0.122 \pm 0.021$ & $0.932 \pm 0.036$ & $1.054 \pm 0.024$ \\
\hline & 0.4 & $1.72 \mathrm{E}-02$ & $6.65 \mathrm{E}-03$ & $1.44 \mathrm{E}-02$ & $3.50 \mathrm{E}-03$ & $0.042 \pm 0.012$ & $1.004 \pm 0.029$ & $1.046 \pm 0.023$ \\
\hline & 0.6 & $1.29 \mathrm{E}-02$ & 8.83E-03 & $1.08 \mathrm{E}-02$ & $4.64 \mathrm{E}-03$ & $0.014 \pm 0.003$ & $1.041 \pm 0.034$ & $1.055 \pm 0.034$ \\
\hline & 0.8 & $7.48 \mathrm{E}-03$ & $1.16 \mathrm{E}-02$ & $6.26 \mathrm{E}-03$ & $6.08 \mathrm{E}-03$ & $0.003 \pm 0.001$ & $1.089 \pm 0.048$ & $1.092 \pm 0.049$ \\
\hline $10 \%$ & 0.05 & $2.95 \mathrm{E}-02$ & $5.53 \mathrm{E}-04$ & $2.46 \mathrm{E}-02$ & $2.86 \mathrm{E}-04$ & $0.580 \pm 0.026$ & $0.689 \pm 0.005$ & $1.268 \pm 0.031$ \\
\hline (wt/wt) & 0.1 & 2.72E-02 & $1.17 \mathrm{E}-03$ & $2.27 \mathrm{E}-02$ & $6.06 \mathrm{E}-04$ & $0.278 \pm 0.001$ & $0.928 \pm 0.008$ & $1.205 \pm 0.007$ \\
\hline \multirow{3}{*}{ Methanol } & 0.4 & $1.73 \mathrm{E}-02$ & $6.66 \mathrm{E}-03$ & $1.43 \mathrm{E}-02$ & $3.30 \mathrm{E}-03$ & $0.057 \pm 0.008$ & $1.175 \pm 0.016$ & $1.231 \pm 0.025$ \\
\hline & 0.6 & $1.24 \mathrm{E}-02$ & $9.22 \mathrm{E}-03$ & $1.02 \mathrm{E}-02$ & 4.48E-03 & $0.037 \pm 0.011$ & $1.201 \pm 0.015$ & $1.238 \pm 0.004$ \\
\hline & 0.8 & $8.43 \mathrm{E}-03$ & $1.14 \mathrm{E}-02$ & $6.88 \mathrm{E}-03$ & $5.45 \mathrm{E}-03$ & $0.025 \pm 0.002$ & $1.228 \pm 0.005$ & $1.253 \pm 0.003$ \\
\hline $30 \%$ & 0.05 & $2.70 \mathrm{E}-02$ & $4.00 \mathrm{E}-04$ & $2.20 \mathrm{E}-02$ & $1.90 \mathrm{E}-04$ & $0.501 \pm 0.010$ & $0.708 \pm 0.010$ & $1.209 \pm 0.000$ \\
\hline (wt/wt) & 0.1 & 2.67E-02 & $1.23 \mathrm{E}-03$ & $2.17 \mathrm{E}-02$ & $5.73 \mathrm{E}-04$ & $0.263 \pm 0.006$ & $0.979 \pm 0.003$ & $1.241 \pm 0.003$ \\
\hline \multirow[t]{3}{*}{ Methanol } & 0.2 & $2.28 \mathrm{E}-02$ & $3.48 \mathrm{E}-03$ & $1.84 \mathrm{E}-02$ & $1.58 \mathrm{E}-03$ & $0.122 \pm 0.005$ & $1.161 \pm 0.025$ & $1.283 \pm 0.030$ \\
\hline & 0.4 & $1.65 \mathrm{E}-02$ & 7.27E-03 & $1.31 \mathrm{E}-02$ & $3.17 \mathrm{E}-03$ & $0.067 \pm 0.020$ & $1.220 \pm 0.001$ & $1.287 \pm 0.021$ \\
\hline & 0.6 & $1.21 \mathrm{E}-02$ & $1.02 \mathrm{E}-02$ & $9.51 \mathrm{E}-03$ & $4.30 \mathrm{E}-03$ & $0.032 \pm 0.004$ & $1.238 \pm 0.007$ & $1.270 \pm 0.003$ \\
\hline $50 \%$ & 0.05 & $2.79 \mathrm{E}-02$ & $4.23 \mathrm{E}-04$ & $2.17 \mathrm{E}-02$ & $1.71 \mathrm{E}-04$ & $0.520 \pm 0.007$ & $0.819 \pm 0.019$ & $1.340 \pm 0.026$ \\
\hline (wt/wt) & 0.1 & $2.66 \mathrm{E}-02$ & $1.27 \mathrm{E}-03$ & $2.06 \mathrm{E}-02$ & $5.07 \mathrm{E}-04$ & $0.255 \pm 0.090$ & $1.054 \pm 0.010$ & $1.309 \pm 0.100$ \\
\hline \multirow[t]{4}{*}{ Methanol } & 0.2 & $2.34 \mathrm{E}-02$ & $3.58 \mathrm{E}-03$ & $1.80 \mathrm{E}-02$ & $1.37 \mathrm{E}-03$ & $0.148 \pm 0.009$ & $1.215 \pm 0.027$ & $1.362 \pm 0.018$ \\
\hline & 0.4 & $1.75 \mathrm{E}-02$ & $7.58 \mathrm{E}-03$ & $1.32 \mathrm{E}-02$ & $2.75 \mathrm{E}-03$ & $0.079 \pm 0.003$ & $1.289 \pm 0.035$ & $1.368 \pm 0.038$ \\
\hline & 0.6 & $1.22 \mathrm{E}-02$ & $1.07 \mathrm{E}-02$ & 9.09E-03 & $3.75 \mathrm{E}-03$ & $0.053 \pm 0.014$ & $1.334 \pm 0.004$ & $1.387 \pm 0.017$ \\
\hline & 0.8 & $8.26 \mathrm{E}-03$ & $1.34 \mathrm{E}-02$ & $6.10 \mathrm{E}-03$ & 4.55E-03 & $0.033 \pm 0.002$ & $1.316 \pm 0.012$ & $1.350 \pm 0.010$ \\
\hline $70 \%$ & 0.05 & $2.83 \mathrm{E}-02$ & $3.44 \mathrm{E}-04$ & $2.07 \mathrm{E}-02$ & $1.11 \mathrm{E}-04$ & $0.515 \pm 0.007$ & $0.869 \pm 0.010$ & $1.384 \pm 0.003$ \\
\hline$(w t / w t)$ & 0.1 & $2.72 \mathrm{E}-02$ & $1.09 \mathrm{E}-03$ & $1.98 \mathrm{E}-02$ & $3.46 \mathrm{E}-04$ & $0.267 \pm 0.020$ & $1.128 \pm 0.025$ & $1.396 \pm 0.005$ \\
\hline \multirow[t]{4}{*}{ Methanol } & 0.2 & 2.32E-02 & $3.44 \mathrm{E}-03$ & $1.67 \mathrm{E}-02$ & $1.06 \mathrm{E}-03$ & $0.144 \pm 0.009$ & $1.254 \pm 0.008$ & $1.398 \pm 0.001$ \\
\hline & 0.4 & $1.73 \mathrm{E}-02$ & $7.56 \mathrm{E}-03$ & $1.22 \mathrm{E}-02$ & $2.16 \mathrm{E}-03$ & $0.081 \pm 0.012$ & $1.334 \pm 0.014$ & $1.415 \pm 0.026$ \\
\hline & 0.6 & $1.21 \mathrm{E}-02$ & $1.07 \mathrm{E}-02$ & 8.38E-03 & $2.92 \mathrm{E}-03$ & $0.056 \pm 0.001$ & $1.379 \pm 0.002$ & $1.435 \pm 0.003$ \\
\hline & 0.8 & $8.30 \mathrm{E}-03$ & $1.30 \mathrm{E}-02$ & $5.70 \mathrm{E}-03$ & $3.45 \mathrm{E}-03$ & $0.043 \pm 0.003$ & $1.429 \pm 0.065$ & $1.471 \pm 0.062$ \\
\hline
\end{tabular}


Table 4.2. Experimental data for Na-Ca exchange on Wyoming bentonite in ethanol-water mixtures at constant total chloride concentration $(\mathrm{TN}=0.03 \mathrm{~N})$ at room temperature.

\begin{tabular}{|c|c|c|c|c|c|c|c|}
\hline $\mathbf{X}_{\mathbf{C a}}$ & $\mathrm{C}_{\mathrm{Na}}$ & $\mathrm{C}_{\mathrm{Ca}}$ & (Na) & (Ca) & $\mathbf{q}_{\mathrm{Na}}$ & $\mathbf{q}_{\mathrm{Ca}} \mathrm{mol}_{\mathrm{c}}$ & $\mathbf{Q}$ \\
\hline \multicolumn{8}{|c|}{$8.6 \%(\mathrm{wt} / \mathrm{wt})$ Ethanol } \\
\hline 0.05 & $2.69 \mathrm{E}-02$ & $3.87 \mathrm{E}-04$ & $2.26 \mathrm{E}-02$ & $2.03 \mathrm{E}-04$ & $0.552 \pm 0.043$ & $0.449 \pm 0.028$ & $1.001 \pm 0.071$ \\
\hline 0.1 & $2.65 \mathrm{E}-02$ & $1.30 \mathrm{E}-03$ & $2.21 \mathrm{E}-02$ & $6.68 \mathrm{E}-04$ & $0.336 \pm 0.065$ & $0.684 \pm 0.03$ & $1.020 \pm 0.035$ \\
\hline 0.2 & $2.36 \mathrm{E}-02$ & $3.38 \mathrm{E}-03$ & $1.95 \mathrm{E}-02$ & $1.70 \mathrm{E}-03$ & $0.130 \pm 0.016$ & $0.932 \pm 0.07$ & $1.062 \pm 0.086$ \\
\hline 0.4 & $1.66 \mathrm{E}-02$ & $6.65 \mathrm{E}-03$ & $1.36 \mathrm{E}-02$ & $3.27 \mathrm{E}-03$ & $0.040 \pm 0.004$ & $0.971 \pm 0.032$ & $1.010 \pm 0.036$ \\
\hline 0.6 & $1.18 \mathrm{E}-02$ & $9.38 \mathrm{E}-03$ & $9.67 \mathrm{E}-03$ & $4.51 \mathrm{E}-03$ & $0.019 \pm 0.001$ & $1.084 \pm 0.061$ & $1.103 \pm 0.062$ \\
\hline 0.8 & $8.20 \mathrm{E}-03$ & $1.16 \mathrm{E}-02$ & $6.66 \mathrm{E}-03$ & $5.48 \mathrm{E}-03$ & $0.002 \pm 0.001$ & $0.994 \pm 0.008$ & $0.995 \pm 0.008$ \\
\hline \multicolumn{8}{|c|}{$26.6 \%(\mathrm{wt} / \mathrm{wt})$ Ethanol } \\
\hline 0.05 & $2.80 \mathrm{E}-02$ & $3.72 \mathrm{E}-04$ & $2.26 \mathrm{E}-02$ & $1.69 \overline{\mathrm{E}-04}$ & $0.486 \pm 0.009$ & $0.460 \pm 0.038$ & $0.946 \pm 0.028$ \\
\hline 0.1 & $2.66 \mathrm{E}-02$ & $1.06 \mathrm{E}-03$ & $2.14 \mathrm{E}-02$ & 4.79E-04 & $0.258 \pm 0.027$ & $0.673 \pm 0.04$ & $0.931 \pm 0.068$ \\
\hline 0.2 & $2.40 \mathrm{E}-02$ & $3.14 \mathrm{E}-03$ & $1.91 \mathrm{E}-02$ & $1.37 \mathrm{E}-03$ & $0.111 \pm 0.002$ & $0.891 \pm 0.004$ & $1.001 \pm 0.006$ \\
\hline 0.4 & $1.74 \mathrm{E}-02$ & $6.85 \mathrm{E}-03$ & $1.37 \mathrm{E}-02$ & $2.88 \mathrm{E}-03$ & $0.042 \pm 0.004$ & $1.067 \pm 0.019$ & $1.109 \pm 0.015$ \\
\hline 0.6 & $1.22 \mathrm{E}-02$ & $9.50 \mathrm{E}-03$ & $9.50 \mathrm{E}-03$ & $3.91 \mathrm{E}-03$ & $0.019 \pm 0.014$ & $1.062 \pm 0.022$ & $1.081 \pm 0.037$ \\
\hline 0.8 & $8.23 \mathrm{E}-03$ & $1.19 \mathrm{E}-02$ & $6.38 \mathrm{E}-03$ & 4.78E-03 & $0.002 \pm 0.001$ & $1.056 \pm 0.025$ & $1.058 \pm 0.023$ \\
\hline \multicolumn{8}{|c|}{$46.3 \%(\mathrm{wt} / \mathrm{wt})$ Ethanol } \\
\hline 0.05 & $2.78 \mathrm{E}-02$ & $3.32 \mathrm{E}-04$ & $2.11 \mathrm{E}-02$ & $1.22 \mathrm{E}-04$ & $0.535 \pm 0.003$ & $0.462 \pm 0.011$ & $0.997 \pm 0.015$ \\
\hline 0.1 & $2.67 \mathrm{E}-02$ & $1.09 \mathrm{E}-03$ & $2.02 \mathrm{E}-02$ & $3.97 \mathrm{E}-04$ & $0.305 \pm 0.017$ & $0.737 \pm 0.038$ & $1.042 \pm 0.055$ \\
\hline 0.2 & $2.36 \mathrm{E}-02$ & $3.19 \mathrm{E}-03$ & $1.77 \mathrm{E}-02$ & $1.12 \mathrm{E}-03$ & $0.133 \pm 0.007$ & $0.926 \pm 0.023$ & $1.059 \pm 0.03$ \\
\hline 0.4 & $1.65 \mathrm{E}-02$ & $6.57 \mathrm{E}-03$ & $1.22 \mathrm{E}-02$ & $2.23 \mathrm{E}-03$ & $0.050 \pm 0.006$ & $1.058 \pm 0.063$ & $1.108 \pm 0.068$ \\
\hline 0.6 & $1.18 \mathrm{E}-02$ & $9.59 \mathrm{E}-03$ & $8.63 \mathrm{E}-03$ & $3.12 \mathrm{E}-03$ & $0.017 \pm 0.009$ & $1.135 \pm 0.137$ & $1.153 \pm 0.147$ \\
\hline 0.8 & $7.98 \mathrm{E}-03$ & $1.16 \mathrm{E}-02$ & $5.78 \mathrm{E}-03$ & $3.70 \mathrm{E}-03$ & $0.003 \pm 0.001$ & $1.097 \pm 0.047$ & $1.099 \pm 0.048$ \\
\hline \multicolumn{8}{|c|}{$67 \%(w t / w t)$ Ethanol } \\
\hline 0.05 & $2.61 \mathrm{E}-02$ & $3.22 \mathrm{E}-04$ & $1.79 \mathrm{E}-02$ & $8.36 \mathrm{E}-\overline{-05}$ & $0.563 \pm 0.007$ & $0.456 \pm 0.02$ & $1.019 \pm 0.027$ \\
\hline 0.1 & $2.51 \mathrm{E}-02$ & $1.03 \mathrm{E}-03$ & $1.71 \mathrm{E}-02$ & $2.64 \mathrm{E}-04$ & $0.326 \pm 0.004$ & $0.716 \pm 0.03$ & $1.041 \pm 0.034$ \\
\hline 0.2 & $2.29 \mathrm{E}-02$ & $3.11 \mathrm{E}-03$ & $1.53 \mathrm{E}-02$ & 7.44E-04 & $0.172 \pm 0.003$ & $0.957 \pm 0.019$ & $1.129 \pm 0.016$ \\
\hline 0.4 & $1.56 \mathrm{E}-02$ & $6.24 \mathrm{E}-03$ & $1.04 \mathrm{E}-02$ & $1.45 \mathrm{E}-03$ & $0.065 \pm 0.007$ & $1.031 \pm 0.028$ & $1.096 \pm 0.035$ \\
\hline 0.6 & $1.14 \mathrm{E}-02$ & $9.16 \mathrm{E}-03$ & 7.38E-03 & $2.00 \mathrm{E}-03$ & $0.022 \pm 0.001$ & $1.182 \pm 0.016$ & $1.204 \pm 0.017$ \\
\hline 0.8 & $7.79 \mathrm{E}-03$ & $1.15 \mathrm{E}-02$ & $4.99 \mathrm{E}-03$ & $2.41 \mathrm{E}-03$ & $0.006 \pm 0.001$ & $1.153 \pm 0.071$ & $1.158 \pm 0.073$ \\
\hline
\end{tabular}


Table 4.3. Experimental data for Na-Ca exchange on Wyoming bentonite in acetone- water mixtures at constant total chloride concentration $(\mathrm{TN}=0.03 \mathrm{~N})$ at room temperature.

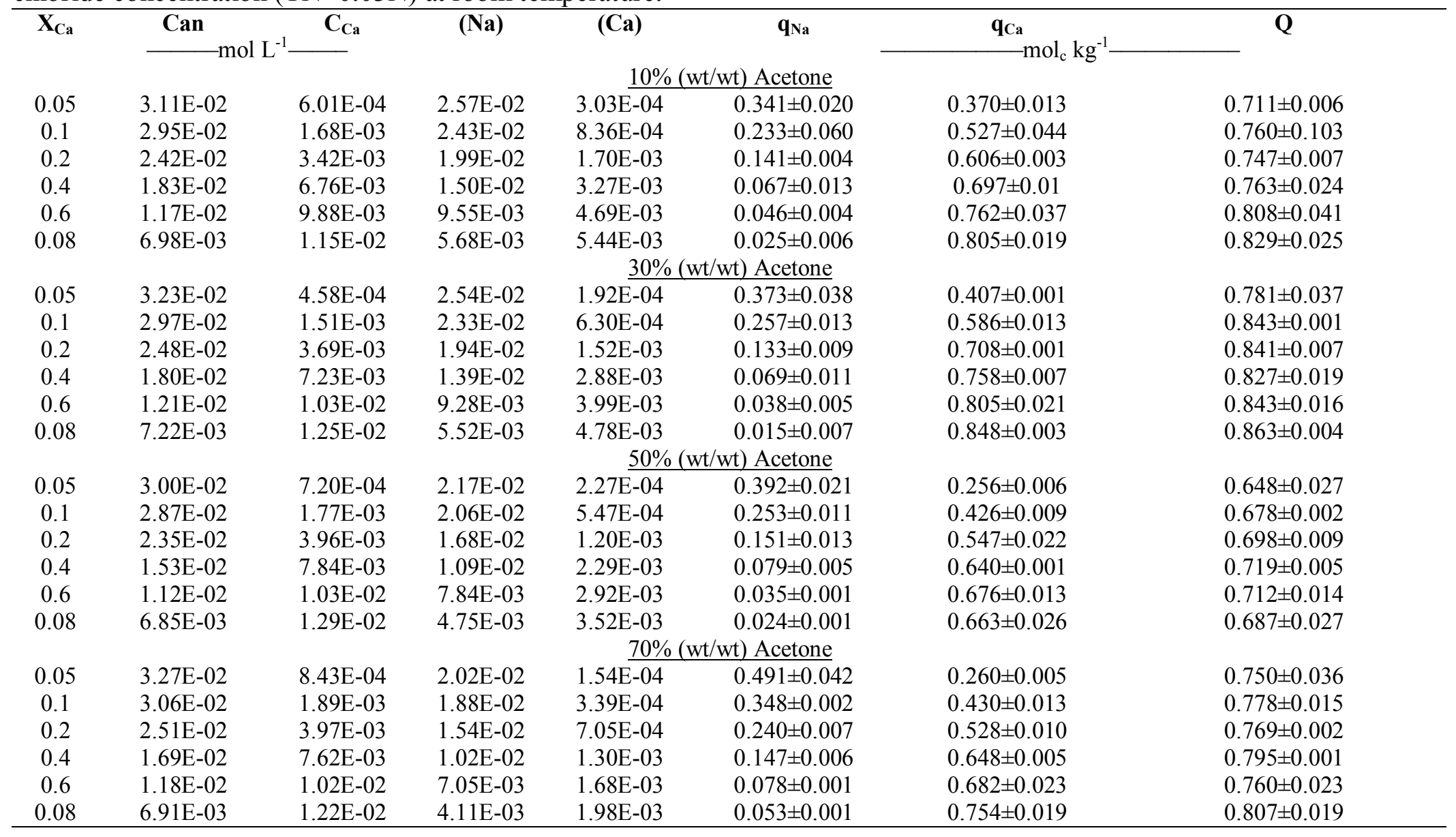




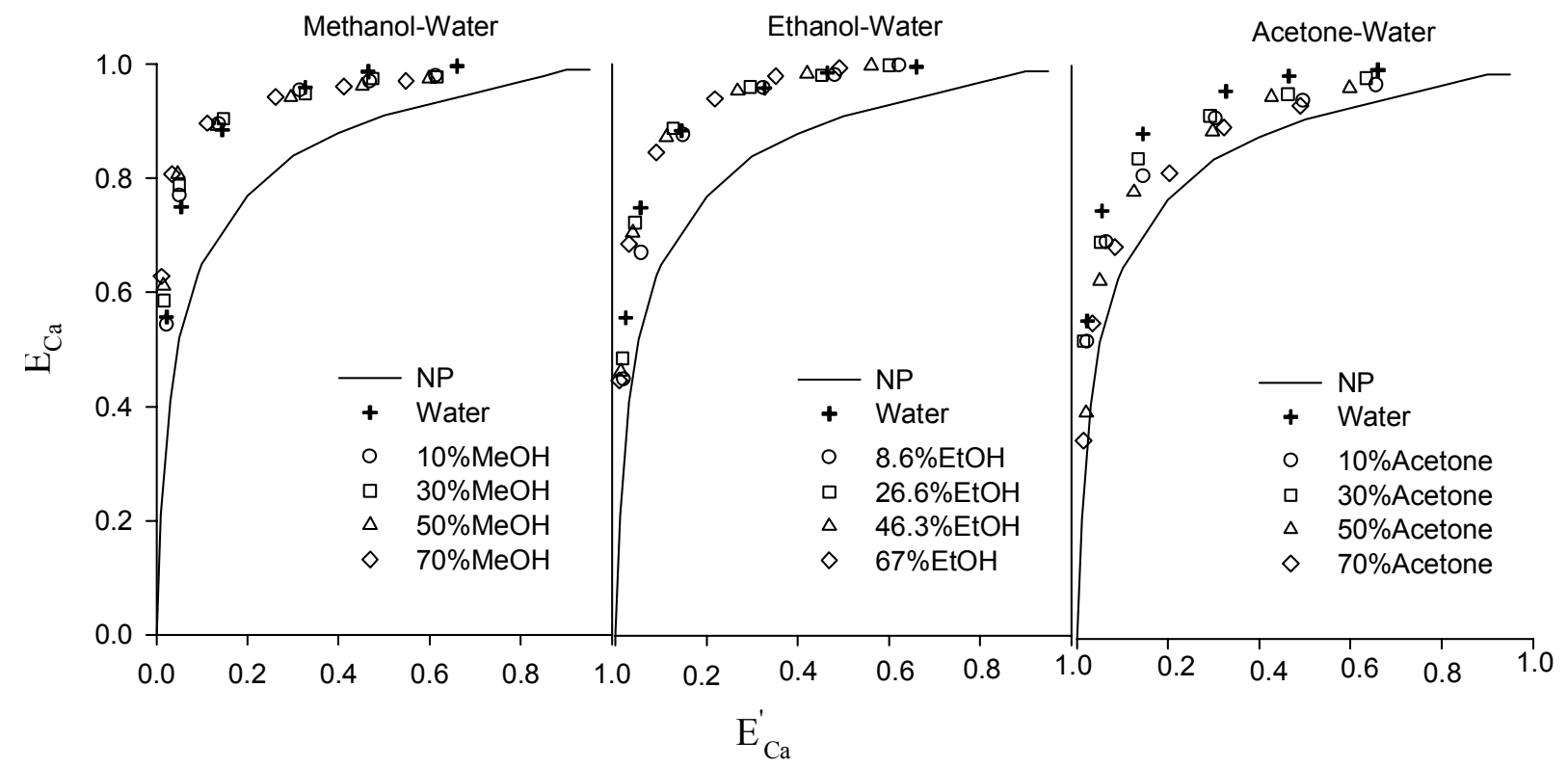

Figure 4.2. Ca-Na exchange isotherms on Wyoming Bentonite at $0.03 \mathrm{~mol} \mathrm{~L}-1$ total electrolyte concentration in methanol, ethanol and acetone-water systems. 
Table 4.4. Values of $\mathrm{Q}_{0}$ in cosolvent solutions as determined by a cubic polynomial regression of $\mathrm{Q}$ versus equivalent fraction of $\mathrm{Ca}$ in solution.

\begin{tabular}{ccc}
\hline Solvent & \% wt & $\mathbf{Q}_{\mathbf{0}}$ \\
\hline \multirow{3}{*}{ Methanol } & 0 & 0.865 \\
& 10 & 1.247 \\
& 30 & 1.191 \\
Ethanol & 50 & 1.328 \\
& 70 & 1.384 \\
& 8.6 & 1.012 \\
Acetone & 26.6 & 0.919 \\
& 46.3 & 1.008 \\
& 67 & 1.018 \\
& 10 & 0.719 \\
& 30 & 0.785 \\
& 50 & 0.640 \\
\hline
\end{tabular}



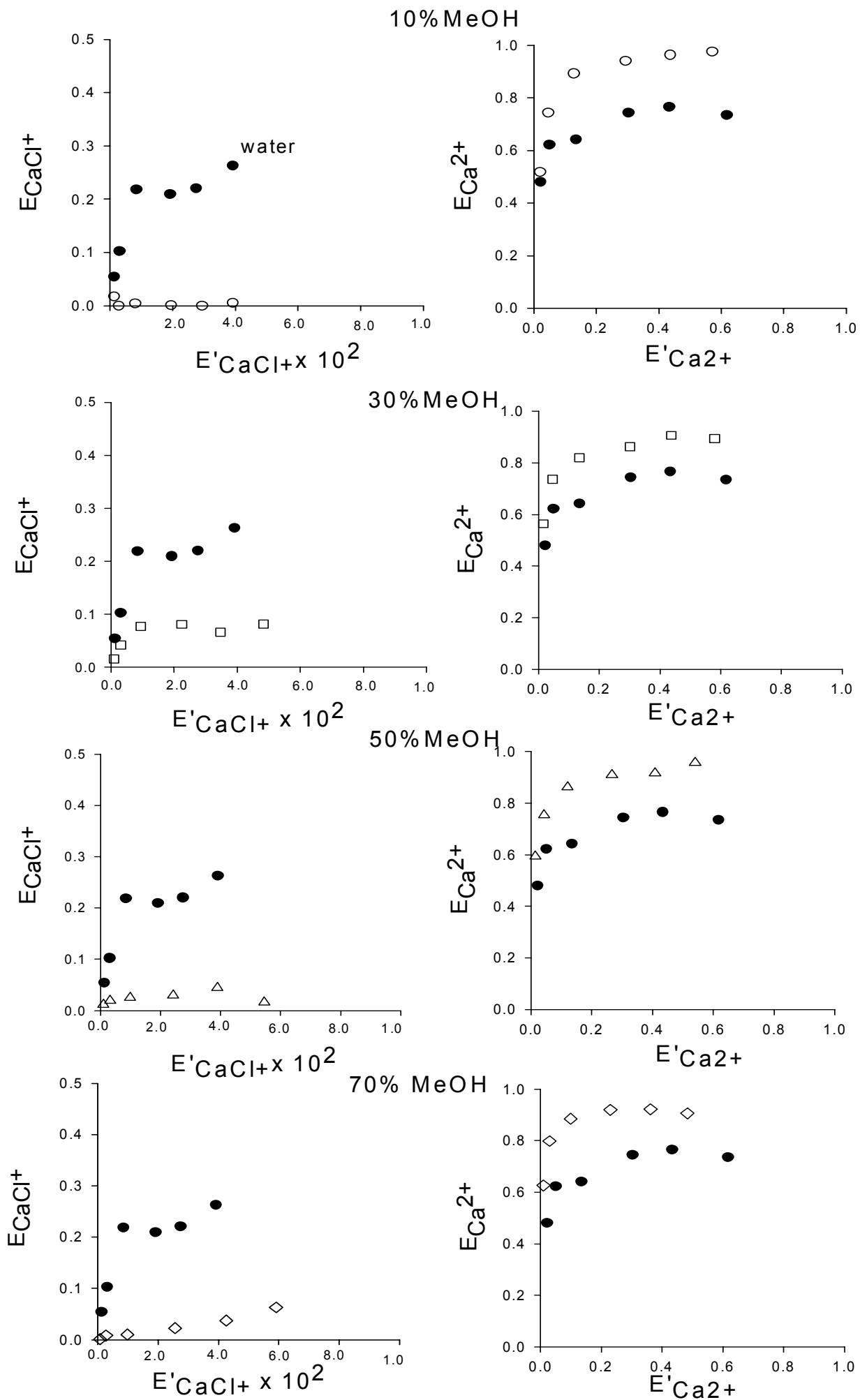

Figure 4.3. Exchange isotherms for $\mathrm{CaCl}^{+}$(left-hand side) and $\mathrm{Ca}^{2+}$ (right-hand side) on Wyoming bentonite at constant total chloride concentration $\left(0.03 \mathrm{~mol} \mathrm{~L}^{-1}\right)$ in methanol water systems, corrected for $\mathrm{CaCl}^{+}$. 

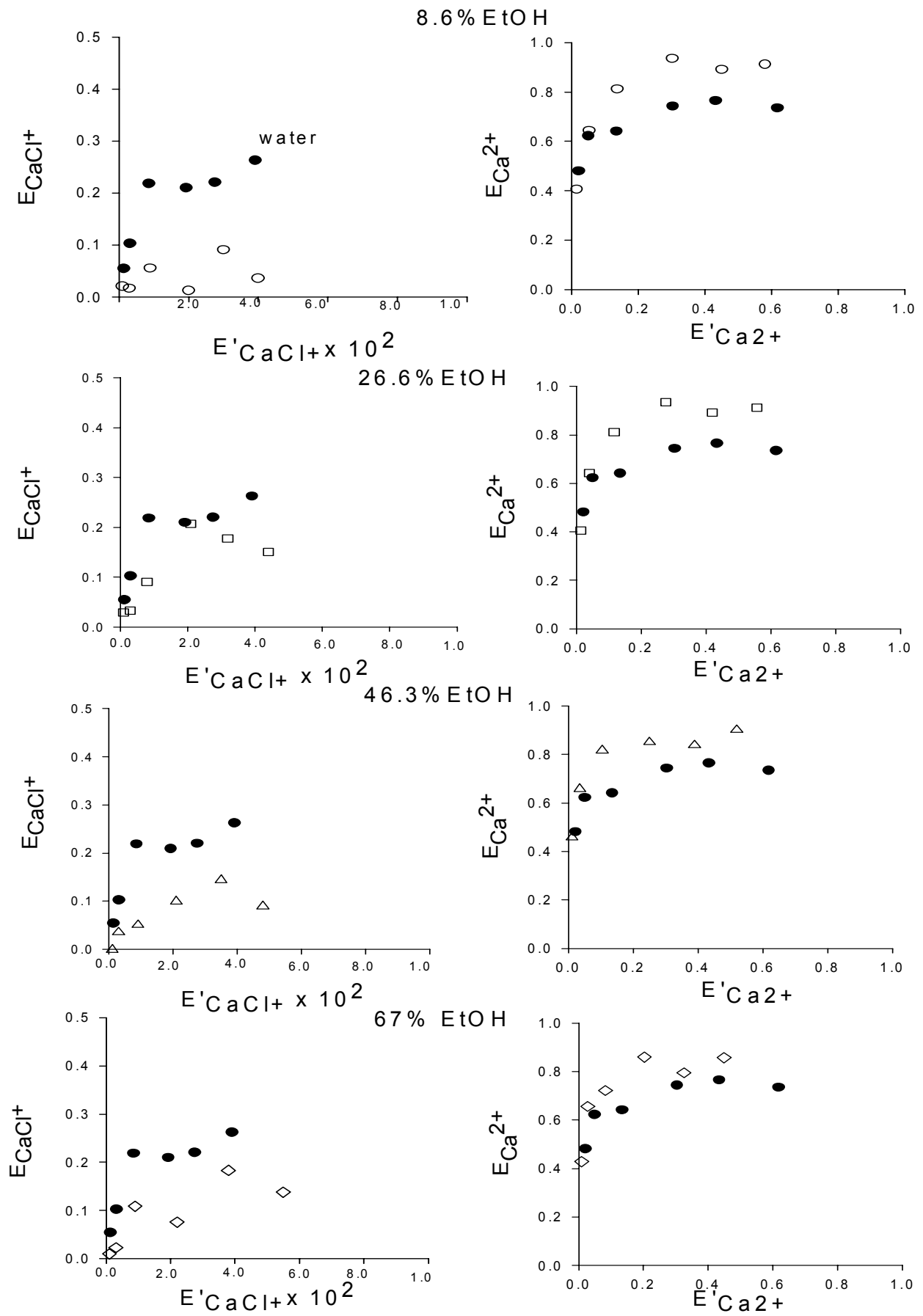

Figure 4.4. Exchange isotherms for $\mathrm{CaCl}^{+}$(left-hand side) and $\mathrm{Ca}^{2+}$ (right-hand side) on Wyoming bentonite at constant total chloride concentration $\left(0.03 \mathrm{~mol} \mathrm{~L}^{-1}\right)$ in ethanol-water systems, corrected for $\mathrm{CaCl}^{+}$. Full symbol; water, hollow symbols; studied cosolvent. 

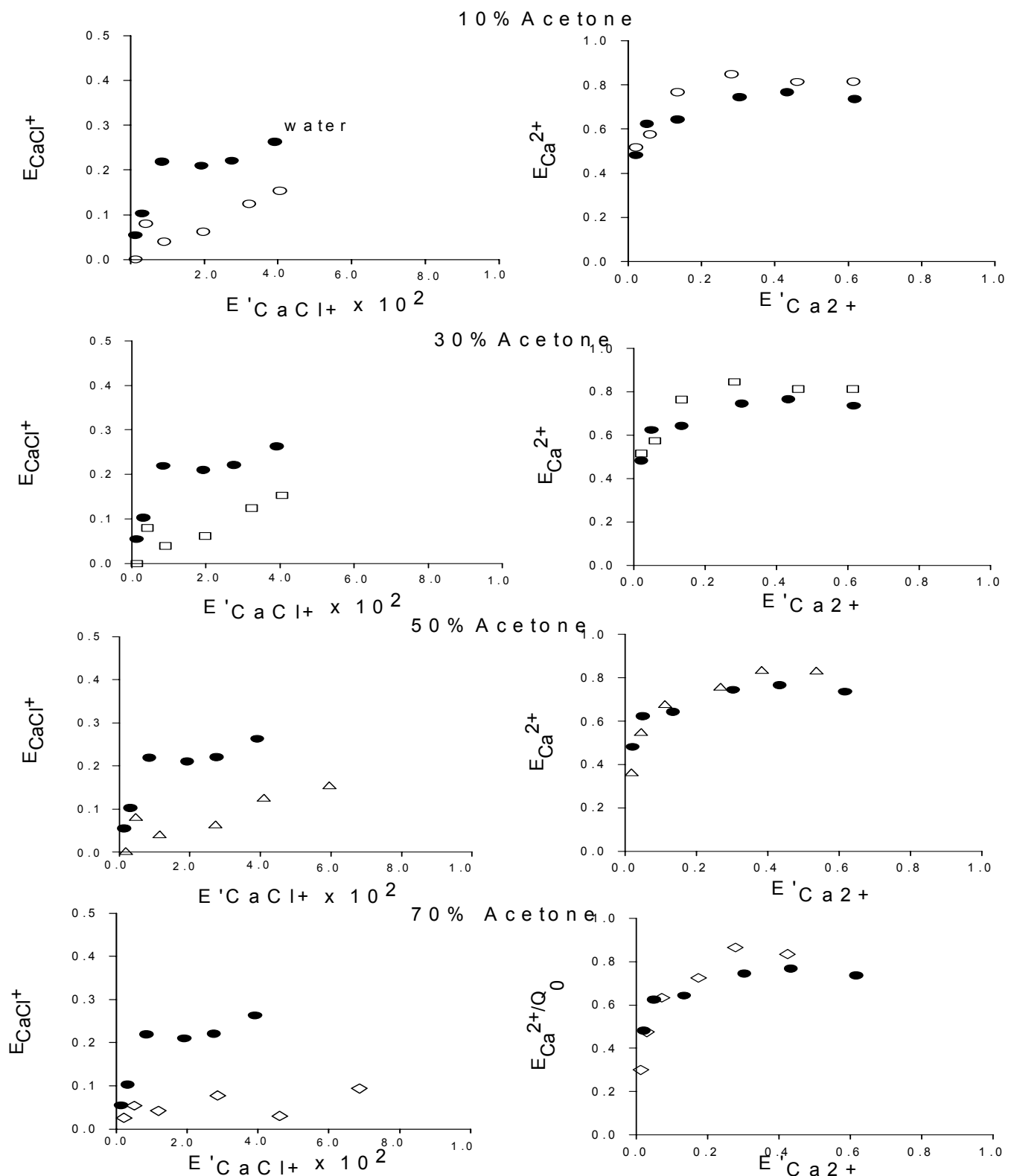

Figure 4.5. Exchange isotherms for $\mathrm{CaCl}^{+}$(left-hand side) and $\mathrm{Ca}^{2+}$ (right-hand side) on Wyoming bentonite at constant total chloride concentration $\left(0.03 \mathrm{~mol} \mathrm{~L}^{-1}\right)$ in acetone-water systems, corrected for $\mathrm{CaCl}^{+}$. Full symbol; water, hollow symbols; studied cosolvent. 
When the total adsorbed metal charge, $\mathrm{Q}$ was corrected for $\mathrm{CaCl}^{+}$adsorption, no change in $\mathrm{Q}_{0}$ was observed (Table 4.5). This implies that the observed increase in the values of $\mathrm{Q}$ in Table 4.1 for methanol-water systems with percent weight cosolvent were experimental artifact resulting from assigning a value of +2 to all adsorbed $\mathrm{Ca}$ species rather than an increase in the number of apparent sites available for adsorption as reported by Xue and Traina, (1996a) for goethite in acetone and methanol-water mixtures. In their work, this increase was mainly attributed to the increased strength of some originally weak iron oxide and iron hydroxide bonds in water because of the increased long range electrostatic bonds. In addition, the low dielectric constant observed at high cosolvent fractions decreased the solubility of $\mathrm{H}^{+}$ ions and reduced the solvation forces that usually compete with surface sites for $\mathrm{H}^{+}$ protonation. In this experiment, bentonite clays are predominantly permanent charge clays ( $>70 \%$ of total adsorbed metal charge) with a small percentage of $\mathrm{pH}$-dependent charges (Anderson and Sposito, 1991). Any change in the number of apparent sites within the $\mathrm{pH}$-dependent charges as a function of cosolvent fraction is likely too small to be detected in this experiment.

Decreasing the solvent dielectric constant has been reported to affect the intracrystalline swelling of clay minerals. Brindley et al., (1969) reported that the intracrystalline swelling of Ca-montmorillonite increases with an increase in the fraction of organic solvent $\left(f_{c}\right)$ up to a certain threshold dictated by the medium dielectric constant, after which collapse of the interlayer spacing occurs. They explained this observed phenomena through the effects of solvents on the cations hydration whereby expansion occurred as a result of water molecules being replaced 
with those of the solvent. In this study, the effect of cosolvents on the intracrystalline swelling of Na-bentonite has not been experimentally determined. However visual observations of clays during the exchange experiments indicate that flocculation was much greater in solutions where the percent weight cosolvent exceeded 50\%. Despite the changes in the intracrystalline swelling of Na-bentonite as a function of exchangeable $\mathrm{Ca}$ fraction and percent weight cosolvent, flocculation does not necessarily result in inaccessible interlayers because we note that there were no changes in $\mathrm{Q}$ and $\mathrm{Q}_{0}$ as a function of cosolvent concentrations. However, the effect of exchanger composition and cosolvent concentration on physical structure of clays deserves further study.

Calcium-sodium exchange on Wyoming bentonite in chloride background in mixed-water systems can be expected to involve the ternary cation exchange $\left(\mathrm{Ca}^{2+}-\right.$ $\mathrm{CaCl}^{+}-\mathrm{Na}^{+}$). In the three studied cosolvents, the affinity of the surface for $\mathrm{Ca}^{2+}$, after correction for $\mathrm{CaCl}^{+}$formation in the surface and in solution, is larger than that of $\mathrm{Na}^{+}$, with the magnitude decreasing as we move from methanol to ethanol to acetone. The selectivity of bentonite for $\mathrm{Ca}$ in cosolvents is primarily driven by solventsurface interactions. Both electrostatic and specific surface-cosolvent interactions such as dielectric saturation are believed to control these interactions and hence the selectivity of the surface for a specific cation. 


\section{CHAPTER V}

Effect of Cosolvents on the Retention Mechanisms of Cd and Zn on Clay Minerals

\section{$5.1 \quad$ Introduction}

Transition metal sorption to clay minerals has been widely studied in the past and various mechanisms of retention have been proposed. Authors generally agree that at low initial metal concentration, sorption is a process (Elrashidi and O'Connor, 1982) that involves physical, electrostatic (Shainberg and Kemper, 1967) and nonelectrostatic (Kinniburgh et al., 1975) attractions to the surface, depending on the nature of the surface and the cation involved. In non-aqueous and mixed aqueous organic solvents, where changing the solvent properties (dielectric constant, viscosity, acidity, etc), is expected to affect both metal and surface physicochemical properties, the mechanisms of metal sorption are yet to be elucidated (Miller et al., 1991).

Because of the important role played by the solvent dielectric constant in determining the electrostatic interactions between oppositely charged ions in a liquid medium (i.e. Debye-Hückel Eq, Born Eq and Coulomb's Law), it is often used as the parameter to predict the effect of solvents on chemical reactions (Izutsu, 2002). However in solvents with high dielectric constant $\left(\varepsilon_{\mathrm{r}}>40\right)$ and for easily polarizable anions at low ionic strength, the electrostatic forces are too weak to affect ion pairing (Figure 3.3 and 3.4) and activity (Figure 1.2). In these media, solvent microscopic properties such as acidity/basicity, the ability to form hydrogen and covalent character bonds also affect chemical equilibria. 
The effects of solvents on clay surface reactivity include increased surface acidity (Loeppert et al., 1977; Loeppert et al., 1979) in kaolinite, decreased surface potential of silicates, (Kosmulski and Matijevic, 1992), and decreased surface charge density coupled with increased solvent adsorption in rutiles (Kosmulski, 1990; Kosmulski, 1996). An increase in the surface charge density of goethite in acetone and methanol-water mixed systems with increasing cosolvent volume fraction as compared to aqueous systems was reported by Xue and Traina (1996a).

In aqueous systems, direct and indirect effects of $\mathrm{pH}$ on cation sorption include increased surface charge density induced by high $\mathrm{pH}$ values, and changes in metal solubility, speciation and chelation. These effects are more pronounced in variable than in permanent-charge clays (Naidu et al., 1997). In these latter, the effect of $\mathrm{pH}$ is related to the type of adsorption sites (interlayer versus planar and edge sites) and their relative contribution to the adsorption of a particular metal. According to Abollino et al., (2003), $\mathrm{Cd}^{2+}$ sorption on Na-montmorillonite occurs mainly through the formation of inner-sphere complexes with silanol and aluminol functional groups at the clay particle edge, whereas $\mathrm{Zn}$ sorption occurs mainly through ion exchange in the interlayers. For both metals, no $\mathrm{pH}$ effect was observed at values ranging from 5.5 to 8.0. For illite where the edge sites are the primary sorption sites, Cd sorption strongly increased within the $\mathrm{pH}$ range $6.0 \leq \mathrm{pH} \leq 8.0$. In non-aqueous and mixed aqueous organic solvents, the poor control of $\mathrm{pH}$ makes it difficult to generate a simple model to predict the behavior of metals in hazardous systems (Kosmulski, 1995). 
The objective of this study is to describe $\mathrm{Cd}$ and $\mathrm{Zn}$ sorption to two clay minerals, bentonite and illite in cosolvents of high dielectric constant at low ionic strength. The $\mathrm{pH}$ of the equilibrium solution was determined to provide an estimate of the $\mathrm{pH}$ range at which these reactions take place. The alcohol-water mixtures selected for this study represent neutral amphiprotic solvents (methanol and ethanol). Illites are nonexpanding clays with low cation exchange capacity, high surface charge density and high edge/interlayer ratio (Anderson and Sposito, 1991). Bentonites are highly expandable clays with high cation exchange capacity, lower edge/interlayer ratio and lower surface charge density than illites. $\mathrm{Cd}$ and $\mathrm{Zn}$ are both important environmental pollutants with the mechanisms of retention on bentonite and illite fairly well described in aqueous media (Ziper et al., 1988; Van Bladel, 1993).

\subsection{Materials and Methods}

\subsubsection{Clays}

Wyoming Bentonite clay was obtained from the American Colloid Company at Upton Plant, Wyoming. Illite (IMt-2), Silver Hill was obtained from the Source Clay Minerals Repository, University of Missouri, MO. Before clay size separation, soluble and insoluble salts, organic matter and iron oxides were removed according to standard procedures (Kunze and Dixon, 1986). The $<2.0 \mu \mathrm{m}$ clay fraction was separated by repeated washing and centrifugation (Jackson, 1974). Ca-saturated clays were prepared by repeated equilibration with $0.5 \mathrm{M} \mathrm{Ca}\left(\mathrm{NO}_{3}\right)_{2}$. Four washings with distilled water were necessary to remove excess salts. The salt-free gel was freezedried and stored for further analysis. The CECs were determined by $\mathrm{Ca}-\mathrm{Mg}$ exchange 
and found to be 108.63 and $23.81 \mathrm{cmol}_{\mathrm{c}} \mathrm{kg}^{-1}$ for bentonite and illite respectively, which compares well to literature values (Sposito, 1998).

\subsubsection{Reagents}

The solvents used in this study were deionized water, HPLC grade methanol and reagent grade ethanol. All solvents were used without further purification. The properties of these cosolvents are presented in Table 2.1. $\mathrm{Cd}\left(\mathrm{NO}_{3}\right)_{2} \cdot 4 \mathrm{H}_{2} \mathrm{O}$ and $\mathrm{Zn}\left(\mathrm{NO}_{3}\right)_{2} \cdot 6 \mathrm{H}_{2} \mathrm{O}$ stock solutions were prepared in distilled water from reagent grade salts and were standardized against 0.01M EDTA.

\subsubsection{Adsorption studies}

$\mathrm{Cd}$ and $\mathrm{Zn}$ adsorption to Bentonite and Illite were studied using batch-type experiments. Solids concentrations were $1.0 \mathrm{~g} \mathrm{~L}^{-1}$ for $\mathrm{Zn}$ and $2.67 \mathrm{~g} \mathrm{~L}^{-1}$ for $\mathrm{Cd}$. The Ca-saturated samples were placed in 15-ml polyethylene centrifuge tube (Fisher Scientific, Pittsburgh, PA), found previously not to sorb $\mathrm{Cd}$ and $\mathrm{Zn}$, with appropriate amounts of distilled water and methanol or ethanol to yield $0,10,30$, and $50 \%$ (wt/wt) cosolvent concentrations. All experiments were conducted in $2.5 \mathrm{mM}$ $\mathrm{Ca}\left(\mathrm{NO}_{3}\right)_{2}$ as the background electrolyte. Initial $\mathrm{Cd}$ and $\mathrm{Zn}$ concentrations ranged from

0 to $10^{-5} \mathrm{M}$. Dispersed samples were placed on an end-over-end shaker for 16 hours at room temperature for the equilibration period. The suspensions were centrifuged at 6000rpm for $20 \mathrm{~min}$, (for the water treatment, an additional $20 \mathrm{~min}$ was necessary to settle the clays) and $5 \mathrm{~mL}$ of supernatant was removed, evaporated to dryness in Pyrex tubes on a Technicon BD-40 digestion block at $130^{\circ} \mathrm{C}$. The evaporates were 
then dissolved in $0.5 \mathrm{M} \mathrm{HNO}_{3}$ for metal determination. Equilibrium $\mathrm{Cd}$ and $\mathrm{Zn}$ concentrations were determined using a Perkin Elmer 400 Inductively Coupled plasma spectrometer.

\subsection{4 pH determination}

Equilibrium $\mathrm{pH}$ was determined spectrophotometrically (Yamazaki, 1992 and Yao et al.,2001) using the conditional dissociation constants, $\mathrm{pK}_{I}$, (Table 2.5) and the absorptive properties (Table 2.4) of Methyl Red (MR) and Phenol Red (PR) indicators, as described in Chapter 2. Briefly, exactly $2 \mathrm{ml}$ of supernatant solution were placed in $15-\mathrm{mL}$ centrifuge tube with appropriate volume of either indicator solution to yield a total indicator concentration of $2.197 \times 10^{-5}$ for MR and $2.125 \times 10^{-5}$ mol L ${ }^{-1}$ for PR, the same total concentration used for the determination of the indicators ${ }_{\mathrm{p}} \mathrm{pK}$ ' $\mathrm{s}$. MR was chosen, as opposed to PR, as the appropriate indicator because both its acidic (HMR) and basic (MR) forms absorbed well at $\lambda_{\mathrm{HMR}}=520 \mathrm{~nm}$ and $\lambda_{\mathrm{MR}}=425 \mathrm{~nm}$ respectively, indicating that the $\mathrm{pH}$ of the solution was within the indicator's buffer region and hence allowing the use of its ${ }_{s} \mathrm{pK}_{I}$ and absorptive properties for $\mathrm{pH}$ determination.

5.2.5 Determination of Stability Constants of the 1:1 ion-pair of $\mathrm{Ca}\left(\mathrm{NO}_{3}\right)_{2} \cdot 4 \mathrm{H}_{2} \mathrm{O}, \mathrm{Zn}\left(\mathrm{NO}_{3}\right)_{2} \cdot 6 \mathrm{H}_{2} \mathrm{O}$ and $\mathrm{Cd}\left(\mathrm{NO}_{3}\right)_{2} \cdot 4 \mathrm{H}_{2} \mathrm{O}$

The stability constants of $\mathrm{Ca}\left(\mathrm{NO}_{3}\right)_{2} \cdot 4 \mathrm{H}_{2} \mathrm{O}, \quad \mathrm{Zn}\left(\mathrm{NO}_{3}\right)_{2} \cdot 6 \mathrm{H}_{2} \mathrm{O}$ and $\mathrm{Cd}\left(\mathrm{NO}_{3}\right)_{2} \cdot 4 \mathrm{H}_{2} \mathrm{O}$ in methanol-water and ethanol-water mixtures were determined at $25^{\circ} \mathrm{C} \pm 0.1$ using conductometric titrations (Table 3.6). Data were treated using the 
Fuoss and Edelson equation (Fuoss and Edelson, 1951). A detailed description of the procedure followed is described in Chapter 3.

\subsubsection{Statistical analysis}

The isotherm parameters $\left(\mathrm{K}_{\mathrm{f}}\right.$ and $\left.1 / \mathrm{n}\right)$ for $\mathrm{Cd}^{2+}$ and $\mathrm{Zn}^{2+}$ sorption to bentonite and illite in methanol-water and ethanol-water mixtures were calculated by fitting Freundlich isotherms using both linear and power regression equations, to all data points in the treatments, before and after correction for $\mathrm{Cd}\left(\mathrm{NO}_{3}\right)^{+}$and $\mathrm{Zn}\left(\mathrm{NO}_{3}\right)^{+}$ speciation in solution. Based on the goodness of fit, $\mathrm{R}^{2}$, power regression equations were fitted for all treatments except for $\mathrm{Cd}^{2+}$ sorption to bentonite where a linear regression equation was more appropriate $\left(\mathrm{R}^{2} \geq 0.98\right)$.

A statistical analysis of the data consisted of a factorial experiment for the partitioning coefficients, $\mathrm{K}_{\mathrm{f}}$, for each metal assembled in a Completely Randomized Design including four factors: clay type at two levels (bentonite and illite), cosolvent type at two levels (ethanol and methanol), percent weight cosolvent at four levels $(0$, 10,30 , and $50 \%$ ) and pairing at two levels (pairing and no-pairing). The experiment was replicated twice. Statistical analysis of variance was performed using the SAS Statistical Package. Treatment means were separated by the Tukey's Studentized Range (HSD) test at 5\% significance levels. Regression analysis was conducted using Excel. 


\section{$5.3 \quad$ Results}

In this experiment, no significant effect of pairing on the partitioning coefficients of $\mathrm{Cd}^{2+}$ and $\mathrm{Zn}^{2+}$ to clay minerals was recorded (Table 5.1 and 5.2) because of the low initial metal concentrations and the low ionic strength ( $\mathrm{I}=0.0075)$ used. For $\mathrm{Cd}^{2+}$, there were significant effects due to clay and solvent type and the interactions between clay and \%wt cosolvent and solvent and \%wt cosolvent (Table 5.1 and 5.2). For $\mathrm{Zn}^{2+}$, all studied factors and their interactions, except for pairing, were highly significant $(\mathrm{p} \leq 0.01)$.

$\mathrm{Cd}^{2+}$ sorption to Wyoming bentonite was linear at all percent weight cosolvents in both methanol and ethanol and the linear partition coefficient, $\mathrm{K}_{\mathrm{f}}$, was constant across all treatments (Table 5.3). $\mathrm{Zn}^{2+}$ sorption to Wyoming bentonite was nonlinear for all percent weight cosolvent in both methanol and ethanol (Table 5.3). There is a general trend to decrease $\mathrm{K}_{\mathrm{f}}$ with weight percent methanol above $10 \%$ methanol. In ethanol, $\mathrm{K}_{\mathrm{f}}$ increased from 0 to $10 \%$, was constant between $10 \%$ and $30 \%$ and decreased at $50 \%$ weight cosolvent. The nonlinearity of $\mathrm{Zn}^{2+}$ sorption to bentonite, as indicated by changes in the parameter $1 / \mathrm{n}$, decreased with increasing percent weight cosolvent in both methanol and ethanol except at 30\% ethanol (Table 5.3). The relative change in isotherm nonlinearity was larger in methanol than ethanol-water mixtures.

Both $\mathrm{Cd}^{2+}$ and $\mathrm{Zn}^{2+}$ sorption to illite was nonlinear at all percent weight cosolvent (Table 5.3). For $\mathrm{Cd}^{2+}, \mathrm{K}_{\mathrm{f}}$ was constant across all treatments except at 50\% methanol where $\mathrm{K}_{\mathrm{f}}$ decreased. For $\mathrm{Zn}^{2+}$ sorption, there is a general trend to increase $\mathrm{K}_{\mathrm{f}}$ with increasing percent weight cosolvent in both methanol and ethanol. Both clays 
showed a higher affinity for $\mathrm{Zn}^{2+}$ than $\mathrm{Cd}^{2+}$ (higher $\mathrm{K}_{\mathrm{f}}$ values) with the affinity being larger for both metals in illite than bentonite. No specific trend in isotherms nonlinearity could be discerned for $\mathrm{Cd}^{2+}$ or $\mathrm{Zn}^{2+}$ sorption to illite.

Figure 5.1 is a plot of the changes in the partition coefficient, $\mathrm{K}_{\mathrm{f}}$, for $\mathrm{Cd}^{2+}$ and $\mathrm{Zn}^{2+}$ sorption on bentonite and illite as a function of $100 / \varepsilon_{\mathrm{r}}$, where, $\varepsilon_{\mathrm{r}}$ is the medium dielectric constant. For $\mathrm{Cd}^{2+}$ sorption to bentonite and illite in both alcohol-water mixtures, $K_{\mathrm{f}}$ was essentially independent of the medium dielectric constant except at $50 \%$ methanol. This indicates that forces other than Coulombic attractions may be involved in $\mathrm{Cd}^{2+}$ sorption to both clays in alcohol-water mixtures (Echeverria et al., 2002).

Table 5.1. Analysis of variance for the partitioning coefficient, $\mathrm{K}_{\mathrm{f}}$, of $\mathrm{Cd}^{2+}$ on clay minerals in mixed aqueous alcohol mixtures.

\begin{tabular}{lcc}
\hline \multicolumn{1}{c}{ Source of variation } & Degrees of freedom & $\mathrm{p}>\mathrm{F}$ \\
\hline Clay & 1 & $<0.0001$ \\
Solvent & 1 & $<0.0001$ \\
Clay * Solvent & 1 & 0.5071 \\
$\%$ wt cosolvent & 3 & 0.9837 \\
Clay * \% wt cosolvent & 3 & $<0.0001$ \\
Solvent* \% wt cosolvent & 2 & 0.0001 \\
Clay * Solvent * \% wt cosolvent & 2 & 0.3702 \\
Pairing & 1 & 0.3778 \\
\hline
\end{tabular}

Table 5.2. Analysis of variance for the partitioning coefficient, $\mathrm{K}_{\mathrm{f}}$, of $\mathrm{Zn}^{2+}$ on clay minerals in mixed aqueous alcohol mixtures.

\begin{tabular}{lcc}
\hline Source of variation & Degrees of freedom & $\mathrm{p}>\mathrm{F}$ \\
\hline Clay & 1 & $<0.0001$ \\
Solvent & 1 & $<0.0001$ \\
Clay * Solvent & 1 & $<0.0001$ \\
$\%$ wt cosolvent & 3 & $<0.0001$ \\
Clay * \% wt cosolvent & 3 & $<0.0001$ \\
Solvent *\%wt cosolvent & 2 & $<0.0001$ \\
Clay $*$ Solvent *\%wt cosolvent & 2 & $<0.0001$ \\
Pairing & 1 & 0.1575 \\
\hline
\end{tabular}


$\mathrm{Zn}^{2+}$ sorption, on the other hand, did vary with $\varepsilon_{\mathrm{r}}$. For illite where sorption is believed to occur primarily on the edge sites (as indicated by the higher adsorption on illite, large edge/interlayer sites ratio, as compared to bentonite, low interlayer/edge sites ratio), $\mathrm{K}_{\mathrm{f}}$ increased almost linearly with $100 / \varepsilon_{\mathrm{r}}$ except between $10 \%$ and $30 \%$ weight cosolvent. This suggests that electrostatic forces may be involved in $\mathrm{Zn}^{2+}$ retention on illite, an observation further supported by the larger $\mathrm{K}_{\mathrm{f}}$ values in ethanol than methanol. In bentonite, $\mathrm{K}_{\mathrm{f}}$ decreased almost linearly with $100 / \varepsilon_{\mathrm{r}}$ in methanol. In ethanol, $\mathrm{K}_{\mathrm{f}}$ decreased only after a threshold value of $\varepsilon_{\mathrm{r}}$ corresponding to $30 \%$ cosolvent weight, the same threshold found in the exchange experiment for ethanolwater mixtures (Chapter 4) and in other literature (Brindley et al., 1969).

Percent coverage of bentonite and illite in various cosolvents at low $(2 \mu \mathrm{M})$ and high $(10 \mu \mathrm{M})$ initial metal concentration is plotted in Figure 5.2. Low total percent coverage was observed for both metals on both clay mineral surfaces. This is attributed to the low initial metal concentrations $\left(0\right.$ to $\left.10 \mu \mathrm{mol} \mathrm{L}^{-1}\right)$ and low ionic strength (0.0075). In all treatments, percent coverage for illite was greater than for bentonite, for both $\mathrm{Cd}$ and $\mathrm{Zn}$. This may be related to the high charge density of edge sites (Ziper et al., 1988) and lower CEC of illite. For Cd and $\mathrm{Zn}$ on bentonite, \% coverage was essentially independent of cosolvent concentration. At higher initial metal concentrations, increasing ethanol concentration to $10 \%$ increased $\%$ coverage on illite, but increasing methanol concentration had no effect. For $\mathrm{Zn}$ on illite, at higher initial metal concentrations, \% coverage increased linearly with increasing methanol concentration. In ethanol, the maximum $\%$ coverage was observed at 30\%. 
The effect of $100 / \varepsilon_{\mathrm{r}}$ on the equilibrium solution $\mathrm{pH}$ is presented in Figure 5.3 for $\mathrm{Cd}$ and $\mathrm{Zn}$ on bentonite and illite. In both clay minerals, $\mathrm{pH}$ ranged from 4.5 to 6.9. In ethanol, there is slight increase in $\mathrm{pH}$ with decreased $\varepsilon_{\mathrm{r}}$ for both $\mathrm{Zn}$ and $\mathrm{Cd}$ on both clay minerals. In methanol, an initial decrease in $\mathrm{pH}$ (from 1.27 to $1.35100 / \varepsilon_{\mathrm{r}}$, which corresponds to 0 and $10 \%$ methanol respectively) followed by a linear increase (after 1.35 ) with $100 / \varepsilon_{\mathrm{r}}$ is observed for both metals on both clay minerals. For $\mathrm{Cd}^{2+}$, higher $\mathrm{pH}$ values were recorded in illite as opposed to bentonite in both methanol and ethanol. For $\mathrm{Zn}^{2+}$, no significant difference between clay types was observed.

\subsection{Discussion}

\subsubsection{Mechanisms of Cd Retention}

In water treatment, $\mathrm{Cd}^{2+}$ sorption to both bentonite and illite at concentrations ranging from 0 to $10 \mu \mathrm{mol} \mathrm{L}-1$ was low as expressed by the low partitioning coefficients, $\mathrm{K}_{\mathrm{f}}$ (Table 5.3) and the low percent surface coverage (Figure 5.2). This low sorption is explained by the low initial clay concentration $\left(2.67 \mathrm{~g} \mathrm{~L}^{-1}\right.$ for both clay types) and the presence of $\mathrm{Ca}^{2+}$ both on the clay sorbing sites and as the index cation (Naidu et al., 1998). A detailed analysis of the effect of clay concentration on cation adsorption is given by Nir (1986) and a study of this effect on Cd sorption to montmorillonite is presented by Hirsh et al., (1989). Briefly, increasing clay concentration should increase the total amount of $\mathrm{Cd}$ sorbed. The effect of index cation on metal sorption was reported by Naidu et al., (1998) who observed that the sorption of $\mathrm{Cd}$ in the presence of $0.03 \mathrm{~mol} \mathrm{~L}^{-1} \mathrm{NaNO}_{3}$ was at least 2-4 times more than in $0.03 \mathrm{~mol} \mathrm{~L}-1 \mathrm{Ca}\left(\mathrm{NO}_{3}\right)_{2}$. The effect of index cation can be attributed to 
increased competition between $\mathrm{Ca}^{2+}$ and $\mathrm{Cd}^{2+}$ for sorbing sites, the effect of the divalent cation on the suspension $\mathrm{pH}$ and the greater specificity of the divalent $\mathrm{Ca}^{2+}$ and its effect on the thickness of the double layer.

In this study, the effect of decreasing $\varepsilon_{\mathrm{r}}$ on metal complexation in solution was negligible in all treatment and could be ignored. Therefore, any changes in the sorption of $\mathrm{Cd}^{2+}$ to either clay mineral can be solely attributed to the effects of cosolvents on the surface properties and its interactions with the metal. At low initial metal concentration, $\mathrm{Cd}^{2+}$ sorption to both bentonite and illite in various cosolvents and at various cosolvent fractions, except in 50\% methanol on illite, is independent of the solvent dielectric constant and therefore may indicate inner-sphere complexes with aluminol and silanol on the clay edge sites. The edge sites are believed to be the major sites for Cd sorption because of the low initial metal concentration used, the weak ability of $\mathrm{Cd}^{2+}$ to compete with interlayer $\mathrm{Ca}^{2+}$ ions due to its large hydrated radius $(9.7 \AA)$ and its soft Lewis acid character, and the observed higher sorption of $\mathrm{Cd}^{2+}$ onto illite (high edge/interlayer sites ratio) as compared to bentonite (low edge/interlayer sites ratio) in all treatments (Figure 5.1). These results correlate well with data reported in aqueous systems (Abollino et al., 2003; Ziper et al.,1988 and Naidu et al.,1994). The nature of bonding between the metal and the edge surface functional groups are believed to be nonelectrostatic as shown by the independent variation of $\mathrm{K}_{\mathrm{f}}$, as a function of $100 / \varepsilon_{\mathrm{r}}$ (Figure 5.1). If electrostatic interactions were involved in the sorption process, a linear increase of $\mathrm{K}_{\mathrm{f}}$ with decreasing $\varepsilon_{\mathrm{r}}$ should have been observed. 
Table 5.3. Freundlich constants for $\mathrm{Cd}^{2+}$ and $\mathrm{Zn}^{2+}$ sorption to Wyoming Bentonite and Illite in methanol-water and ethanol-water mixtures in $2.5 \mathrm{mmol} \mathrm{L}-1 \mathrm{Ca}\left(\mathrm{NO}_{3}\right)_{2}$ background electrolyte. (Solution phase concentrations were $\mu \mathrm{mol} \mathrm{L}^{-1}$, solid phase concentrations were $\left.\mu \mathrm{mol} \mathrm{g} \mathrm{g}^{-1}\right)$.

\begin{tabular}{|c|c|c|c|c|c|c|}
\hline \multirow[b]{2}{*}{ Metal } & \multirow[b]{2}{*}{ Cosolvent } & \multirow[b]{2}{*}{$\begin{array}{l}\% \text { Weight } \\
\text { Cosolvent }\end{array}$} & \multicolumn{2}{|c|}{ Bentonite } & \multicolumn{2}{|c|}{ Illite } \\
\hline & & & $\mathrm{K}_{\mathrm{f}}$ & $1 / n$ & $\mathrm{~K}_{\mathrm{f}}$ & $1 / \mathrm{n}$ \\
\hline \multirow[t]{7}{*}{$\mathrm{Cd}^{2+}$} & Water & 0 & 0.26 & 1.0 & 0.69 & 0.47 \\
\hline & Methanol & 10 & 0.26 & 1.0 & 0.74 & 0.64 \\
\hline & & 30 & 0.29 & 1.0 & 0.71 & 0.53 \\
\hline & & 50 & 0.30 & 1.0 & 0.59 & 0.63 \\
\hline & Ethanol & 10 & 0.27 & 1.0 & 0.72 & 0.40 \\
\hline & & 30 & 0.30 & 1.0 & 0.71 & 0.51 \\
\hline & & 50 & 0.31 & 1.0 & 0.69 & 0.43 \\
\hline \multirow[t]{7}{*}{$\mathrm{Zn}^{2+}$} & Water & 0 & 1.03 & 0.42 & 1.42 & 0.28 \\
\hline & Methanol & 10 & 1.02 & 0.55 & 1.67 & 0.23 \\
\hline & & 30 & 0.87 & 0.68 & 1.47 & 0.31 \\
\hline & & 50 & 0.64 & 1.05 & 1.63 & 0.40 \\
\hline & Ethanol & 10 & 1.10 & 0.68 & 2.87 & 0.54 \\
\hline & & 30 & 1.11 & 0.57 & 1.59 & 0.64 \\
\hline & & 50 & 0.75 & 0.92 & 2.31 & 0.54 \\
\hline
\end{tabular}


The decrease in $\mathrm{K}_{\mathrm{f}}$ for $\mathrm{Cd}$ at $50 \%$ methanol onto illite clays is not clearly understood and may involve the participation of different surface functional groups in the sorption process, some of which may be activated or depressed by changing the solvent dielectric constant, $\varepsilon_{\mathrm{r}}$. The percent $\mathrm{Cd}^{2+}$ coverage to both bentonite and illite was essentially constant and independent of the percent weight cosolvent (Figure 5.2). Any observed deviations (less than $0.5 \%$ ) are considered to be within experimental error. However, this figure was plotted using the cation exchange capacity value of illite and bentonite, as measured in water and not in the various cosolvents. More specific conclusion could be drawn if CEC had been measured in the various cosolvents. An effort to measure these values was made; however procedure complications arose from increased metal complexation and precipitation when high concentration extracting solutions were used and unusually low CEC values when lower concentration extraction solutions were used. Evidence from the literature suggests both a decrease and an increase in the surface charge density in response to cosolvents (Xue and Traina, 1996a; Kosmulski, 1990). The former is related to interlayer collapse (Brindley et al., 1969) or solvent molecules adsorption whereas the latter is explained by an activation of the surface functional groups as a result of decreased solvent dielectric constant (Xue and Traina, 1996a).Given the fact that $\mathrm{Cd}^{2+}$ is mostly adsorbed to edge surface sites, a collapse in the interlayer spacing would not affect its percent metal coverage on either bentonite or illite. Whether any solvent-surface interactions are affecting the edge surface sites on illite cannot be deduced from this study, but warrants further investigation. 


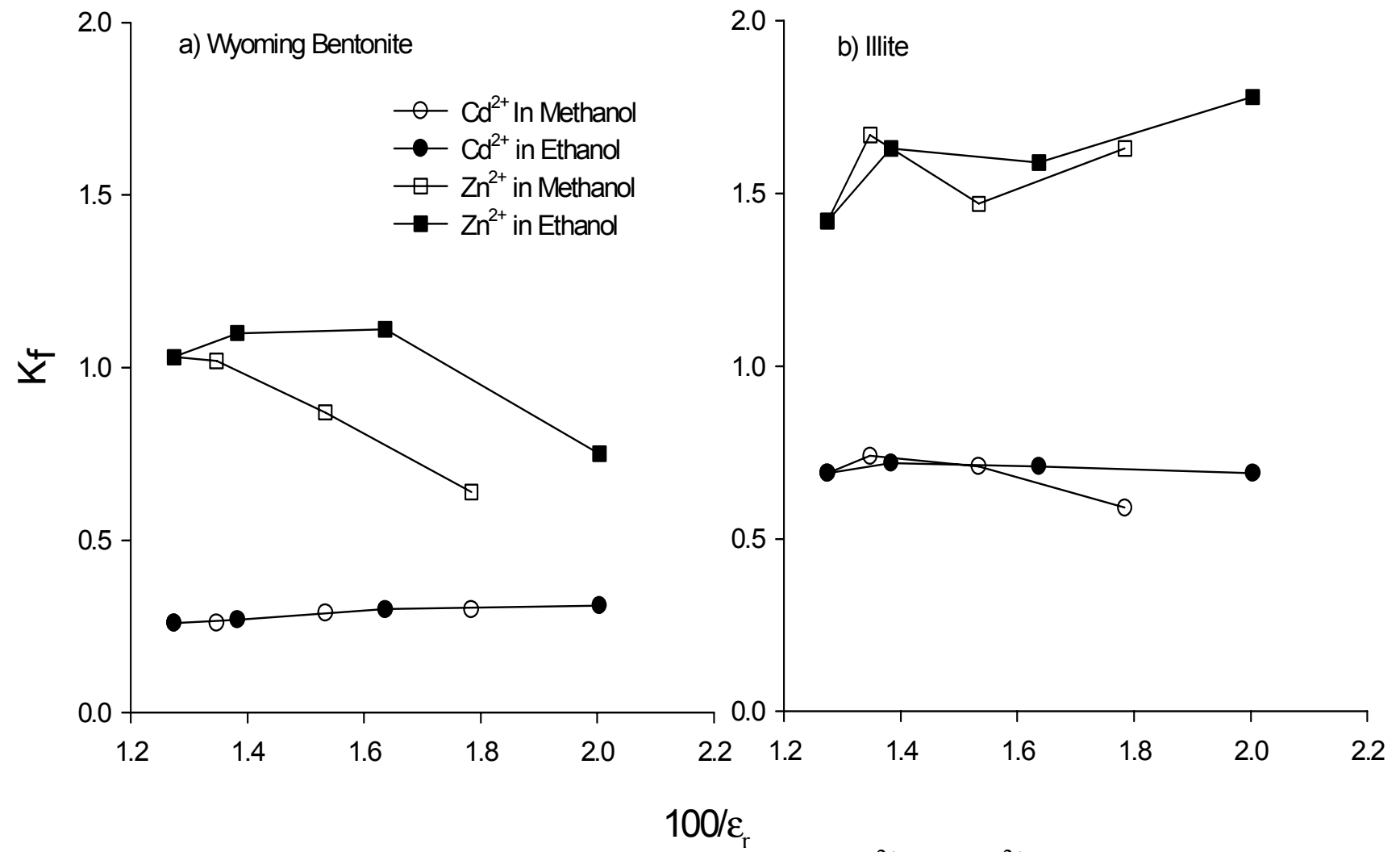

Figure 5.1. Effect of $100 / \varepsilon_{\mathrm{r}}$ on the partition coefficient, $\mathrm{K}_{\mathrm{f}}$, of $\mathrm{Cd}^{2+}$ and $\mathrm{Zn}^{2+}$ sorption to clay minerals in $2.5 \mathrm{mmol} \mathrm{L}^{-1}$ $\mathrm{Ca}\left(\mathrm{NO}_{3}\right)_{2}$ background electrolyte. 


\section{Cadmium}
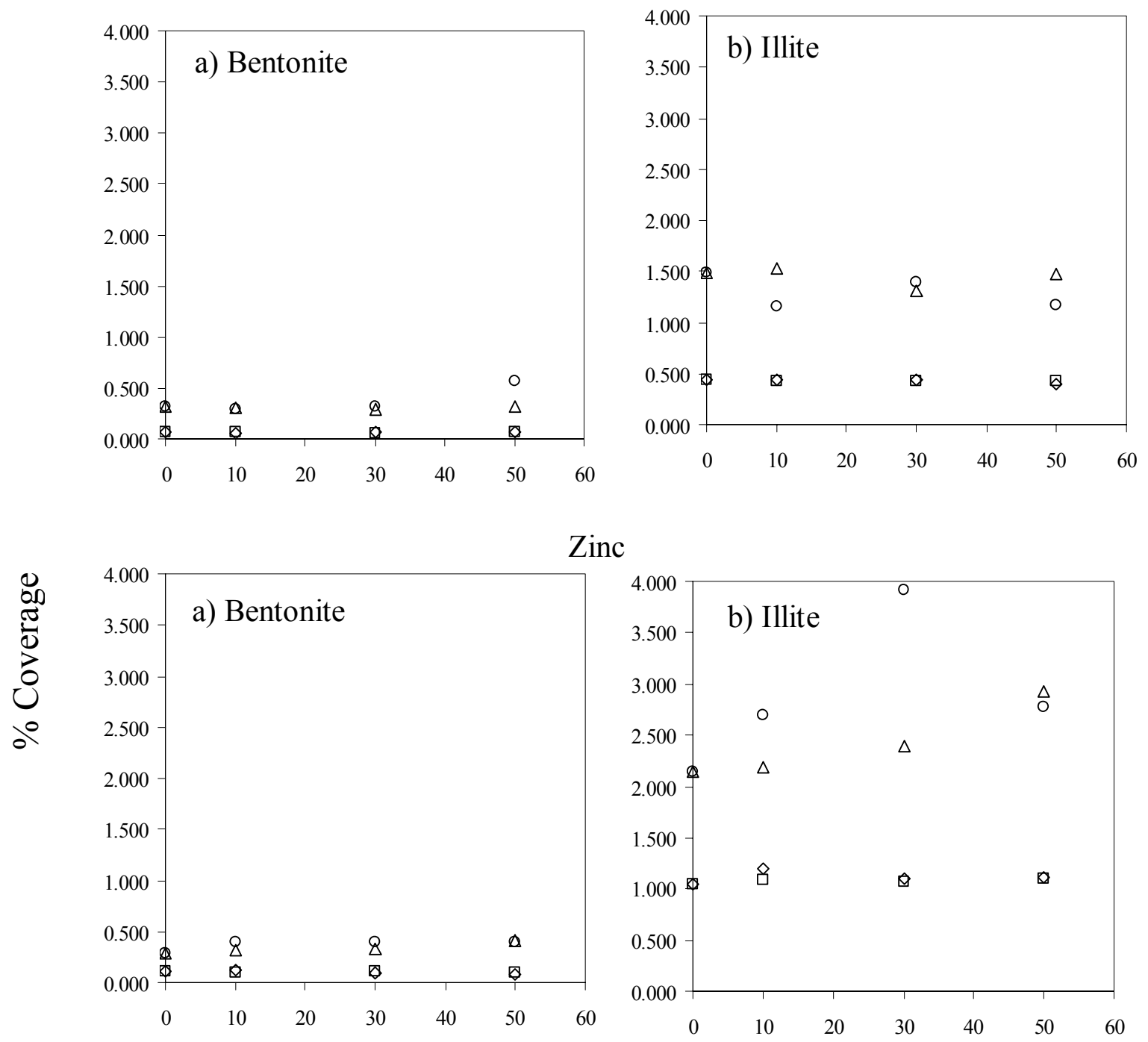

$\%$ weight cosolvent

Figure 5.2. Cosolvent effect on $\%$ metal coverage at low $(2 \mu \mathrm{M})$ and high $(10 \mu \mathrm{M})$ initial metal concentrations, $\mathrm{C}_{\mathrm{i}}$ : $\square$, Low $\mathrm{C}_{\mathrm{i}}, \mathrm{EtOH}$; ○, High $\mathrm{C}_{\mathrm{i}}$, EtOH; $\diamond$, Low $\mathrm{C}_{\mathrm{i}}$, $\mathrm{MeOH} ; \Delta$, High $\mathrm{C}_{\mathrm{i}}, \mathrm{MeOH}$. 


\subsubsection{Mechanisms of Zn Retention}

$\mathrm{Zn}$ sorption varied significantly between clay types in various solvents and at various cosolvent fractions (Table 5.2) suggesting different mechanisms for its retention by clay minerals. The nearly linear increase in $\mathrm{Zn}^{2+}$ sorption to illite in both ethanol and methanol (except between 0 and $10 \%$ weight cosolvent) with increased $100 / \varepsilon_{\mathrm{r}}$ (Figure 5.1) supports that at least some $\mathrm{Zn}^{2+}$ sorption to illite is due to electrostatic interactions between the metal and the edge sorbing sites. The sharp increase in $\mathrm{Zn}^{2+}$ sorption to illite between 0 and $10 \%$ weight cosolvent in both methanol and ethanol coupled with an increase in the percentage surface coverage (Figure 5.3) may be explained by increased availability of functional surface sites (Xue and Traina, 1996a). The results of Figure 5.2 further support this conclusion; however due to the same limitations discussed above, further investigation is necessary. In bentonite, $\mathrm{Zn}^{2+}$ sorption seems to involve two mechanisms: cation exchange between $\mathrm{Zn}^{2+}$ and $\mathrm{Ca}^{2+}$ in the interlayers and formation of electrostatic bonds between $\mathrm{Zn}^{2+}$ and the edge surface sites. The decrease in $\mathrm{K}_{\mathrm{f}}$ of $\mathrm{Zn}^{2+}$ onto bentonite in both ethanol and methanol and the threshold at which this decrease is occurring ( $>30 \%$ for ethanol and $>10 \%$ for methanol) suggest a reduction in the surface charge density as a result of either a partial collapse in the interlayer spacing (Brindley et al., 1969) or a reduction in the number of apparent surface functional group as a result of solvent adsorption (Xue and Traina, 1996a). The exchange of interlayer cations with $\mathrm{Zn}^{2+}$ has been reported in aqueous systems at higher initial $\mathrm{Zn}^{2+}$ concentration $\left(10^{-4} \mathrm{M}\right)$ (Abollino et al., 2003), however, it cannot be excluded from this experiment given the low hydrated radius of $\mathrm{Zn}^{2+}(7.4 \AA)$ and its 
intermediate Lewis acid character. Why both increased (illite) and decreased (bentonite) surface charge density are believed to occur may be related to the differential participation of aluminol and silanol surface edge groups in the sorption process.

\subsubsection{Effect of $p H$}

In aqueous systems, the effect of $\mathrm{pH}$ on metal sorption varies between clay minerals and metal type. In the range 2.5-8.0, no effect of $\mathrm{pH}$ on $\mathrm{Zn}^{2+}$ sorption to montmorillonite is reported whereas below $\mathrm{pH} \leq 3.5, \mathrm{Cd}^{2+}$ sorption strongly decreased (Abollino et al., 2003). In illite, $\mathrm{Cd}^{2+}$ is strongly affected by $\mathrm{pH}$ values for 4.0 $\leq \mathrm{pH} \leq 6.0$ (Echeverria et al., 2002). In this experiment, the equilibrium solution $\mathrm{pH}$ was measured and ranged from 4.5-7.0. In this range and for bentonite clays, $\mathrm{pH}$ is believed to have minimum effect on $\mathrm{Cd}^{2+}$ and $\mathrm{Zn}^{2+}$ sorption for the following reasons; first, the low initial metal concentration and the low percent metal coverage $(0.5-4 \%)$ (Figure 5.2); second, the constant $\mathrm{pH}$ range within a single treatment and with increased metal concentration; and third, the lack of correspondence between changes in $\mathrm{pH}$ and $\mathrm{K}_{\mathrm{f}}$ with the reciprocal dielectric constant (Figure 5.1 and 5.4). To further investigate this relationship, we calculated the equilibrium $\mathrm{pH}$ that would result if all sorbed $\mathrm{Cd}^{2+}$ and $\mathrm{Zn}^{2+}$ displaced $\mathrm{H}^{+}$ions from the surfaces. For a maximum coverage of 0.5 and $1 \%$ (Figure 5.2) and for a CEC value of $108.63 \mathrm{cmol}_{\mathrm{c}} \mathrm{Kg}^{-1}$ and a solid concentration of $1.0 \mathrm{~g} \mathrm{~L}^{-1}\left(\mathrm{Zn}^{2+}\right)$ and $2.67 \mathrm{~g} \mathrm{~L}^{-1}\left(\mathrm{Cd}^{2+}\right)$, these values were calculated as 5.3 and 4.5 for $\mathrm{Zn}^{2+}$ and $\mathrm{Cd}^{2+}$, respectively. For illite, these values were calculated as 5.0 and 4.9 for $\mathrm{Zn}^{2+}$ and $\mathrm{Cd}^{2+}$, respectively (CEC $23.81 \mathrm{cmol}_{\mathrm{c}} \mathrm{Kg}^{-1}$ ). For bentonite, 
the similarity in variation between $\mathrm{pH}$ and ${ }_{s} \mathrm{pK}_{I}$ of methyl red with the reciprocal dielectric constant (Table 2.5) and the range of $\mathrm{pH}$ calculated (for complete $\mathrm{H}^{+}$ displacement) and measured (falling within the no $\mathrm{pH}$ range effect on $\mathrm{Cd}^{2+}$ and $\mathrm{Zn}^{2+}$ sorption to bentonite in water) suggest strong solvent-solvent interactions rather than metal-surface interactions. This conclusion is preliminary and needs further investigation. A better assessment of $\mathrm{pH}$ effect would be possible by comparing initial to equilibrium solution $\mathrm{pH}$, as well as cosolvent $\mathrm{pH}$ to the $\mathrm{pH}$ of clay suspensions when no metals are added. In this way, the source of $\mathrm{pH}$ variation can be isolated and its effect on metal sorption identified.

This study is among the first to try to isolate the effects of solvents on metalsurface reactions. Sorption of $\mathrm{Cd}$ and $\mathrm{Zn}$ to clay minerals at low initial metal concentration and low ionic strength was dependent on metal ( $\mathrm{Zn}$ or $\mathrm{Cd}$ ), clay type (bentonite or illite), cosolvent type (methanol or ethanol) and cosolvent concentration. No general mechanism of metal retention in cosolvents can yet be described partly because metal- sorption appears to be species, surface and solvent specific, at least for the two metals studied. Cosolvents are clearly affecting metal surface and solution properties. Additional studies on the effects of cosolvents on clay surface properties including surface charge density, surface acidity and interlayer spacing will certainly provide useful insights. 


\section{Cadmium}
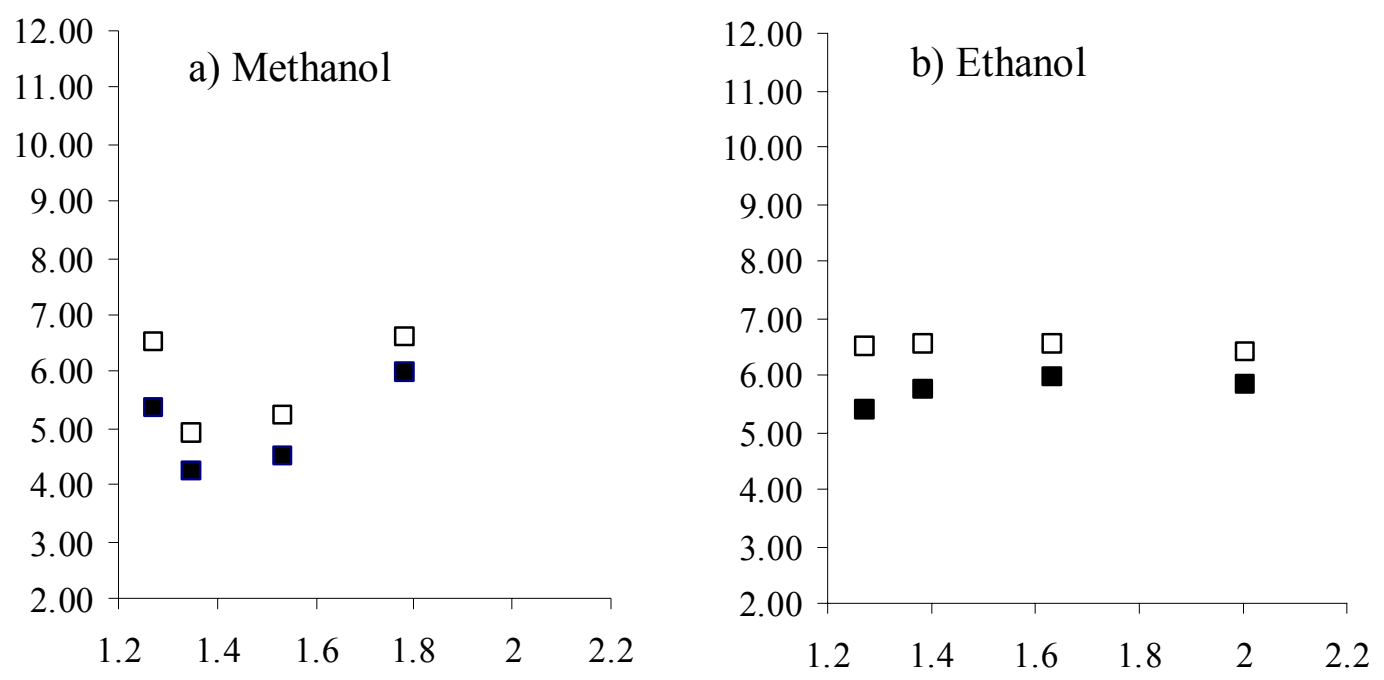

空

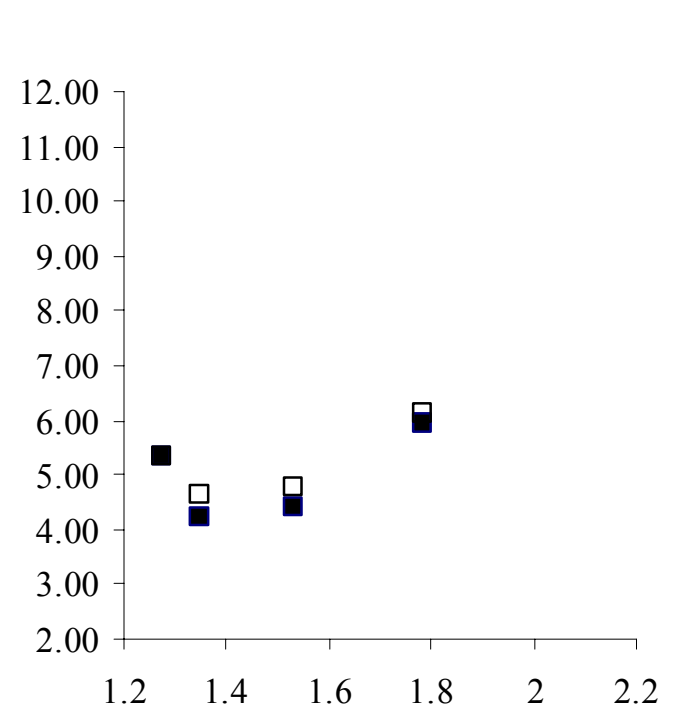

Zinc

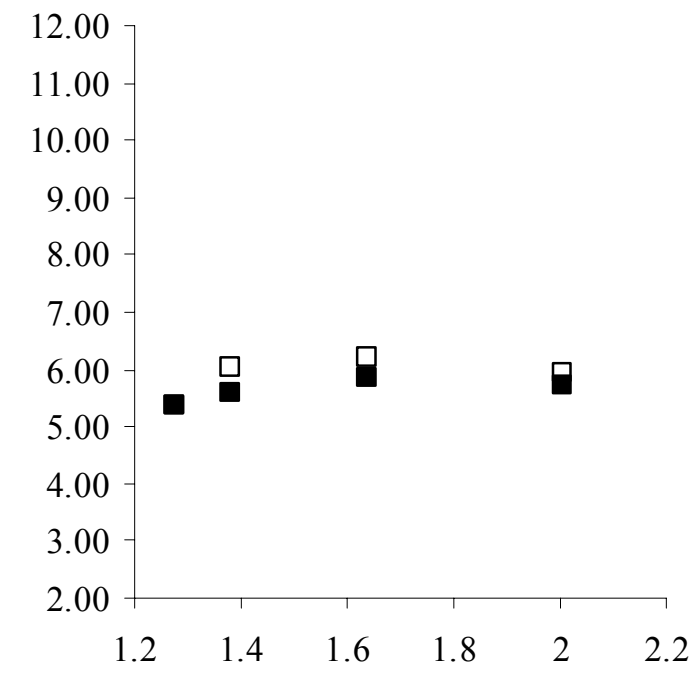

$100 / \varepsilon_{\mathrm{r}}$

Figure 5.3. Effect of $100 / \varepsilon_{\mathrm{r}}$ on the equilibrium $\mathrm{pH}$, as determined by spectrophotometry in $\mathrm{Cd}$ and $\mathrm{Zn}$ sorption to $\boldsymbol{\square}$ Bentonite and $\square$ Illite clays. 


\section{CHAPTER VI}

\section{CONCLUSION}

In this study, the effect of cosolvents on metal-surface reactions, more specifically exchange and adsorption, has been investigated in an attempt to understand the major physical and chemical processes that control metal-surface interactions in waste disposal sites. Because these surface reactions are a function of metals activities, special attention was given to the effect of these cosolvents on metal single ion activity coefficients (Debye-Hückel equation) and ion-pairing. In the absence of published values for the ion association constants for our selected cosolvents, we determined those experimentally using conductometric methods. The formation of $\mathrm{CaCl}^{+}$and $\mathrm{M}\left(\mathrm{NO}_{3}\right)^{+}(\mathrm{M}=\mathrm{Ca}, \mathrm{Cd}$, and $\mathrm{Zn})$ in the studied cosolvents involved, in addition to electrostatic interactions, specific solvent-solute interactions (interactions between the acid-base properties of both solvent and solute) and solventsolvent interactions such as ion solvation and water structure disruption.

Given the importance of $\mathrm{pH}$ in describing metal adsorption processes and mechanisms onto clay minerals, an equation for $\mathrm{pH}$ calculation, within the range $4.5 \leq \mathrm{pH} \leq 8.5$, in mixed methanol and ethanol-water systems under specified conditions $\left(\mathrm{I}=2.5 \times 10^{-3} \mathrm{~mol} . \mathrm{L}^{-1}\right.$, and $\left.\mathrm{T}=25^{\circ} \mathrm{C} \pm 2.0\right)$ was developed using the conditional dissociation constants, $\mathrm{pK}_{I}$, and the absorbance ratios $\left(A_{\lambda_{I n^{-}}} / A_{\lambda_{H I n}}\right)$ of two sulphonephthalein indicators; methyl red and phenol red. In both cosolvents, ${ }_{s} \mathrm{pK}_{I}$ varied nonlinearly with the reciprocal solvent dielectric constant indicating that the dissociation of the studied indicators in alcohol-water mixtures is not solely a function of the solvent dielectric constant. Other specific-solvent-indicator 
interactions, the nature of which could not be deduced from the current study, were indicated.

In calcium-sodium exchange on Wyoming bentonite (chloride background), the affinity of the surface for $\mathrm{Ca}^{2+}$, after correction for $\mathrm{CaCl}^{+}$formation on the surface and in solution, was larger than that of $\mathrm{Na}^{+}$, with the magnitude decreasing as we moved from methanol to ethanol to acetone. This implied that specific surfacecosolvent interactions such as dielectric saturation were involved in determining the selectivity of the surface for a specific cation. This increased selectivity of bentonite clays for $\mathrm{Ca}^{2+}$ will result in enhanced flocculation of clays in landfill liners and a subsequent increase in hydraulic conductivity. Cadmium and $\mathrm{Zn}$ sorption to clay minerals was also affected by cosolvents, but the effects were not simply related to solution dielectric constant. Again, specific solvent-metal and solvent-surface interactions were apparent.

It is not yet possible to predict the effect of cosolvents on metal-surface reactions partly because they appear to be solvent and surface specific. These effects also appear to be metal-specific, at least for the two metals ( $\mathrm{Cd}$ and $\mathrm{Zn})$ tested here. However, this work suggests that these clay liners, in the presence of cosolvents, are at greater risk of failing and releasing contaminants than what is predicted by studies conducted in aqueous solutions or based on the effect of cosolvents on the physical properties of clays (interlayer spacing). Considerably more research is needed before contaminant transport in cosolvent solutions can be predicted, the way it is now for aqueous solutions. In particular, there is a need to expand the data base of metalligand formation constants, particularly in mixed aqueous solutions, and in solutions 
that contain more than one cosolvent. Information is also needed on the effects of cosolvents on interlayer clay spacing, especially as a function of interlayer cation composition. There is also a need for an improved understanding of the role of cosolvents on the properties of mineral surface functional groups, especially those with acid-base character. And finally, there is a need to understand the effect of cosolvent type and concentration on the structure of the interfacial region. Contributions in any of these areas can only improve our understanding of contaminant fate and transport in real contaminant plumes. 
APPENDIX A

Experimental Data for Indicators

Table A.1. Experimental data for phenol red indicator in water.

\begin{tabular}{|c|c|c|c|c|c|c|c|c|c|}
\hline \multirow{12}{*}{ Set $I^{a}$} & & & & \multicolumn{2}{|c|}{$\begin{array}{c}\text { Measured } \\
\text { Absorbance }\end{array}$} & \multicolumn{2}{|c|}{$\begin{array}{c}\text { Corrected } \\
\text { Absorbance }\end{array}$} & \multirow[b]{2}{*}{$\begin{array}{l}\log \left[\mathrm{PR}^{-}\right. \\
] /[\mathrm{HPR}]^{\mathrm{f}}\end{array}$} & \multirow[b]{2}{*}{${ }_{s} \mathrm{pK}_{I}{ }^{\mathrm{g}}$} \\
\hline & $\mathrm{KH}_{2} \mathrm{PO}_{4} / \mathrm{Na}_{2} \mathrm{HPO}_{4}{ }^{\mathrm{b}}$ & e.m. $f^{c}$ & ${ }_{s} \mathrm{pH}^{\mathrm{d}}$ & $\lambda_{H P R}^{H P R}($ measured $)$ & $\lambda_{P R^{-}}^{P R^{-}}($measured $)$ & $\lambda_{H P R}^{H P R}$ & $\lambda_{P R^{-}}^{P R^{-}}$ & & \\
\hline & 4 & 11.3 & 6.65 & 0.3743 & 0.0392 & 0.3304 & 0.0368 & -1.4422 & 8.09 \\
\hline & 2 & -4.2 & 6.91 & 0.3634 & 0.0717 & 0.3195 & 0.0693 & -1.1532 & 8.06 \\
\hline & 1 & -20.6 & 7.19 & 0.3387 & 0.1183 & 0.2948 & 0.1159 & -0.9089 & 8.10 \\
\hline & 0.5 & -35.8 & 7.45 & 0.3117 & 0.2201 & 0.2678 & 0.2177 & -0.5853 & 8.03 \\
\hline & 0.25 & -48.7 & 7.66 & 0.2806 & 0.3111 & 0.2367 & 0.3087 & -0.3837 & 8.05 \\
\hline & 0.2 & -50 & 7.69 & 0.2922 & 0.2985 & 0.2483 & 0.2961 & -0.4090 & 8.09 \\
\hline & 0.1 & -68.2 & 7.99 & 0.221 & 0.5058 & 0.1771 & 0.5034 & -0.0401 & 8.03 \\
\hline & 0.05 & -76.4 & 8.13 & 0.1943 & 0.6021 & 0.1504 & 0.5997 & 0.1192 & 8.01 \\
\hline & \multicolumn{3}{|c|}{ Acidic solution } & 0.3889 & 0.0024 & 0.3450 & & & \\
\hline & \multicolumn{3}{|c|}{$\begin{array}{c}\text { Basic solution } \\
\mathbf{R}_{\mathbf{P R}}\end{array}$} & 0.0439 & $\begin{array}{c}1.0579 \\
0.3270\end{array}$ & & 1.0555 & & \\
\hline \multicolumn{4}{|c|}{$\begin{array}{l}\text { a Each set represents individual replicate } \\
{ }^{\mathrm{b}} \text { This column present the ratio of buffer solution used } \\
{ }^{\mathrm{c}} \text { e.m.f is the electromotive force measured in } \mathrm{mV} \text { for each solution } \\
\mathrm{d} \text { Calculated from Eq [2.4] } \\
{ }^{\mathrm{e}} \text { Corrected absorbance calculated using Eq }[2.14]\end{array}$} & \multicolumn{2}{|c|}{$\begin{array}{l}{ }^{\mathrm{f}} \text { Calculated using log Eq [2.12 } \\
{ }_{\mathrm{g}} \text { Calculated using Eq [2.15] } \\
{ }^{\mathrm{h}} \text { Calculated using Eq [2.13] }\end{array}$} & & & & \\
\hline
\end{tabular}


Table A.2. Experimental data for methyl red indicator in water.

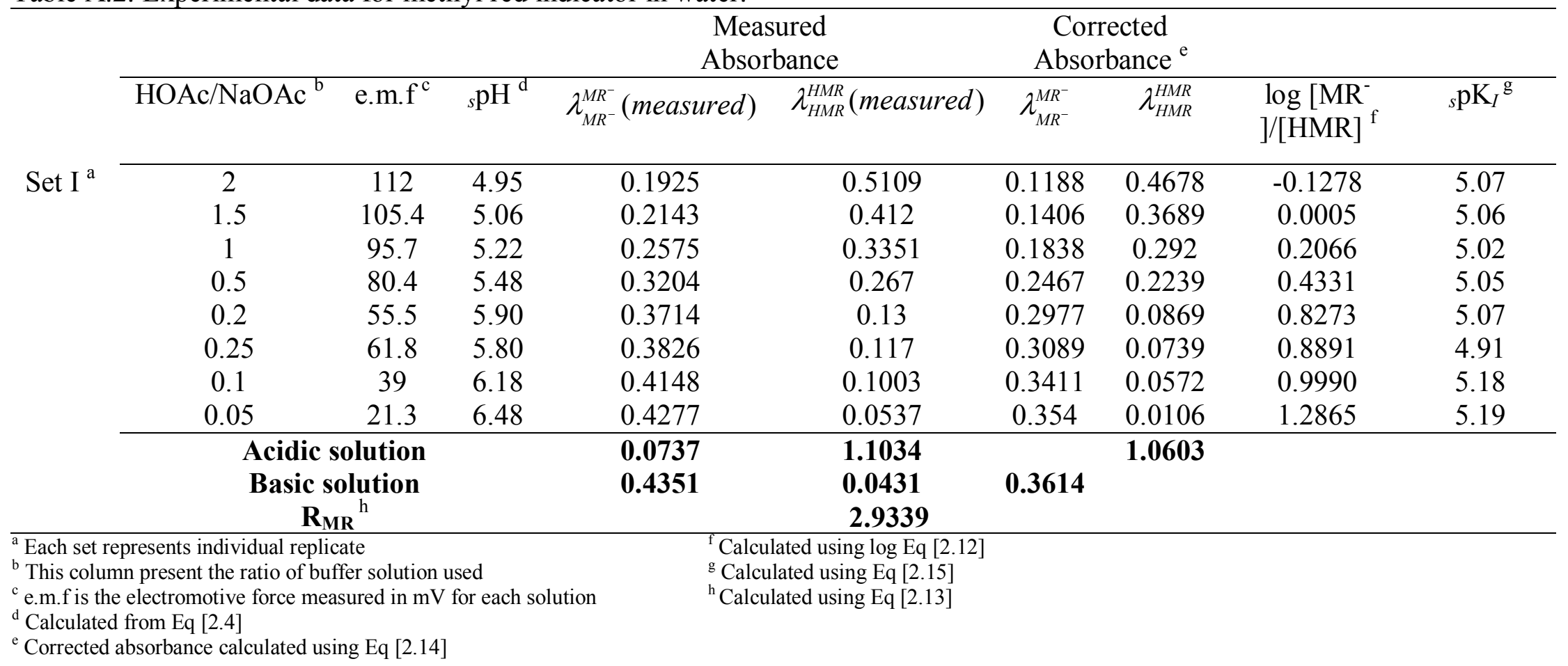


Table A.3. Experimental data for phenol red indicator in 30\% methanol.

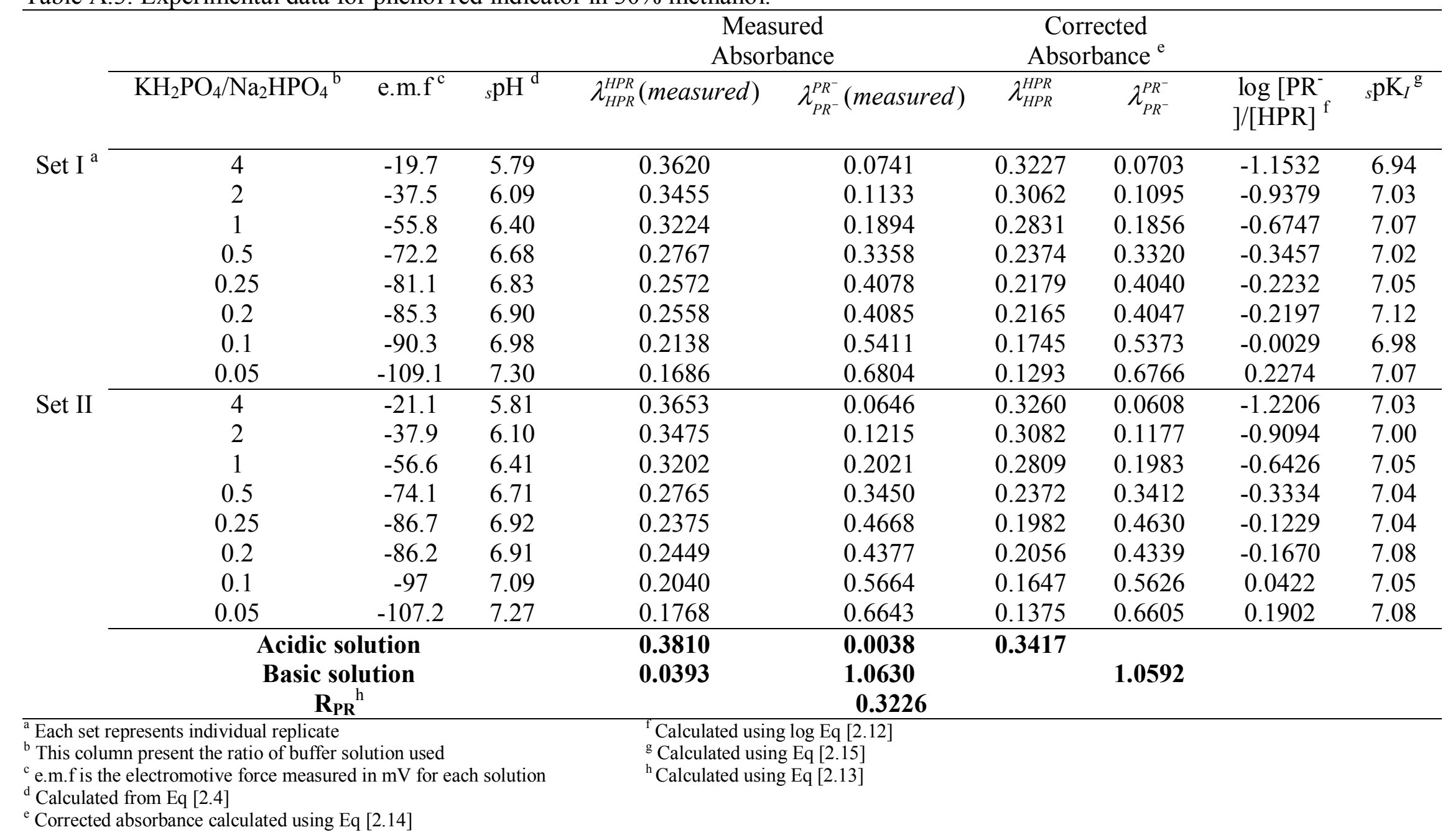


Table A.4. Experimental data for methyl red indicator in 30\% methanol.

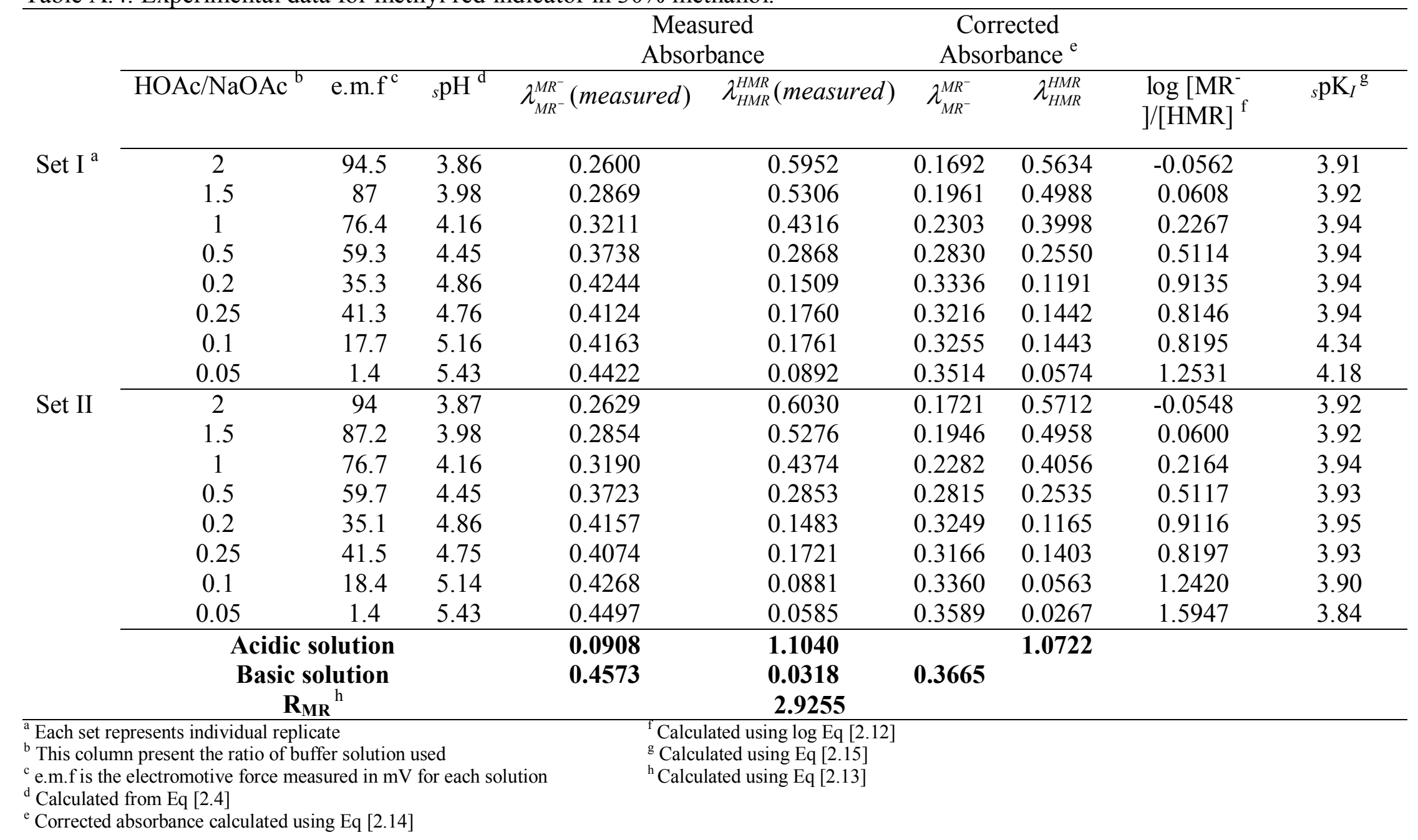


Table A.5. Experimental data for phenol red indicator in 50\% methanol.

\begin{tabular}{|c|c|c|c|c|c|c|c|c|c|}
\hline \multirow[b]{3}{*}{ Set $\mathrm{I}^{\mathrm{a}}$} & \multirow[b]{2}{*}{$\mathrm{KH}_{2} \mathrm{PO}_{4} / \mathrm{Na}_{2} \mathrm{HPO}_{4}{ }^{\mathrm{b}}$} & \multirow[b]{2}{*}{ e.m.f $f^{c}$} & \multirow[b]{2}{*}{${ }_{s} \mathrm{pH}^{\mathrm{d}}$} & \multicolumn{2}{|c|}{$\begin{array}{c}\text { Measured } \\
\text { Absorbance }\end{array}$} & \multicolumn{2}{|c|}{$\begin{array}{c}\text { Corrected } \\
\text { Absorbance }\end{array}$} & \multirow[b]{2}{*}{$\begin{array}{l}\log \left[\mathrm{PR}^{-}\right. \\
] /[\mathrm{HPR}]^{\mathrm{f}}\end{array}$} & \multirow[b]{2}{*}{${ }_{s} \mathrm{pK}_{I}{ }^{\mathrm{g}}$} \\
\hline & & & & $\lambda_{H P R}^{H P R}($ measured $)$ & $\lambda_{P R^{-}}^{P R^{-}}($measured $)$ & $\lambda_{H P R}^{H P R}$ & $\lambda_{P R^{-}}^{P R^{-}}$ & & \\
\hline & 4 & -51.1 & 7.56 & 0.3592 & 0.0647 & 0.3189 & 0.0630 & -1.1928 & 8.76 \\
\hline \multirow{18}{*}{ Set II } & 2 & -67.2 & 7.84 & 0.3454 & 0.1155 & 0.3051 & 0.1138 & -0.9168 & 8.75 \\
\hline & 1 & -83.1 & 8.11 & 0.3187 & 0.1870 & 0.2784 & 0.1853 & -0.6652 & 8.77 \\
\hline & 0.5 & -94.6 & 8.30 & 0.2855 & 0.2921 & 0.2452 & 0.2904 & -0.4150 & 8.72 \\
\hline & 0.25 & -116.7 & 8.67 & 0.2233 & 0.4863 & 0.1830 & 0.4846 & -0.0655 & 8.74 \\
\hline & 0.2 & -111.5 & 8.59 & 0.2462 & 0.4098 & 0.2059 & 0.4081 & -0.1913 & 8.78 \\
\hline & 0.1 & -129.3 & 8.89 & 0.1825 & 0.6030 & 0.1422 & 0.6013 & 0.1377 & 8.75 \\
\hline & 0.05 & -132.2 & 8.94 & 0.1772 & 0.6242 & 0.1369 & 0.6225 & 0.1693 & 8.77 \\
\hline & 4 & -50.3 & 7.55 & 0.3580 & 0.0637 & 0.3177 & 0.0620 & -1.1981 & 8.75 \\
\hline & 2 & -69.1 & 7.87 & 0.3373 & 0.1210 & 0.2970 & 0.1193 & -0.8846 & 8.75 \\
\hline & 1 & -84 & 8.12 & 0.3125 & 0.1951 & 0.2722 & 0.1934 & -0.6369 & 8.76 \\
\hline & 0.5 & -100.2 & 8.39 & 0.2693 & 0.3322 & 0.2290 & 0.3305 & -0.3291 & 8.72 \\
\hline & 0.25 & -109.2 & 8.55 & 0.2470 & 0.4166 & 0.2067 & 0.4149 & -0.1859 & 8.73 \\
\hline & 0.2 & -95.2 & 8.31 & 0.3221 & 0.2187 & 0.2818 & 0.2170 & -0.6019 & 8.91 \\
\hline & 0.1 & -122.8 & 8.78 & 0.2126 & 0.5317 & 0.1723 & 0.5300 & -0.0005 & 8.78 \\
\hline & 0.05 & -131.5 & 8.92 & 0.2090 & 0.5376 & 0.1687 & 0.5359 & 0.0135 & 8.91 \\
\hline & \multirow{3}{*}{\multicolumn{3}{|c|}{$\begin{array}{l}\text { Acidic solution } \\
\text { Basic solution } \\
\mathbf{R}_{\mathbf{P R}}\end{array}$}} & 0.3769 & 0.0017 & 0.3366 & & & \\
\hline & & & & 0.0403 & 1.0382 & & 1.0365 & & \\
\hline & & & & & 0.3247 & & & & \\
\hline \multirow{3}{*}{\multicolumn{4}{|c|}{$\begin{array}{l}\text { a Each set represents individual replicate } \\
\text { b This column present the ratio of buffer solution used } \\
\text { c e.m.f is the electromotive force measured in } \mathrm{mV} \text { for each solution } \\
\text { d Calculated from Eq [2.4] }\end{array}$}} & \multicolumn{2}{|c|}{${ }^{\mathrm{f}}$ Calculated using log Eq [2.12] } & & & & \\
\hline & & & & \multirow{2}{*}{\multicolumn{2}{|c|}{$\begin{array}{l}\mathrm{g} \text { Calculated using Eq [2.15] } \\
{ }^{\mathrm{h}} \text { Calculated using Eq [2.13] }\end{array}$}} & & & & \\
\hline & & & & & & & & & \\
\hline
\end{tabular}


Table A.6. Experimental data for methyl red indicator in 50\% methanol.

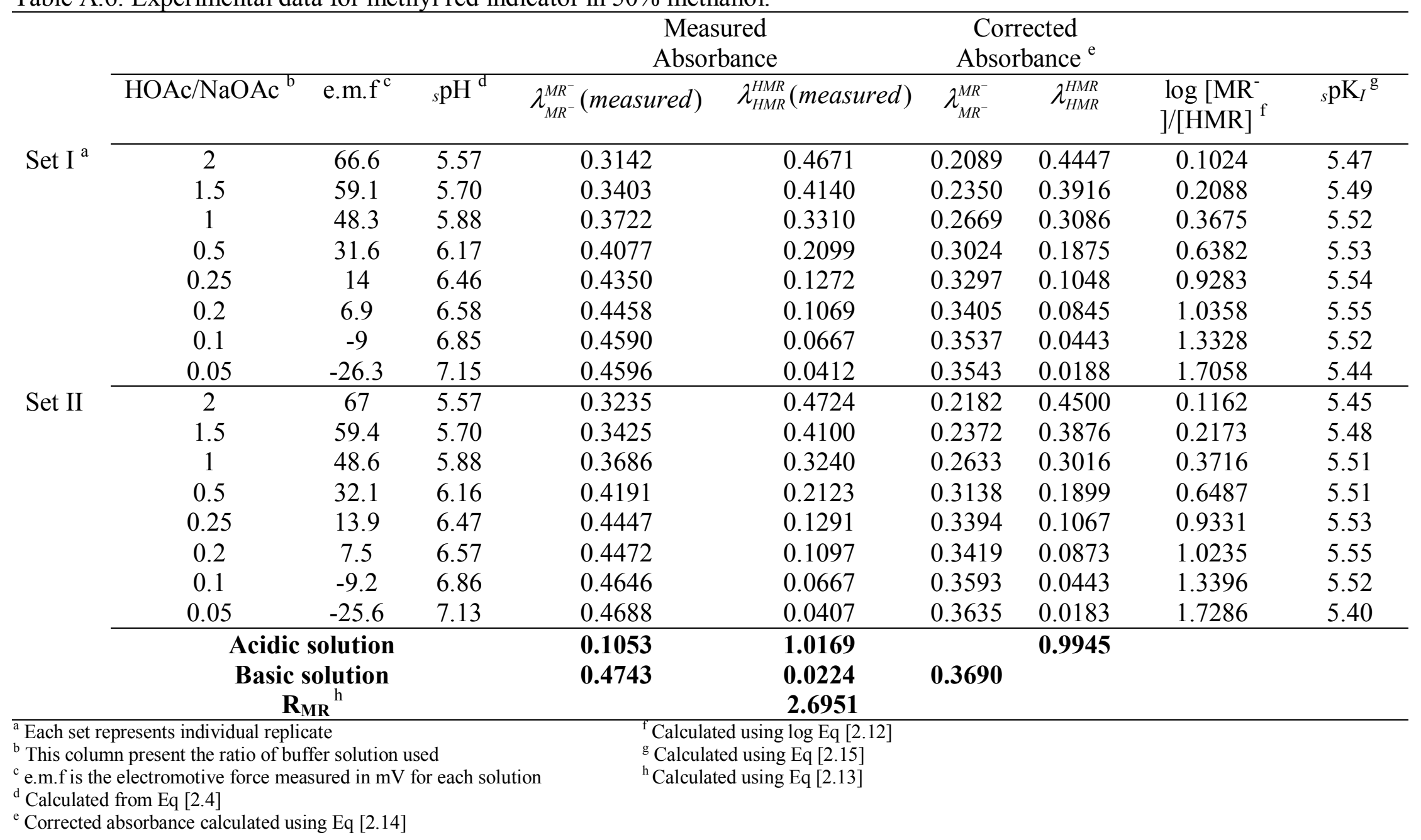


Table A.7. Experimental data for phenol red indicator in 10\% ethanol.

\begin{tabular}{|c|c|c|c|c|c|c|c|c|c|}
\hline \multirow[b]{3}{*}{ Set $\mathrm{I}^{\mathrm{a}}$} & \multirow[b]{2}{*}{$\mathrm{KH}_{2} \mathrm{PO}_{4} / \mathrm{Na}_{2} \mathrm{HPO}_{4}{ }^{\mathrm{b}}$} & \multirow[b]{2}{*}{ e.m. $f^{c}$} & \multirow[b]{2}{*}{${ }_{s} \mathrm{pH}^{\mathrm{d}}$} & \multicolumn{2}{|c|}{$\begin{array}{c}\text { Measured } \\
\text { Absorbance }\end{array}$} & \multicolumn{2}{|c|}{$\begin{array}{c}\text { Corrected } \\
\text { Absorbance }\end{array}$} & \multirow[b]{2}{*}{$\begin{array}{l}\log \left[\mathrm{PR}^{-}\right. \\
] /[\mathrm{HPR}]^{\mathrm{f}}\end{array}$} & \multirow[b]{2}{*}{${ }_{s} \mathrm{pK}_{I}^{\mathrm{g}}$} \\
\hline & & & & $\lambda_{H P R}^{H P R}($ measured $)$ & $\lambda_{P R^{-}}^{P R^{-}}($measured $)$ & $\lambda_{H P R}^{H P R}$ & $\lambda_{P R^{-}}^{P R^{-}}$ & & \\
\hline & 4 & 13.7 & 6.64 & 0.3681 & 0.0388 & 0.3268 & 0.0359 & -1.4456 & 8.09 \\
\hline \multirow{17}{*}{ Set II } & 2 & -4.5 & 6.95 & 0.3547 & 0.0759 & 0.3134 & 0.0730 & -1.1191 & 8.07 \\
\hline & 1 & -21.6 & 7.24 & 0.3409 & 0.1326 & 0.2996 & 0.1297 & -0.8500 & 8.09 \\
\hline & 0.5 & -38.9 & 7.53 & 0.3067 & 0.2326 & 0.2654 & 0.2297 & -0.5491 & 8.08 \\
\hline & 0.25 & -43 & 7.60 & 0.2995 & 0.2582 & 0.2582 & 0.2553 & -0.4913 & 8.09 \\
\hline & 0.2 & -29.6 & 7.38 & 0.3228 & 0.1868 & 0.2815 & 0.1839 & -0.6713 & 8.05 \\
\hline & 0.1 & -55.2 & 7.81 & 0.2732 & 0.3446 & 0.2319 & 0.3417 & -0.3180 & 8.13 \\
\hline & 0.05 & -65.6 & 7.99 & 0.2387 & 0.4478 & 0.1974 & 0.4449 & -0.1335 & 8.12 \\
\hline & 4 & 12.8 & 6.66 & 0.3700 & 0.0449 & 0.3287 & 0.0420 & -1.3799 & 8.04 \\
\hline & 2 & -4.9 & 6.96 & 0.3551 & 0.0785 & 0.3138 & 0.0756 & -1.1045 & 8.06 \\
\hline & 1 & -20.7 & 7.23 & 0.3384 & 0.1321 & 0.2971 & 0.1292 & -0.8480 & 8.07 \\
\hline & 0.5 & -37 & 7.50 & 0.3067 & 0.2246 & 0.2654 & 0.2217 & -0.5645 & 8.07 \\
\hline & 0.25 & -52.6 & 7.77 & 0.2727 & 0.3327 & 0.2314 & 0.3298 & -0.3325 & 8.10 \\
\hline & 0.2 & -40.4 & 7.56 & 0.2997 & 0.2361 & 0.2584 & 0.2332 & -0.5309 & 8.09 \\
\hline & 0.1 & -68.7 & 8.04 & 0.2241 & 0.4891 & 0.1828 & 0.4862 & -0.0615 & 8.10 \\
\hline & 0.05 & -71.6 & 8.09 & 0.2163 & 0.5123 & 0.1750 & 0.5094 & -0.0224 & 8.11 \\
\hline & \multirow{2}{*}{\multicolumn{3}{|c|}{$\begin{array}{l}\text { Acidic solution } \\
\text { Basic solution } \\
\mathbf{R}_{\mathrm{PR}}^{\mathrm{h}}\end{array}$}} & 0.3788 & 0.0029 & 0.3375 & & & \\
\hline & & & & 0.0413 & $\begin{array}{c}1.0372 \\
0.3263\end{array}$ & & 1.0343 & & \\
\hline \multicolumn{4}{|c|}{$\begin{array}{l}\text { a Each set represents individual replicate } \\
\text { b This column present the ratio of buffer solution used } \\
\text { c e.m.f is the electromotive force measured in } \mathrm{mV} \text { for each solution } \\
{ }^{\mathrm{d}} \text { Calculated from Eq [2.4] } \\
{ }^{\mathrm{e}} \text { Corrected absorbance calculated using Eq [2.14] }\end{array}$} & \multicolumn{2}{|c|}{$\begin{array}{l}{ }^{\mathrm{f}} \text { Calculated using log Eq [2.12] } \\
{ }_{\mathrm{g}} \text { Calculated using Eq [2.15] } \\
{ }^{\mathrm{h}} \text { Calculated using Eq [2.13] }\end{array}$} & & & & \\
\hline
\end{tabular}


Table A.8. Experimental data for methyl red indicator in $10 \%$ ethanol.

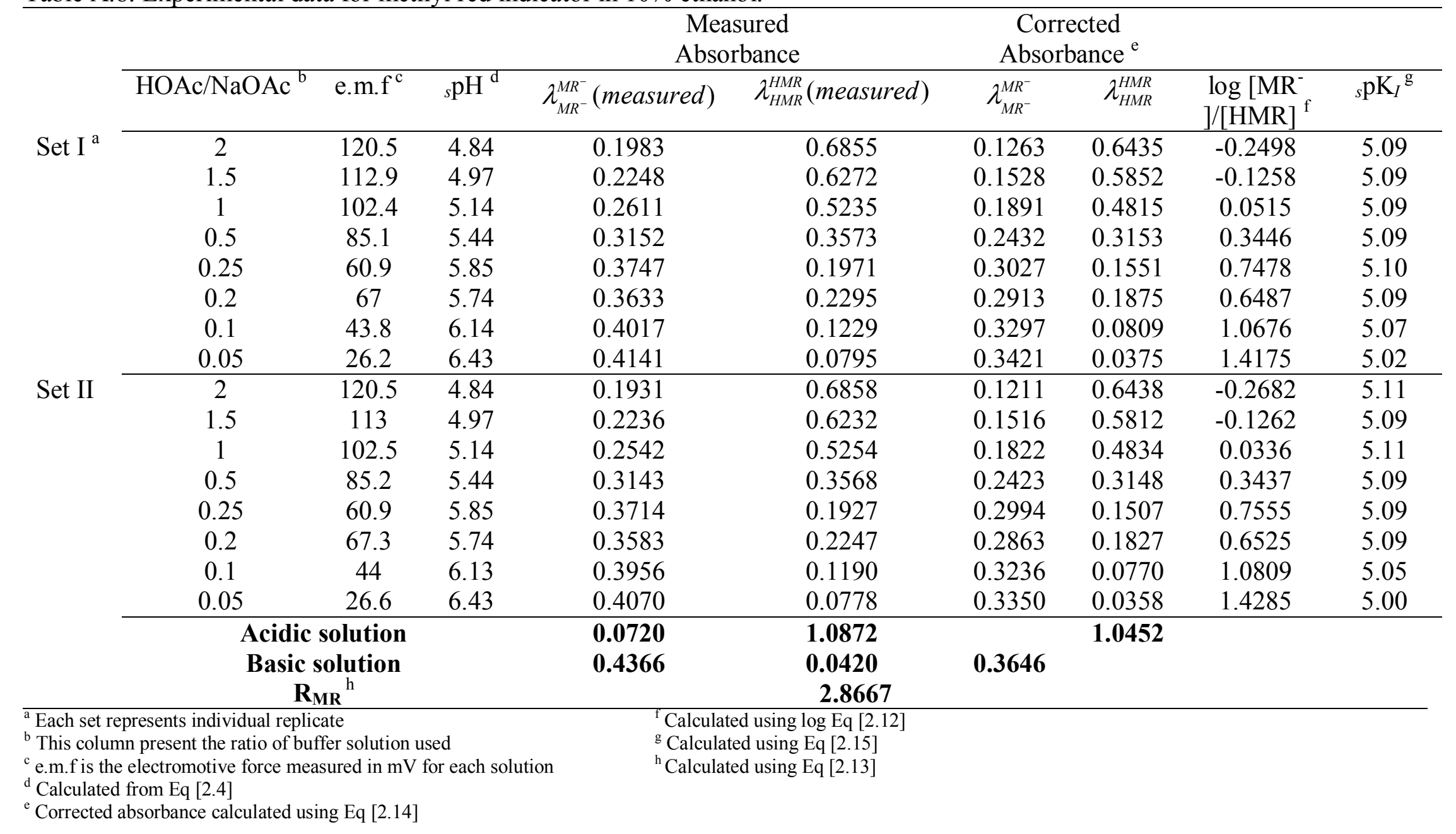


Table A.9. Experimental data for phenol red indicator in 30\% ethanol.

\begin{tabular}{|c|c|c|c|c|c|c|c|c|c|}
\hline \multirow[b]{3}{*}{ Set $\mathrm{I}^{\mathrm{a}}$} & \multirow[b]{2}{*}{$\mathrm{KH}_{2} \mathrm{PO}_{4} / \mathrm{Na}_{2} \mathrm{HPO}_{4}{ }^{\mathrm{b}}$} & \multirow[b]{2}{*}{$\mathrm{e} \cdot \mathrm{m} \cdot \mathrm{f}^{\mathrm{c}}$} & \multirow[b]{2}{*}{${ }_{s} \mathrm{pH}^{\mathrm{d}}$} & \multicolumn{2}{|c|}{$\begin{array}{c}\text { Measured } \\
\text { Absorbance }\end{array}$} & \multicolumn{2}{|c|}{$\begin{array}{c}\text { Corrected } \\
\text { Absorbance }^{\mathrm{e}}\end{array}$} & \multirow[b]{2}{*}{$\begin{array}{l}\log {\left[\mathrm{PR}^{-}\right.}^{\mathrm{f}} \\
] /[\mathrm{HPR}]^{\mathrm{f}}\end{array}$} & \multirow[b]{2}{*}{${ }_{s} \mathrm{pK}_{I}^{\mathrm{g}}$} \\
\hline & & & & $\lambda_{H P R}^{H P R}($ measured $)$ & $\lambda_{P R^{-}}^{P R^{-}}($measured $)$ & $\lambda_{H P R}^{H P R}$ & $\lambda_{P R^{-}}^{P R^{-}}$ & & \\
\hline & 4 & -19.5 & 7.03 & 0.3727 & 0.0476 & 0.3376 & 0.0433 & -1.3685 & 8.40 \\
\hline \multirow{15}{*}{ Set II } & 2 & -36.1 & 7.32 & 0.3564 & 0.0815 & 0.3213 & 0.0772 & -1.0958 & 8.41 \\
\hline & 1 & -52.2 & 7.59 & 0.3377 & 0.1339 & 0.3026 & 0.1296 & -0.8448 & 8.43 \\
\hline & 0.5 & -68.6 & 7.86 & 0.3055 & 0.2310 & 0.2704 & 0.2267 & -0.5531 & 8.42 \\
\hline & 0.25 & -80.4 & 8.06 & 0.2769 & 0.3161 & 0.2418 & 0.3118 & -0.3661 & 8.43 \\
\hline & 0.1 & -95.1 & 8.31 & 0.2385 & 0.4437 & 0.2034 & 0.4394 & -0.1420 & 8.45 \\
\hline & 0.05 & -100.2 & 8.40 & 0.2238 & 0.4958 & 0.1887 & 0.4915 & -0.0608 & 8.46 \\
\hline & 4 & -20.5 & 7.05 & 0.3695 & 0.0406 & 0.3344 & 0.0363 & -1.4409 & 8.49 \\
\hline & 2 & -36.5 & 7.32 & 0.3581 & 0.0842 & 0.3230 & 0.0799 & -1.0832 & 8.40 \\
\hline & 1 & -50.7 & 7.56 & 0.3404 & 0.1302 & 0.3053 & 0.1259 & -0.8612 & 8.42 \\
\hline & 0.5 & -69 & 7.87 & 0.3126 & 0.2411 & 0.2775 & 0.2368 & -0.5454 & 8.42 \\
\hline & 0.25 & -81.8 & 8.09 & 0.2719 & 0.3262 & 0.2368 & 0.3219 & -0.3432 & 8.43 \\
\hline & 0.1 & -94 & 8.29 & 0.2444 & 0.4297 & 0.2093 & 0.4254 & -0.1685 & 8.46 \\
\hline & 0.05 & -101.6 & 8.42 & 0.2147 & 0.5317 & 0.1796 & 0.5274 & -0.0087 & 8.43 \\
\hline & \multicolumn{3}{|c|}{ Acidic solution } & 0.3822 & 0.0043 & 0.3471 & & & \\
\hline & \multicolumn{3}{|c|}{$\begin{array}{c}\text { Basic solution } \\
\mathbf{R}_{\mathbf{P R}}\end{array}$} & 0.0351 & $\begin{array}{r}1.0442 \\
0.3338\end{array}$ & & 1.0399 & & \\
\hline \multicolumn{4}{|c|}{ 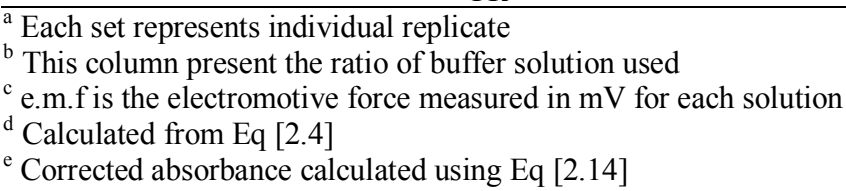 } & \multicolumn{2}{|c|}{$\begin{array}{l}{ }^{\mathrm{g}} \text { Calculated using Eq [2.15] } \\
{ }^{\mathrm{h}} \text { Calculated using Eq [2.13] }\end{array}$} & & & & \\
\hline
\end{tabular}


Table A.10. Experimental data for methyl red indicator in 30\% ethanol.

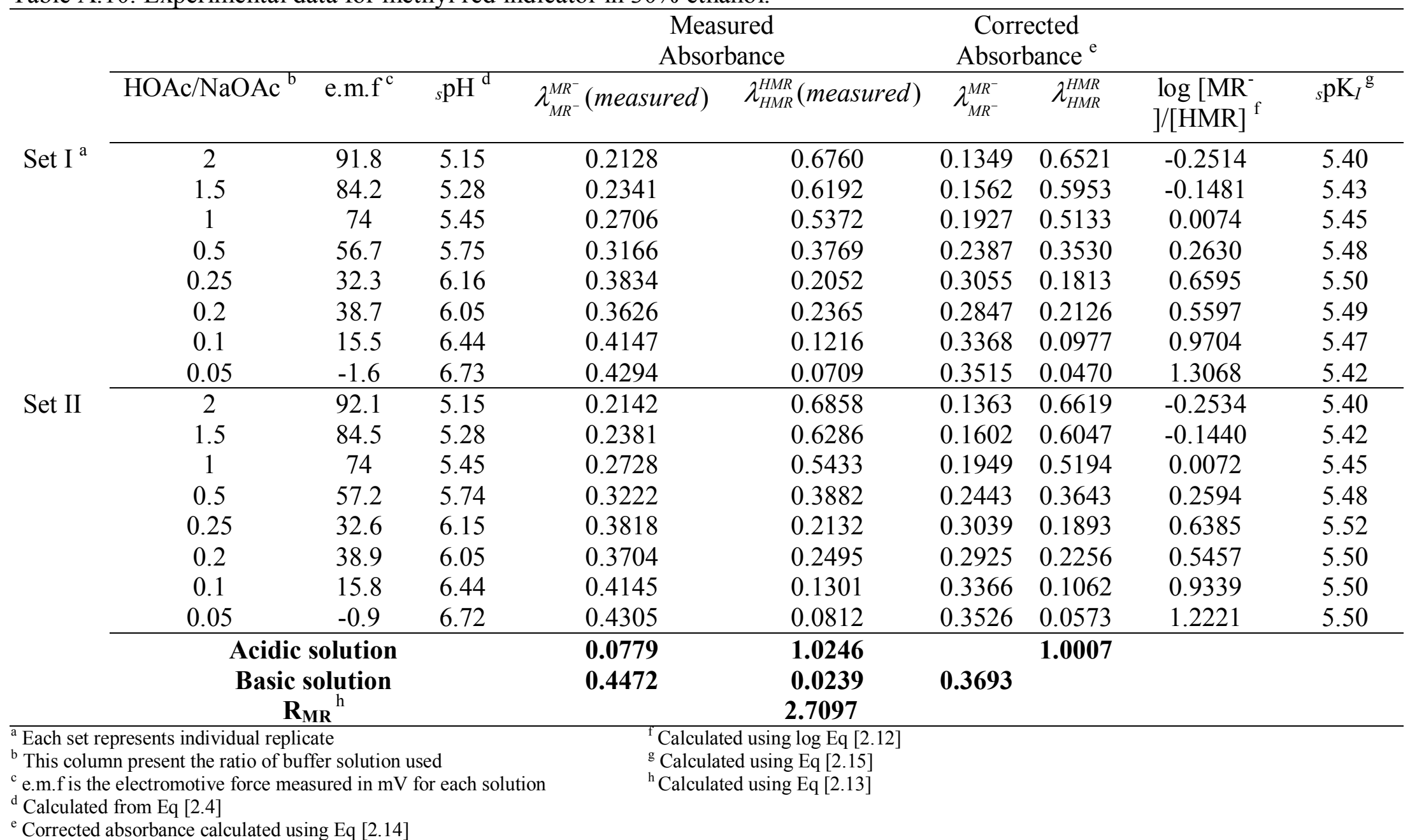


Table A.11. Experimental data for phenol red indicator in 50\% ethanol.

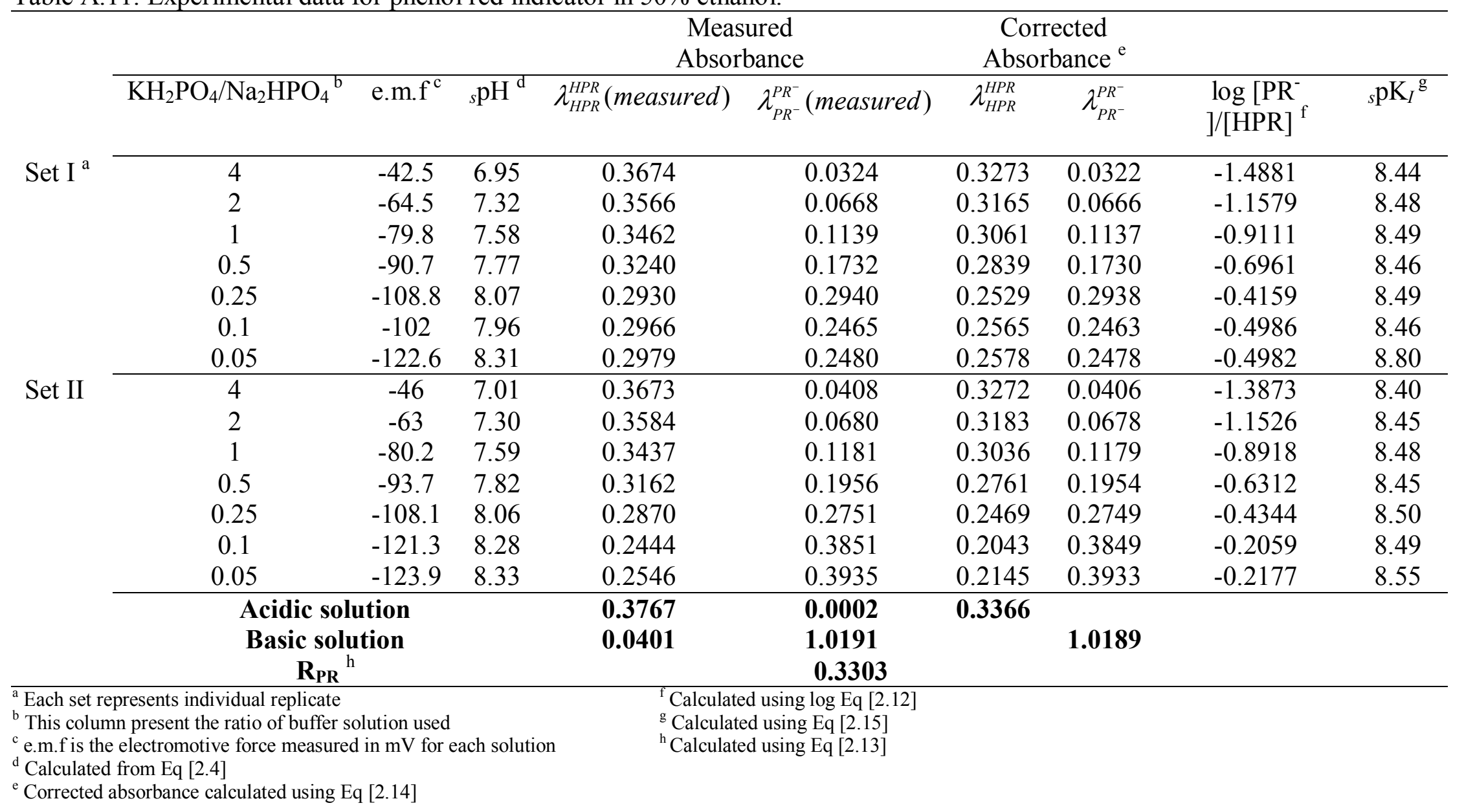


Table A.12. Experimental data for methyl red indicator in 50\% ethanol.

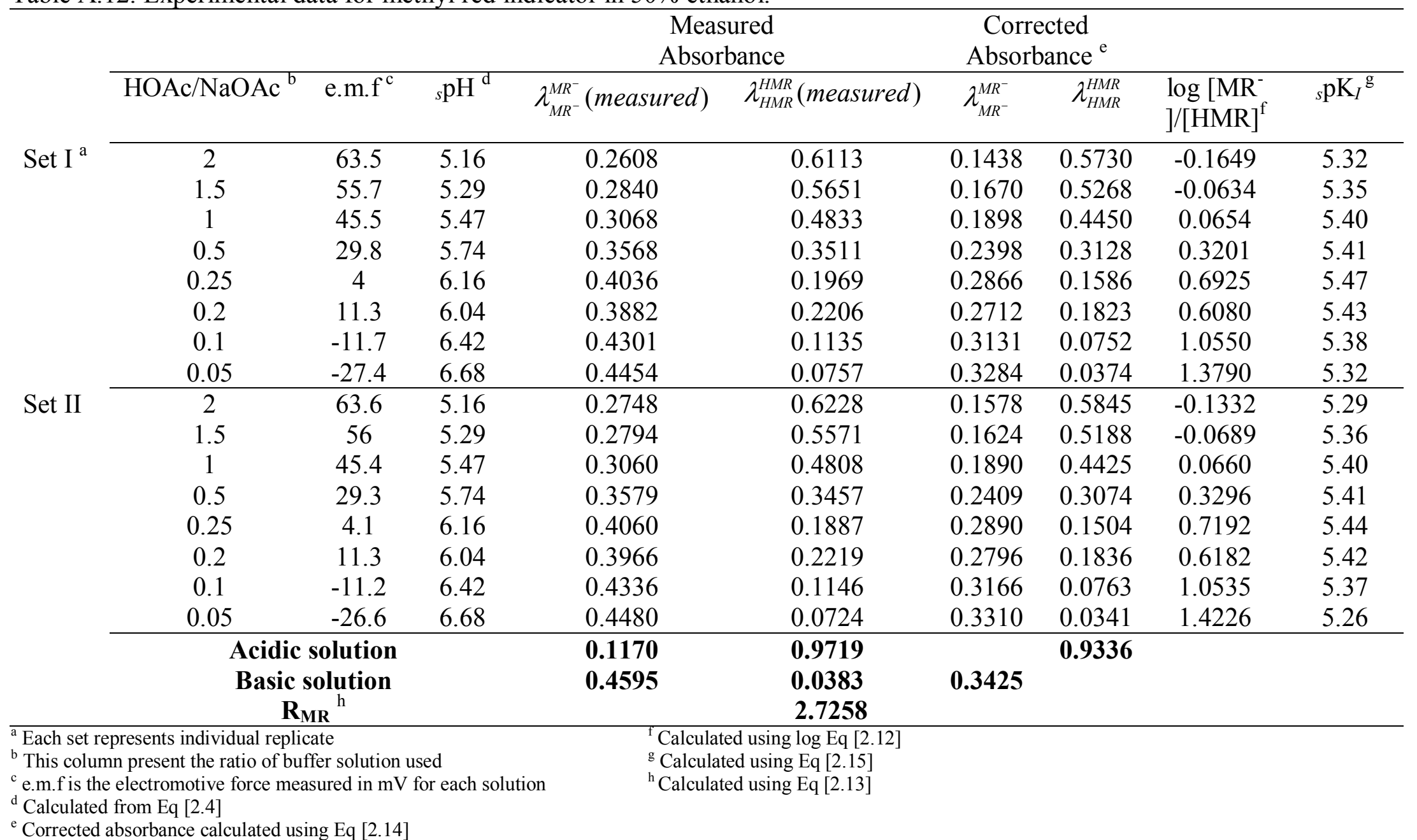


APPENDIX B

Conductance Data for $\mathrm{Ca}(\mathrm{II}), \mathrm{Cd}(\mathrm{II}), \mathrm{Zn}(\mathrm{II})$ Nitrates and $\mathrm{Ca}(\mathrm{II})$ Chlorides in Cosolvents

Table B.1. Conductance of $\mathrm{Ca}\left(\mathrm{NO}_{3}\right)_{2} \cdot 4 \mathrm{H}_{2} \mathrm{O}$ in alcohol-water mixtures at $25^{\circ} \mathrm{C}$.

\begin{tabular}{|c|c|c|c|c|c|c|c|c|c|c|c|}
\hline \multicolumn{12}{|c|}{ Methanol } \\
\hline \multicolumn{4}{|c|}{-------10\% Methanol-------- } & \multicolumn{4}{|c|}{-------30\% Methanol-------- } & \multicolumn{4}{|c|}{-------50\% Methanol-------- } \\
\hline \multicolumn{2}{|c|}{ Series I } & \multicolumn{2}{|c|}{ Series II } & \multicolumn{2}{|c|}{ Series I } & \multicolumn{2}{|c|}{ Series II } & \multicolumn{2}{|c|}{ Series I } & \multicolumn{2}{|c|}{ Series II } \\
\hline $10^{4} \mathrm{C}$ & $\Lambda$ & $10^{4} \mathrm{C}$ & $\Lambda$ & $10^{4} \mathrm{C}$ & $\Lambda$ & $10^{4} \mathrm{C}$ & $\Lambda$ & $10^{4} \mathrm{C}$ & $\Lambda$ & $10^{4} \mathrm{C}$ & $\Lambda$ \\
\hline 1.94 & 106.44 & 1.94 & 106.43 & 1.94 & 78.49 & 1.94 & 78.49 & 1.94 & 70.23 & 1.94 & 70.33 \\
\hline 3.88 & 105.56 & 3.88 & 105.53 & 3.88 & 77.80 & 3.88 & 77.80 & 3.88 & 69.61 & 3.88 & 69.68 \\
\hline 5.81 & 104.84 & 5.81 & 104.83 & 5.82 & 77.31 & 5.82 & 77.22 & 5.82 & 69.12 & 5.82 & 69.08 \\
\hline 7.74 & 104.28 & 7.74 & 104.28 & 7.75 & 76.87 & 7.75 & 76.80 & 7.75 & 68.66 & 7.75 & 68.64 \\
\hline 9.67 & 103.77 & 9.67 & 103.78 & 9.68 & 76.33 & 9.68 & 76.38 & 9.68 & 68.21 & 9.68 & 68.19 \\
\hline 11.6 & 103.38 & 11.6 & 103.40 & 11.6 & 76.08 & 11.6 & 76.03 & 11.6 & 67.76 & 11.6 & 67.74 \\
\hline 13.5 & 102.91 & 13.5 & 102.93 & 13.5 & 75.62 & 13.5 & 75.66 & 13.5 & 67.30 & 13.5 & 67.36 \\
\hline 15.4 & 102.58 & 15.4 & 102.60 & 15.4 & 75.36 & 15.4 & 75.33 & 15.4 & 66.92 & 15.4 & 67.03 \\
\hline 17.3 & 102.17 & 17.3 & 102.20 & 17.4 & 75.06 & 17.4 & 75.04 & 17.4 & 66.63 & 17.4 & 66.67 \\
\hline 19.2 & 101.81 & 19.2 & 101.79 & 19.3 & 74.79 & 19.3 & 74.71 & 19.3 & 66.36 & 19.3 & 66.40 \\
\hline \multicolumn{12}{|c|}{ Ethanol } \\
\hline \multicolumn{4}{|c|}{--------10\% Ethanol-------- } & \multicolumn{4}{|c|}{--------30\% Ethanol-------- } & \multicolumn{4}{|c|}{--------50\% Ethanol-------- } \\
\hline \multicolumn{2}{|c|}{ Series I } & \multicolumn{2}{|c|}{ Series I } & \multicolumn{2}{|c|}{ Series I } & \multicolumn{2}{|c|}{ Series I } & \multicolumn{2}{|c|}{ Series I } & \multicolumn{2}{|c|}{ Series I } \\
\hline $10^{4} \mathrm{C}$ & $\Lambda$ & $10^{4} \mathrm{C}$ & $\Lambda$ & $10^{4} \mathrm{C}$ & $\Lambda$ & $10^{4} \mathrm{C}$ & $\Lambda$ & $10^{4} \mathrm{C}$ & $\Lambda$ & $10^{4} \mathrm{C}$ & $\Lambda$ \\
\hline 1.94 & 101.64 & 1.94 & 101.34 & 1.94 & 62.99 & 1.94 & 62.91 & 1.94 & 50.24 & 1.94 & 50.33 \\
\hline 3.87 & 100.86 & 3.87 & 100.51 & 3.88 & 62.36 & 3.88 & 62.36 & 3.87 & 49.70 & 3.87 & 49.69 \\
\hline 5.80 & 100.17 & 5.80 & 99.97 & 5.81 & 61.97 & 5.82 & 62.04 & 5.80 & 49.29 & 5.81 & 49.33 \\
\hline 7.73 & 99.65 & 7.73 & 99.39 & 7.74 & 61.63 & 7.75 & 61.68 & 7.73 & 48.93 & 7.73 & 48.91 \\
\hline 9.65 & 99.17 & 9.65 & 98.98 & 9.67 & 61.25 & 9.67 & 61.28 & 9.65 & 48.50 & 9.66 & 48.59 \\
\hline 11.6 & 98.80 & 11.6 & 98.56 & 11.6 & 60.93 & 11.6 & 60.95 & 11.6 & 48.24 & 11.6 & 48.30 \\
\hline 13.5 & 98.41 & 13.5 & 98.14 & 13.5 & 60.64 & 13.5 & 60.66 & 13.5 & 47.98 & 13.5 & 48.04 \\
\hline 15.4 & 98.02 & 15.4 & 97.72 & 15.4 & 60.37 & 15.4 & 60.39 & 15.4 & 47.61 & 15.4 & 47.72 \\
\hline 17.3 & 97.67 & 17.3 & 97.35 & 17.3 & 60.18 & 17.3 & 60.13 & 17.3 & 47.45 & 17.3 & 47.49 \\
\hline 19.2 & 97.31 & 19.2 & 96.98 & 19.2 & 59.88 & 19.2 & 59.89 & 19.2 & 47.22 & 19.2 & 47.20 \\
\hline
\end{tabular}


Table B.2. Conductance of $\mathrm{Cd}\left(\mathrm{NO}_{3}\right)_{2} \cdot 4 \mathrm{H}_{2} \mathrm{O}$ in alcohol-water mixtures at $25^{\circ} \mathrm{C}$.

\begin{tabular}{|c|c|c|c|c|c|c|c|c|c|c|c|}
\hline \multicolumn{12}{|c|}{ Methanol } \\
\hline \multicolumn{4}{|c|}{-------10\% Methanol-------- } & \multicolumn{4}{|c|}{-------30\% Methanol-------- } & \multicolumn{4}{|c|}{-------50\% Methanol-------- } \\
\hline \multicolumn{2}{|c|}{ Series I } & \multicolumn{2}{|c|}{ Series II } & \multicolumn{2}{|c|}{ Series I } & \multicolumn{2}{|c|}{ Series II } & \multicolumn{2}{|c|}{ Series I } & \multicolumn{2}{|c|}{ Series II } \\
\hline $10^{4} \mathrm{C}$ & $\Lambda$ & $10^{4} \mathrm{C}$ & $\Lambda$ & $10^{4} \mathrm{C}$ & $\Lambda$ & $10^{4} \mathrm{C}$ & $\Lambda$ & $10^{4} \mathrm{C}$ & $\Lambda$ & $10^{4} \mathrm{C}$ & $\Lambda$ \\
\hline 2.10 & 93.01 & 2.09 & 92.98 & 2.10 & 68.19 & 2.10 & 68.19 & 2.10 & 61.53 & 2.10 & 61.59 \\
\hline 4.19 & 92.22 & 4.18 & 92.16 & 4.20 & 67.52 & 4.20 & 67.49 & 4.20 & 60.80 & 4.20 & 60.94 \\
\hline 6.28 & 91.46 & 6.26 & 91.55 & 6.29 & 66.92 & 6.29 & 66.97 & 6.29 & 60.27 & 6.29 & 60.38 \\
\hline 8.37 & 91.00 & 8.34 & 91.02 & 8.38 & 66.48 & 8.38 & 66.52 & 8.38 & 59.80 & 8.38 & 59.88 \\
\hline 10.5 & 90.48 & 1.04 & 90.46 & 10.5 & 66.15 & 10.5 & 66.17 & 10.5 & 59.35 & 10.5 & 59.51 \\
\hline 12.5 & 90.08 & 12.5 & 90.11 & 12.5 & 65.86 & 12.5 & 65.81 & 12.5 & 58.92 & 12.6 & 58.96 \\
\hline 14.6 & 89.68 & 14.6 & 89.68 & 14.6 & 65.41 & 14.6 & 65.50 & 14.6 & 58.62 & 14.6 & 58.66 \\
\hline 16.7 & 89.23 & 16.6 & 89.26 & 16.7 & 65.14 & 16.7 & 65.22 & 16.7 & 58.23 & 16.7 & 58.32 \\
\hline 18.7 & 88.84 & 18.7 & 88.84 & 18.8 & 64.84 & 18.8 & 64.91 & 18.8 & 57.89 & 18.8 & 58.02 \\
\hline 20.8 & 88.49 & 20.7 & 88.48 & 20.8 & 64.56 & 20.8 & 64.58 & 20.8 & 57.58 & 20.8 & 57.69 \\
\hline \multicolumn{12}{|c|}{ Ethanol } \\
\hline \multicolumn{4}{|c|}{--------10\% Ethanol-------- } & \multicolumn{4}{|c|}{-------30\% Ethanol-------- } & \multicolumn{4}{|c|}{--------50\% Ethanol-------- } \\
\hline \multicolumn{2}{|c|}{ Series I } & \multicolumn{2}{|c|}{ Series I } & \multicolumn{2}{|c|}{ Series I } & \multicolumn{2}{|c|}{ Series I } & \multicolumn{2}{|c|}{ Series I } & \multicolumn{2}{|c|}{ Series I } \\
\hline $10^{4} \mathrm{C}$ & $\Lambda$ & $10^{4} \mathrm{C}$ & $\Lambda$ & $10^{4} \mathrm{C}$ & $\Lambda$ & $10^{4} \mathrm{C}$ & $\Lambda$ & $10^{4} \mathrm{C}$ & $\Lambda$ & $10^{4} \mathrm{C}$ & $\Lambda$ \\
\hline 2.10 & 88.75 & 2.10 & 88.75 & 2.10 & 54.52 & 2.10 & 54.56 & 2.10 & 44.16 & 2.10 & 44.16 \\
\hline 4.19 & 87.96 & 4.19 & 87.93 & 4.20 & 53.91 & 4.20 & 53.93 & 4.20 & 43.56 & 4.20 & 43.56 \\
\hline 6.28 & 87.46 & 6.28 & 87.40 & 6.29 & 53.53 & 6.29 & 53.51 & 6.30 & 43.07 & 6.29 & 43.09 \\
\hline 8.36 & 86.71 & 8.36 & 86.66 & 8.38 & 53.19 & 8.38 & 53.19 & 8.39 & 42.71 & 8.38 & 42.74 \\
\hline 1.04 & 86.39 & 1.04 & 86.35 & 10.5 & 52.82 & 10.5 & 52.82 & 10.5 & 42.31 & 10.5 & 42.35 \\
\hline 12.5 & 85.88 & 12.5 & 85.85 & 12.5 & 52.50 & 12.5 & 52.52 & 12.6 & 42.15 & 12.5 & 42.10 \\
\hline 14.6 & 85.47 & 14.6 & 85.45 & 14.6 & 52.29 & 14.6 & 52.31 & 14.6 & 41.83 & 14.6 & 41.80 \\
\hline 16.6 & 85.25 & 16.7 & 85.23 & 16.7 & 52.03 & 16.7 & 52.05 & 16.7 & 41.43 & 16.7 & 41.46 \\
\hline 18.7 & 84.77 & 18.7 & 84.80 & 18.8 & 51.78 & 18.8 & 51.81 & 18.8 & 41.28 & 18.8 & 41.21 \\
\hline 20.7 & 84.45 & 20.7 & 84.44 & 20.8 & 51.60 & 20.8 & 51.62 & 20.8 & 40.93 & 20.8 & 40.92 \\
\hline
\end{tabular}


Table B.3. Conductance of $\mathrm{Zn}\left(\mathrm{NO}_{3}\right)_{2} \cdot 6 \mathrm{H}_{2} \mathrm{O}$ in alcohol-water mixtures at $25^{\circ} \mathrm{C}$.

\begin{tabular}{|c|c|c|c|c|c|c|c|c|c|c|c|}
\hline \multicolumn{12}{|c|}{ Methanol } \\
\hline \multicolumn{4}{|c|}{-------10\% Methanol-------- } & \multicolumn{4}{|c|}{-------30\% Methanol-------- } & \multicolumn{4}{|c|}{-------50\% Methanol-------- } \\
\hline \multicolumn{2}{|c|}{ Series I } & \multicolumn{2}{|c|}{ Series II } & \multicolumn{2}{|c|}{ Series I } & \multicolumn{2}{|c|}{ Series II } & \multicolumn{2}{|c|}{ Series I } & \multicolumn{2}{|c|}{ Series II } \\
\hline $10^{4} \mathrm{C}$ & $\Lambda$ & $10^{4} \mathrm{C}$ & $\Lambda$ & $10^{4} \mathrm{C}$ & $\Lambda$ & $10^{4} \mathrm{C}$ & $\Lambda$ & $10^{4} \mathrm{C}$ & $\Lambda$ & $10^{4} \mathrm{C}$ & $\Lambda$ \\
\hline 2.10 & 94.82 & 2.10 & 94.84 & 2.10 & 68.12 & 2.10 & 68.12 & 2.10 & 62.09 & 2.10 & 62.07 \\
\hline 4.19 & 94.03 & 4.20 & 93.96 & 4.20 & 67.49 & 4.20 & 67.47 & 4.19 & 61.46 & 4.19 & 61.39 \\
\hline 6.28 & 93.30 & 6.30 & 93.19 & 6.29 & 66.89 & 6.30 & 66.97 & 6.28 & 60.89 & 6.28 & 60.92 \\
\hline 8.37 & 92.75 & 8.39 & 92.61 & 8.38 & 66.44 & 8.39 & 66.49 & 8.37 & 60.53 & 8.37 & 60.56 \\
\hline 10.5 & 92.26 & 10.5 & 92.21 & 10.5 & 66.10 & 10.5 & 66.13 & 10.5 & 60.24 & 10.4 & 60.17 \\
\hline 12.5 & 91.80 & 12.6 & 91.81 & 12.6 & 65.73 & 12.6 & 65.75 & 12.5 & 59.91 & 12.5 & 59.86 \\
\hline 14.6 & 91.37 & 14.6 & 91.34 & 14.6 & 65.42 & 14.6 & 65.43 & 14.6 & 59.55 & 14.6 & 59.58 \\
\hline 16.7 & 91.00 & 16.7 & 90.95 & 16.7 & 65.08 & 16.7 & 65.09 & 16.7 & 59.24 & 16.7 & 59.32 \\
\hline 18.7 & 90.63 & 18.8 & 90.62 & 18.8 & 64.78 & 18.8 & 64.84 & 18.7 & 58.95 & 18.7 & 58.87 \\
\hline 20.8 & 90.25 & 20.8 & 90.27 & 20.8 & 64.55 & 20.8 & 64.55 & 20.8 & 58.69 & 20.8 & 58.62 \\
\hline \multicolumn{12}{|c|}{ Ethanol } \\
\hline \multicolumn{4}{|c|}{-------10\% Ethanol-------- } & \multicolumn{4}{|c|}{-------30\% Ethanol-------- } & \multicolumn{4}{|c|}{--------50\% Ethanol-------- } \\
\hline \multicolumn{2}{|c|}{ Series I } & \multicolumn{2}{|c|}{ Series I } & \multicolumn{2}{|c|}{ Series I } & \multicolumn{2}{|c|}{ Series I } & \multicolumn{2}{|c|}{ Series I } & \multicolumn{2}{|c|}{ Series I } \\
\hline $10^{4} \mathrm{C}$ & $\Lambda$ & $10^{4} \mathrm{C}$ & $\Lambda$ & $10^{4} \mathrm{C}$ & $\Lambda$ & $10^{4} \mathrm{C}$ & $\Lambda$ & $10^{4} \mathrm{C}$ & $\Lambda$ & $10^{4} \mathrm{C}$ & $\Lambda$ \\
\hline 2.10 & 87.44 & 2.10 & 87.58 & 2.10 & 54.20 & 2.10 & 54.22 & 2.10 & 44.42 & 2.10 & 44.44 \\
\hline 4.20 & 86.69 & 4.19 & 86.69 & 4.19 & 53.62 & 4.20 & 53.66 & 4.20 & 43.82 & 4.19 & 43.86 \\
\hline 6.29 & 86.13 & 6.28 & 86.14 & 6.29 & 53.15 & 6.30 & 53.24 & 6.30 & 43.41 & 6.29 & 43.40 \\
\hline 8.37 & 85.68 & 8.37E & 85.58 & 8.37 & 52.80 & 8.39 & 52.84 & 8.39 & 43.04 & 8.37 & 42.97 \\
\hline 10.5 & 85.16 & 10.5 & 85.08 & 10.5 & 52.52 & 10.5 & 52.52 & 10.5 & 42.68 & 10.5 & 42.64 \\
\hline 12.5 & 84.75 & 12.5 & 84.78 & 12.5 & 52.19 & 12.6 & 52.25 & 12.6 & 42.37 & 12.5 & 42.35 \\
\hline 14.6 & 84.35 & 14.6 & 84.38 & 14.6 & 51.96 & 14.6 & 52.00 & 14.6 & 41.96 & 14.6 & 41.95 \\
\hline 16.7 & 84.01 & 16.7 & 84.05 & 16.7 & 51.69 & 16.7 & 51.71 & 16.7 & 41.72 & 16.7 & 41.72 \\
\hline 18.7 & 83.66 & 18.7 & 83.69 & 18.7 & 51.43 & 18.8 & 51.49 & 18.8 & 41.38 & 18.7 & 41.44 \\
\hline 20.8 & 83.35 & 20.8 & 83.38 & 20.8 & 51.24 & 20.8 & 51.23 & 20.8 & 41.17 & 20.8 & 41.18 \\
\hline
\end{tabular}


Table B.4. Conductance of $\mathrm{CaCl}_{2}$ in methanol-water mixtures at $25^{\circ} \mathrm{C}$.

\begin{tabular}{|c|c|c|c|c|c|c|c|}
\hline \multicolumn{4}{|c|}{------------10\% Methanol---------- } & \multicolumn{4}{|c|}{-----------30\% Methanol---------- } \\
\hline \multicolumn{2}{|c|}{ Series I } & \multicolumn{2}{|c|}{ Series II } & \multicolumn{2}{|c|}{ Series I } & \multicolumn{2}{|c|}{ Series II } \\
\hline $10^{4} \mathrm{C}$ & $\Lambda$ & $10^{4} \mathrm{C}$ & $\Lambda$ & $10^{4} \mathrm{C}$ & $\Lambda$ & $10^{4} \mathrm{C}$ & $\Lambda$ \\
\hline 1.99 & 107.27 & 1.98 & 106.78 & 1.99 & 75.98 & 1.99 & 76.13 \\
\hline 3.97 & 105.06 & 3.96 & 105.68 & 3.97 & 75.17 & 3.97 & 75.38 \\
\hline 5.95 & 104.09 & 5.94 & 104.86 & 5.95 & 74.53 & 5.95 & 74.65 \\
\hline 7.92 & 103.27 & 7.91 & 104.12 & 7.93 & 74.00 & 7.93 & 74.20 \\
\hline 9.89 & 102.62 & 9.88 & 103.41 & 9.90 & 73.50 & 9.90 & 73.66 \\
\hline 11.9 & 102.14 & 11.8 & 102.72 & 11.9 & 72.86 & 11.9 & 73.24 \\
\hline 13.8 & 101.67 & 13.8 & 102.04 & 13.8 & 72.49 & 13.8 & 72.66 \\
\hline 15.8 & 101.22 & 15.8 & 101.68 & 15.8 & 72.17 & 15.8 & 72.32 \\
\hline 17.7 & 100.84 & 17.7 & 101.25 & 17.7 & 71.71 & 17.8 & 71.89 \\
\hline 19.7 & 100.81 & 19.7 & 100.78 & 19.7 & 71.36 & 19.7 & 71.51 \\
\hline \multicolumn{4}{|c|}{----------50\% Methanol---------- } & \multicolumn{4}{|c|}{-----------70\% Methanol---------- } \\
\hline \multicolumn{2}{|c|}{ Series I } & \multicolumn{2}{|c|}{ Series II } & \multicolumn{2}{|c|}{ Series I } & \multicolumn{2}{|c|}{ Series II } \\
\hline $10^{4} \mathrm{C}$ & $\Lambda$ & $10^{4} \mathrm{C}$ & $\Lambda$ & $10^{4} \mathrm{C}$ & $\Lambda$ & $10^{4} \mathrm{C}$ & $\Lambda$ \\
\hline 1.99 & 65.76 & 1.98 & 65.77 & 1.98 & 68.42 & 1.98 & 68.13 \\
\hline 3.97 & 64.77 & 3.96 & 64.83 & 3.96 & 67.38 & 3.97 & 66.96 \\
\hline 5.95 & 64.08 & 5.94 & 64.30 & 5.93 & 66.49 & 5.94 & 66.16 \\
\hline 7.92 & 63.51 & 7.91 & 63.69 & 7.90 & 65.73 & 7.91 & 65.34 \\
\hline 9.89 & 63.09 & 9.88 & 63.15 & 9.87 & 65.10 & 9.88 & 64.67 \\
\hline 11.9 & 62.58 & 11.8 & 62.64 & 11.8 & 64.45 & 11.8 & 64.07 \\
\hline 13.8 & 62.16 & 13.8 & 62.22 & 13.8 & 63.92 & 13.8 & 63.52 \\
\hline 15.8 & 61.74 & 15.8 & 61.79 & 15.7 & 63.36 & 15.8 & 62.93 \\
\hline 17.7 & 61.36 & 17.7 & 61.47 & 17.7 & 62.82 & 17.7 & 62.43 \\
\hline 19.7 & 60.97 & 19.7 & 61.07 & 19.6 & 62.34 & 19.7 & 61.93 \\
\hline
\end{tabular}


Table B.5. Conductance of $\mathrm{CaCl}_{2}$ in ethanol-water mixtures at $25^{\circ} \mathrm{C}$.

\begin{tabular}{|c|c|c|c|c|c|c|c|}
\hline \multicolumn{4}{|c|}{------------10\% Ethanol------------ } & \multicolumn{4}{|c|}{------------30\% Ethanol------------ } \\
\hline \multicolumn{2}{|c|}{ Series I } & \multicolumn{2}{|c|}{ Series II } & \multicolumn{2}{|c|}{ Series I } & \multicolumn{2}{|c|}{ Series II } \\
\hline $10^{4} \mathrm{C}$ & $\Lambda$ & $10^{4} \mathrm{C}$ & $\Lambda$ & $10^{4} \mathrm{C}$ & $\Lambda$ & $10^{4} \mathrm{C}$ & $\Lambda$ \\
\hline 1.99 & 97.23 & 1.98 & 97.58 & 1.98 & 60.24 & 1.98 & 60.42 \\
\hline 3.97 & 96.29 & 3.95 & 96.62 & 3.95 & 59.38 & 3.95 & 59.27 \\
\hline 5.94 & 95.38 & 5.92 & 95.89 & 5.92 & 58.62 & 5.92 & 58.72 \\
\hline 7.92 & 94.73 & 7.89 & 95.19 & 7.89 & 58.20 & 7.88 & 58.30 \\
\hline 9.89 & 94.06 & 9.85 & 94.60 & 9.86 & 57.66 & 9.84 & 57.76 \\
\hline 11.9 & 93.48 & 11.8 & 93.99 & 11.8 & 57.16 & 11.8 & 57.25 \\
\hline 13.8 & 92.95 & 13.8 & 93.43 & 13.8 & 56.74 & 13.8 & 56.76 \\
\hline 15.8 & 92.45 & 15.7 & 92.90 & 15.7 & 56.31 & 15.7 & 56.46 \\
\hline 17.7 & 91.96 & 17.7 & 92.40 & 17.7 & 55.93 & 17.7 & 56.02 \\
\hline 19.7 & 91.49 & 19.6 & 91.92 & 19.6 & 55.59 & 19.6 & 55.63 \\
\hline \multicolumn{4}{|c|}{-----------50\% Ethanol------------ } & \multicolumn{4}{|c|}{------------70\% Ethanol------------- } \\
\hline \multicolumn{2}{|c|}{ Series I } & \multicolumn{2}{|c|}{ Series II } & \multicolumn{2}{|c|}{ Series I } & \multicolumn{2}{|c|}{ Series II } \\
\hline $10^{4} \mathrm{C}$ & $\Lambda$ & $10^{4} \mathrm{C}$ & $\Lambda$ & $10^{4} \mathrm{C}$ & $\Lambda$ & $10^{4} \mathrm{C}$ & $\Lambda$ \\
\hline 1.99 & 47.16 & 1.99 & 47.23 & 1.99 & 42.38 & 1.99 & 42.29 \\
\hline 3.97 & 46.32 & 3.97 & 46.44 & 3.97 & 41.38 & 3.97 & 41.35 \\
\hline 5.95 & 45.70 & 5.95 & 45.89 & 5.95 & 40.70 & 5.95 & 40.60 \\
\hline 7.92 & 45.35 & 7.93 & 45.29 & 7.92 & 40.13 & 7.92 & 40.01 \\
\hline 9.90 & 44.91 & 9.90 & 44.95 & 9.90 & 39.61 & 9.89 & 39.52 \\
\hline 11.9 & 44.63 & 11.9 & 44.49 & 11.9 & 39.11 & 11.9 & 39.04 \\
\hline 13.8 & 44.37 & 13.8 & 44.03 & 13.8 & 38.70 & 13.8 & 38.63 \\
\hline 15.8 & 43.80 & 15.8 & 43.94 & 15.8 & 38.26 & 15.8 & 38.21 \\
\hline 17.7 & 43.37 & 17.8 & 43.55 & 17.7 & 37.93 & 17.7 & 37.83 \\
\hline 19.7 & 42.98 & 19.7 & 43.19 & 19.7 & 37.58 & 19.7 & 37.49 \\
\hline
\end{tabular}


Table B.6. Conductance of $\mathrm{CaCl}_{2}$ in acetone-water mixtures at $25^{\circ} \mathrm{C}$.

\begin{tabular}{|c|c|c|c|c|c|c|c|}
\hline \multicolumn{4}{|c|}{-----------10\% Acetone------------ } & \multicolumn{4}{|c|}{----------30\% Acetone----------- } \\
\hline \multicolumn{2}{|c|}{ Series I } & \multicolumn{2}{|c|}{ Series II } & \multicolumn{2}{|c|}{ Series I } & \multicolumn{2}{|c|}{ Series II } \\
\hline $10^{4} \mathrm{C}$ & $\Lambda$ & $10^{4} \mathrm{C}$ & $\Lambda$ & $10^{4} \mathrm{C}$ & $\Lambda$ & $10^{4} \mathrm{C}$ & $\Lambda$ \\
\hline 1.98 & 110.19 & 1.98 & 109.93 & 1.98 & 84.33 & 1.98 & 85.00 \\
\hline 3.96 & 108.94 & 3.96 & 108.78 & 3.96 & 82.83 & 3.96 & 83.40 \\
\hline 5.94 & 107.88 & 5.94 & 107.79 & 5.94 & 81.55 & 5.94 & 81.92 \\
\hline 7.91 & 107.16 & 7.91 & 106.85 & 7.91 & 80.45 & 7.91 & 80.85 \\
\hline 9.88 & 106.76 & 9.88 & 106.22 & 9.88 & 79.62 & 9.88 & 79.72 \\
\hline 11.8 & 106.11 & 11.8 & 105.58 & 11.8 & 78.66 & 11.8 & 79.00 \\
\hline 13.8 & 105.39 & 13.8 & 105.01 & 13.8 & 77.71 & 13.8 & 78.29 \\
\hline 15.8 & 104.74 & 15.8 & 104.35 & 15.8 & 77.14 & 15.8 & 77.65 \\
\hline 17.7 & 104.21 & 17.7 & 103.86 & 17.7 & 76.32 & 17.7 & 76.88 \\
\hline 19.7 & 103.64 & 19.7 & 103.44 & 19.7 & 75.83 & 19.7 & 76.28 \\
\hline \multicolumn{4}{|c|}{----------50\% Acetone----------- } & \multicolumn{4}{|c|}{----------70\% Acetone----------- } \\
\hline \multicolumn{2}{|c|}{ Series I } & \multicolumn{2}{|c|}{ Series II } & \multicolumn{2}{|c|}{ Series I } & \multicolumn{2}{|c|}{ Series II } \\
\hline $10^{4} \mathrm{C}$ & $\Lambda$ & $10^{4} \mathrm{C}$ & $\Lambda$ & $10^{4} \mathrm{C}$ & $\Lambda$ & $10^{4} \mathrm{C}$ & $\Lambda$ \\
\hline 1.99 & 73.07 & 1.98 & 73.04 & 1.99 & 71.04 & 1.99 & 70.89 \\
\hline 3.97 & 71.26 & 3.96 & 70.94 & 3.97 & 68.59 & 3.97 & 68.06 \\
\hline 5.95 & 70.11 & 5.94 & 69.53 & 5.95 & 66.60 & 5.95 & 66.07 \\
\hline 7.92 & 68.92 & 7.91 & 68.50 & 7.92 & 64.88 & 7.92 & 64.37 \\
\hline 9.89 & 67.73 & 9.88 & 67.51 & 9.89 & 63.58 & 9.89 & 63.07 \\
\hline 11.9 & 66.96 & 11.8 & 66.61 & 11.9 & 62.47 & 11.9 & 61.89 \\
\hline 13.8 & 66.21 & 13.8 & 65.85 & 13.8 & 61.34 & 13.8 & 60.99 \\
\hline 15.8 & 65.47 & 15.8 & 65.03 & 15.8 & 60.44 & 15.8 & 59.95 \\
\hline 17.7 & 64.57 & 17.7 & 64.41 & 17.7 & 59.52 & 17.7 & 59.15 \\
\hline 19.7 & 63.91 & 19.7 & 63.73 & 19.7 & 58.70 & 19.7 & 58.31 \\
\hline
\end{tabular}



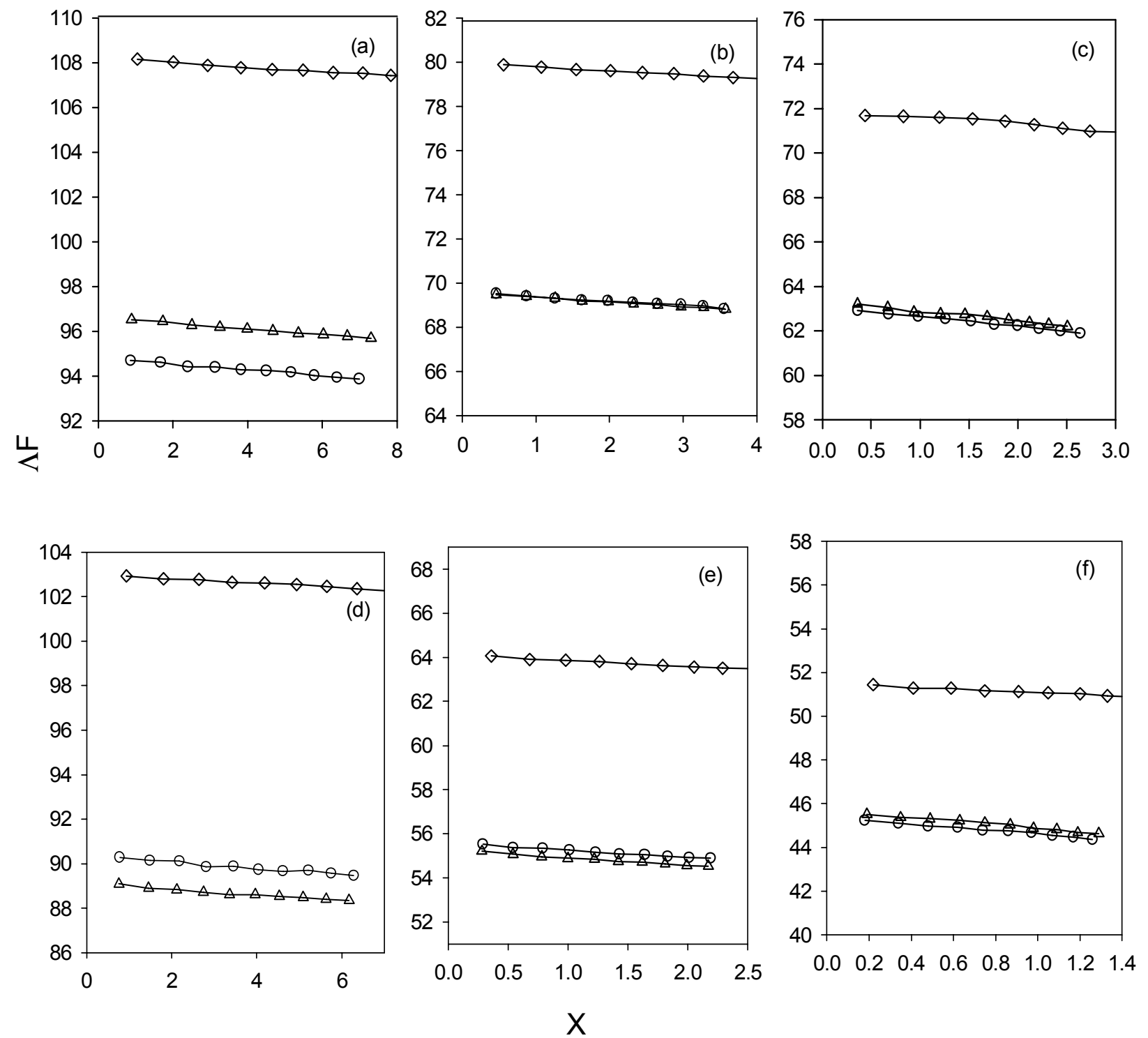

Figure B.1. Fuoss and Edelson plots based on Eq [3.6]; $\diamond \mathrm{Ca}$ (II), o Cd (II) and $\Delta$ $\mathrm{Zn}$ (II) nitrates at $25 \mathrm{oC}$ : (a) $10 \% \mathrm{MeOH}$, (b) $30 \% \mathrm{MeOH}$, (c) $50 \% \mathrm{MeOH}$, (d) $10 \%$ $\mathrm{EtOH}$, (e) $30 \% \mathrm{EtOH}$, (f) $50 \% \mathrm{EtOH}$. 

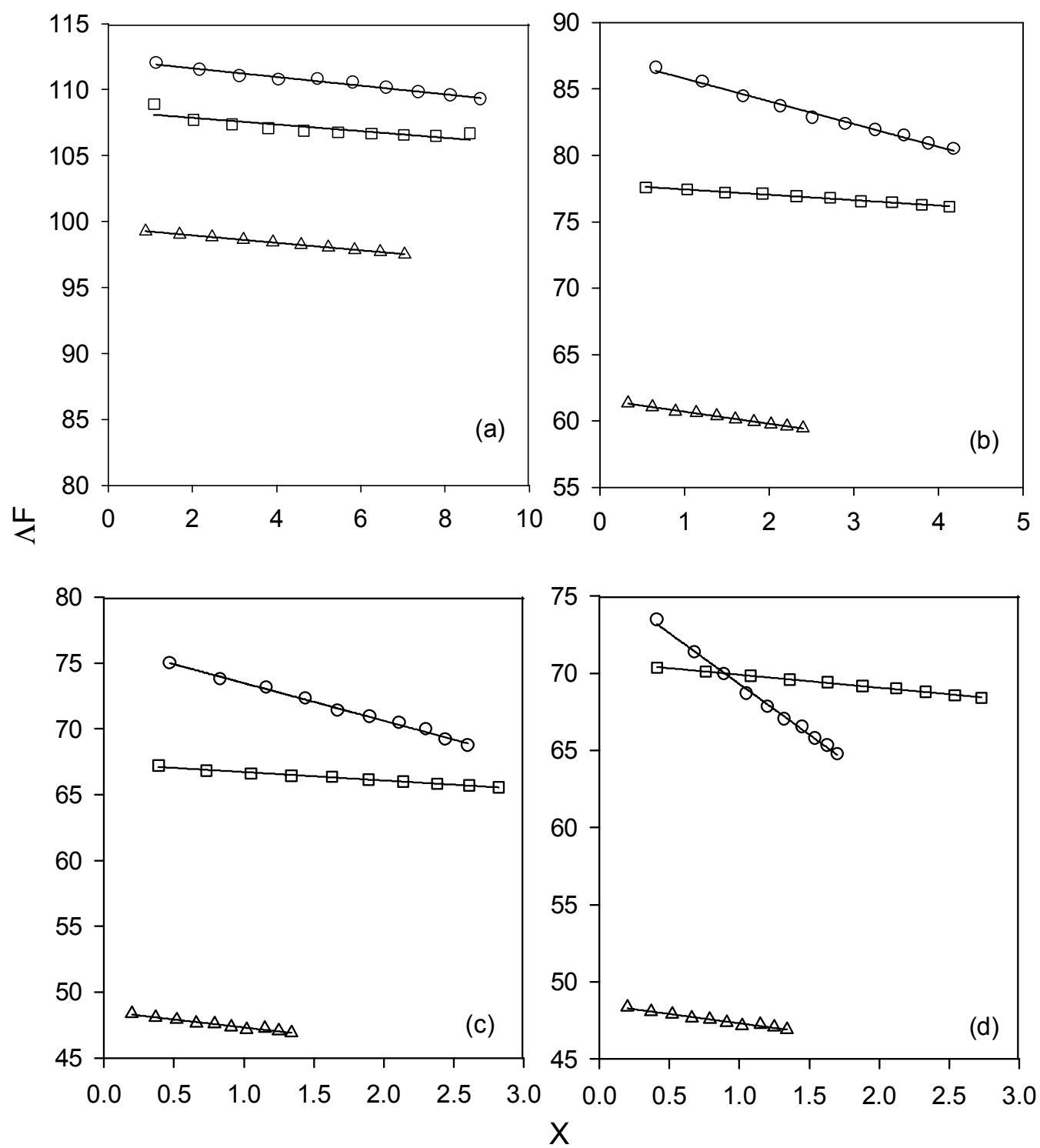

Figure B.2. Fuoss and Edelson plots for $\mathrm{CaCl}_{2}$ based on $\mathrm{Eq}$ [3.6]; $\square$ methanol, o ethanol, and $\Delta$ acetone-water mixtures at $25^{\circ} \mathrm{C}$. (a) $10 \% \mathrm{wt}$, (b) $30 \% \mathrm{wt}$, (c) $50 \% \mathrm{wt}$, (d) $70 \% \mathrm{wt}$. 


\section{LITERATURE CITED}

Abollino, O., M. Aceto, M. Malandrino, C. Sarzanini and E. Mentasti. 2003. Adsorption of heavy metals on Na-montmorillonite. Effect of $\mathrm{pH}$ and organic substances. Water Research. 37:1619-1627.

Amrhein, C. and D.L. Suarez. 1991. Sodium-calcium exchange with anion exclusion and weathering corrections. Soil Sci. Soc. Am. J. 55:698-706.

Ananthaswamy, J., B. Sethuram and T. Navaneeth Rao. 1979. Conductometric study of ion-ion and ion-solvent interactions. I. Conductances of silver acetate in $0-50 \%(w / w)$ methanol-water mixtures at $35^{\circ}$ C. Bull. Chem. Soc. Jpn. 52:30763079 .

Anderson, D.C., K.W. Brown and J.C. Thomas. 1985. Conductivity of compacted clay soils to water and organic liquids. Waste Management \& Research. 3:339349.

Anderson, J.S. and G. Sposito. 1991. Cesium-adsorption method for measuring accessible structural charge. Soil Sci. Soc. Am. J. 55:1569-1576.

Artiola-Fortuny, J. and W.H. Fuller. 1982. Phenols in municipal solid waste leachates and their attenuation by soil clays. Soil Sci. 133:218-227.

Atkins, P. 1998. Physical Chemistry. $6^{\text {th }}$ edition. W.H. Freeman and Company. New York.

Barshad, I. 1952. Factors affecting the interlayer expansion of vermiculite and montmorillonite with organic substances. Soil Sci. Soc. Proceedings: 176-182.

Bates, R. G. 1973. Determination of pH: Theory and Practice; Wiley. New York.

Bedient, P.B., A.M. Asce, N.K. Springer, E. Baca, T.C. Bouvette, S.R. Hutchins and M.B. Tomson. 1983. Groundwater transport from wastewater infiltration. $J$. Environ. Sci. 109:485-501.

Berkheiser, V. and M.M. Mortland. 1975. Variability in exchange ion position in smectites: dependence on interlayer solvent. Clays and Clay Minerals. 23:404410.

Bjerrum, N. 1926. Ionic association. I. Influence of ionic association on the activity of ions at moderate degrees of association. Kgl. Danske Videnskab. Selskab. 7:1-48.

Bockris, J. O’M. and A.K.N. Reddy. 1973. Modern Electrochemistry. Vol. 1. 
Plenum Press, New York.

Bosch E, and M. Roses. 1988. Ionic equilibria in neutral amphiprotic solvents: variation of electrolyte dissociation constants in tert-butyl alcohol with addition of a second solvent. Anal. Chem. 60:2008-2013.

Braun, R. D. 1982. Introduction to Chemical Analysis. McGraw-Hill, New York. pp.197-199.

Brindley, G.W., K. Wiewiora and A. Wiewiora. 1969. Intercrystalline swelling of montmorillonite in some water-organic mixtures (Clay-Organic studies XVII). The American Mineralogist 54:1635-1644.

Broadwater, T.L., T.J. Murphy and D.F. Evans. 1976. Conductance of binary asymmetric electrolytes in methanol. J. Phy. Chem. 80:753-757.

Brown K.W. and J.C. Thomas. 1987. A mechanism by which organic liquids increase the hydraulic conductivity of compacted clay materials. Soil Sci. Soc. Am. J. 51:1451-1459.

Brusseau, M. L., A.L. Wood and P.S. Rao. 1991. Influence of organic cosolvents on the sorption kinetics of hydrophobic organic chemicals. Environ. Sci. Technol. 25: 903-910.

Doe, H., T. Kitagawa, and K. Sasabe. 1984. Conductometric study of some metal(II) perchlorates in methanol. J. Phys. Chem. 88: 3341-3345.

Doe, H., K. Wakamiya, C. Yoshida, H.Ozaki, K.N. Soe and T. Kitagawa. 1987. Potentiometric study of cadmium(II) halide and thiocyanate complexes in methanol. Inorg. Chem. 26:2244-2247.

Doe, H., H. Ohe, H. Matoba, A. Ichimura and T. Kitagawa. 1990. Conductometric study of calcium(II), strontium(II), and barium(II) perchlorates in methanolethylene glycol mixtures. Bull. Chem. Soc. Japan. 63:2785-2789.

Echeverria, J.C., E. Churio, and J.J. Garrido. 2002. Retention mechanisms of Cd on illite. Clays and Clay Minerals. 50:614-623.

Elrashidi, M.A. and G.A. O'Connor. 1982. Boron Sorption and desorption in soils. Soil Sci. Soc. Am. J. 46:27-31.

Evangelou, V.P. 1998. Soil minerals and surface chemical properties. In Environmental Soil and Water Chemistry: Principles and Applications. New York: Wiley. P. 100-224. 
Evers, E.C. and A.G. Knox. 1951. Conductivity studies in methanol. J. Phys. Chem. 73:1739-1744.

Fernandez, F. and R.M. Quigley. 1985. Hydraulic conductivity of natural clays permeated with simple liquid hydrocarbons. Can. Geotech. J. 22:205-214.

Friedman, N.J, and R.A. Plane. 1963. Solvation of copper(II) ion in acetone-water and ethanol-water solutions. Inorg. Chem. 2:11-14

Fuoss, R.M. 1958. Ionic association. III. The equilibrium between ion pairs and free ions. J. Am. Chem. Soc. 80:5059-61.

Fuoss, M.R. and D. Edelson. 1951. Bolaform electrolytes. I. Di- $(\beta-$ trimethylammonium ethyl) succinate dibromide and related compounds. J. Phys. Chem. 73:269-273.

Fuoss, R.M. and L. Onsager. 1957. Conductance of unassociated electrolytes. $J$. Phys. Chem. 61:668-682.

Fuoss, R.M. and L. Onsager. 1958. The kinetic term in electrolytic conductance. J. Phys. Chem. 62:1339-1340.

Gaizer, F., H.B. Silber and J. Lázár. 1985. Stability constants of zinc halide complexes in DMSO-water and DMF-water mixtures. Polyhedron. 4:1467-1470.

Ghasemi, J., A. Niazi, M. Kubista and A. Elbergali. 2002. Spectrophotometric determination of acidity constants of 4-(2-pyridylazo) resorcinol in binary methanol-water mixtures. Analytica Chimica Acta 455:335-342.

Green, W. J., G.F. Lee, R.A. Jones and T. Pall. 1983. Interaction of clay soils with water and organic solvents: implications for the disposal of hazardous wastes. Environ. Sci. Technol. 17:278-282.

Handbook of Chemistry and Physics (2003-2004), 84 ${ }^{\text {th }}$ edition. CRC Press, Bocaraton, Fl.

Hawes, J.L. and R.L. Kay. 1965. Ionic association of potassium and cesium chlorides in ethanol-water mixtures from conductance measurements at $25^{\circ} \mathrm{C} . J$. Phy. Chem. 69:2420-2431.

Hiemenz, P.C. 1986. Principles of Colloid and Surface Chemistry. $2^{\text {nd }}$ edition. Marcel Dekker, INC. New York and Basel.

Hirsch, D., S. Nir, A. Banin. 1989. Prediction of Cadmium complexation in solution and adsorption to montmorillonite. Soil Sci. Soc. Am. J. 53:716-721.

Israelachvili, J.N. 1987. Solvation forces and liquid structure, as probed by direct 
force measurements. Acc. Chem. Res. 20:415-421.

Izutsu, K. 2002. Electrochemistry in Nonaqueous Solutions. Wiley-VCH, Weinheim.

Jackson, M.L. 1956. Dispersion of Soil Minerals. In Soil Chemical Analysis Advanced Course. $5^{\text {th }}$ print.

Jackson, M.L.1974. Soil chemical analysis-advanced course. Dept. of Soil Science, Univ. of Wisconsin, Madison, WI.

Janz, G.J. and R.T.Tomkins. 1973. Non-Aqueous Electrolytes Handbook. Volume I. Academic Press, Inc.

Johnston, C.T. and E. Tombácz. 2002. Surface Chemistry of soil minerals. In Soil Mineralogy with Environmental Applications. No.7. American Society of Agronomy, Madison, WI.

Kielland, J. 1937. Individual activity coefficients of ions in aqueous solutions. $J$. Phys. Chem. 60:1675-1678.

Kinniburgh, D.G., J.K. Syers and M.L. Jackson. 1975. Specific adsorption of trace amounts of calcium and strontium by hydrous oxides of iron and aluminum. Soil Sci. Soc. Am. Proc. 39:464-470.

Kolthof, M. 1953. Acid-base indicators. $2^{\text {nd }}$ edition. The Macmillan Company, New York.

Kolthoff, I.M. 1974. Acid-base equilibria in dipolar aprotic solvents. Anal. Chem. 46:1992-2003.

Kosmulski, M. 1990. Effect of n-alcohols on the surface charge density and adsorption of supporting electrolytes on aluminas. J. Coll. Interf. Sci. 135:590593.

Kosmulski, M. 1993. Adsorption of methanol and supporting electrolytes on silica and alumina in mixed solvent systems. J. Coll. Interf. Sci. 156:305-310.

Kosmulski, M. 1994. Standard enthalpies of ion adsorption onto oxides from aqueous solutions and mixed solvents. Colloids Surfaces A: Physicochemical and Engineering Aspects 83:237-243.

Kosmulski, M. 1995. Oxide/electrolyte interface: electric double layer in mixed solvent systems. Colloids and Surfaces A: Physicochemical and Engineering Aspects 95:91-100. 
Kosmulski, M. 1996. The effect of the nature of the organic cosolvent on surface charge density of silica in mixed solvents. J. Coll. Interf. Sci. 179:128-135.

Kosmulski, M. 1999. Zeta potentials in nonaqueous media: how to measure and control them. Colloids and Surfaces A: Physicochemical and Engineering Aspects 159:277-281.

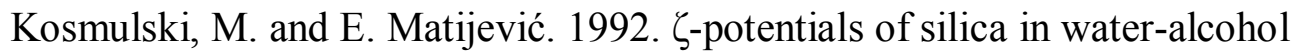
mixtures. Langmuir. 8:1060-1064.

Kunze, G.W. and J.B. Dixon.1986. Pretreatment for mineralogical analysis. In Methods of Soil Analysis, Part I. Physical and Mineralogical Methods-Agronomy Monograph no. 9 ( $2^{\text {nd }}$ edition).

Lee, W. H.; Wheaton, R. J. 1978. Analysis of conductance data for associated unsymmetrical electrolytes. J. Phys. Chem. 82:605-8.

Lindsay, W.L. 1979. Chemical Equilibria in Soils. Wiley \& Sons. New York.

Loeppert, R.H., L.W. Zelazny and B.G. Volk. 1977. Acidic properties of kaolinite in water and acetonitrile. Soil Sci. Soc. Am. J. 41:1101-1106.

Loeppert, R.H., L.W. Zelazny and B.G. Volk. 1979. Titration of pH-dependent sites of kaolinite in water and selected nonaqueous solvents. Clays and Clay Minerals. 27: 57-62.

Martell, A.E. and R.J. Motekaitis. 1992. Determination and Use of Stability Constants. $2^{\text {nd }}$ edition. Wiley-VCH.

McDonald, L.M. 1995. Cosolvent effects on the sorption of Sr, Zn, and Cd to bentonite. Ph.D. thesis, Univ. of Kentucky, Kentucky, U.S.

Miller, R.M., L.S. Stitzer, J.F. Artiola and W.H. Fuller. 1992. Effect of four alcohols on adsorption and movement of $\mathrm{Cd}$, nickel and zinc through soils. Chemosphere. 24:1855-1866.

Mui K.K. and W.E. McBride. 1974. The stability of some metal complexes in mixed solvents. Can. J. Chem. 52:1821-1833.

Murray, R.S and J. P. Quirk. 1982. The physical swelling of clays in solvents. Soil Sci. Soc. Am. J. 46:865-868.

Mussini, T., A.K. Covington, P. Longhi and S. Rondinini. 1985. Criteria for standardization of $\mathrm{pH}$ measurements in organic solvents and water + organic solvent mixtures of moderate to high permittivity. Pure \& Appl. Chem. 57: 865876. 
Nancollas, G.H. and M.N. Tomson. 1982. Guidelines for the determination of stability constants. Pure \& Appl. Chem. 54: 2675-2692.

Nkedi- Kizza, P., P.S.C. Rao and A.G. Hornsby.1985. Influence of organic cosolvents on sorption of hydrophobic solvents. Soil Science. 108:11-23.

Olejnik, S., A. M. Posner and J. P. Quirk. 1974. Swelling of montmorillonite in polar organic liquids. Clays and Clay Minerals. 22: 361-365.

Naidu, R., N.S. Bolan, R.S. Kookana, K.G. Tiller. 1994. Ionic-strength and pH effects on the sorption of cadmium and the surface charge of soils. Euro. J. Soil Sci. 45:419-429.

Nir, S. Specific and non-specific cation adsorption to clays: Solution concentration and surface potentials. Soil Sci. Soc. Am. J. 50:52-57.

Popovytch, O. and R.P.T. Tomkins. 1981. Nonaqueous Solution Chemistry. Wiley \& Sons, NY.

Rao, P.S.C., L.S. Lee and R. Pinal.1990. Cosolvency and soprtion of hydrophobic organic chemicals. Environ. Sci. Technol. 24:647-654.

Reichardt, C. 1988. Solvents and Solvents Effects in Organic Chemistry. $2^{\text {nd }}$ edition. VCH, Weinheim.

Riley, R.G and J.M. Zachara. 1992. Chemical Contaminants on DOE Land and Selection of Contaminant Mixtures for Subsurface Science Research. US Department of Energy. Office of Energy Research, Subsurface Science Program. Washington, D.C. 20585.

Rondinini, S., P.Longhi, P.R. Mussini and T. Mussini. 1987. Autoprotolysis constants in nonaqueous solvents and aqueous organic solvent mixtures. Pure \& Appl. Chem. 59: 1693-1987.

Rondinini, S., P.R. Mussini, T. Mussini and A. Vertova. 1998. $\mathrm{pH}$ measurements in non-aqueous and mixed solvents: predicting $\mathrm{pH}(\mathrm{PS})$ of potassium hydrogen phthalate for alcohol-water mixtures. Pure Appl. Chem. 70:1419-1422.

Robert-Baldo, G.M., Morris, R.H. Byrne.1985. Spectrophotometric Determination of Seawater pH Using Phenol Red. Anal. Chem. 57:2564.

Rosés, M., C. Ràfols and E. Bosch. 1993. Autoprotolysis in aqueous organic solvent mixtures. Anal. Chem. 65:2294-2299.

Salomon, M. 1989. Electrolyte solvation in aprotic solvents. J. Power Sources. 26:9-21. 
Sawhney, B.L and R.P. Kozloski. 1984. Organic pollutants in leachates from landfill sites. J. Environ. Qual. 13:349-352.

Schulthess, C.P., and C.P. Huang. 1990. Adsorption of heavy metals by silicon and aluminum oxide surfaces on clay minerals. Soil Sci. Soc. Am. J. 54:679-688.

Shainberg, I., and W.D. Kemper. 1967. Ion exchange equilibria on montmorillonite. Soil Science. 103:4-9.

Shedlovsky. 1932. The electrolytic conductivity of some univalent-univalent electrolytes in water at $25^{\circ}$ C. J. Phys. Chem. 54:1411-1429.

Sheets, P.J. and W.H. Fuller. 1986. Transport of cadmium by organic solvents through soils. Soil Sci. Soc. Am. J. 50:24-28.

Smith, R. M. and A.E. Martell. 1976. Critical Stability Constants. Vol. 4: Inorganic Complexes.

Spivey, H.O. and T. Shedlovsky. 1967. Studies of electrolytic conductance in alcohol-water mixtures. I. Hydraulic acid, sodium chloride, and sodium acetate at 0, 25, and $35^{\circ}$ in ethanol-water mixtures. J. Phy. Chem. 71:2165-2171.

Sposito, G. 1980. Derivation of the Freundlich equation for ion exchange reactions in soils. Soil Sci. Soc. Amer. J. 44:652-654.

Sposito, G. 1981. The Thermodynamics of Soil Solutions. Oxford University Press, New York.

Sposito, G. 1984. The Surface Chemistry of Soils. Oxford University Press, London.

Sposito G, K. Holtzclaw, L. Charlet, C. Jouany and A.L. Page.1983. Sodiumcalcium and sodium-magnesium exchange on Wyoming bentonite in perchlorate and chloride background ionic media. Soil. Sci. Soc. Am. J. 47:51-56.

Sposito, G., N.T., Skipper, R. Sutton, S. Park. A.K. Soper and J.A. Greathouse. 1999. Surface geochemistry of the clay minerals. Proc. Natl. Acad. Sci. 96:33583364.

Stul, M. S., J.B. Uytterhoeven and J. Bock. 1979. The adsorption of n-aliphatic alcohols from dilute aqueous solutions on $\mathrm{RNH}_{3}$-montmorillonites. II. Interlamellar association of the adsorbate. Clays and Clay Minerals. 27:377-386.

Timmermans, J. 1960. The Physico-Chemical Constants of Binary Systems in Concentrated Solutions. Volume IV. InterScience Publishers, Inc. New York. 
Tobey, S. 1958. The acid dissociation constant of methyl red. A spectrophotometric measurement. J. Chem. Education. 35:514-515.

Undabeytia, T., S. Nir, G. Rytwo, E. Morillo, and C. Maqueda. 1998. Modeling adsorption-desorption processes of $\mathrm{Cd}$ on montmorillonite. Clays and Clay Minerals. 46:423-428.

Van Bladel, R. and H.R. Gheyi. 1980. Thermodynamic study of calcium-sodium and calcium-magnesium exchange in calcareous soils. Soil Sci. Soc. Am. J. 44:938-942.

VanBladel, R., H. Halen and P. Cloos. 1993. Calcium-zinc and calcium-cadmium exchange in suspensions of various types of clays. Clay Minerals. 28:33-38.

Xue, Y. and S. J. Traina. 1996a. Cosolvent effect on goethite surface protonation. Environ. Sci. Technol. 30:3161-3166.

Xue, Y. and S. Traina. 1996b. Stability of metal-organic complexes in acetoneand methanol-water mixtures. Environ. Sci. Technol 30:3177-3183.

Yalkowsky, S.H., S.C. Valvani and G.L. Amidon. 1976. Solubility of nonelectrolytes in polar solvents: IV. Nonpolar drugs in mixed solvents. $J$. Pharm. Sci. 65:1488-1494.

Yamazki, H., R.P. Sperline and H. Freiser. 1992. Spectrophotometric determination of $\mathrm{pH}$ and its application to determination of thermodynamic equilibrium constants. Anal. Chem. 64:2720-2725.

Yamazaki, H., R.P. Sperline and H. Freiser. 1993. Spectrophotometric determination of the dissociation constant $\left(\mathrm{pK}_{\mathrm{a}}\right)$ of arsenous acid. Analytica Chimica Acta. 284:379-384.

Yao, W. and R.H. Byrne. 2001. Spectrophotometric determination of freshwater pH using bromocresol purple and phenol red. Environ. Sci. Technol. 35:11971201.

Yeager, E. and A.J. Salkind. 1973. Techniques of Electrochemistry. Vol.2. A Wiley \& Sons.

Zhang, Z.Z. and D.L. Sparks. 1996. Sodium-copper exchange on Wyoming montmorillonite in chloride, perchlorate, nitrate, and sulfate solutions. Soil Sci. Soc. Am. J. 60:1750-1757.

Ziper, C., S. Komarneni and D.E. Baker. 1988. Specific cadmium sorption in relation to the crystal chemistry of clay minerals. Soil. Sci. Soc. Am. J. 52:49-53. 